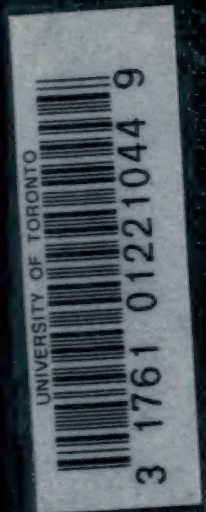



Digitized by the Internet Archive in 2008 with funding from Microsoft Corporation 





\section{THE ANCESTRY OF}

\section{VERTEBRATES}

AS A MEANS OF UNDERSTANDING THE PRINCIPAL FEATURES OF THEIR STRUCTURE AND DEVELOPMENT

BY

\section{Dr. H. C. DELSMAN.}

Published with support of the Koninklijke Natuurkundige Vereeniging (Batavia).
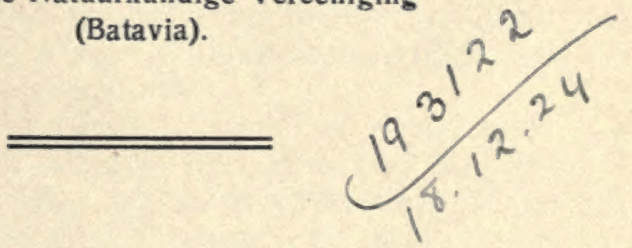

N. V. BOEKH. VISSER \& Co. Weltevreden (Java).

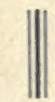

VALKHOFF \& Co. Amersfoort (Holland).

1922. 


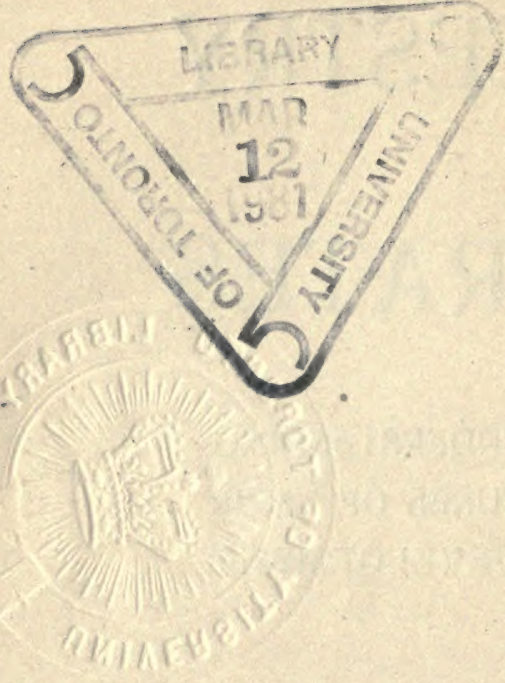

The facts are related to the ideas of the science as statistics to history - meaningless without interpretation.

W, A. LOCY, Biology and its makers.

Immer von neuem sind die Gefahren zu betonen, in welche die Forschung verfällt wenn sie über dem Hang zur Speculation das Vermögen naiver Beobachtung verliert und damit die eigentliche Wurzel ihrer geistigen Freiheit preis giebt.

W. HIS 1887 p. 380 .

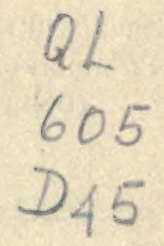




\section{PREFACE.}

The publication of this book which was completed in 1918 has been greatly delayed. This is due partly to the unfavourable times and partly to the doubts with which every new theory is received. Thus, having presented it first to the Royal Academy of Sciences of Amsterdam, I was invited, after a year had elapsed, to ask for its return since the commission which had to report on it could not come to unanimity. Two of the three members refused to share the opinion of the third, professor VAN WYHE, according to whom the present book ought to be confiscated and consigned to the flames ${ }^{1}$ ). Finally, however, they yielded to the implacability of the latter. Thus the excuse of too high costs was advanced to help the three p.ofessors out of this difficult position.

All the more, therefore, do I feel under an obligation to the "Koninklijke Natuurkundige Vereeniging" (Royal Society of Natural Sciences) of Batavia for its confidence, and for its permission to insert the article into the "Natuurkundig Tijdschrift voor Nederlandsch Indie" and to use the type for this present book.

Having experienced how superficial sometimes the judgment even of well reputed zoologists may be, I should like to urge the reader not to set aside this book after having read some ten pages, saying: "a stomodaeum becoming converted into a medullary tube . . . nonsense".

1) Professor VAN WYHE who is a supporter of the "trimerism" theory was so indignant at the publication of this book that he even refused at my request to give me the names of a few of his own articles, for the completion of my literature list. Since in my present residence I could not look them up, they are missing in the list, for which I ask the readers indulgence. 
Those who have read the book to the end will admit that this theory, to say the least of it, merits earnest consideration. They will admit that, unlike most other similar theories, it not only serves to explain known facts but that also its application has advanced us further in several respects. Of these I will mention here only the problem of the hypoglossus and its relation to the gill-slits and the cranium (cf. Plate I), and the results given in the last chapter.

In the treating of the different problems, I have tried each time to give the reader first an idea of the divergent opinions and the confusion often prevailing. Though thiş does not make the reading of the book easier and more agreeable - problems having been made often much more complicated by the investigators than they are in reality I have thought it advisable to do so in order to emphasize the value of a means of escaping from this confusion.

The expressing of a persons thoughts correctly in a foreign language is no easy matter. I am greatly indebted, therefore, to Mr. HUMPHREYS, officer of the Royal Flying Corps who was interned in The Hague during the year 1918, for having gone over with me the whole article, and to Mr. MooN, engineer of Batavia, for having once more reread with me the proofs If in spite of this the English be not yet perfect, I trust that these imperfections, if any, will not give rise to any misunderstandings.

BATAVIA, March 1922.

Laboratory for Marine Investigations.

H. C. DELSMAN. 


\section{O N T E N T S.}

\section{Stomodaeum and medullary Tube ....... p. 1}

Ascidians, p. 2 -Segmented Invertebrates, p. 2 -Annelids, p. 2-Other theories, p. 4-The old mouth, p. 4 - Protostomians and Deuterostomians, p. 5-My theory, p. 6-Meaning of the medullary tube, p. 7-Medullary tube and stomodaeum, p. 8 - Neuropore, p.11-GASKELL, p. 11 - Conversion of stomodaeum into medullary tube, $p .12$ - Spinal ganglia, p. 14 - Spinal nerves, p. 15 - Musculature and its innervation, p. 17 - Double innervation, $p .18$ - Spinal ganglia in Amphioxus, p. 19 - No stomodaeum in Chordates, p. 20 - Taste in Chordates, p. 20 - Protostomia, Deuterostomia, Tritostomia, p. 21.

\section{Origin and Structure of the Head ....... p. 22}

Brain and cerebral ganglia, p. 22 - Praeoral lobe in Annelids, p. 23 -Mesenchyme and coelomesoblast, p. 24 - Praeoral lobe in Amphioxus, p. 25 - Secondary mesoblast in the prostomium, p. 26 - Praechordal brain in Craniates, p. 27 - Optic organs of Acrania, p. 27 - Attempts to derive the Craniate eyes from them, p. 28-Eyes of Annelids and Molluscs, p. 29-Absence of paired eyes in Acrania, p. 31 - Optic pits in Craniates, p. 31 - Encephalogenetic origin and inversion of Craniate eyes, p. 32-Homology of Craniate and Protostomian eyes, p. 34 - Situation of the animal pole, $p$. 35 - HATSCHEK's view on the Craniate brain, p. 36 - Archencephalon and deuterencephalon, p. 37 - Neuropore of Crantates and of Amphioxus, p. 39-Cranial flexure, p. 39 - Auditory organs in Acranta, p. 39-Organs of equilibrium of Annelids and Molluscs, p. 39-Auditory vesicles in Craniates, p. 41 - Praeoral lobe in Craniates, p. 41 Olfactory organ, $p .43$-Ciliated pits in Annelids and Molluscs, p. 44-Homology of olfactory pits of Protostomians and Craniates, $p .46$ - Three main sense organs inherited from Annelids, p. 46-Brain of Annelids and Craniates, p. 48-Primary brain axis, p. 50-Different situation of the neuropore in Urodelans and Anurans, p. 51 - 
The animal pole not a fixed point? p.52-KUPFFER's view to be preferred to that of HIS, p.54-Lateral sense-organs in Annelids, $p .55+$ - Metameric arrangement, p.56-Innervation, p. 56 - BEARD versus EISIG, p. 57 - Lateral ganglia of Annelids homologous to spinal ganglia of Vertebrates? p. 59 - Dermatogenetic part of the cranial ganglia, p. 60 .

Different theories on the metameric structure of the head, p. 61 - Ontogenetic researches, p. 63 - Mesomerism, neuromerism and branchiomerism, p. 63-Branchiomerism independent of mesomerism? p. 64-No mesomerism at all in the Vertebrate head? p. 65 - FRORIEP versus GEGENBAUR and VAN WYHE, $p .66$ - Mesomerism in branchial region of Elasmobranchs, p. 67-Main points on which opinions differ, p. 69 -Unsegmented region of the head, p. 69-Is there an unsegmented head-mesoblast? p. 70-Proamnion, $p$. 73. - Diagrams of VAN WYHE and ZIEGLER, $p$. 74-Neural crest of head and trunk, p. 76 - Eye muscle nerves, p. 77 - Auditory vesicle in second segment, p. 78 - Branchiomerism and mesomerism, p. 78 - Branchiomerism and mesomerism in lower Chordata, $p .81$ - Paired intestinal diverticula among Protostomia, p. 8? - Significance of praemandibular cavity, p 84-Nature of the trigeminus, p. 87-Oculomotorius p. 88Relation of hypophysis and olfactory pits to the mouth, p.90Derivation of mouth from gill-slits, p. 91-Head of Arthropods, p. 94-Primitive features of the branchial region, p. 94 - The third segment the simplest head segment, p. 96 .

Backward extension of the skull, p.97-Ventral occipital nerves, p. 97 - FRORIEP's and FüRBRINGER's views, $p .98$ - Objections against their views, p. 100 - Branchial muscles, $p .101$ - The origin of the hypobranchial musculature p. 103 -Agreement with the fin muscles, p. 106-Not all occipital nerves hypoglossus roots, p. 107 -Variation in length of the Selachian skull, p. 108 -Primarily and secondarily epibranchial somites and nerves, $p .110$ - FüRBRINGER's rule applied to the hypoglossus, p. 111 - Hypoglossus of Amniotes, p. 113 - Amphibian and Selachian skull, p. 114.

Head of Amphioxus, p. 118 - First pair of somites, p. 119 - Trimerism, p. 121 - Brain vesicle of Amphioxus, 
p. 122-Amphioxus in the light of my theory, p.124-The mouth of Amphioxus, p. 126 - First pair of gill-pouches, p. 127 - Anterior spinal nerves, p. 129 - Neuropore and praeoral lobe in Ascidians, p. 131 - Mouth of Ascidians, $p$. 133 - Segmentation in Ascidians, p. 133.

History of the Vertebrate head, p. 135 - Animal pole of egg and blastula, p. 135 - Head of Amphioxus, p. 137 - Head of Petromyzon, p. 138 - Amphibian head. p. 144 - Head of Selachians, p. 147 - Head of Amniotes, p. 152 - General conclusions, p. 153 - Hypoglossus homologous in Vertebrates? p. 154.

\section{Gastrulation and earliest Development .... p. 156}

Fate of the animal pole, p. 157 - Teleostean eggs, p. 157 - Amphibian eggs, p. 159 - Acrania and Craniata, $p$. 160 - Gastrulation, p. 161 - Different views, p. 163 Theory of concrescence, p. 166 -Objections, p. $167-$ Experiments, p. 168 - Spina bifida, p. 169 - Invagination of ectoderm cells? p. 170 - LWOFF's views, p. 173-HUBRECHT's speculations, $p .174$ - Conception arising from my theory, $p$. 175 - Eccentric closure of the blastopore, p. 176 - Different views on movement of blastopore border, p. 177 - Conclusions from pricking experiments, p. 179 -Interpretation of the results, $p$. 185 -- Comparison with Annelids, $p$. 185 - Displacement of the endoderm area, p. 188 - Interpretation of the eccentric closure of the blastopore, p. $190-$ Summary, p. 192 - Relation of anus and blastopore, $p$. 193 - Different views on Anurans, p. 193 - Rana esculenta, p. 195 - Different views on Urodelans, p. 198 - Amblystoma tigrinum, p. 199 -Different interpretations, $p$. 203 - Primary relation between anus and blastopore? $p$. 204 - Secondary relation between anus and blastopore, p. 206 - Perianal and periporal growing zones, p. 206 - Interference of both with the gastrulation, p. 207 - Formation of the tail, p. 210 - Difference between Urodelans, Anurans and Selachians, p. $212-$ Mesoderm of Vertebrates, p. 213 - Notochord, p. 215 - Gill slits, p. 216.

Literature.

p. 217. 



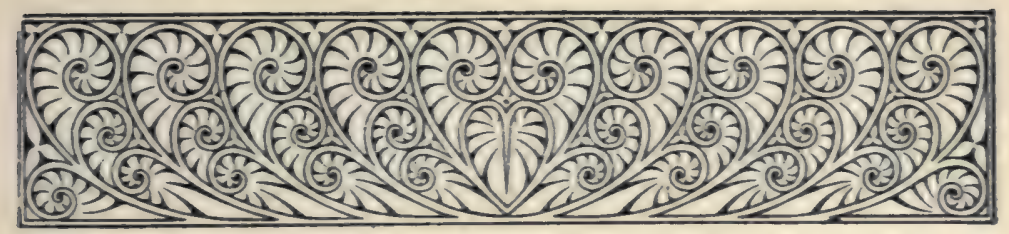

\section{CHAPTER 1 .}

\section{Stomodaeum and medullary tube.}

Phylogeny, the study of the evolution of life on earth, has lost the universal veneration paid to it by a former generation of zoologists. As a guiding thread in systematic studies on restricted groups it still may do service; but the general discouragement evoked by so numerous vain attempts to trace the relations of the main branches of the genealogical tree of the animal kingdom has diverted attention from the great work of the reconstruction of this tree to other problems and other paths of science, neglected until now. How much interest did a theory on the origin of Vertebrates awake some thirty or forty years ago. How little, I fear, will it do in our materialistic days! New and vain speculations on things we can never know, new hypotheses based on a hypothesis: the theory of evolution. What is their value? Give us facts!

It is to encounter these objections that I gave this book a sub-title which, I hope, will need no further elucidation. It is equally as a plea pro domo-I nearly would have said: as an excuse for my boldness to treat of such a subject that I placed the first quotation under the title, though, as a complement, I added the second under it. And further, may the theory to be exposed here speak for itself anc 
convert those who deny a priori the possibility of solving a problem like that of the derivation of Vertebrates from Invertebrates. How wide once seemed the gulf between Cryptogams and Phanerogams. Yet the bridge between them has been found.

Ascidians. - The first step towards the solution of the problem of the origin of Vertebrates seemed to have been done with KOWALEWSKY's (1866) researches on the development of the Ascidians which revealed such remarkable points of agreement between these animals, formerly considered as Invertebrates, and the Chordates. Pretty universally the view was gaining ground that in the Ascidians we have to look for the root of the Vertebrate genealogical tree. Yet, though in recent days it has found again an advocate in BROOKS (1893), this first step soon proved to take us no further than so many a mighty offensive in the present European war carried those who undertook them ${ }^{1}$ ). There still remained an unbridged gap between Ascidians and Invertebrates.

Segmented Invertebrates. - While according to the above conception the metameric structure of the Vertebrates could have nothing to do with that of certain groups of Invertebrates, others especially laid stress on this point of agreement between Vertebrates on the one side and Arthropods and Annelids on the other. It is a well known fact that already in the beginning of the nineteenth century GEOFFROY ST-HILAIRE (1822, p. 11) compared the Vertebrates to Arthropods walking upside down, as was necessary to assume in order to render possible the identification of the central nervous system in both. The same idea was carried on by LEYDIG (1864, p. 185) who compared the supra- and infraoesophageal ganglia of Arthropods to a brain of Vertebrates pierced by the gut between the crura cerebri.

Annelids. - In the same year, but independently, SEMPER and DOHRN (1875) then transferred the comparison from Arthropods to Annelids, no doubt an impoitant step forwards. Thus was born the celebrated theory of the Annelidan affinity of Vertebrates, which for a long time has occupied a dominating place in zoological work. DOHRN was led to it by general considerations, SEMPER by the discovery that

1) This book, though published later, has been written during the great European war. 
in Vertebrates the first rudiment of the kidney arises as a number of separate, segmentally arranged, tubules which show a remarkable resemblance to the so-called segmental organs of Annelids. The agreement of Vertebrates and Annelids in the excretory system and its rela:ion to the genital products and the segmented coelome has always remained one of the strongest arguments in favour of the Annelidan theory. In recent times the discovery of BOVERI (1890) and GOODRICH (1902) that also the closed protonephridia of parenchymatous worms, Rotifers and several Annelids, are

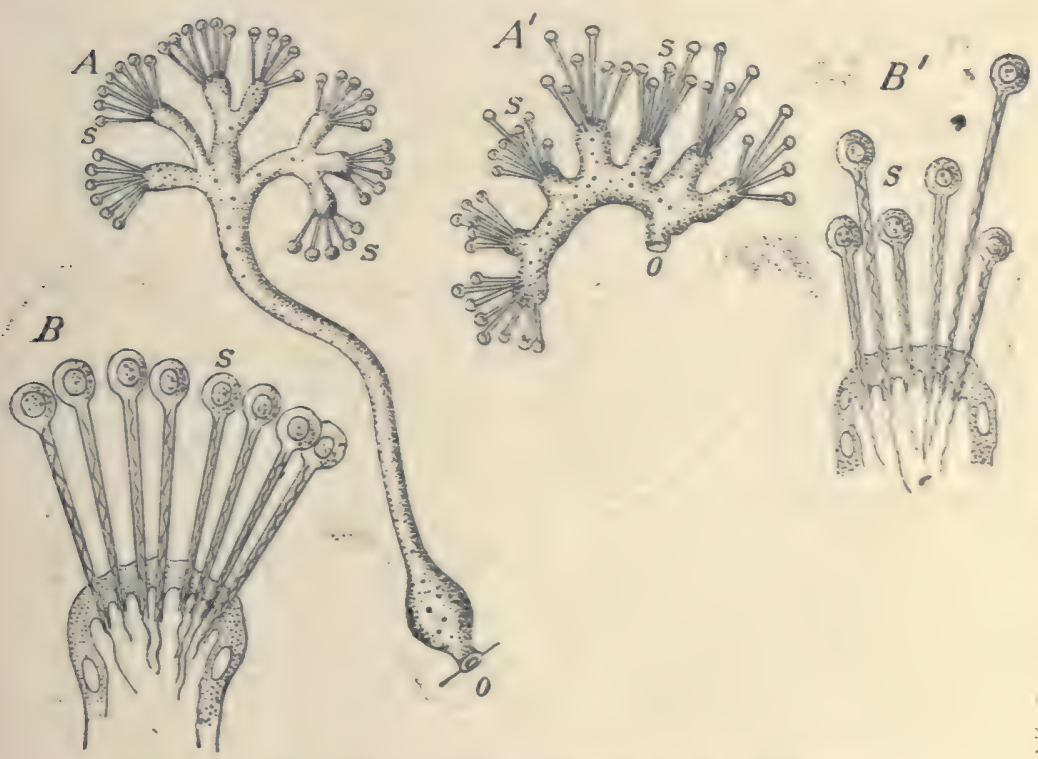

Fig. 1. A. Segmental organ of the Polychaet Phyllodoce.

o. external aperture.

$s$. solenocyts.

B. One of the terminal branches.

$A^{1}$ Segmental organ of Amphioxus.

$\mathrm{B}^{1}$ One of the terminal branches.

From BOAS (1914), after GCaこRı́H.

found again among Chordates in Amphioxus has lent a valuable support to this theory. The solenocytes, a very specialized form of flame-cells, are found only in Amphicxus and certain Polychaets; their structure and arrargeme:it in 
both groups so wholly agree, that, as BOAS (1914, p. 532) remarks, "der Gedanke an blosse Analogie entschieden von der Hand gewiesen werden muss". Indeed, the agreement of a protonephridium of Amphioxus with that of a worm like Phyllodoce is so complete that it is hardly possible to assume that two so similar structures could have originated independently.

Another point of agreement is found in the circulatory system, if only we assume again that the neural side in both Annelids and Vertebrates correspond. We see the blood circulating from in front backwards in the ventral vessel of the Annelid and in the dorsal aorta of the Vertebrate, and in the reverse direction dorsally in the Annelid and ventrally in the Vertebrate. Also the structure of the main senseorgans and their situation at the anterior end of the body shows affinity between the Vertebrates and the Annelids.

Other theories. - What then is the reason that the theory of the Annelidan ancestry of the Vertebrates, which many have adhered to, has yet not given the complete satisfaction we might have expected? How is it possible that other theories have grown up at its side like mushrooms, deriving the Vertebrates from anemones (LAMEERE, 1891, HUBRECHT, 1902), Nemerteans (HUBRECHT, 1883), Turbellarians (GOETTE: 1884, 1895), Arachnids (PATTEN, 1890), Palaeostracans (GASKELL, 1908), Enteropneusts (BATESON, 1886), nay, from nearly every group of Invertebrates, often along the most unexpected ways? How could one of these theories, viz. the last of those mentioned above, gain such a wide acceptance in recent time, that in text-books of zoology we find more and more the Chordates placed behind the Enteropneusts. and the latter often designated as Prochordates?

The old mouth. - One difficulty connected with the derivation of Vertebrates from Annelids has never found a satisfactory solution, and has remained a serious obstacle to this theory ever since DOHRN first encountered it. It is the old question, that in Annelids the central nervous system is situated on both sides of the gut - the cerebral ganglia at the dorsal, the ventral ganglion chain at the ventral side -, while in Vertebrates the whole nervous system, brain as well as medulla, is situated dorsally from the gut and is not pierced by the latter. DOHRN tried to account for it by assuming, as suggested already by LEYDIG (1864), that formerly in Vertebrates also such a passage of the enteron through the 
nervous system had existed and that the exact situation of this passage was to be looked for in the fossa rhomboidea, between the crura cerebelli.

In this way only was it possible to homologize the cerebral ganglion of Annelids with the brain of Vertebrates. Rightly DOHRN (1875, p. 4) emphasizes the fact that the mouth of Vertebrates is an organ which ontogenetically appears only very late and therefore cannot be estimated as of high phylogenetic antiquity. "Der Embryonalleib eines Wirbelthiers ist fast vollständig ausgebildet, alle grossen Organsysteme bestehen bereits, die Circulation vollzieht sich schon, - und noch immer besitzt der Embryo keine Mundöffnung," while in all other groups the mouth is one of the first organs to be formed.

Other solutions have been proposed for the difficulty of the different situation of the cerebral part of the nervous system in Annelids and Vertebrates, a number of them being mentioned at the beginning of the second chapter. One of the most acceptable seems to me to be that suggested by HATSCHEK which is mentioned on page 36 . Yet there is one drawback which it has in common with the others cited above, viz: that the entirely different behaviour and fate of the blastopore in Chordates and in Annelids are not accounted for, and it is just the latter circumstance, which no doubt has converted so many to the derivation of Vertebrates from forms related to the Enteropneusts.

Protostomians and deuterostomians. - A great importance has been attributed recently to the fate of the blastopore by GROBBEN (1908) in his well-known classification of the animal kingdom. By RAY LANKESTER the sub-division of the Coelomata was opposed to that of the Coelenterata, both constituting together the subregnum Metazoa of HAECKEL. By HATSCHEK (1888-1891) the Coelomata were subdivided into three phyla: the Zygoneura, the Ambulacralia and the Chordonia. The foundation of the first group to which the Platyhelminthes, Nemertinea, Nemathelminthes, Rotifera, Brachiopoda, Bryozoa, Annelida, Mollusca and Arthropoda belong, followed from HATSCHEK's trochophora-theory, the trochophora and the protrochula larva being the point of origin from which the different forms belonging to it have developed. In the second group it is equally the pelagic larva which unites Echinodermata and Enteropneusta, while the combination of Tunicates and 
Vertebrates to Chordonia was a necessary consequence of KOWALEWSKY's (1866) embryological work. GROBBEN now designated the Zygoneura as Protostomia, and opposes them to both the other groups as Deuterostomia, since in the former the blastopore directly passes into the ingestionopening, whereas in Deuterostomia it passes into the egestion-opening, the anus, or at least exhibits certain relations to the latter and none to the mouth, which is formed as a seccndary perforation quite independent from the blastopore. The first to attribute such a primary importance to the fate of the blastopore has been GOETTE (1884), who distinguished the hypogastric from the pleurogastric Bilateria. In the former, to which Annelids, Nemertines, Nematodes etc. belong, the blastopore passes into the mouth, in the latter, comprising Vertebrates, Echinoderms and probably also Enteropneusts, into the anus.

Thus the place assigned to the Chordates in this system is in agreement with he attempts of BATESON (1886) and his followers to found a relationship between Chordates and Enteropneusts and by means of the latter again with Echinoderms (cf. GAFSTANG, 1894), to which the Enteropneusts are undoubtedly related. I will not go here into a criticism of BATESON's theory. Others, more competent than I, as e.g. SPENGEL (1893, p. 721), have done this already and have shown how unconvincing are the homologies proposed by BATESON. Indeed, if we ask ourselves with which group the Chordates show closer affinity, whether with the Annelids, a trunk to which more than one branch showing tendency to higher development - like Arthropods and Molluscs - is related, or with the dull Echinoderms with their lack of intellectual and other development, the answer can be hardly doubtful.

My theory. - The theory on the origin of Vertebrates, which I published some years ago (19/3), can be ranked among those theories which in different ways try to find a solution of the difficulties connected with the derivation of Vertebrates from Annelids; difficulties which have resisted for so long all attempts to overcome them, that the case seemed to appear almost hopeless. I must emphasize, however, that, unlike most of the authors cited in the beginning of the next chapter, it was not in the least my intention to make an attempt to render DOHRN's and SEMPER's theory acceptable, nor to look for a solution of the 
difficulties connected with it. I was not thinking at all of the problem of the origin of Vertebrates nor did I expect ever to occupy myself with it by proposing a new theory when, in the course of embryological researches on Invertebrates, an idea occurred to me which, when I tried to work it out, scon led me in the direction of the theory of the Annelidan origin of Vertebrates. The combination of both proved to be of unexpected fruitfulness and to open up new perspectives in many directions. And not only did all the difficulties which had proved unsurmountable for nearly half a century appear to be solved at once in a most unexpected way, but as many new arguments in favour of the Annelidan theory were provided by the elaboration of this idea.

After the first publication in 1913(a), further reflections and investigations have yielded more than one valuable confirmation of the results reached therein, and sometimes also have led to certain modifications, completions and corrections of my original views. Since these later results were published in a number of short articles which are not always easily consulted by everybody, it has for some time been my intention to unite them all into a new publication on my theory, as given by the present bojs.

Meaning of the medullary tube. - The starting point, then, is the peculiar way in which the central nervous system is founded in Chordates. It originates as a tube opening anteriorly to the exterior and posteriorly into the archenteron and showing at its posterior end certain relations to the blastopore and the anus. Several suppositions have been made to account for these peculiarities. Thus SEDGWICK (1884) proposed the following hypothesis "on the original function of the canal of the central nervous system in Vertebrates." First there has been a longitudinal groove, which closed to form a canal, open at the anterior and the posterior end and having a partly respiratory and partly protective function. The water entered into the canal "by the anterior pore, was driven through it by cilia, and at the hind end passed through the neurenteric canal into the alimentary canal and so out by the anus."

A similar suggestion was made in the same year by VAN WYHE (1884 p. 683). Originally the water from the tube and the excrements from the archenteron passed out through a common opening. Afterwards, when this opening was 
dif closed by the medullary folds, both took their way through the anus. Similar are the views of MORGAN (1890).

Another suggestion had been made cursorily by KowALEWSKY (1877, p. 201), who together with GOETTE (1869, p. 115) has discovered the canalis neurentericus, that curious connection between the medullary tube and the archenteron. He wrote: "Die sonderbare Bildung des Nervensystems bei den Embryonen vieler Wirbelthiere (Amphioxus, Amphibien, Störe, Plagiostomen), bei denen Darm- und Nervenrohr ein zusammenhängendes Rohr darstellen, lässt uns vermuthen, dass vielleicht solche Thierformen existirten oder auch existiren, welche ein dem Nervenrohr der Wirbelthiere homologes Rohr besitzen, obgleich dasselbe eine andere Function erfüllt, dass es z. B ein Theil des Darmcanals sei." This idea, however, was not worked out further by KOWALEWSKY. He only mentions in this connection the U-shaped alimentary tract of Bryozoa; afterwards he has made no further reference to the subject.

The gist of my theory is the supposition that indeed the neural tube, as KOWALEWSKY once suggested, has been a part of the alimentary tract, that it corresponds to the ectodermal part of the latter in Invertebrates and that it is the homologue of nothing else than the stomodaeum of those animals which HATSCHEK took together as the Zygoneura and which GROBBEN named the Protostomia. In this group the blastopore of the gastrula becomes the definitive ingestion-opening, not the mouth, since round the blastopore the ectodermal stomodaeum invaginates and only the exterior opening of the latter is the mouth, while the blastopore is found in the inner opening. leading in to the entodermal stomach, which opening I (1917, p. 1267) have proposed to call the cardiac-pore.

Medullary tube and stomodaeum. - There are indeed many points of agreement between the medullary tube of chordate embryos and the stomodaeum of Protostomia. In the development of both groups the border of the blastopore, originally wide and large, contracts to a very narrow opening which I should like to call the definitive blastopore and not, as some do, the rest of the blastopore, since in my opinion the blastopore is the mouth of the gastrula and only the latter stage can be called the gastrula, irrespective of whether the contraction of the blastopore proceeds in an eccentric or in a concentric manner. In the 
Jast chapter we will revert to this question. In both Annelids and Chordates there is formed, in connection with this very narrow definitive blastopore, a tube of ectodermal origin which at one end opens to the exterior, at the other end leads into the archenteron through an opening which is the former blastopore. In Annelids this ectodermal tube is the stomodaeum, the outer opening being the mouth, the inner the caidiac pore; in Chordates it is the neural tube with the neuropore and the neurenteric canal. Cell-lineage investigations on Ascidians by VAN BENEDEN and JULIN (1884), CASTLE (1896) and CONKLIN (1905) have taught us that here the first rudiment of the
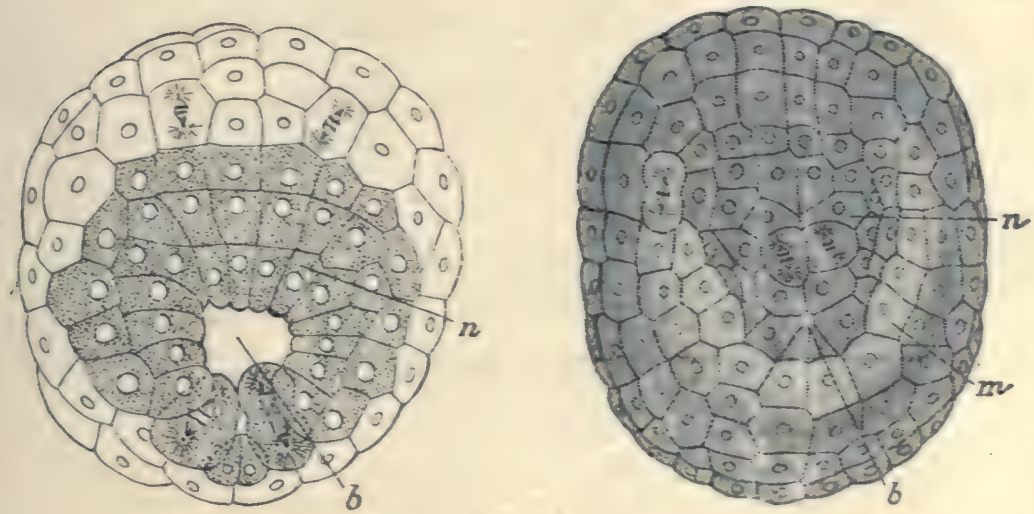

Fig, 2. Gastrula-stage and formation of the medullary folds in Clavellina Rissoana.

$b$. blastopore, $m$. medullary fold, $n$. neural plate.

From KORSCHELT and HEIDER (1893, p. 1274, 1275), after VAN BENEDEN and JULIN (1887).

medullary plate originally surrounds the blastopore as a ring, or, accordine to CASTLE, as a crescent, a conclusion equally reached for Craniates by the brothers HERTWIG (1892) in their "Urmundtheorie". A comparison which I happened to make between the gastrula-stage of a Protostomian of which I was studying the development (1912) and that of Ascidians, directed my attention to the fact that a similar cell-ring as in the latter gives rise to the neural tube, in Prostostomia represents the rudiment of the stomodaeum, which is equally an ectodermal tube leading 
from the exterior into the archenteron. While all other developmental processes in the segmented animals proceed from in front backwards, the formation of the medullary tube in lower Chordates has its starting point at the blastopore and proceeds in a forward direction. Characteristic of the stomodaeum, at least in young siages, is the dense coat of cilia which induces a current of water. In Amphioxus the neural tube is also clothed with cilia, equally producing a water current from in front backwards (HATSCHEK, 1882, p. 59, 71) and in higher Chordates a fine coat

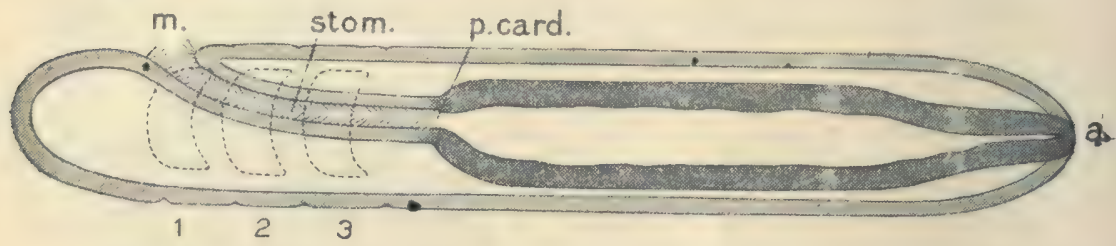

neur. $p$. can med. p.neuse

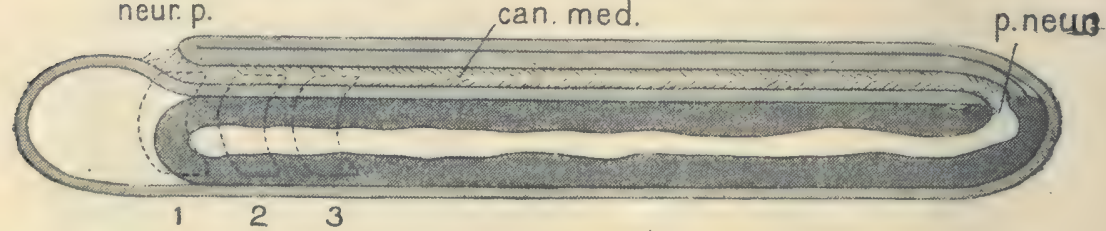

Fig. 3. (cf. fig. 11). Diagram representing the derivation of a Chordate (Acraniate) from an Annelid (the Annelid is placed with the ventral side up).

Can. med. medullary canal, $m$. mouth, neur. $p$. neuropore, $p$. card. cardiac pore, p. neur. neurenteric pore, stom. stomodaeum. 1, 2, 3, mesoderm segments.

The endoderm has a darker colour than the ectoderm.

of cilia is often observable covering the ependyme of the neural tube or the neural plate. Thus MORGAN (1890) remarks: "MR. WIGHTMAN has demonstrated to me in the neural tube of adult frogs the ciliated epithelium in the living condition, and further by the addition of suspended carmine granules these cilia are seen to drive the particles towards the tail."

The agreement between the stomodaeum and the embryonal medullary tube is almost complete if only we assume that in Chordates the former has become very long and has extended over the whole length of the body, carrying the cardiac pore backwards to the hinder end where we find it now as the neurenteric canal. In the last chapter we 
will see that in ontogeny this backward shifting of the blastopore, being the future neurenteric canal, is quite evident. We then have to assume that the stomodaeum has lost its original function and a new, secondary mouth had to be formed. This gives us at the same time the solution of the problem of "the old mouth and the new" (BEARD, 1888, a), cf the palaeostoma and the neostoma of KUPFFER (1894) and shows us clearly, how the old mouth could have been lost and why a new one had to be formed in a way which reminds us of the Deuterostomia. This new mouth accordingly breaks through only very late in embryonic life, as DOHRN first emphasized (see quotation above). Moreover we will see in the second chapter that the new mouth in Ascidians, Amphioxus and Craniates is formed in three different ways and, as a consequence, is not homologous in these three groups. This points equally to the secondary nature of the Vertebrate mouth.

Nelropore. - The primary mouth, being that of the Annelias, is represented by the neuropore of Amphioxus, and this itself again is phylogenetically secondary in respect to the "Urmund", the mouth of the hydroid polyps, which in Annelids we find again in the cardiac pore, and in Chordates in the neurenteric canal, both representing the former blastopore. Thus in the ontogeny of Vertebrates we see the three successive mouths appear in the same succession as they appeared in phylogeny: the blastopore ("Urmund"), the neuropore (the Annelidan mouth) and finally the definitive mouth.

Gaskell. - It truly seems a bold supposition that a part of the alimentary canal should have changed its function and have become the central nervous system. Yet, as we will see especially in the last chapter, the facts of embryology plead so strongly for it that KOWALEWSKY and the writer are not alone in their idea. A somewhat similar suggestion has been made by the physiologist GASKELL (1908) in his theory on the origin of Vertebrates. More than once, in conversation and in correspondence, I have heard my theory compared with that of GASKELL, a comparison which I must add at once did not exactly flatter me. I readily believe that GASKELL was a good physiologist, but I cannot admire his phylogenetic speculations, to which 1 think my theory bears only a superficial resemblance. GASKELL derives the Vertebrates from Arthropod-like ancestors by making 
the whole intestinal tract of the latter, from the mouth to the anus, pass into the neural tube of the former. the stomach giving rise to the brain and the intestine to the spinal canal, while the infundibulum marks the place of the old mouth. A new alimentary canal to replace the lost one is formed from a median groove of the ventral body wall which by the growing out of two lateral folds is converted into a tube. Of course GASKELL is engaged in grave conflict with the doctrine of the germinal layers - the central nerv- ous system of Vertebrates would be of entodermal ${ }^{1}$ ), the gut of ectodermal origin! - and with the other principles of embryology. GASKELL truly tries to show, that his theory does not contravene these principles, but he can do so only by expressing as his opinion, that "the cmbryologists have to a large extent gone wrong in their fundamental principles" (p. 459) and by rejecting the doctrine of the homology of the two primary germinal layers in Metazoa. I need not emphasize, that my theory on the contrary is in perfect accordance with the doctrine of the germinal layers; as is the general rule in the animal kingdom the nervous system in Chordates is of ectodermal origin. Almost the only point in which I agree with GASKELL is "that the clue to the origin of vertebrates is to be found in the tubular nature of the central nervous system of the vertebrate"; however, GASKELL and the writer differ widely in their application of this principle

To the question as to what may have been the cause of such a remarkable change of function as is the conversion of the stomodaeum of the Protostomia into the neural tube of the Chordates, the answer is not easily given. Some reflections perhaps will assist in making us a little more familiar with the idea.

Conversion of stomodae um into medullary tube. - In the first place the question can be asked: what is the original significance and function of the stom odaeum? Why did not the blastopore, the "Urmund", as e. g. in hydroid polyps, remain also in higher forms the definitive mouth. Why was an ectodermal entrance to the gut formed in connection to it? Partly no doubt this finds its explanation in the dense coat of cilia investing the inner surface of the stomo-

1) In part at least, for according to GASKELL the ganglia of the Arthropod ancestors have applied themselves to and enclosed the alimentary canal, forming together with it the neural tube. 
daeum and which perhaps is to be considered as a part of the original coat of cilia covering the surface of different kinds of primitive larvae. By the action of these strong cilia food is driven into the gut. But we can hardly doubt that the stomodaeum has still another function. For every animal it is of prime importance to perceive and test what it eats, to inquire as to the nature of matter which passes through the mouth into the stomach. Thus in the stomodaeum, no doubt, next to the tentacles of Coelenterata (LOEB, 1895, p. 415), we find an organ of taste.

A similar suggestion was made with regard to the neural plate and the neural tube by ZIEGLER (1908, p 677):

"Gehen wir von der Gastrula aus, so müssen wir annehmen, dass sie sich ursprünglich durch den Blastoporus ernährte. Die Medullarplatte wimperte ursprünglich die Nahrung nach dem Blastoporus hin und konntedabei a ch schon die Funktion eines Sinnesepithels besitzen. Als die Medullarplatte sich zum Medullarrohr umgestaltete, ging der Strom des Wassers durch den vorderen Neuroporus ein und gelangte durch den Canalis neurentericus in den Darm". Soon after, the anus is formed for the evacuation of the water. "Erst die folgende Stufe ist durch die Bildung der Kiemenspalten und des Mundes charakterisiert. Nun ging das Wasser durch den Mund und die Kiemenspalten ein, und der $\mathrm{Ca}-$ nalis neurentericus wurde überflüssig. Infolgedessen obliterierte der Canalis neurentericus. So k on n te das M edullarrohr, welches schon bisher zur Prüfung des Wassers und der Nahrungsbestandteile ein Sinnesepithel enthielt, ein ausschliesslich nervöses Organ, das Zentralorgan des Nervensystems werden".

Here indeed only one step remained to be made and the tie between Vertebrates and Invertebrates would have been found!

In some cases part of the nervous system of the Protostomia is derived from the stomodaeum, in Gasteropods e.g. the buccal ganglia originate from a proliferation of its wall (SARASIN 1883, p. 53, DELSMAN 1914, p. 316). All this can serve to reconcile us to the idea that the ectodermal part of the alimentary tract in Protostomia has been converted into part of the nervous system in Vertebrates. 
The way in which we must imagine the conversion of the Annelid into the Chordate is represented in fig. 3. As in all other theories of the Annelidan origin of Vertebrates, here also the ventral surface of the Annelid corresponds to the dorsal one of the Vertebrate. One serious objection to my theory seems to present itself here: the way in which in ontogeny the medullary tube forms does not exactly answer to what we should have expected after the above diagram and in accordance with the law of recapitulation. We might expect the neural tube to originate as a tubular invagination of the ectoderm, afterwards lengtiening very much from in front backwards and thus pushing its inner end and the former blastopore under the neural body-wall to the caudal end of the embryo. This is not the case, as we know. In the last chapter, however, we will see that this apparent difficulty is not only completely solved, but that the earliest ontogenetic processes on the contrary yield the strongest possible support to my theory and that only the peculiar way in which some of these processes interfere has proved a hindrance to their interpretation and delayed for so long a - time the solution of the problem of the origin of Vertebrates.

Spinal ganglia. - The great difference between the central nervous system of Vertebrates and Protostomia is that in the former it originates as a tube, whereas in the latter it consists of ganglia, though in both cases it is of ectodermal origin. Ganglia, however, are found in Vertebrates also and they even play a very important role in the formation of the nervous system. We find a pair of them, the spinal ganglia, in every segment af the body, just like in Annelids. Also the situation and place of origin, the median line of the neural body-wall, where the medullary folds have met and coalesced, correspond exactly to what we find in Annelids. It seems to me fairly evident that, if we are right until now, we can hardly doubt the homology of the spinal ganglia of Vertebrates and the ventral ganglia of Annelids and Arthropods. On the other hand this assumption might - contribute to make us understand the conversion of the stomodaeum into the neural tube. If indeed a strong longitudinal growth of the stomodaeum had taken place phylo-genetically, as represented in fig. 3 , it would have come to lie along its whole length against the ventral chain of ganglia. From these ganglia, nerve-fibres, formerly uniting a iright and a left ganglion, might have grown into the stomo- 
daeum, and in this way the latter might have been taken up into the nervous system so as to form part of it. With such a supposition the facts of ontogeny are in harmony. As His (1886) first observed in the human embryo, the dorsal nerve roots are produced exclusively by the spinal ganglia. Fro:n these grow out the nerve-fibres which const tute the peripheral part of the dorsal nerve, whereas on the other side they grow out into the medullary tube, thus constituting the root of the dorsal nerve. With this result, those obtained experimentally by cutting off the dorsal nerve under and above the ganglion and studying the degeneration of the nerve fibres, as shown first by WALLER (1852) and afterwards by many others, are in harmony. It can be demonstrated in this way that the ganglion is the trophic centre for the whole dorsal root. Finally it may be observed that the sympathetic nervous system with its ganglia is a derivative of the spinal ganglia. Spinal nerves. - If now the assumption made above is correct the dorsal component of the spinal nerves issuing from the spinal ganglion must be compared with the segmental nerves radiating from the ventral ganglion of the Annelid. These latter nerves, however, are of mixed motor and sensory function, and thus we are led to a conclusion, put forward for Vertebrates by FRANCIS BALFOUR as early as 1878. BALFOUR did not observe ventral roots in Amphioxus and the dorsal nerves are of a mixed sensory and motor nature. The same applies to the dorsal nerves of the head of Craniotes, where also BALFOUR did not recognize any ventral roots. Thus he expressed as his opinon (1.c. p. 193): "that primitively the cranio-spinal nerves of Vertebrates were nerves of mixed function with one root only, and that root a dorsal one, and that the present anterior or ventral root is a secondary acquisition" (cf. also '1881, II, p. 382). The original condition is found still in Amphioxus and in the head of Craniates

To this conclusion VAN WYHE $(1882$, p. 40$)$ has objected:

$1^{0}$. that soon afterwards ventral roots have been discovered in Amphioxus (SCHNEIDER, 1879, p. 15),

$2^{\circ}$. that in the trunk the dorsal root originates independently of the ventral one. VAN WYHE here evidently assumes that in BALFOUR's opinion the ventral nerves are to be derived from the dorsal ones,

$3^{\circ}$. thai BALFOUR did not consider the oculomotorius, trochlearis and abducens as ventral roots, as proposed by 
VAN WYHE, and that he considered GEGENBAUR's (1871, p. 521) "ventral vagus roots", the hypoglossus of other" authors, (to which we will refer again in the second chapter), as belonging not to the vagus and to the head, but to the spinal nerves. Thus BALFOUR believed that there wereno ventral cranial nerves:

VAN WYHE (1882, p. 40) points to another circumstance which may serve to account for the different character of the dorsal cranial and of the spinal nerves. BELL's (1811) rule of the exclusively sensory character of the dorsal and the motor character of the ventral roots only applies to the striate, voluntary, musculature which is derived from the myotomes, and not for the smooth, visceral, musculature which ows its origin to the lateral plate. While the former is innervated by the ventral spinal nerves, the latter is supplied by the sympathetic nervous system, the ganglia of: which, as shown first by ONODY (1885), are separated ontogenetically from the primordial rudiments of the spinal' ganglia, while moreover it has been shown that nerve fibres sometimes pass through the dorsal roots to the visceral muscles, as suggested already by VAN WYHE (1882, p. 41). Thus STEINACH (1895) demonstrated experimentally that in the frog the dorsal spinal roots contain motor fibres: for the visceral musculature and the bladder.

In the same way the motor portion of the crania! nerves does not supply muscles derived from myotomes, but the primordial branchial muscles which, although being striate and voluntary, according to VAN WYHE must be numbered' amongst the visceral muscles, since they are derived from the lateral plate. The difference between the cranial and the trunk nerves, then, is reduced to the separation of the sympathetic ganglia from the primary spinal ganglia in the trunk, while in the head this process is absent. Thus in a somewhat different manner we arrive again at BALFOUR's' conclusion that the head in this respect exhibits more primitive features than the trunk, and that, returning to my theory, the dorsal cranial ganglia are more strictly homologous to the ventral ganglia of Annelids than are the spinal ganglia, from which the visceral ganglia have separated. Thus according to VAN WYHE the ancestral form of Chordates would have had not only dorsal roots of mixed function but, in addition to the latter, which only innervate the involuntary visceral musculature, ventral roots of purely. 
motor function supplying the voluntary musctilature from the myotomes. This condition is found in Amphioxus where indeed HATSCHEK (1892, p. 141) and VAN WYHE (1893, p. 171) demonstrated that the splanchnic musculature is supplied by branches from the dorsal nerve rocts (Rami viscerales). The ventral roots, supplying the striate musculature, here exhibit a more or less diffuse character, each springing with a great number of roots from the medulla.

Now there is much to be said for the conception that the voluntary, striate, musculature is a new acquisition of

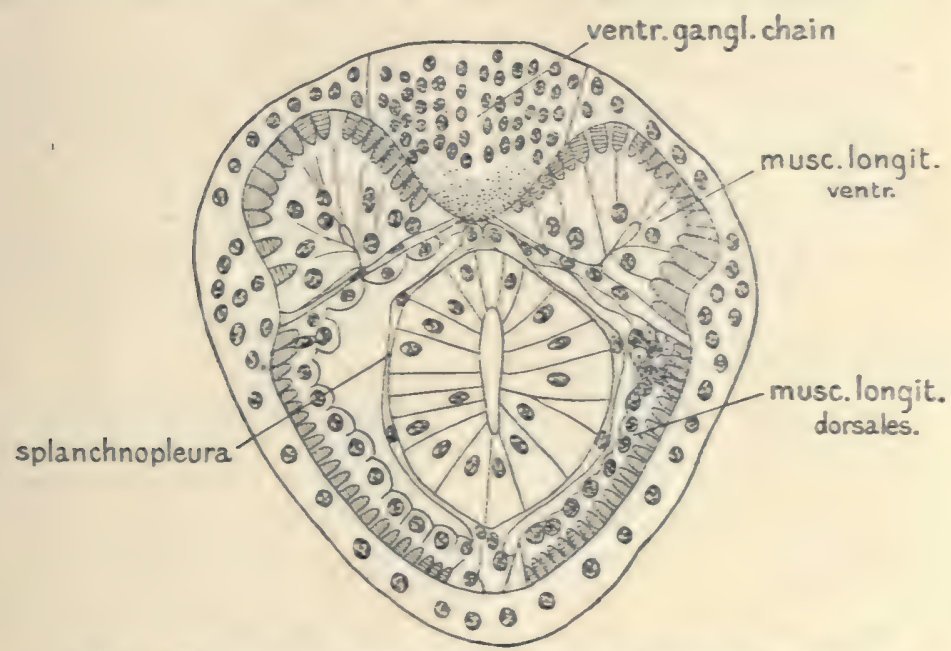

Fig. 4. Transverse section through the trunk of a young Polygordius, after HATSCHEK, 1878, fig. 89.

Vertebrates with regard to Annelids, a special differentiation from part of the smooth musculature of Annelids. From here to the conclusion that the ventral nerve roots supplying the striate muscles are also a new acquisition is only one step, and then BALFOUR's original view would still prove to be ultimately correct, equally with VAN WYHE's opinion.

Musculature and its innervation. - The first beginning of the striate longitudinal trunk musculature, of the myotomes, can perhaps be already recognized in Annelids. Here we can distinguish the ventral and the dorsal longitudinal musculature. The rudiment of the former separates very distinctly from the rest of the mesoderm and in transverse sections reminds one vividly of the myotomes of Vertebrates, 
being situated outside the somatic layer of the mesoderm surrounding the coelom. The latter mesoderm might be compared then to the lateral plate of Chordates. All this is shown by fig. 4, reproduced from HATSCHEK (1878, fig. 89). Also in Scoloplos I (1916, fig. 69,70) found similar figures in transverse sections and was struck by the resemblance in their situation to that of the myotomes.

The rudiment of the dorsal longitudinal musculature is much less conspicuous. I feel inclined to see in the rudiment of the ventral longitudinal musculature, being by far the most important component of the musculature of an Annelid, the beginning of the voluntary longitudinal musculature of the trunk of Vertebrates, as suggested equally by HATSCHEK (1878, p. 117). We can only suggest that the dorsal longitudinal musculature of Annelids, already less developed here than the ventral, has been lost in Vertebrates. To the circular muscles of Annelids the musculus transversus of Amphioxus shows a certain resemblance, consisting also of circular muscle fibres while it is innervated by the dorsal spinal nerves. The position, it is true, cannot be directly compared to that of Annelids.

Double innervation. - As to the innervation of the longitudinal musculature of Annelids FRAIPONT (1884, p. 280-281, 1887, p. 36), studying Polygordius, Protodrilus and Saccocirrus, observed in all these forms in the longitudinal muscles a diffuse nervous plexus which is not only connected with the ventral ganglion chain but also directly with cells of the epidermis, as could be shown in sections and by dilaceration. As a consequence of this double innervation "les impressions reçues de l'extérieur peuvent être transmises directement aux cellules ganglionnaires du plexus intermusculaire, sans avoir besoin de passer par les éléments centraux de la moelle." In the posterior region of the body, where the ventral medulla is no longer found, the second mode of innervation is even the only one that is present. It would be extremely interesting to know if also the ectoderm of the stomodaeum possibly stands in a similar relation to the intermuscular plexus. For after the stomodaeum had grown out to the medullary tube of Vertebrates and had extended along the neural surface of the body, similar relations may easily have been established between it and the contiguous lateral musculature. I feel inclined to suppose that in this way the ventral spinal roots, at first in a more 
diffuse form as in Amphioxus, have originated. In this connection the following observation of FRAIPONT (1884, p. 281) is noteworthy: "J'ai constaté sur des coupes transversales et verticales, dans la profondeur de la couche epithéliale de l'oesophage à droite et à gauche chez le Protodrilus, chez le Polygordius et chez le Saccocirrus, qu'il existe, à une place déterminée, une masse d' une substance finement granuleuse, entourée de noyaux de cellules un peu différents de ceux de l'épithélium. Je n'ai pu voir les rapports de ces deux masses ni avec le cerveau ni avec la moelle, ni avec le plexus intermusculaire et cependant elles me paraissent de nature nerveuse, d'après leur aspect général. Je me contente de consigner ce fait, sans pouvoir entrer, pour le moment, dans d'autres détails".

If our conclusions until now are right, we ought to assume that originaliy the striate musculature of Vertebrates, in the same way as the visceral musculature, has been supplied by the dorsal spinal nerves, though already in primitive Annelids, as we see from FRAIPONT's observation, a double innervation occurs. Such a double innervation now has been demonstrated recently also in Vertebrates. Here also, as has been shown especially by the researches of BOEKE (1911, 1913), a double innervation of the voluntary musculature is found, these muscles being supplied not only by the medullated fibres of the ventral roots but also by non-medullated sympathetic nerve-fibres which probably serve especially for sustaining the muscle tonus. Wide opportunities exist here for further investigation, also in Invertebrates.

Spinal ganglia in Amphioxus. - Our further considerations will lead us to a confirmation of the generally prevailing view, that Amphioxus is a form exhibiting in several respects the most primitive features among Chordates. So, if anywhere, we should expect to find here welldeveloped spinal ganglia, relatively independent from the medullary tube. This is not the case; on the contrary, distinct spinal ganglia have until now not been demonstrated in Amphioxus. After HATSCHEK (1892, p. 140,141$)$ they are represented by little nests of ganglion cells of a more or less diffuse character situated in the cutis, close under the epidermis from which they have originated, at the place where the dorsal spinal nerves branch into a ramus dorsalis and a ramus ventralis. 
HEYMANS and VAN DER STRICHT (1898) in studying the ontogeny of the spinal nerves could not detect spinal ganglia. This is indeed a difficulty from the point of view of my theory which I will not try at all to diminish by any far-fetched hypothesis. The only thing we can do is to assume that the spinal ganglia have fused with the medullary tube or have disappeared in the same way as all the sense-organs and the cerebral ganglia have been lost by Amphicxus which, as we will see, exhibits, in addition to its primitive features, many peculiarities which point to degeneration.

No stomodaeum in Chordates. - It is in accordance with my theory that in lower Vertebrates, in Amphioxus, Ascidian larvae and Appendicularia nothing like the ectodermal stomodaeum of the Zygoneura or Protostomia is found. The whole oesophagus is entodermal and the cardia is something quite different from the cardiac pore of Annelids. The mouth, breaking through only very late in embryonic development, leads directly into the entodermal branchial basket.

Taste in Chordates. - Now if our supposition is right that the stomodaeum was one of the first sense-organs, that of the taste, we must conclude that the Chordates would have lost this important sense, if they have not acquired a substitute. Probably the neural gland of Tunicates may be explained in this way. This peculiar organ, opening by the ciliated funnel in the roof of the anterior part of the branchial basket, originates from the central nervous system, as was pointed out by KOWALEWSKY (1866) for the Ascidians and by myself for the Appendicularia (1912). Evidently a new communication between the former stomodaeum and the gut was established after the old one had atrophied, originating as a diverticulum from the so-called brain-vesicle, afterwards separating from it and thus giving rise to a little ciliated funnel-shaped sense-organ of ectodermal origin in the entodermal gut-wall. It remains in close connection with the cerebral vesicle, the swollen anterior end of the medullary tube, the former stomodaeum.

In Amphioxus and the Craniata we see arise an ectodermal involution, the oral cavity, into which in Craniata the endbuds - in fishes still widely distributed in the mouth, the branchial cavities and the outer surface of the head, in some even over almost the whole surface of the bodygradually concentrate to form the taste-buds which in higher Craniates are chiefly confined to the epithelium of the tongue 
and the soft palate, and are innervated by the gustatoyr branches of the N.trigeminus, facialis and glossopharyngeus.

Protostomia, Deuterostomia, Tritostomia. - We have come to the conclusion that the old distinction by HATSCHEK of the three groups Zygoneura, Ambulacralia and Chordonia is to be piefered to GROBBEN's division into Proto- and Deuterostomia, since the latter group does not constitute a natural unit. HATSCHEK and his assistant SCHNEIDER have also been inclined to unite their Ambulacralia and Chordonia into one group, the Enterocoela, in which the coelomic mesoderm is of entodermal origin, whereas in the Zygoneura or Ecterocoela it would be of ectodermal origin (cf. HATSCHEK, 1S11, p. 18). That this last opinion is erroneous has been conclusively demonstrated by the cell-lineage investigations.

My theory, on the contrary, would rather point into the direction of a union of the Chordonia with the Zygoneura, from which they are to be derived. Yet a subdivision of the "Coelomata", the three-layered Metazoa, into three groups is no doubt the more preferable method. In GROBBEN's nomenclature we could designate these three groups as Protostomia, De uterostomia and Tritostomia. In the first group the primordial opening of the gut to the exterior, the blastopore, becomes the ingestion-opening. In the second group it passes into the anus and a second opening becomes the mouth. In the Tritostomia the first and the second opening pass into the canalis neurentericus (former ingestion-opening) and the anus, while the mouth breaks through only late in embryonic life as a third opening. To the question if there is any relation of the anus to the blastopore we will revert in the last chapter. There I hope to show that not only the application of the principles of my theory will bring us the solution of the old problem of the relation between anus and blastopore, which will prove to be a secondary one, but also that, considered in the light of this solution, the facts to be observed yield one of the strongest supports in favour of the view that the neural tube indeed represents nothing but the former stomodaeum that has grown out in caudal direction as far as the posterior end of the body and even further still (formation of the tail). 


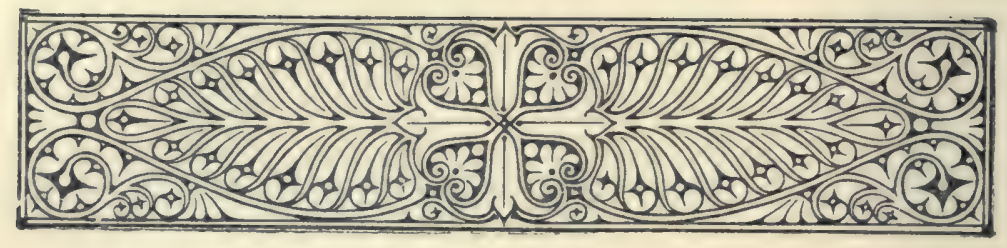

CHAPTER II.

\section{Origin and structure of the head.}

Brain and cerebral ganglia. - As pointed out above, the great and unsurmountable difficulty connected until now with the Annelidan theory of the origin of Vertebrates is the derivation of the head of the latter from that of Annelids. If we homologize the central nervous system of Vertebrates to that of Annelids and especially the brain of the former to the cerebral ganglia, we find the difficulty before us that we have to assume - as DOHRN did - that originally in the region of the hindbrain or the medulla oblongata the central nervous system must have been pierced by the gut, and that the mouth had originally a dorsal position but afterwards has atrophied and been replaced by a new, ventral, mouth, opposite the old one. A last trace of the former mouth passage of the gut through the nervous system was viewed by DOHRN $(1875$, p. 3) in the fossa rhomboidea between the crura cerebelli.

BEARD (1888, p. 22) imagined the cerebral ganglion to have got totally lost, he considered the ventral ganglion chain of Annelids to be the homologue of the whole central nervous system of Vertebrates, and found the rest of the old mouth again in the hypophysis. MINOT (1897) suggested still another way of getting out of the difficulty by 
supposing that the two cerebral ganglia, which originate separately, have not united by a commissure. They have remained separate, the oesophageal nerve-ring as a consequence not being closed anteriorly, and have passed, together with the oesophageal connectives which form tre communication with the ventral ganglion chain, into the optic vesicles with their stalks, while the anterior ganglia of the ventral chain give rise to the brain. He too, however, considered the Vertebrate mouth as a secondary formation and found, with KUPFFER (1894), the palaeostoma again in the common invagination from which in Cyclostomes both the olfactory organ and the hypophysis take their origin. No facts, however, can be adduced in favour of any of these hypotheses and after their examination we can only conclude that MINOT's statement that “il n'a été proposé aucune hypothèse ayant rapport à l'évolution de la tête du Vertébré aux dépens du type Annélide qui ne puisse encourir des objections insurmontables" has not yet lost its validity.

All the above cited authors agree in that the Vertebrate mouth is a secondary one, but why the old mouth should have been lost and replaced by a new one, is not easily explained from their theories. GASKELL (1908, p 55), who derives the Vertebrates from Arthropodan ancestors in a very adventurous way, lets the cerebral and infra-oesophageal ganglia in the latter increase. so much in size that the oesophageal ring is reduced to a very narrow passage for the gut, a process which finally resulted in a squeezing out the latter by the increasing nerve-mass ("antagonism between cephalization and alimentation"). The whole gut then passes into the medullary tube of Vertebrates (cf. above, p. 11). I hardly need point out once more how evident and natural an explanation of such a curious phenomenon as the loss of a mouth is afforded by my theory. But with reference also to the problem of the formation of the Vertebrate head the theory leads to most unexpected results, as I hope now to show.

Praeoral lobe in Annelids. - In the development of the Annelids the umbrella or episphere of the trochophoralarva gives rise to the praeoral lobe or prostomium and to the cerebral ganglia of the worm, the subumbrella or hyposphere lengthens out into the segmented soma. It was KLEINENBERG (1886, p. 181) who first opposed these two regions of the Annelids body to each other and distinguished them as 
head and trunk, emphasizing the separate origin of the nervous system (cerebral and ventral ganglia) in the two. HATSCHEK (1878, p. 69), as a result of his researches on Polygordius, had used the word head in a somewhat different sense, comprising not only the umbrella but also the subumbrella of which the segmented soma is considered by him to be only a kind of outgrowth or appendix. So to this "head segment", corresponding to prostomium + peristomium (first segment of the soma), not only the mouth, which lies immediately beneath the prototroch, but also the protonephridia and the statocysts were considered to belong (cf. anon). KLEINENBERG, however, emphasized that the development of the larva of Polygordius, where a great deal of the umbrella and the subumbrella, together with the prototroch, is cast off during metamorphosis, exhibits somewhat peculiar features which may easily lead to misinterpretation. In general it is quite evident in Annelidan larvae that the first segment, the peristomium, containing the first pair of ventral ganglia (the infra-oesophageal ganglia), lies immediately behind the prototroch. The prototroch accordingly must be considered as the limit of the nonsegmented head or prostomium and the segmented trunk, and the mouth and the statocysts as belonging to the latter. This view has found general acceptance among later investigators of which I will mention only SALENSKY (1887 p. 632), MEYER (1890 p. 296), RACOVITZA (1896), GOODRICH (1897) and EISIG (1899, p. 226).

Mesenchyme and coelomesoblast. - The prostomium (a term introduced by HUXLEY) contains originally the cerebral ganglia which originate from its wall, though in Oligochaeta they secondarily may wander backwards into the anterior trunk segments. The latter contain each a pair of ventral ganglia and a pair of mesoblastic somites which surround a portion of the alimentary canal. The cavity of the prostomium, however, belongs to HATSCHEK's primary body-cavity, the blastocoele; it is, as GOODRICH (1897) remarks, "primitively of the nature of a blood-space, most clearly seen in trochosphere larvae, where it is much enlarged." The scattered mesenchymatous cells originally contained in it have an ectodermal and probably a radial origin, as shown by the cell-lineage investigations, whereas the trunk- or coelomatic mesoderm is produced in a bilaterally symmetrical way by the two teloblasts which must be considered 
as derived from the primary entoderm. The contrast between the "primary mesoderm or embryonal mesenchyme" and the "secondary or coelomatic mesoderm" was first emphasized by MEYER (1890) who compared the former to the mesenchyme of plathelminthes and derived the coelom:c pouches from the genital follicles of the latter (gonocoeltheory). These follicles often even already exhibit a tendency to regular metameric arrangement. According to this view we may consider the ectodermal mesenchyme of the trochophora as a last remnant of that of mesenchymatous worms, of their larva, the protrochula (HATSCHEK) - MüLLER's larva of Polyclads, pilidium and DESOR's larva of Nemerteans-and of the Ctenophores, in the same way as the protonephridial head-kidney found in several trochophoras reminds us of the richly branched excretory system of ancestors like the mesenchymatous worms or the Rotatoria.

Praeoral lobe in Amphioxus. - The mouth belongs to the first trunk segment, the peristomium. It is situated just behind the limit of the prostomium and the first segment. Now, if we compare this with what we find in a young embryonic stage of Amphioxus, as represented in fig. 5 and

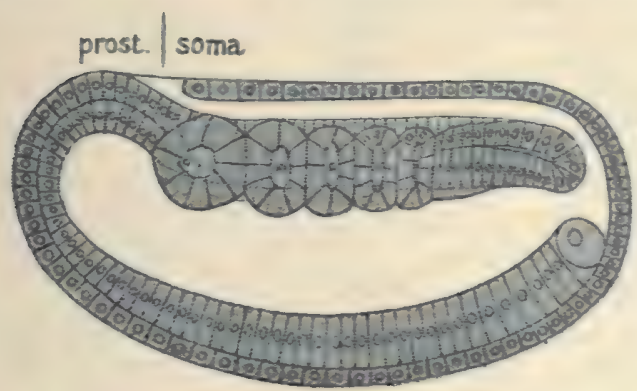

Fig. 5. Optic longitudinal section of a young stage of Amphioxus (after HATSCHEK, 1882, fig. 46).

6 , there is a remarkabie agreement to be noticed. In front of the first pair of coelomic pouches we find here also a part of the body in which originally no coelomic mesoderm, and even no mesoderm at all, is present, and which we can compare to the praeoral lobe or prostomium of the

Annelids. This supposition is confirmed by the exactly corresponding situation of the mouth in the two cases. In Amphioxus of course the old mouth, the neuropore, is meant. Just like the mouth in Annelids, it is found at the limit of the cephalic lobe and the first segment, which is here indicated by the first pair of coelomic pouches. The agreement so far hardly could be more complete. 
If we compare the embryo of fig. 5 and 6 with an outgrowing trochophora which has already produced a number of segments, the episphere is the part lying in front of the first mesodermic segment and the outgrowing soma is the rest of the body. A difference is that the ectomesoblast seems to have totally disappeared.

Secondary mesoblast in the prostomium. - In Annelids not only the original mesenchyme of ectodermal origin is found. in the prostomium but also the coelomic trunk mesoderm sends out into it secondary prolongations. This was stated by HATSCHEK (1886, p. 11) and KLEINENBERG (1886, p. 148) already, and MEYER (1890, p. 299) remarks: "Bei den Anneliden besitzt der Kopflappen keine eigenen Mesodermsegmente, sondern erhält seine peritoneale Auskleidung, wie ich mich überall davon iberzeugt habe, durch Ausdehnung der Wandungen des ersten postoralen, also Rumpfsomitenpaares nach vorn, wodurch die primäre Kopfhöhle vollständig verdrängt wird." This latter statement, according to EISIG (1899, p. 230), is not right : in front of the brain, which remains connected with the ectoderm, the coelomesoblast cannot penetrate.

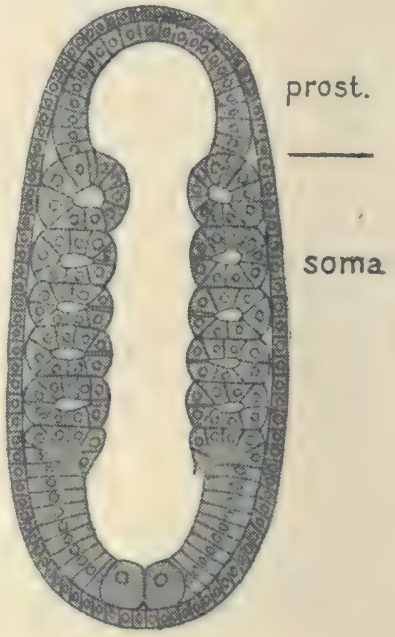

Fig. 6. Horizontal section through the same stage (after HATSCHEK, 1882, fig. 47). Thus the antecerebral part of the prostomial cavity preserves its blastocoelic nature and the muscle fibres extended in it are of ectomesoblastic origin.

Just as in Annelids, the foremost pair of somites in Amphioxus secondarily provides the prostomium with mesoderm, each sending out a forward prolongation into it, known as the rostral or head-prolongation (Kopffortsatz). The anterior end of the notochord in fig. 5 exactly corresponds to that of the series of somites; it indicates the limit of prostomium and soma and accordingly lies right under the neurope. Afterwards, however, the notochord, together with the rostral prolongations of the first pair of somites, grows out into the prostomium, providing a firm 
support for the snout which is used by the animal for burying itself in the sand. By this process the anterior end of the notochord secondarily soon reaches a considerable distance in front of the neuropore.

Praechordal brain in Craniates. - If presently we turn to the head of Craniata, we find here a disposition which exhibits a fundamental difference from things as they occur in the head of Amphioxus. While in the latter the fore-end of the notochord, originally at least, is lying right

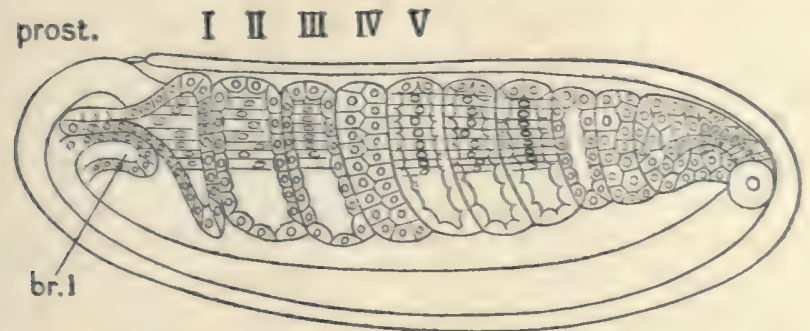

Fig. 7 Young stage of development of Amphioxus (after HATSCHEK, 1882, fig. 51).

br. I: first gill pouch of the left side ("anterior entoderm pocket"). prost. prostomium

I, II, III etc. segments of the soma

under the neuropore, the whole nervous system being epichordal and its anterior end indicating the limit of prostomium and soma, things are different in Craniates. Here part of the brain reaches in front of the anterior end of the notochord, being thus praechordal, and if this fore-end of the notochord here also marks the limit of prostomium and soma, we are induced to suppose that the medullary tube must have acquired a forward prolongation and, as it were, has annexed part of the epithelium of the prostomium. Thus it would be explained that the rudiment of the central nervous system reaches up to the anterior end of the embryo, thus differing from that of Amphioxus. This is the second main principle of my theory. I first, however, was led to it along a quite different path, scil. by a comparison of the manner in which the eyes originate in Craniates and in worms.

Optic organs of Acrania. - A comparison of the optic organs of Craniates with those of Amphioxus or the Ascidian larvae does not take us very far. It is true that in both cases they take 
their origin not from the epidermis, like other sense-organs, but from the wall of the brain vesicle. In the brain vesicle the larvae of the Ascidians possess a little eye, provided with a lens. In Amphioxus we find in the anterior wall of the brain vesicle only a little median pigment-spot. A number of similar pigment-spots occur also in the wall of the whole medullary tube with the exception of a few anterior segments. No transitions, however, are found between these extremely simple organs and the highly complicate Vertebrate eye, which is built on a wholly different plan and to the composition of which not only the brainwall but also the bodywall (lens) and the mesoderm contribute "Fertig, wie Athene aus dem Haupte des Zeus", FRORIEP (1906, p. 140) says, "tritt das Vertebratenauge in die Erscheinung" and from the evidently more or less degenerate eyes of Cyclostomes onwards no other organ in the phyletic series of the Craniates exhibits such a uniformity in the essential features of its organisation.

Attempts to derive the Craniate eyes from them. - Yet attempts have not been wanting to trace back the eyes of Craniates to the corresponding structures in Amphioxus and the Ascidian larvae. Thus RAY LANKESTER (1880) expressed as his conviction: "that the original Vertebrate must have been a transparent animal, and had an eye or pair of eyes inside its brain, like that of the Ascidian tadpole. As the tissues of this ancestral Vertebrate grew denser and more opaque, the eye-bearing part of the brain was forced by natural selection to grow outwards towards the surface, in order that it might still be in a position to receive the influence of the sun's rays". BALFOUR (1881, p. 419) points to another possibility, viz: that the eye of the Ascidians is a degenerate form of the Vertebrate eye.

JELGERSMA (1906) traces in details the way in which the transformation of the Ascidian optic organ into the Vertebrate eye could have been performed. According to FRORIEP (1906 b), however, the Craniate eye cannot be derived directly from that of the Ascidian larva but both have developed from an original condition in which two eye-pits were lying at the suiface. After the involution they strove to regain the light. In the Ascidians one was lost and the other applied itself closely to the transparent body-wall. WILLEY (1894), on the other hand, homologizes the parietal eye of Craniates to the optic organ of Ascidian larvae. 
Among those who recognize the fore-runner of the Vertebrate eye in the so-called eye-spot at the anterior end of the brainvesicle of Amphioxus may be mentioned MüLLER (1874), AYERS (1890), who discovers traces already of a bilateral symmetry and a tendency to bipartition in it, and HAECKEL (1895). BOVERI (1904), on the contrary, derives the Vertebrate eye from the segmentally arranged pigment-spots which are found, except in a few anterior segments, in the ventral wall of the medullary tube. They each consist, according to HESSE (1898 p. 36), of two cells, a cup-shaped pigment-cell applied to a visual cell with a nerve-fibre, embedded in the convexity of the former. In the visual cells BOVERI sees the homologue of the rods- and cone-cells in the Craniate eye. The transformation is imagined by him in this way: that primarily one of the segments of the medulla containing the visual cells, approaches the body-surface by devagination and that both the walls of the thus formed eye vesicle, when it passed into the optic cup, have differentiated in such a way that in the outer one the pigment-cells disappeared; in the proximal one, on the contrary, the visual cells have been lost. In this way the retina and the pigmentlayer of the eye have originated. JOSEPH (1904, p. 24) rightly emphasizes the many difficulties connected with this conception.

It cannot be denied that all the above cited theories, however ingenuous or fascinating, are of a purely speculative nature. In general they are not based on convincing evidence derived from comparative anatomy or embryology. They cannot serve as an argument for the view that the Craniate eye is to be derived from that of Acrania, an assumption they take as granted. In these two groups the eyes have nothing in common but their encephalogenetic origin.

Eyes of Annelids and Molluscs. - My theory permits us to give an explanation of the cephalogenesis of Craniates, which at the same time has the advantage of providing the solution of the second problem, the phylogeny of the Vertebrate eye, and which moreover is supported by valuable embryological arguments. On the episphere of the trochophora - and even already in the protrochula-larva of mesenchymatous worms we find a pair of pigment-spots which are already present before the cerebral ganglia have been formed. In the adult worm they are found again on the prostomium. No doubt 
they can only serve to distinguish light and dark, and their resemblance to the highly perfected eyes of Vertebrates is very slight. Further differentiation, however, of these primitive optic organs leads quite gradually to the varied forms of eyes met with among Annelids and the closely allied Molluscs, some of which very nearly approach the complexity of the Vertebrate eye. The structure of the Annelid eyes has been investigated especially by CARRIËR (1885), ANDREWS (1891, 1892) and HESSE (1899). The first step towards further perfection is a depression of the ectoderm, giving rise to so-called pit-eyes, as found especially among sedentary Polychaets. These pits may get very deep and finally close and separate from the ectodermal epithelium, thus giving rise to vesicular eyes, as found especially among predatory Polychaets, and which reach their highest perfection in the pelagic Alciopids. Here the eyes, first described by GREEFF (1876) and afterwards by several other authors, are large swelling vesicles, provided with an internal lens, a cornea, a vitreous body and even a ring of accomodative muscles Next to the Cephalopods the Alciopids, as HESSE (1899, p. 475) remarks, afford the only example of accomodative power among Invertebrates (cf. also HESS, 1909, $1914^{1}$ ).

In Molluscs a similar, parallel series may be composed (cf. HESSE 1902, p. 622) from the pit-eyes found in several primitive Gastropods and in Nautilus to the vesicular eyes of the other Gasteropods and those of Cephalopods, where the organisation reaches a height closely approaching that of the Vertebrate eye to which it shows a resemblance so striking that, ever since, it has attracted the attention of zoologists. Yet it cannot be doubted that this complex structure has developed out of the paired pigment spots which we find also ir the trochophoras of primitive Molluscs, such as Amphineura, Lamellibranchiata and several Gastropoda. The points of resemblance between Cephalopod and Craniate eyes are no more striking, however, than is the difference between them: the successive layers of the retina and the optic ganglion applied to it in the one case showing the reverse arrangement from those in the other.

1) A third case has since been described by HESS and GERWERZHAGEN, in Pterotrachea (1914). 
That the eyes also of Arthropods, which in their situation and their relation to the cerebral ganglia so closely agree with those of worms, are to be derived from the same starting point cannot be doubted.

Absence of paired eyes in Acrania. - Now in Amphioxus we should expect to find a pair of eyes on the surface of the prostomium, in front of the neuropore, corresponding to those of Annelids. Neither eyes, however, nor cerebral ganglia are to be found here; evidently we must assume that they have been lost as a result of the change of function of the snout, which in Amphioxus serves. for burrowing into the sand while in Ascidians, according to WILLEY (1894), it is the same organ that serves for attachment.

Optic pits in Craniates. - If in Craniates, however, the praechordal region of the body may be compared to the

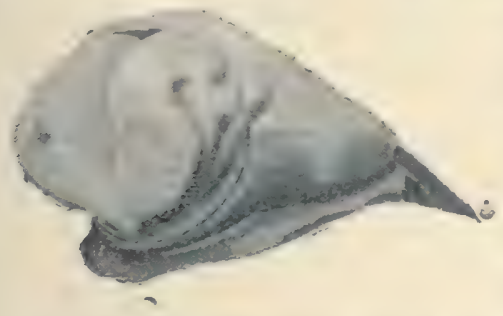

Fig. 8. Rostrolateral view of the head of an embryo of Sus scrofa, with 10 mesoderm segments.

From HERTWIG's Handbuch T II,

2, p. 156, after a modell of KEIBEL. praeoral lobe in Annelids, as suggested above, we meet here in very early ontogenetic stages a disposition which strongly reminds us of what is found in Annelids. In the development of Craniates the first indication of the retinal area is often noticed already on the still open and flat praechordal cerebral plate as a pair of shallow depressions of the thickened ectoderm. As well in Elasmobranchs and Amphibians as also in Mammals the occurrence of these optic pits has been known for a long time. The cerebral plate with the eye-pits, situated in front of the provisory neuropore, reminds us strongly of the apical plate of the trochophora with the rudiments of the eyes situated in front of the mouth, especially in such cases where the medullary plate has closed while the cerebral plate is still open, and where, accordingly, the anterior opening of the former represents a kind of provisory neuropore corresponding to that of Amphioxus and, if our conclusions until now are right, to the mouth of Annelids. An example of such a case is given by fig. 8 , after KEIBEL. Especially interesting in this respect are the observations of EYCLESHEIMER $(1893,1895)$ on 
Rana palustris and on Amblystoma. Here the open cerebral plate shows two shallow depressions in which the epitheliumcells produce in their distal parts fine pigment granules in such a quantity that, according to the statement of the author, these optic areas are already recognizable on examination of the complete egg, as two pigment-spots on the cerebral plate. In more advanced stages, when the cerebral plate closes, the pigment gradually disappears and at the same spots the optic vesicles now evaginate.

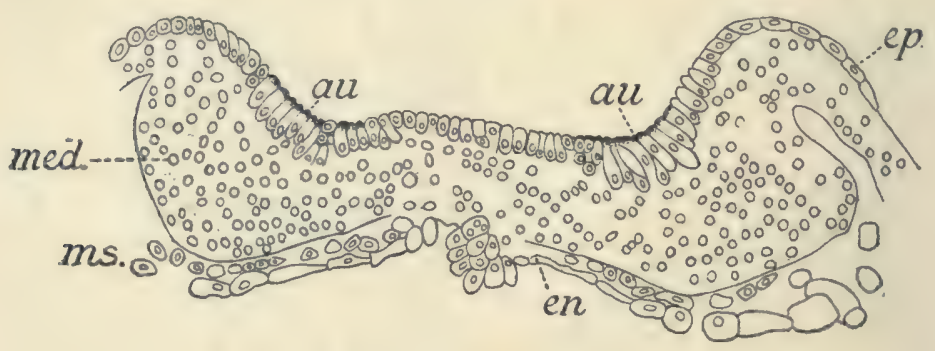

Fig. 9. Transverse section through the cerebral plate of an embryo of Rana palustris.

au optic pits, en endoderm, ep superficial layer of the ectoderm, med. cerebral plate, $m s$ mesoderm (after EYCLESHYMER, 1895).

Encephalogenetic origin and inversion of Craniate eyes.-The attention of investigators has been long drawn to the fact that the Vertebrate eye takes its origin from a place not directly exposed to the light which it will have to perceive. Thus it differs from all other sense-organs in that it is not derived from the surface of the body which is first impressed by all kinds of external stimuli. No less remarkable is the fact that the optic ganglion in Craniate eyes does not lie under the retina, as in Invertebrates, but on it, and that, as a consequence, the light rays must pass first through the ganglion to reach the retina in which the rods and cones are averted from the light. No wonder, then, that a phylogenetic significance has been attributed to the pigmented eye-pits on the cerebral plate. As early as 1881 BALFOUR in his Treatise (Vol. II, p. 419) suggested the following explanation of the phenomena mentionned above: 
"I can only suggest that the development of a primary optic vesicle, and its conversion into an optic cup, is due to the retinal part of the eye having been involved in the infolding which gave rise to the canal of the central nervous system. The position of the rods and cones on the posterior side of the retina is satisfactorily explained by this hypothesis, because, as may be easily seen from fig. 285 , the posterior face of the retina is the original external surface of the epidermis, which is infolded in the formation of the brain, so that the rods and cones are, as might be anticipated, situated on what is morphologically the external surface of the epiblast of the retina." (cf. fig. 10). CARRIËRE (1885, p. 89) joins BALFOUR in the assumption that in Vertebrates "der Theil des Ektoderms, aus welchem sich die Augenanlage bildet. in den Bereich der Gehirneinstülpung gezogen wurde," and in 1888 BEARD
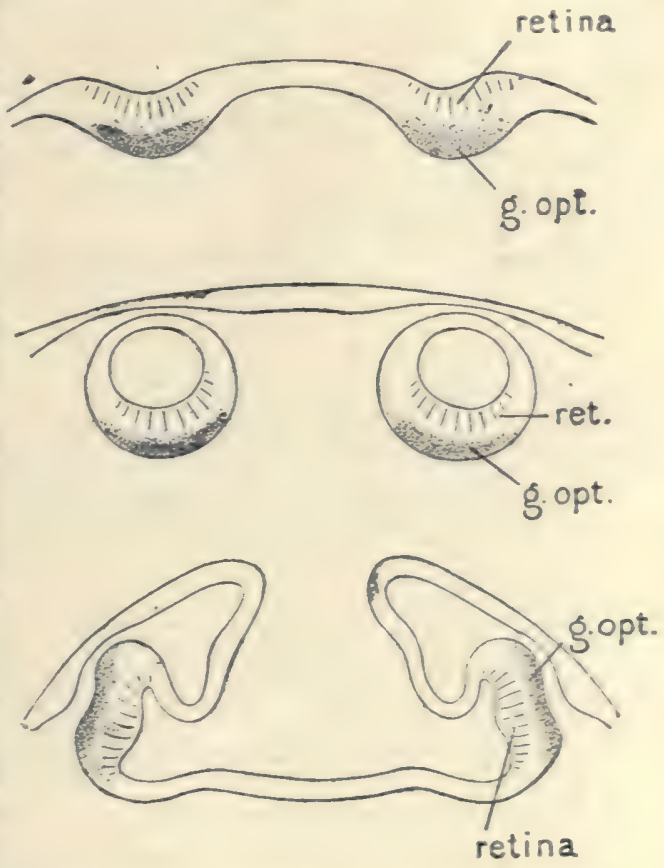

Fig. 10. Diagrams of groove-eyes, eyevesicles and the development of inverted Craniate eyes. g. opt. optic ganglion.

(1888, p. 68) declares: "Most of us now accept the view of BALFOUR, CARRIERE and others, that the eyes were once structures opening dorsally on the surface of the unclosed neural plate." V. KENNEL (1891) made the further step to derive the primary eyecups from the vesicular eyes of predatory Annelids, though his attempt cannot be called very successful. He imagines the cerebral ganglia to have receded along the circumoesophageal commissures and to have 
fused with the anterior ganglia of the ventral nerve chain, from which the Vertebrate brain is derived. The eye rudiments follow them and are incorporated with the brain involution from which they grow out again to the surface with an inverted retina. No such fusion of the cerebral ganglia with the ventral nerve-chain needs to be assumed, however, if we apply the principles of my theory to this case.

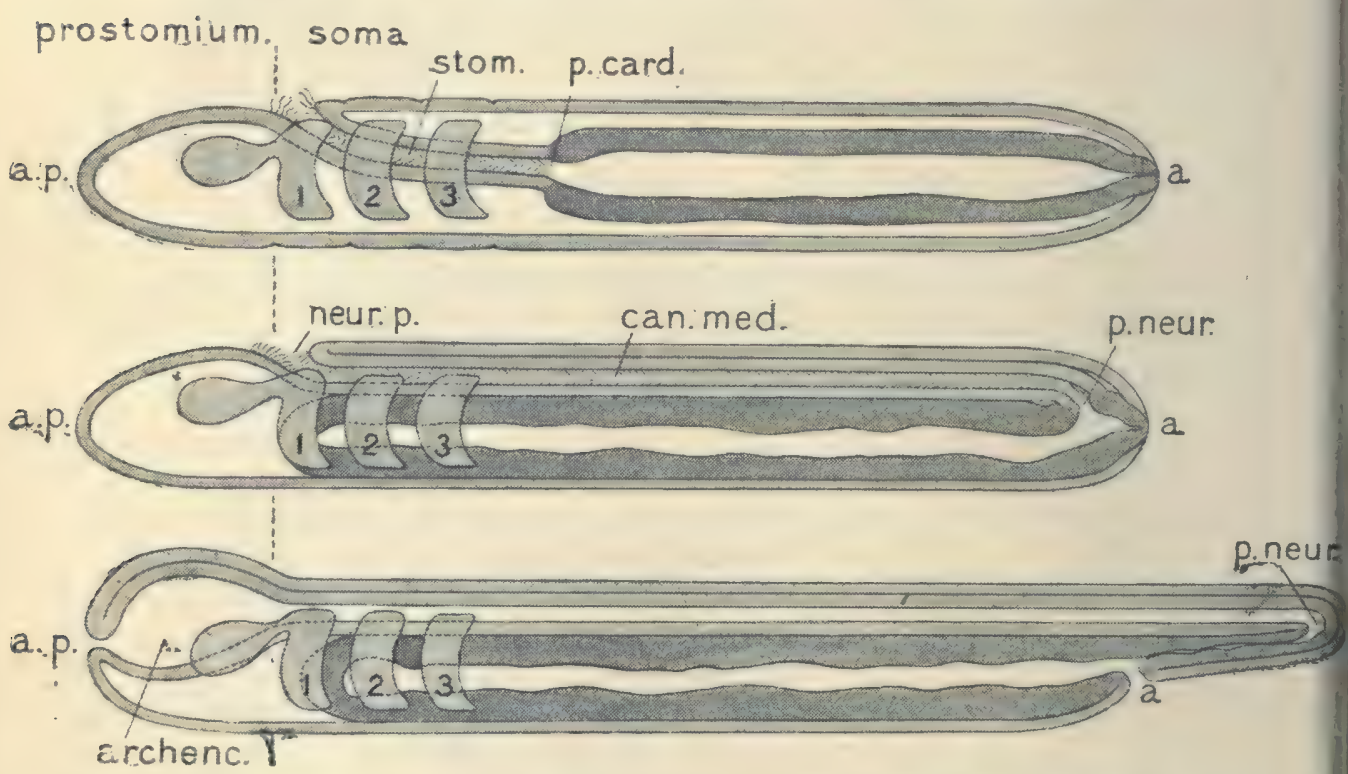

Fig. 11. Diagrams of an Annelid, an Acraniate Chordate before the formation of the tail has begun and a Craniate Chordate with tail (cf. Chapter III). $a$ anus, $a$. $p$. animal pole, archenc. archencephalon, can. med. medullary tube, neur. $p$. neuropore, $p$. card. cardiac pore, $p$. neur. neurenteric pore, stom, stomodaeum.

Homology of Craniate and Protostomian eyes. - Thus we are led along a quite different path to a conclusion already indicated by a consideration of the relation of the fore-end of the notochord to that of the medullary tube, scil. that part of the surface of the episphere or prostomium containing the pigment-spots, has, so to speak, been annexed by the forward extension of the medullary tube, thus forming the praechordal part of the brain with the optic vesicles which in Vertebrates have evidently developed along lines 
parallel to those which in Molluscs led to the strikingly similar Cephalopod eyes and in Annelids to the Alciopid eyes. We must conclude that the epichordal part of the medullary tube of Craniates, including the hind-brain, corresponds to the whole central nervous system of Amphioxus and to the stomodaeum in Annelids and that the praechordal forebrain, with the eyes, is a new acquisition of a quite different origin, but derived from the same source which in Annelids gives rise to the cerebral ganglia and the eyes. The inverted structure and encephalogenetic origin of the Craniate eyes are explained at once. Since the first publication of my theory, pricking experiments, to be described in detail in the last chapter, have yielded a valuable confirmation of the views expressed above. Here may be mentioned the main results only.

Situation of the animal pole. - While in the first publication of this theory (1913) I assumed that the praechordal part of the brain was to be derived from the info!ding of the whole apical plate or episphere of the worm larva. I afterwards (1916) concluded that this conception could not be correct, for, besides the fore-brain, the episphere must furnish also in Craniates, just as in Annelids and in Amphioxus, the ectodermal wall of the snout. Thus the fore brain can be derived only from part of the apical plate or of the ectodermal wall of the prostomium. This must be the part contiguous to the mouth, i.e. the neuropore of Amphioxus. Now in worms and molluscs we find in the centre of the apical plate of the larva the animal pole of the egg, being the aboral pole of the gastrula, indicated as a rule by the presence of the polar bodies and by the regular radiate arrangement of the cleavage cells round it. If the whole apical plate were to be transformed into the fore-brain of Craniates we should expect to find the animal pole in the latter on the cerebral plate, and this conclusion was drawn in my first article. If, however, as I have corrected it afterwards, only half the apical plate gives rise to the fore-brain of Craniates and the other half to the ectodermal investment of the prostomium, we may expect to find the animal pole in the vicinity of the anterior border of the cerebral plate, known as the transverse cerebral fold, or of the neuropore after the closure of the brain vesicle. Pricking experiments on amphibian and fish eggs, to be described in the last chapter, fully confirm this conclusion. 
In Amphioxus, on the contrary, we may expect the animal pole at the same place as in Annelids, i. e. on the anterior surface of the prostomium, a good distance in front of the neuropore. This also is confirmed by the facts. In Amphioxus, it is true, we cannot trace the fate of the animal pole with such certainty as in worms and molluscs, the cleavage being of the indeterminate type which soon renders it impossible to distinguish the individual cells from each other and to determinate from their arrangement the place of the animal pole. The polar bodies, however, often remain attached to the developing egg for a considerable time, up to the gastrula-stage. One of these eggs, as observed by CERFONTAINE (1906), is reproduced here in fig. 12.

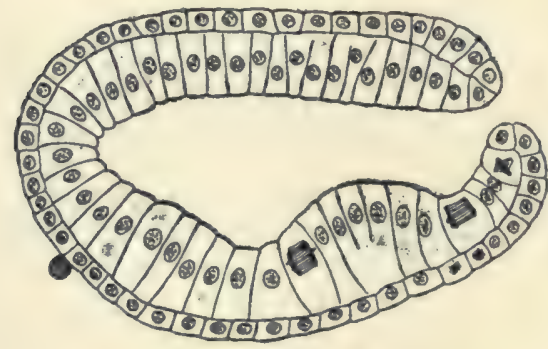

Fig. 12 Gastrula of Amphioxus, with polar body, after CERFONTAINE, 1906

If we compare this stage with that of fig. 5 , it will be evident at once that, if it might be possible to observe the polar bodies in the latter stage, they would be found on the surface of the prostomium at a considerable distance in front of the neuropore. Thus for the third time we reach the same conclusion, viz: that the fore-brain of Craniates is a new acquisition with reference to the Acrania.

HATSCHEK's view on the Craniate brain. - A similar assumption, combined with the view that the infundibulum represents the primitive fore-end of the brain, comparable to the neuropore of Amphioxus, has, anticipated already by V. BAER's investigations, found several adherents and has recently been defended by HATSCHEK (1909. p. 497). The praechordal part of the brain is imagined by them to be a secondary outgrowth from the epichordal part as found in Amphioxus (cf. the quotation from WIEDERSHEIM anon). According to my theory, however, there is no question of a forward outgrowth of the original epichordal brain of Amphioxus but of a forward extension and an incorporation of ectoderm in front of it. 
Archencephalon and deuterencephalon. - The Craniate brain is composed then of two parts of different origin. the first being the epichordal part which represents nothing else but the
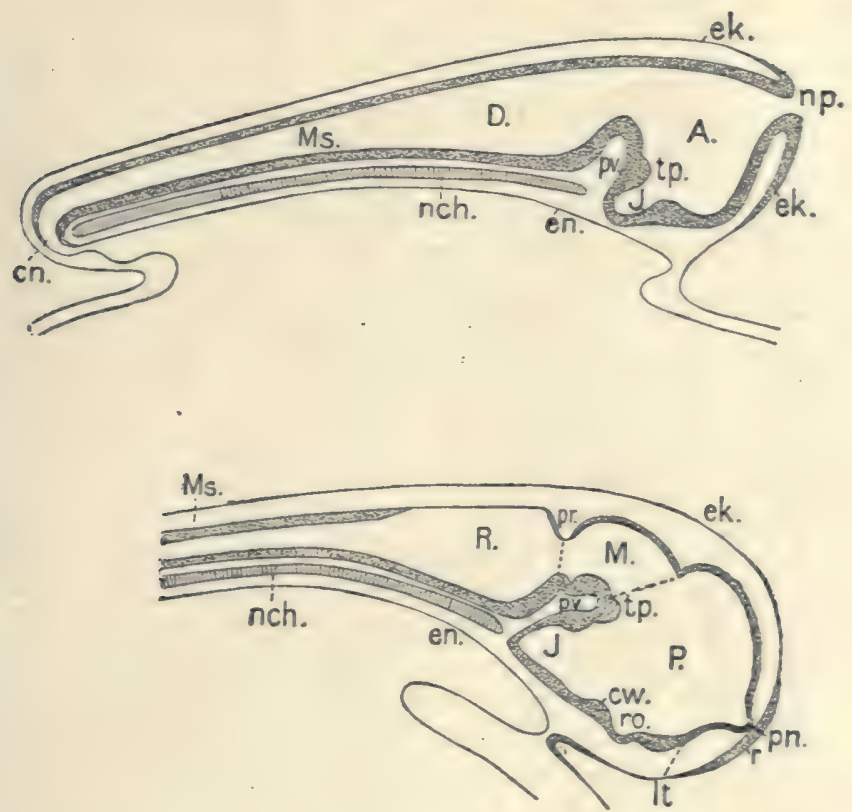

Fig. 13 Diagrams of the development of the Craniate brain.

$A$ archencephalon, $c n$ neurenteric canal, $c w$ chiasma, $D$ deuterencephalon, ek ectoderm, en entoderm, $I$ infundibulum, It lamina terminalis, $M$ mesencephalon, $M s$ spinal chord, $n c$ notochord, $n p$ neuropore, $P$ prosencephalon, $p n$ processus neuroporicus, $p r$ plica rhombo-mesencephalica, $p v$ plica ventralis. $R$ rhombencephalon, $r$ olfactory placode, ro recessus opticus, $t p$ tuberculum posterius.

(after KUPFFER, 1906, p. 13, 14).

anterior, somewhat dilated, end of the former stomodaeum, comparable to the brain vesicle of Amphioxus - which consequently is not homologous to the brain of Craniates the other being that part of the prostomium which has been folded in. In early ontogenetic stages a corresponding division 
into two regions is very evident. Immediately after the closure of the medullary plate we can distinguish, with V. KUPFFER (1905), the archencephalon and the deuterencephalon, the former praechordal and giving rise to the optic vesicles, and the latter epichordal. The two are separated from each other by the plica ventralis, a transverse fold of the ventral wall of the brain, right over the fore-end of the notochord. The archencephalon is thus a well defined vesicle; the deuterencephalon tapers insensibly, without a distinct limit, into the medullary tube of which it is indeed only the anterior dilated part. The plica ventralis indicates at the same time the place of the cephalic flexure and lies right over the sella turcica which, after GEGENBAUR (1872, p. 119), indicates the limit between the segmented "vertebral" and the unsegmented "praevertebral" part of the skull. From the archencephalon the telencephalon and the diencephalon afterwards develop, from the deuterencephalon, whose cavity becomes the fourth ventricle, the myelencephalon and, if present, the metencephalon. For the mesencephalon, whose cavity becomes the iter, it is hard to say from which of the two it is to be derived and if it is to be derived from either of them. It lies exactly above the plica ventralis. At any rate it is in the region of the isthmus, between mesoand metencephalon, that we have to look in Craniates for the neuropore of Amphioxus which represents the old mouth.

From the above considerations it follows that the brain vesicle of Amphioxus is to be compared with the deuterencephalon of Craniates and not with the archencephalon, as KUPFFER himself supposed. From this point of view it might appear adequate to interchange the names arch- and deuterencephalon, the latter phylogenetically being present before the archencepalon. I will not, however, propose a change of names when introduced by such an authority as V. KUPFFER and generally adopted. Not only would such a change give rise to confusion but arguments may be equally well adduced for the present nomenclature, for the archencephalon, together with the eyes, develops from the same source as the cerebral ganglia and eyes in worms, molluscs and arthropods, viz: from the apical plate, and that their homologue is absent in Amphioxus is evidently due only to secondary circumstances. In this respect then the archencephalon has older claims to the name of brain than the deuterencephalon. 
Neuropore of Craniates and of Amphioxus. - Thus only in Amphioxus the neuropore corresponds to the mouth of the Annelids and represents the old mouth of the Vertebrates. In the development of Craniates we shall see the old mouth appear only. in cases where the closure of the medullary tube precedes that of the cerebral plate so that the praechordal cerebral plate, with the optic pits, is still open when the hindbrain and the spinal cord have already closed to a tube which opens to the exterior at its fore-end with a kind of provisional neuropore, as KEIBEL figures for the pig (fig. 8). This provisory neuropore, at the place where later the isthmus will be found, here represents the old mouth. Perhaps also the thin roof of the fossa rhomboidea is to be regarded as a trace of the former mouth.

Cranial flexure. - At the same time the almost invariable appearance of the so-called cranial flexure or "Kopfbeuge" between the praechordal and the epichordal part of the brain may be explained as corresponding to the angle between apical plate and stomodaeum in Annelidan larvae. In Amphioxus, as might be expected, we do not find a trace of such a flexure.

Auditory organs in Acrania. - The conclusion, reached along three different paths, of the homology of fore-brain and part of the apical plate, will be confirmed by further considerations. Having traced back the eyes of Vertebrates to those of the Protostomia, we shall now turn our attention to the auditory and olfactory organs. The auditory organs of Craniates can in no way be derived from those of Tunicates. In Ascidians we find, close to the eye, a statolith on a little stalk in the interior of the brain vesicle. The statocyst of Appendicularians originates as well from the brain vesicle which by one-sided thickening of the wall gives rise to the cerebral ganglion, at the left side of which the statocyst, evidently comparable to the sense-vesicle of Ascidian larvae, is situated (DELSMAN, 1912). In both cases the organ of equilibrium is of encephalogenetic origin. Amphioxus has no such organ.

Organs of equilibrium of Annelids and Molusscs. - With the organs of equilibrium of worms and molluscs the internal ear of Craniates exhibits an undeniable affinity. In both cases we have a paired structure originating as two vesicles which invaginate from the epidermis. Sometimes there remains a communication with the exterior in the form of longer or 
shorter canals, as in the Annelids Arenicola marina, Branchiomma vesiculosum and others, in the primitive Lamellibranchiata Nucula, Leda, Malletia, Solemya, where the canal opens at both sides of the surface of the foot, and among Vertebrates in the Elasmobranchs where the two ductus endolymphatict open dorsally. In other cases we find a blindly ending canal as a last remnant of such a communication, like the KöLLIKER's canal in Cephalopods and the ductus endolymphaticus in most Vertebrates, where it fails only in Teleosteans. Just as in the case of the eyes it is in Cephalopods that the organ of equilibrium, lastly described by HARRIS (1903), exhibits the highest differentiation among Protostomia and at the same time, just as the eyes, a certain resemblance to the corresponding organs of Vertebrates. In Nautilus the statocysts are closely applied to the cartilaginous endoskeleton, in the Dibranchia they are wholly embedded in it so that we can distinguish here a membranous and a bony (cartilaginous) labyrinth. Besides the blindly ending KöLLIKER's canal, the wall of the statocyst is raised into several well-marked ridges separated by furrows. The sensory epithelium is restricted to one macula acustica, or, better, macula statica princeps (HARRIS, 1.c.p. 330) on which the large statolith rests, to two maculae staticae neglectae (at least in Decapods), on which a great number of little statoconia, embedded in a gelatinous mass, are found, and to a crista statica. The nerve supplying the organ sends a branch to the maculae and to the crista.

In Annelids the statocysts are neither so common nor such typical organs as in Molluscs but in their situation and their structure they exhibit in both groups a great resemblance. The last author who has studied the statocysts in worms is FAUVEL (1902, 1907). They are found only in four families, all sedentary, viz: the Ariciidae, Arenicolidae, Terebellidae and Sabellidae, of which 34 species with statocysts are enumerated. In Molluscs, on the contrary, they are of extremely general occurrence and even in a few Polyclads and Nemerteans paired statocysts are found.

In Molluscs as well as in Annelids the statocysts appear very early in ontogeny, as a rule already in the trochophora in such forms that have one. For Annelids this is shown e.g. by HATSCHEK (1886, plate V). They take their origin from the lateral body wall between mouth and anus, as a rule not far behind the mouth. Often soon after their 
formation they closely apply themselves to the stomodaeum, which fact I have proved to my own satisfaction e.g. in pelagic stages of Lanice conchilega, Mytilus edulis (1910) and especially in Littorina obtusata (1913). Transverse sections through this region of the body, showing the stomodaeum flanked by the two statocysts, often remind one of a section through the embryonal medulla oblongata flanked by the two auditory vesicles.

Now in Annelids the statocysts are always found in the anterior segments of the soma. In the more primitive forms there are several pairs, in Ariciildae e.g. five or six pairs in successive segments, of which the first e.g. in Aricia acustica is found in the ninth segment of the soma. "Chez les Polychètes plus différençiés", FAUVEL says, "les otocystes ne se rencontrent jamais que sur un seul segment qui est le premier segment (buccal ou péristome) pour les Arénicoliens, le deuxième segment (premier branchifère) pour les Térébelliens et invariablement le deuxième segment (1 $1^{\text {er }}$ sétigère) pour les Sabelliens"' (of which 22 species with statocysts are enumerated). The statocysts are always innervated by the ganglia of the segment in which they are found, never by the cerebral ganglia as in Molluscs.

Auditory vesicles in Craniates. - If we compare with this the state of things in Vertebrates, we find a complete accordance. For if our conclusion is right that the isthmus indicates the place of the old mouth, the first rudiment of the auditory organs here also appears as two vesicles closely behind the mouth, situated on either side of the former stomodaeum, more especially of the anterior part of it, constituting the deuterencephalon. In the transparert larvae of Teleosteans they may be seen to retain for a considerable time the form of a pair of round vesicles, each containing two statoliths. They are, as will be discussed further on, seated in Vertebrates in one of the anterior segments of the soma, probably to be considered as the second, and supplied by a branch of the segmental nerve of that segment, the facialis. This statement on the other hand confirms our conception of the deuterencephalon as the anterior part of the former stomodaeum.

Praeoral lobe in Craniates. - As the reader will have already observed, another old and important question is brought nearer to its solution by the present considerations, viz: that of the metamerism of the head and the cranium. 
We will revert to this question and to the many divergent views on it in due time (cf, p. 61). The difference in the character of the praechordal part of the head, with the fore-brain and the olfactory and optic organs and their nerves, from the epichordal part, which in several respects shows traces of a former segmentation like that of the trunk or like that of Amphioxus, are known to every student of zoology. Great is the number of investigators that have worked on this subject and the complicated problems involved in it. To these, often troublesome, investigations the theory propounded here supplies a phylogenetic basis which makes us understand the significance of the unsegmented anterior part of the body and its relation to the segmented soma. It is again BALFOUR (1881) who seems to have anticipated this result when he writes in his Treatise on Comparative Embryology Vol. II (p. 260): "In Arthropods and Chaetopods there is a very distinct element in the head known as the precephalic lobe in the case of Arthropods, and the praeoral lobe in that of Chaetopods; and this lobe is especially characterized by the fact, that the supraoesophageal ganglia and optic organs are formed as differentiations of part of the epiblast covering it. Is such an element to be recognized in the head of the Chordata? From a superficial examination of Amphioxus the answer would undoubtedly be no; but then it has to be born in mind that Amphioxus, in correlation with its habit of burying itself in sand, is especially degenerate in the development of its sense-organs; so that it is not difficult to believe that its praeoral lobe may have become so reduced as not to be recognizable ${ }^{1}$ ). In the true Vertebrata there is a portion of the head which has undoubtedly many features of the praeoral lobe in the types. already alluded to, viz. the part containing the cerebral hemispheres and the thalamencephalon. If there is any part of the brain homologous with the supraoesophageal ganglia of the Invertebrates, and it is difficult to believe there is Inct such a part, it must be part of, or contain, the forebrain. The forebrain resembles the supraoesophageal ganglia in being intimately connected in its development

2) We have seen above that in early stages of development it is. quite distinctly recognizable. 
with the optic organs, and in supplying with nerves only organs of sense. Its connection with the olfactory organs is an argument in the same direction."

"The evidence at our disposal appears to me to indicate that the third nerve belongs to the cranio-spinal series of segmental nerves, while the optic and olfactory nerves appear to me equally clearly not to belong to this series. The mid-brain, as giving origin to the third nerve, would appear not to have been part of the ganglion of the praeoral lobe."

"These considerations indicate with fair probability that the part of the head containing the fore-brain is the equivalent of the praeoral lobe of many Invertebrate form s." "It must however be admitted that this part of the head is not sharply separated in development from that behind; and though the fore-brain is usually differentiated very early as a distinct lobe of the primitive nervous tube, yet that such a differentiation is hardly more marked than in the other parts of the brain. The termination of the notochord immediately behind the fore-brain is, however, an argument in favour of the morphological distinctness of the latter structure." A little further BALFOUR remarks: "there is strong embryological evidence that the mid- and hind-brains had primitively the same structure as the spinal cord." All this is in the most complete accordance with the results to which my theory eads.

Olfactory organ. - A third sense-organ in Craniates which, in consequence of my theory, appears to be derivable from the corresponding organ in Annelids is the olfactory organ. In its simplest and most primitive form we find it in Craniates as a pair of ectodermal invaginations in front of the mouth internally coated with cilia.

Some hypotheses regarding the phylogeny of the olfactory grooves may be mentioned here. DOHRN (1875) considered them as originally being a pair of praeoral gill-clefts, an idea which afterwards was worked out especially by MILNES MARSHALL (1879), but rejected by BALFOUR (1881) and GEGENBAUR $(1887$ p. 9,20$)$ who emphasize that the olfactory grooves are wholly ectodermal while the gill-pouches are produced by the entoderm. BEARD (1885) views in the olfactory grooves the branchial sense-organs of a pair of "non-existing" praeoral gill-slits which, however, remain 
wholly hypothetical. GEGENBAUR (1887) points, in his dicussion of MARSHALL's view, to the olfactory grooves of Cephalopods which are just as little derived from gill-slits and to which those of Vertebrates show a certain resemblance, though he does not think of an homologization of the two. KUPFFER (1890) attempted to show that the olfactory epithelium develops from a placode extending across the middle line and hence has an unpaired character. KOLTZOFF (1902) demonstrated the inadequacy of this view and the paired nature of the olfactory organ is now universally admitted.

The monorhinism of Cyclostomes, though present from the beginning of development, is to be considered as a secondarily acquired character in view of the fact that the olfactory nerve is double from the beginning. In Elasmobranchs we evidently find a more primitive disposition. Here, as in higher Vertebrates, the olfactory grooves originate in front of the cerebral plate or, if somewhat later, on both sides of the neuropore, between the latter and the mouth, i.e. on the ventral side of the snout or prostomium. Now, if we look in Annelids at the same spot, that is here at the dorsal half of the prostomium, we find a pair of ciliated pits, closely resembling the olfactory grooves of Craniates.

Ciliated pits in Annelids and Molluscs. - These ciliated pits, nuchal grooves, olfactory pits etc., as they are designated by different authors, have a very wide distribution among Annelids, much more so indeed than the statocysts. In his memoir on Oligognathus bonelliae SPENGEL (1881) has for the first time given a survey of all that was known about them up till that time. In Capitellids EISIG (1887) found them regularly present and carefully investigated their structure. They here represent a pair of transverse grooves situated dorsally at the base of the prostomium. Out of them a club-shaped, vigorously ciliating, organ can be everted like the finger of a glove. Though EISIG, with most authors, considers it as an olfactory organ, yet, until its function has been proved by experiments, he keeps to the neutral name ciliated organ. Between the ciliated organs and the posterior lobes of the cerebral ganglia very intimate relations exist: in Notomastus and Mastobranchus the only function of the latter is the innervation of the ciliated organs, so that the hinder of the two pairs of ganglia of nearly 
equal size, of which the brain of these forms is composed, may be justly called "ganglia of the ciliated organs", while the anterior pair innervates the eyes and the surface of the praeoral lobe. KLEINENBERG $(1886$, p. 71$)$ has shown that ontogenetically the posterior pair of ganglia arise in closest connection with the olfactory pits, to which they evidently owe their existence. This is confirmed by KEPNER and CASH (1915 p. 245) who, after having studied the development of the ciliated pits in a flatworm, make the following remark: "In conclusion, it is interesting to observe the striking parallelism presented by this organ in its function and mode of origin with the olfactory organ of a vertebrate so far as its function (i. e. its function in the fish) and its mode of origin is concerned."

RACOVITZA (1896), after having enumerated a great number of species provided with ciliated organs, says: "Les familles où l'on ne connaît pas sa présence, le plus souvent pour ne pas l'avoir cherché, contiennent les formes très dégradées et sûrement pas primitives. On peut donc dire que lorgane nucal est un organe typique du lobe céphalique des Polychètes ce qui veut dire qu'il est hérité de la souche et non une nouvelle acquisition, ou encore que tous les Polychètes l'ont ou ont dû l'avoir à un certain stade de leur développement embryonnaire ou phylogénétique." RACOVITZA subdivides the ciliated organs ot Annelids into five categories; the pits can be more or less deep and may be capable of eversion or not. Also in Planarians, Nemerteans and Molluscs we find similar ciliated pits in corresponding places, of which those of Cephalopods were already mentionned above. They are situated behind the eyes. In Nautilus and in Opisthobranchs the rhinophores have the form of prominent appendages, no doubt to be derived from the devaginable olfactory organs of certain Annelids.

As indicated above, the ciliated organs are usually found near or at the posterior border of the prostomium on the dorsal side (hence their name "nuchal organs"). Such forms as the trochophora of Polygordius (cf. WOLTERECK, 1902) show clearly that there can be no doubt that they belong to the organs originating from the surface of the prostomium, though they often lie close to its border. The peripheral cells of the episphere, round the little apical plate sensu stricto, are in this form extremely flattened and 
dilated. The ciliated pits here arise at the dorsal edge of the little apical plate, a considerable distance in front of the prototroch.

Homology of olfactory pits of Protostomians and Craniates.This situation of the ciliated pits in Annelids on the dorsal side of the prostomium corresponds to the ventral side of the prostomium of Chordates, where we find just such a pair of ciliated pits, the olfactory grooves. It seems hardly possible to deny the weight of this complete agreement not only in their function and mode of origin, as observed by KEPNER and CASH (1915), but also, as appears now, in their situation. Especially in connection with our results for the optic and auditory organs, the conclusion seems inevitable that the olfactory organs of Craniates must also be derived from the corresponding organs in Annelids.

Three main sense-organs inherited from Annelids. - Thus the rudiments of the three principal sense-organs of the Craniate head are older than the Vertebrate stock itself and have been inherited from the Annelids. During the preparation of the present second publication on my theory, five years after I had first worked it out, I was pleased to find that the same idea, as well as so many others at which I arrived, has been anticipated, indeed has been already put forward, though very shortly and cursorily, by HATSCHEK in the year 1878 (p. 116). He has never reverted to it and soon afterwards seems to have abandoned the idea of an Annelidan origin of Vertebrates ${ }^{1}$ ) and to have adopted a quite different conception of the origin of the Craniate fore-brain (cf. p. 36). His suggestions, however, so closely approach my own results that I will quote them here in extenso, and add the figure which served to illustrate them (fig. 14).

"Die Scheitelplatte", says HATSCHEK, "und die Anlage der Schlundcommissur der Anneliden ist, unserer Ansicht nach, dem vordersten Theile der Medullarplatte, aus welchem sich.das Gehirn der Wirbelthiere entwickelt, homolog.

1) In 1911 at least HATSCHEK declares that the first view of an Amphioxus-embryo, fished in the Pantano, as a living argument "alle meine früheren Vorstellungen der Annelidenverwandtschaft der Wirbeltiere im ersten Moment hinwegfegte". 
Bei den Wirbelthieren erreicht namentlich dieser Theil des Centralnervensystems eine viel weitere Ausbildung als bei den Anneliden, er ist in seinem Baue am meisten von dem Verhalten der ursprünglichen Stammform entfernt, und ist daher nur in Bezug a uf seine Primitivanlage mit dem entsprechenden Abschnitte des Centralnervensystems der Anneliden zu vergleichen

Die Sinnesorgane, die mit dem Gehirn in Zusammenhang stehen, scheinen noch von jener gemeinschaftlichen Stammform ererbt zu sein. In nebenstehendem Schema ist die Lage von Geruchsorgan (Ol), Auge (Oc) und Gehörorgan $(\mathrm{O})$ bei

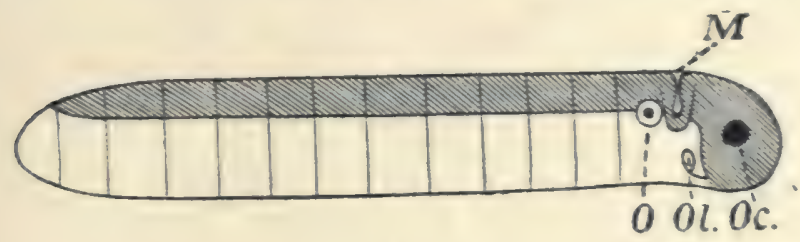

Fig. 14 Situation of the main senseorgans of an Annelid

$M$ mouth, $O$ auditory vesicle, $O c$ eye, Ol olfactory groove

(after HATSCHEK, 1878, p. 116).

Anneliden dargestellt. Dasse $\mathrm{lbe} \mathrm{Sch}$ e ma $\mathrm{l}$ i ess e sich a u ch a f die Wirbelthiere anwenden (spacing by me, D.).

The medullary tube, however, is derived by HATSCHEK directly from the ventral ganglion chain by a slit-like invagination along the median line of the ventral side. A remnant of the old mouth HATSCHEK finds in the infundibulum (1.c. p. 115), which has lost its communication with the exterior by the closure of the nervous tube. Thus the difficulty remains that the different fate of the blastopore in Annelids and Vertebrates is not accounted for. It is just this difficulty which seemed, e.g. to GOETTE (1895, p. 25), to render the whole Annelidan theory untenable since in Vertebrates the neural side lies in front of the prostoma, whereas in Annelids it is formed by the closure of the posterior part of the blastopore. The present theory brings us the solution of this difficulty. Further we must remark that the first segment according to HATSCHEK's scheme follows 
behind the auditory capsule only, the latter being considered by HATSCHEK as belonging to the unsegmented anterior end of the Annelid, distinguished by him as the head (cf. anon). KLEINENBERG (1886, p. 190) has shown the inadequacy of HATSCHEK's definition of the head and has replaced it by another by which this term was restricted to the prostomium and the statocysts were counted to the segmented soma. Yet the suggestion made here by HATSCHEK agrees closely with the second fundamental idea of my theory which at first sight might appear so hazardous thas I was glad to. find a predecessor like HATSCHEK.

Brain of Annelids and Craniates. - A question which now presents itself is, whether it might be possible to trace back the foundations upon which in the course of phylogeny the complicated brain of higher Craniates has built itself up to certain structures of the apical plate of Annelids. The cerebral ganglion or brain of Annelids does not represent a simple structure but is composed of several centres, each having a separate function and origin. According to HATSCHEK (1891, p. 424) and RACOVITZA (1896) we may distinguish in the prostomium from in front backward:

1. an anterior pair of "Tentacularganglien" or "cerveau antérieur," innervating the so-called primary tentacles or palps which originate at bcth sides of the larval apical sense organ at the animal pole,

2. a "Mittelhirn" or "cerveau moyen," innervating the eyes and the antennae,

3. a pair of "Riechlappen" or "cerveau postérieur" innervating the ciliated pits

Each of these three centres owes its origin phylogenetically and ontogenetically to a sense-organ of the praeoral lobe; the nervous centre is produced by the sense-organ innervated by it, as stated by KLEINENBERG (1886). Three sensitivonervous regions then may be distinguished in the cephalic lobe: "la région palpaire est gustative et tactile, la région sincipitale est tactile et visuelle, la région nucale est olfactive". Often the ganglia in Annclids remain in direct contact and are connected to the part of the epidermis from which they have originated and with the sense-organs to which they belong. Often, however, part of the ganglion detaches itself and now lies in the interior of the praeoral lobe. connected by a short nerve with the other part which remains applied to the sense-organ. In this way three centres of the Annelid 
brain according to RACOVITZA have originated, but to each of them corresponds a ganglion or a pair of ganglia applied to a sense-organ. These are the "ganglions palpaires", which belong to the "cerveau antérieur", the "ganglions optiques" and "antennaires", which belong to the "cerveau moyen" and the "ganglion nucal", belonging to the "cerveau postérieur".

Now the nuchal pits are certainly dorsal structures and so are accordingly the oltactory lobes of the Annelid brain. Of the eyes it is not so easy to say whether they belong to the dorsal or to the ventral side of the prostomium. In the adult Annelid they are usually situated on the dorsal side, in the trochophora and in somewhat further advanced pelagic stages we find them situated rearly laterally but somewhat more to the ventral side. Often the ventral situation is even very evident, in Annelid as well as in Mollusc trochophora-larvae. I therefore believe that the eyes must be regarded as originally ventral structures, and this is in accordance with the circumstance, that they are closed round when the ventral half of the apical plate folds in to become the fore-brain in Vertebrates, while this is not the case with the olfactory pits. Firally we may regard the "cerveau antérieur" as terminal and neither ventral nor dorsal in its origin.

Thus only the optic nervous centre of Annelids is involved at the closing of the cerebral plate in Craniates and probably may be found again in the optic ganglia of the retina (the superficial granular and fibrillar layers) and in the region of the chiasma. In front of the latter we find in lower Craniates, especially in fishes, the strongly developed basal ganglia as thickenings of the lamina terminalis - corresponding to the corpus striatum of higher Vertebrates - while the roof of the forebrain, the pallium, consists here merely of a thin epithelium, without nerve cells. In higher Vertebrates the pallium more and more develops, producing the hemispheres which take over the function of the basal gang'ia as an olfactory centre, until in Mammals the corpus striatum sinks into obscurity by the enormous development of the pallium. Can we compare these basal ganglia with one of the three centres of the Annelid brain, especially with the olfactory centre? I do not think so, at least not directly, for the "Riechlappen" or "cerveau postérieur" originate, as shown by KLEINENBERG, in close connection with the olfactory pits. Such is not the case with the basal ganglia of Vertebrates; they take their origin from the part 
of the prostomium incorporated into the brain, i.e. from the ventral half in Annelids. while the ciliated pits belong to the dorsal half and are not closed round. Thus we can only assume, that the connection between the brain and the olfactory pits in Vertebrates is a secondary one compared to that in Annelids.

Primary brain-axis. - A number of authors have discussed the question of the primary brain axis and its anterior end and have come to divergent conclusions. This brain axis of course is the forward continuation of the axis of the meduliary tube, the anterior dilated part of which is considered as being represented by the brain. According to V. BAER (1828), MIHALKOVICS (1877), HIS '1893, p. 98), KOLTZOFF (1902, p. 553) and HATSCHEK (1892, p. 139, 1909, p. 497) the original fore-end of the Craniate brain, corresponding to the neuropore of Amphioxus, is to be found in the infundibulum, and the part that lies in front of the latter, the praechordal part, has secondarily grown out over it by the strong development of the originally dorsal parts. This conception finds its most striking expression in VAN WYHE's (1882, p. 39) view that the nervus olfactorius in reality is the second, the nervus opticus ihe first nerve of the head. V. KUPFFER $(1894,196)$, on the contrary, starts from the idea, that, to find the fore-end of the brain-axis we must look for the neuropore of Craniates, which in his opinion is directly comparable with the neuropore of Amphioxus (cf. p. 38). He finds the latter in the sturgeon as a point where the brainwall remains fused with the epiderm of the head for a somewhat longer time, the angulus terminalis (HIS) or recessus neuroporicus (cf. fig. 13), situated more dorsally, just in front of the lamina terminalis or front-wall of the brain. It indicates at the same time the anterior end of the medullary suture, just as in Amphioxus, and the front-wall of the brain has been formed by the growing up of the transverse brain fold of the cerebral plate. To this conception HIS objects, that, in transverse sections, the medullary suture may be shown to continue in front of the angulus terminalis as a frontal suture, probably reaching to a point where in other forms, e.g. in Petromyzon, a much more terminally situated neuropore, or better: an indication of the latter, is found. According to HIS and HATSCHEK both the "angular" and the "terminal" neuropore represent the extremities of an original slit-like neuropore, as observed by 
VAN WYHE (1882, p. 18), reaching from a point over the optic vesicles to a little distance in tront of the latter. The dorsal end of this frontal or terminal suture, the angulus terminalis, according to HIS, represents the fore-end of the medullary suture or the dorsal brain axis, its ventıal extremity, the recessus infundibuli, the termination of the

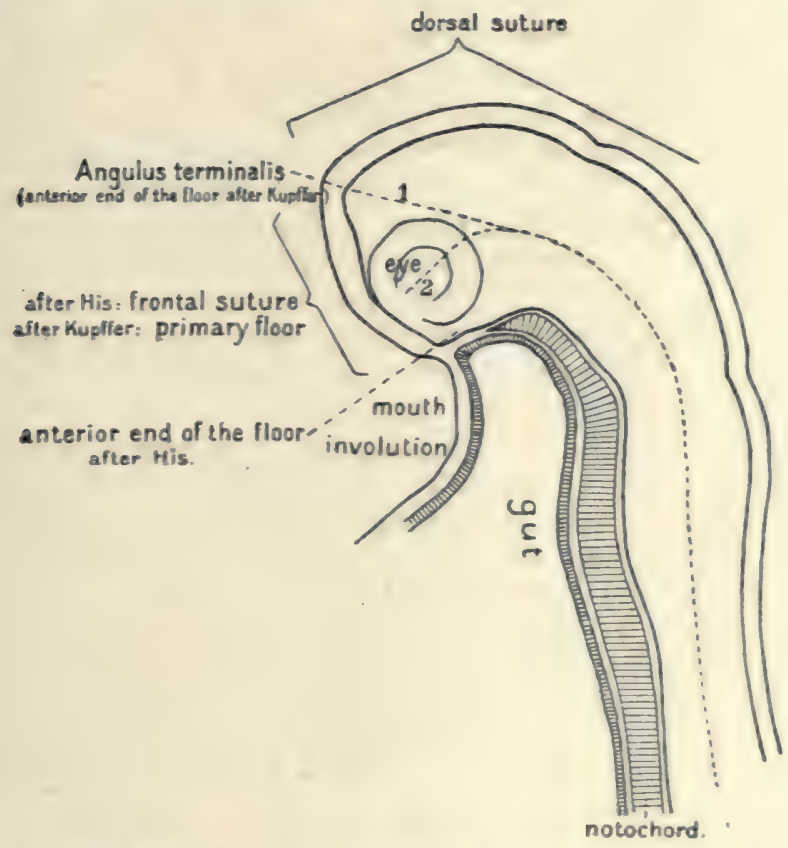

Fig, 15. Diagram of the Craniate brain and its main axis from FRORIEP, 1894 (Ergebn. Anat. Entw. 1II).

axis of the medullary plate or the basal brain axis, its middle, about the recessus opticus, the fore-end of the median brain-axis. Thus the brain does not end in a point, as assumed by $\mathrm{V}$. KUPFFER, but in a frontal linear suture running over the middle of the lamina terminalis. The existence of such a suture in front of the recessus neuroporicus or angulus terminalis is, however, denied by V. KUPFFER (1894, p. 102).

Different situation of the neuropore in Urodelans and Anurans. - Perhaps some observations made by me on the closure of the cerebral plate in Amphibians may contribute 
to the solution of this divergence of opinions. In studying the relation of the anus to the blastopore, myattention was drawn to the different ways in which in Anurans (Rana esculenta) and Urodelans (Amblystoma tigrinum) the cerebral plate closes. In the former there may be noted quite distinctly a growing up of the transverse cerebral fold, a process. which, at the closure of the brain vesicle, plays an equally important role as the growing over of the lateral cerebral folds (Fig. 3 of the plate). In fig. 5 the neuropore is represented, apparently for the first time in Anurans. At least V. KUPFFER (1906) in HERTWIG's Handbuch says concerning the Anurans: "Der Neuroporus ist im letzten Momente vor seinem Schlusse noch nicht zur Beobachtung gekommen," nor is there in investigations of later date anything to be found on this subject. From the situation of the recessus. neuroporicus in median sections of later stages V. KUPFFER corcludes: "Es haben sich wohl die Ränder des Neuroporus bei Einleitung des Schlusses einwärts gerollt und damit die Hirnwand zurückgelagert". The result is a dorsal neuropore, corresponding in its situation to HATSCHEK's "angular" neuropore and confirming V. KUPFFER's views, since it denotes the anterior end of the dorsal suture, which does not continue in front of it.

As a rule an open neuropore seems not to occur, the fusion of the medullary folds being performed over their whole length nearly simultaneously, or, in any case, to have a very short-lived existence. At least in many other longitudinal series of similar stages I did not find it.

These processes are entirely different in the Axolotl. Here there is hardly any question of a growing up of the transverse cerebral fold. The closure of the cerebral plate is exclusively performed by the growing up and the median fusion of the lateral folds. An open neuropore was net found, but an examination of complete eggs and sections shows conclusively, that the anterior end of the dorsal suture, corresponding to the place of the neuropore, is here situated terminally, just as in Petromyzon. The whole praechordal brain vesicle, as shown by a comparison of fig 7 and 8 of the plate, has in the axolotl a much more elongated shape and much more the character of a tube

The animal pole not a fixed point? - Thus we see in two closely related groups the closure of the cerebral plate being performed in entirely different ways. For the 
cause of this difference we must, 1 believe, recur to the same peculiarities of the early development of both groups, from which the difference in the relation of the anus and the blastopore is to be explained (cf. last chapter). In Urodelans we see a very strong development of the dorsal parts, especially of the medullary plate which, as a consequence, in an embryo like that of fig. 8 (plate) encircles much more than $180^{\circ}$ of the circumference of the egg, the ventral being, as it were, compressed to much less than $180^{\circ}$. In Rana fusca both the ventral and the dorsal side encircle $180^{\circ}$, the anus accordingly being situated directly opposite the animal pole or anterior end of the embryo (cf. fig. 35). In Rana esculenta the opposite condition to what we find in the Axolotl is realized, the ventral side encircling somewhat more than $180^{\circ}$, the medullary plate correspondingly less.

The precocious longitudinal growth of the meduliary plate in Urodelans seems to me to explain not only the difference in the relation of the anus to the blastopore in Urodelans and Anurans (cf. last chapter), but aiso the difference in the closure of the cerebral plate. By this precocious lengthening the rear extremity of the medullary plate, with the blastopore, is pushed backwards and the anterior extremity is pushed forwards Thus both extremities approach each other on the ventral side, forcing the latter to extend more in a lateral direction, as shown readily by the study of surface views of Axolotl-eggs (fig. 41).

Now, according to the conceptions reached by us in this article, the closure of the cerebral plate consists in the folding in of that part of the apical plate of the trochophore, or the epithelium of the prostomium of the Annelid, which is situated between the animal pole and the mouth. The rest of the apical plate is situated accordingly in the form of a crescent in front of and round the cerebral plate, which reaches forward to the animal pole, the centre of the apical plate. As shown by fig. 1 (plate) the extra-cerebral part of the apical plate in Rana is thickened in the same way as the cerebral plate itself and shows a similar distinction of a basal and a superficial layer. It closes over the cerebral plate and gives rise to the ectoderm of the snout. This closing in Rana is performed both from the anterior and from the lateral sides. The fusion of the lateral folds produces the dorsal suture which is the prolongation of the 
medullary suture and ends anteriorly in the neuropore, where it meets the transverse cerebral fold (fig. 5). In the Axolotl, however, as suggested above, the anterior end of the cerebral plate and the animal pole are fushed forward by the precocious longitudinal growth of the medullary plate. They push aside to the.left and to the right the praecerebral part of the apical plate, until they have reached nearly the anterior border which, as I will try to demonstrate below (cf. anon), probably corresponds to the place of the future mouth. By this process the præcerebral part of the apical plate has been nearly divided into two halves, lying on either side of the cerebral pate which indeed reaches here much further in front of the anterior end of the notochord than in Anurans (cf. the figures). From this circumstance we can now easily understand, that the closure of the cerebral plate is performed here almost entirely by the growing over of the lateral cerehral folds, that the place of the neuropore is much more terminal than in Rana and that the brain gives much more the impression of a tube. In this way the different results of HIS and KUPFFER are probably to be explained.

KUPFFER's view to be preferred to that of HIS. - But therestill remains the question as to where the brain axis ends. From the point of view of my theory it seems questionable indeed, whether we can speak of a brain axis, and whether the brain represents a tube which is the continuation of the medullary tube. If we start from an Acraniate ancestor in which no fore-brain had yet been formed, as in Amphioxus, but not so degenerated in certain respects as the latter, we might expect to find here in front of the neuropore, which corresponds to that of Amphioxus and to the Annelid mouth, and on the surface of the prostomium, a pair of eye-pits like those of Annelids and Molluscs. These pits tended to become deeper and to disappear from the surface, as may be observed in the ontogenetic development of the eyes of Annelids and Molluscs. Thus it may have happened, that they have been involved into a common invagination which gave rise to the fore-brain vesicle, but it may be doubted if this represents the forward continuation of the medullary tube. Another conception is, that the medullary tube has extended forward and incorporated part of the prostomium, for which the continuity of the medullary and the cerebral folds is an argument. In the latter case the neuropore of the Craniates would be at least more comparable 
to that of Amphioxus than in the former, though there can be no question of $\rightarrow$ direct homologization of the Iwo. This starting point of KUPFFER has been shown to be a false one, though his conclusion, that the end of the brain-axis of Craniates is found in the neuropore, is not therefore necessarily to be rejected and at any rate seems to me to be preferable to tiIS's and HATSCHEK's assumption of a linear fore-end of the brain. No doubt both the latter investigators were right in emphasizing that the part of the brain in front of the infundibulum is a later acquisition, not yet present in the brain of Amphioxus, but their conception of the way in which it has originated needs modification.

The question of the axis of the brain has lost much of its importance in the light of my theory, which no longer permits a comparison of the fore-brain of the Craniates with the brain-vesicle of Amphioxus in the sense of V. KUPFFER, but, if we want to speak of a brain axis, I think it preferable to let it end in the neuropore which, just as in Amphioxus, designates the anterior termination of the dorsal suture. This implies, that the lamina terminalis represents the primary floor of the fore-brain, not a part of the original roof with a median suture, as supposed by HIS and others.

Lateral sense-organs in Annelids. - If our conclusions are hitherto correct, it must be admitted, that hardly two of the great sub-kingdoms or phyla of the animal kingdom show such a close agreement, even in the details of their structure, as Annelids and Vertebrates, and in no other case can the structure of the one be derived so completely from that of the other. This consideration makes it appear not quite so improbable, that EISIG (1887) was not wrong, when he believed he had found again also the so-called sixth sense-crgan of lower Craniates in Annelids. After PARKER's (1905) experiments the function of the organs of the lateral sense-line is the perception of water vibrations of low frequency, produced by the waves on the surface and by bodies falling into the water, while HOFER (1909) ascribes to them only the faculty of perceiving the constant pressure of water-currents. With the exception of Capitella, EISIG (1887, p. 501) finds in all Capitellids, nearly along the whole length of the body, in every segment a pair of roundish prominences, situated laterally between the neural and the haemal parapodium near the hinder limit of the segment. it is just on the boundary-line of haemal and 
neural longitudinal musculature, i. e. the lateral line, in which they are implanted. This line does not always lie exactly halfway between the two parapodia of one side but, e. g., at the beginning of the abdomen rises more 10 the dorsal side and at the end sinks more to the neural side, thus forming a slightly curved $\mathrm{S}$. These knobs are provided in the centre with extremely fine sense-hairs. In this respect these sense-organs show an undeniable resemblance to those of Vertebrates: in both the central cells terminate in fine stiff cilia and are surrounded by so-called supporting cells. The number of sense-hairs is subject to variation in different Vertebrates which possess lateral sense-organs, but is always considerably less than in Capitellids. Their length also appears to be less. Also in other families of polychaetous and oligochaetous Annelids similar sense-organs have been described, while moreover the dorsal cirri of the ventral parapodia are considered homologous to them by EISIG (1887, p. 512), who in this respect follows KLEINENBERG.

Metameric arrangement. - Great weight is laid by EISIG on the metameric arrangement of the lateral sense-organs. In Vertebrates this is clearly pronounced in the ontogeny of Telosteans, and in other groups it is rendered probable by several observations. In part, the occurence of more than one sense-organ in one segment, is accounted for by the faculty of dividing which was first demonstrated by MALBRANC (1876) and afterwards confirmed by others. But only in Teleosteans a truly metameric arrangement of the sense-organs at their first appearance has been observed, which, however, is considered by some investigators as a secondarily acquired character. It is not impossible, that a primitive metameric arrangement of the lateral organs might have been gradually obscured when the external segmentation, so strongly pronounced in the chitin-coated Annelids, became less distinct in Verrebrates, and only in such cases might have been preserved, or have reappeared, where the integument shows metameric segmentation, as e.g. in Siphonops and in Ichthyophis. and in Teleosteans, where the arrangement of the scales in general corresponds to that of the myotoms

Innervation. - If now we consider the innervation of the lateral sense-organs in Vertebrates and Annelids, it appears that this does not correspond in the two groups. In Capitellids the lateral organs from segment to segment are 
innervated each by a branch of a segmental nerve of the ventral chain, that is by a spinal nerve branch. In Vertebrates, on the contrary, the sense-organs of the trunk are all innervated by the ramus lateralis of the nervus vagus, a cranial nerve which, issuing from the brain, runs along the whole trunk and tail, providing on its way every senseorgan with a little side-branch. There is no question about an innervation by spinal nerves in this case. Only the partly transient lateral organs of the head have a segmental innervation, to which we will refer below.

If the lateral organs of Vertebrates are homologous to those of Annelids, we must assume that in some way the innervation by segmental nerves has been replaced by a more concentrated innervation, having its centre in the head We could imagine, for example, that a plexus-formation by the original segmental nerves has begun from the head. This plexus extending progressively further backwards, has resulted in the disappearance of the segmental communication of the lateral sense-organs with the corresponding dorsal spinal nerves. This is also what EISIG (1887, p. 53) supposes, when he writes; "Die einfachste Voraussetzung wäre die, dass in dem Maasse als das Gehirn seine Function als Centralorgan im werdenden Wirbelthiere auf Kosten der relativen Selbständigkeit der segmentalen Ganglienknoten des Anneliden-Bauchstranges auszuüben fortfuhr (EISIG of course has in mind DOHRN's view, at that time prevalent, that the brain is to be comoared with the cerebral ganglia, the spinal chord ' with the ventral ganglion chain, D.). sich zwiscr en den Asten der die Seitenorgane innervirenden Spinalnerven, zum Behufe einer directeren Leitung der Erregungen, successive Anastomosen ausbildeten, mit anderen Worten, dass der Seitennerv oder Ramus lateralis vagi nach dem Principe -eines Collectors zu Stande kam". Such a plexus- and collector-formation is also seen to appear in other cases where unity of function and a more direct communication with the brain is required, e.g. in the innervation of the dorsal fin and of the paired limbs of fishes.

As stated by many authors, lastly by KLINKHARDT (1905, p. 475), the ramus lateralis grows out in a backward direction within the epithelium and only afterwards detaches itself from the latter.

BEARD versus EISIG.-BEARD (1885), though formerly (1884) adhering equally to the homology of the lateral organs in 
Annelids and Vertebrates, came to an opposite opinion, after it had been demonstrated that in Vertebrates several of the cranial ganglia originate parily from the neural ridge and partly from the ectoderm, viz: from ganglionic proliferations of either transient or permanent lateral organs. He now assumed that originally the lateral organs rad some physiological connection with the gills, over which they are situated in the cranial region and which are innervated from their ganglia. He therefore changes their name into branchial sense-organs. Ontogenetically we first see the lateral organs appear on the head and then, together with the outgrowing ramus lateralis vagi, extend backwards over the irunk. From this mode of development BEARD deems it probable, that they were originally restricted to the gill-bearing region and from here have only secondarily spread over the trunk. "Damit wird aber", EISIG infers, "eine ontogenetische Thatsache willkürlich, das heisst ohne Berücksichtigung aller im Wege stehenden Schwierigkeiten. ins Phylogenetische übersetzt. Und die Hauptschwierigkeit besteht darin, plausibel machen zu können, wie denn eigentlich dieses ursprünglich allein am Kopfe entwickelte Seitenorgansystem dazu kommen sollte, sich secundär in segmentaler Anordnung auf den Rumpf auszudehnen, auf denjenigen Körpertheil der doch notorisch als der phylogenetisch ältere und einfachere zu betrachten ist". This latter opinion we cannot share from the point of view of our theory, the soma of Annelids and Vertebrates is no doubt phylogenetically younger than the pros'omium and not older than the segmented part of the head which, as we shall see, in several respects has even retained a more primitive character than the rest of the trunk. Yet in the spreading of organs, originally restricted to the foremost part of the body, over the trunk and in their assuming a metameric arrangement BEARD also acknowledges a curious fact. The ontogenetic development of the lateral organs from the head backwards over the trunk is accounted for by EISIG in this way, tnat the former condition, in which they originated independently in all segments, is no longer recapitulated in the trunk in consequence of the reduction of their segmental innervation, and that they now arise in connection with the collector-nervefrom front to back.

In any case, the homology of the lateral organs in Vertebrates and Annelids remains somewhat questionable, and it 
may be asked if it is advisable or of any use to carry any further our speculations in this direction. Yet I will do so and wiH venture to draw some more conclusions which, whether they are confirmed or disproved in the future, in any case will have been of some use as a stimulus to further research. Lateral ganglia of Annelids homologous to spinal ganglia of Vertebrates? - In Annelids every lateral sense-organ is closely connected with a ganglion, the lateral ganglion, which envelops the elements of the ciliated area like a cap. These lateral ganglia are considered by EISIG (1887, p. 517) to be homologous to the parapodial ganglia of other Annelids, which ganglia, in agreement with this view, are absent in Capitellids and Polyophthalmids, which latter possess the highest developed lateral organs. The development of the parafodial ganglia in Lopadorhynctius has been described and figured by KLEINENBERG (1886 p. 112). They originate as proliferations from the ectoderm, not far from but independent of the ventral ganglia, and separated from the latter by the ventral muscle plate. Now KLEINENBERG (l.c. p. 220) had supposed that the spinal ganglia of Vertebrates correspond to the parapodial ganglia of Annelids, and this view is joined ty EISIG (1887, p. 542). "Und auch die Frage, warum denn erstere Ganglien bei den Vertebraten nicht mehr so wie diejenigen der Hirnnerven zu der Haut, respective den Seitenorganen ontogenetische Beziehungen: aufweisen, lässt sich beantworten. Derselbe durch die Concentrirung des Kopfes oder Gehirnes hervorgerufene Process, der an den übrigen Bestandtheilen des Seitenorgansystemes so tiefgreifende Veränderungen hervorrief, nämlich die Anbahnung eirer einheitlichen und directen (Gehirn-) Leitung an Stelle der segmentalen, hat auch die ursprünglichen Hautbeziehungen der Seitenorganganglien (Srinalganglien) allmählich zum Schwinden gebracht" (1.c. p. 543).

The following, therefore, are, in concise form, the views formulated by EISIG: the original segmental communications of the lateral organs with the spinal ganglia, the latter being the homologues of the parapodial and lateral ganglia of Annelids, have been preserved only in the head; in the trunk, however, they have been lost and replaced by the collector, the ramus lateralis of the vagus.

The views resulting from my theory, though agreeing on the whole with those of EISIG. yet make certain modifications indispensable to bring the latter into agreement with 
my theory and, at the same time, into better agreement with the facts. Eesides the ventral ganglia we find, as mentioned above, in Annelids still another group of segmental ganglia, the lateral or the parapodial ganglia. Now we have traced back already the spinal ganslia of Vertebrates to the ginglia of the ventral nerve-chain in Annelids. What are we to think of the lateral ganglia of the latter in Vertebrates? If they are found here, I think it is only in the branchial region.

Dermatogenetic part of the cranial ganglia. - In the year 1885 it was found simultaneously, but independently, by BEARD in Elasmobranchs, by SPENCER in Amphibians and by FRORIEP in Mammals, that several of the cranial ganglia do not originate, like the spinal ganglia, exclusively from the neural ridge, but that also the lateral epidermis of the head plays here a considerable part. The ganglia referred to are in fact those of the N.trigemenius, the acustico-facialis, the glossopharyngeus and the vagus. The first rudiments of these ganglia, produced by the neural crest, grow downwards between the ectoderm and the outer side of the myotom, and in Ichthyopsids each fuse with the ectoderm at two places, one above the other: a lateral one, somewhat on the level of the notochord, and an epibranchial one, just above the gill-slits. At the point of fusion with the epidermis, thickenings of the latter, placodes, arise, which look much like sense-organs. The corresponding part of the lateral line, which on the head develops earlier than on the trunk, originates afterwards from the lateral series. At the placodes a proliferation of the epidermis sets in; epidermal cells, dividing actively, are given off to the inside, forming a ganzlion. At their first appearance these dermatogenetic placode ganglia in some cases are quite independent from the centrogenetic spinal ganglia, and in the frog, according to BEARD $(1888 b$, p. 900), they separate from the epidermis before the spinal ganglia, growing out downwards, have reached them. FRORIEP (1885, p. 37) and BEARD (1885, p. 221) have suggested independently, that the placodes represent rudiments of segmental sense organs, belonging to the lateral line. Much can be said then for the supposition, that the lateral head-ganglia correspond to the lateral ganglia of Annelids, the ganglia of the lateral sense-organs. Soon afterwards the dermatogenetic ganglion fuses intimately with the centrogenetic one, so 
that they can no longer be distinguished from each other. From the exact place, however, where the lateral placode of the $N$. facialis was formerly found, spring the sensory branches of the facialis, the ramus ophthalmicus superficialis, the ramus buccalis and mandibularis. These innervate the cranial part of the lateral line system and, according to KLINKHARDT, grow out from the lateral placode of the latter in the same way as the ramus lateralis of the vagus, i.e. within the ectoderm, intraepithelially.

The obvious inference, therefore, is, that in these ganglia of the lateral sense-organs we have to look for the lateral or parapodial ganglia of Annelids, which accordingly have been lost in the trunk and preserved only in the segmented region of the head, which in more than one respect exhibits primitive features. The advantages of this conception over that of EISIG will be evident. Just as with the ganglia of the lateral sense-organs in Annelids, the dermatogeneric ganglia of the Vertebrate head arise in close connection with epidermal sense-organs, while the spinal ganglia have no primary relation whatever to them. The segmental communications of the spinal ganglia with the lateral senseorgans have only been preserved in the head, in the trunk they have been replaced by the collector. To this conception the presence of a segmental connection of the spinal ganglia with the corresponding organs of the lateral line, as described in Petromyzon by JULIN (1887) and ALCOCK (1899), but denied by DOHRN (1888, and FüRBRINGER (1897), would no doubt be a valuable support. Similar connections were found by HOFFMANN $(1901$, p. 39, 45) in Urodelans and described and illustrated by him in a very positive way as regular anastomoses of the dorsal branch of the $5^{\text {th }}-20^{\text {th }}$ spinal nerves with the ramus lateralis vagi.

As to the epibranchial fusion of the dorsal cranial nerves with the epidermis, I can only suppose with BEARD (1885) that it has arisen in connection with the gill-slits to which it shows such close relations. FRORIEP (1891, p. 63) has pointed to the close connection between the epibranchial ganglia and the rudiment of the thymus, a connection which, however, gets lost in the adult state. In no case have these branchial sense-organs been found to persist in the adult.

Different theories on the metameric structure of the head. As already observed, the theory advanced here appears to 
throw a new light on the old question of the metamerism of the Vertebrate head, which perhaps will prove able to contribute as much to the disentanglement of this complicated problem as the numerous anatomical and embryological researches to which i has given rise, thus demonstrating once more, that theory and practical research are complementary to each other. It is not my intention to give an historical enumeration of all the investigations and different opinions on this subject. the less so, as I can refer to the excellent reviews of RABL (1892) and GAUPP $(1898,1506)$. The main points may, however, be summarized. HUXLEY (1858), after having demonstrated the in adequacy of GOETHE's and OKEN's vertebral theory of the bony cranium, accor-. ding to which the latter is only the forward continuation of the vertebral column round the brain, was the first to try to analyze the metameric structure of the head by studying the mutual relations of gill clefts and cranial nerves. Equally on grounds borrowed from comparative anatomy were based the conclusions of GEGENBAUR $(1871,1872)$, who was the first to treat the subject from a phylogenetic point of view. He transferred the starting point of the problem from the bony to the cartilaginous head skeleton, as found permanently in such primitive Craniates as the Elasmobranchs, and thus inaugurated a new era in the researches concerning the metameric structure of the head. GEGENBAUR set out from a c $\sim$ mparison of the visceral archs of the head to the inferior archs and the ribs of the trunk skeleton, both being the expression of a corresponding metameric structure. In the cranium itself, truly, this metameric structure. is less evident, an intimate concrescence of the vertebrae having occurred at the anterior end of the body, to provide a firm support for the snout and for the insertion of the visceral muscles, while the incorporation of the auditory capsule in the wall of the cranium has contributed to efface the dividing lines of the vertebrae. Traces of former segmentation, however, were found by GEGENBAUR in the relation of the cranial nerves to the gill-slits. Taking into consideration the extension of the notochord into the base of the cranium, and emphasizing. as HUXLEY had done already, the contrast between the $N$.olfactorius and opticus on the one side and the remaining cranial nerves on the other, GEGENBAUR distinguished a posterior $\mathrm{v}$ e $\mathrm{r} \mathrm{te} \mathrm{b} \mathrm{r}$ al from an anterior prae-or evertebral part, of which 
the latter probably is to be considered as a secondary outgrowih from the former. The vertebral part only is traversed by the notochord, and the number of vertebrae the former contains is indicated by the number of visceral archs - seven in the case of pentanch Elasmobranchs -, to which originaliy two arcnes in front were added by GEGENBAUR, represented by the labial cartilages.

Ontogenetic researches. - As might be expected, since GEGENBAUR a great number of investigators have tried to rediscover in ontogeny the metameric structure so much obscured in the adult Vertebrate head. The resuits of their researches, however, have not yet led to unanimity if opinion, reither in details nor even in fundamental questions. In regard :o the latter we may distinguish two schools of thought viz: those who in the main adhere to GEGENBAUR's opinion, that the arrangement of the gill-clefts corresconds to the number of head segments and that the segmental structure reaches as far as the fore-end of the notocnord, and those who reject this view and consider only the occipital region of the neurocranium to be derivable from segments like those of the trunk. According to the former the situation of the gill-slits is intersegmental, each having broken through between two mesoderm segments; according to the latter the mesoderm in front of the vagus shows no metameric segmentation at all, but is unsegmented, and only the piercing of the gill-slits makes it appear segmented, causing a kind of pseudo-segmentation, the branchiomerism, which has nothing to do with the mesomerism of the trunk. To the adherents of the first view belong those investigators especially who studied the development of Elasmobranchs, like BALFOUR (1878, p. 211), MILNES MARSHALL (1879, 1882). VAN WYHE 11882, 1889), BEARD (1885), DOHRN (1881-1902।, SEWERTZOFF (1899), ZIEGLER (1908) and his disciples, while those of the second view, put forward especially by FRORIEP $(1882,1887)$, were led to their opinion mainly by the study of other Vertebrates, such as Amphibians and Amniotes.

Mesomerism, neuromerism and branchiomerism. - The first group of investigators agrees with GEGENBAUR in that, in gene$\mathrm{ral}$, the number and arrangement of the gill-slits corresponds to that of the somites, and that there is a coincidence of branchiomerism, myomerism and neuromerism. Truly, there is no 
agreement as to the number of segments, since several investigators admit the possibility, that gill-clefts may have fallen out or have changed their function and character. Thus MARSSHALL (1879) supports the view, suggested already by DOHRN (1875) in his theory, that the olfactory grooves are modified gill-clefts and the olfactory nerve a segmental nerve, while according to VAN WYHE (188\%) the hyoid arch corresponds to two segments, since he finds two somites over it, a gill-slit apparently having fallen out here. VAN WYHE rejects MARSHALL's conclusion and MARSHALL that of VAN WYHE, while BEARD (1885), in a somewhat modified form, accepts both. He sees in the $N$. facialis and the acusticus the two dorsal nerves belonging to the double hyoid segment and considers both the olfactory pits and the auditory vesicles not as modified gill-slits, but as their branchial sense-organs, the gill-slits themselves having atrophied. DOHRN even assumes a very considerable number of gill-clefts to have fallen out, or to have been transformed into olfactory grooves, hypophysis, thyroid gland, auditory vesicles, etc. ZIEGLER, on the contrary, doesnot admit any falling out of gill-slits at all, thus arriving at a very simple scheme, which we will refer to later. That the mouth, in its relation to the somites and the cranial nerves and their ganglia, corresponds to a pair of gill-slits, is a point upon which all agree, though the view, first advocated by DOHRN, that the mouth has originated from the union of two gill-clefts, is less generally accepted (cf. e.g. ZIEGLER, 1908).

Branchiomerism independent from mesomerism? - Turning now to the other school of thought, we find that AHLBORN $(1884 \mathrm{p} 321,322)$ was one of the first to deny the correspondence between branchiomerism and mesomerism, the former taking its origin from the entoderm, the latter from the mesoderm. According to him GEGENBAUR's comparison of the visceral archs to the ribs does not hold, the latter originating intersegmentally, in the intermuscular ligaments, the former within the segments delineated by the gill-pouches. The metameric arrangement of the ribs is the expression of the primary mesomerism, that of the gill-bars of the entodermal branchiomerism. Yet, though the latter is independent of the former, AHLBORN does not deny that mesomerism reaches into the head, in this respect he wholly supports VAN WYHE's views. The mesomerism, however, observed dorsally, and the branchiomerism, observed ventrally, are independent of each other. 
No mesomerism at all in the Vertebrate head? - FRORIEP (1882-1887) denies that there is any question of metamerism in the Vertebrate head in front of the occipital region, that is in front of the $N$. vagus. The segmentation observed by VAN WYHE and others in the more anterior part of the head is nothing but branchiomerism which has nothing to do with mesomerism, the mesoderm in front of the vagus being unsegmented and continuous from the beginning. Indeed, in mammals and birds, of which representatives were studied by FRORIEP, just as in Reptiles and Teleosteans, the series of somites in early ontogenetic stages is seen to end some distance behind the auditory vesicle, all being metotic, while anterior to this point there is found an unsegmented mesenchymal cell-mass, the headmesoderm of FRORIEP. Of prootic somites there is no question, only in the occipital region are somites to be observed. Thus it is not the fore-end of the notochord, but the foramen of the vagus which forms, according to FRORIEP, the boundary of two regions in the head of a quite different character, the cerebral or praes $\mathrm{p}$ inal and the $\mathrm{s} p$ in a 1 region. The former, accordingly, comprises the evertebral region of GEGENBAUR together with what FRORIEP calls the pseudovertebral region, that is the region of the parachordalia and of the trigeminus, facialis-acusticus and glossopharyngeus and vagus. The seemingly metamerical arrangement of these nerves is only a secondary consequence of the branchiomerism. To the unsegmented præspinal region belong the three main sense-organs of the head, the olfactory organ, the eye and the auditory vesicle. FRORIEP was mainly led by the study of the vagus and the hypoglossus to the conclusion that reduction had occurred as well at the anterior end of the occipital somites as at the posterior end of the -series of visceral archs, and it was especially this fact which seemed to him to plead for the fundamental contrast of the two regions which meet here. The distinction made by FüRBRINGER (1897) of a palaeocranium and a neocranium coincides with that of FRORIEP. MARCUS (1910,p.121) and DE LANGE (1913), bv their researches on the early development resp. of Hypogeophis and of Megalobatrachus, are led even to the assumption, that the anterior head mesoderm has a quite different origin to that of the segmented trunk and occipital mesoderm, the former being derived from the 
entoderm of the most anterior part of the archenteron-roof, the latter from the ectoderm which, according to LWOFF's (1894) conceptions, is invaginated round the dorsal blastopore border to form the whole, or, after MARCUS, nearly the whole, roof of the archenteron (cf. last chapter). The headmesoderm ("Urmesoderm") is compared by DE LANGE to the mesoderm of the radiate ancestors of the Bilateria, that is to the mesenchyme of the Ctenophores and flatworms, and of the trochophora. Truly, in doing so, he leaves out of consideration, that the cell-lineage investigations have led to the directly opposite view, that the mesenchyme of the radiate Invertebrates and of the larvae of bilateral forms like Annelids and Molluscs is to be considered as ectomesoderm, the segmented trunk mesoderm of Annelids on the contrary as entomesoderm. This, however, is to be explained by the fact that DE LANGE probably has in his mind a derivation of Chordates from Deuterostomians. The controversy has continued until the present time between the views of GEGENBAUR, VAN WYHE etc. and those of FRORIEP. In still recent years both have found a champion, respectively in ZIEGLER (1915) and VEIT (1916), of whom the latter summarizes FRORIEP's views as follows: "In dem anfangs sehr kleinen ungegliederten Bezirk am Vorderende des Körpers bilden sich Kiemenspalten und Kopfsinnesorgane, als Folge hiervon vergrössert sich das Centralnervensystem zum Gehirn. Bei der mächtigen Entfaltung aieses Gebietes kommt es dann zur Zerstörung von Somiten des vorderen Körperendes mitsamt ihrer Nerven; es vereinigen sich die stark entwickelten Kopforgane mit der Chorda dorsalis und den Resten der Somite zum Urkopf, dem sog. Palaeocranium. Nach diesen Anschauungen ist der Kopf von der ersten Anlage an nicht in einer Weise gegliedert wie der übrige Körper. Von der alten Wirbeltheorie und ihrer modernen Nachfolgerin, der Segmenttheorie des Schädels und Kopfes, ist nichts mehr übrig geblieben."

FRORIEP versus GEGENBAUR and VAN WYHE.-Which of these two opinions is now supported by my theory, which is best brought into line with it? Before considering this question some observations must still be made, which may contribute to reduce the gap separating both parties. On the one side GEGENBAUR (1887, p. 77) already granted, and VAN WYHE (1889) emphasized, that it is improbable that at least the palaeocranium has originated by the fusion 
of a number of vertebrae, since ontogeny as well as comparative anatomy of lower Vertebrates teaches us that the cranium is older than the vertebral column, the former being present in Cyclostomes, Chondrostei, Holocephali and lower Elasmobranchs, where vertebrae are still absent. Thus the contrast between FRORIEP's spinal and praespinal region of the head is fully recognized by GEGENBAUR (1887, p. 94) and expressed by him in the names primary or palingenetic and secondary or caenogenetic part, but considered as of less importance than that between chordal and praechordal region. On the other hand, FRORIEP (1887, p. 834) recognizes that in his praespinal region a chordal and a praechordal part may be distinguished, but considers this distinction as of less importance, since the latter is taken to be merely an outgrowth from the former. In reality, as FRORIEP (1887, p. 833) remarks, GEGENBAUR and he are dealing with two distinct problems. FRORIEP starts from the praespinal or palingenetic region of the head as datum and tries to trace the further history of the cranium, while GEGENBAUR tries to analyze the past history of the branchial or praespinal region itself. The latter problem, however, is yet the main point of divergence between them. Mesomerism int branchial region of Elasmobranchs. - Now FRORIEP (1902), turning to the study of early stages of Elasmobranchs, viz. of Torpedo, could only confirm that here indeed the series of somites originally reaches very far forward, nearly as far as the anterior end of the notochord and in front of the first (spiracular) gill-slit. By far the greatest part of the branchial region is occupied by the somites, and, though FRORIEP keeps to his original view that in front of the foremost somite there is to be found an unsegmented mass of "head-mesoderm", it cannot be denied that the latter is reduced here to a very trifling and insignificant remnant. Nothing remains of the chordal part of the praespinal region but the little anterior extremity of the notochord, which atrophies soon after its differentiation from the archenteron-roof. FRORIEP (l.c.p. 43) accordingly calls this stage an Acraniate stage, the whole animal being vertebral column. In studying his clear drawings one would conclude that the series of somites here indeed reaches to in front of the auditory vesicle or, in the youngest stages, of the auditory area, the latter being situated over the second somite (cf. fig. 16 on the next page). 
FRORIEP however, declares that all the somites are metotic or occipital and that prootic somites do not exist (1.c.p. 37). If former investigators believed that they had observed them, this is caused by the erroneous assumption that the auditory vesicle has a fixed situation in regard to somites and visceral clefts. In reality, however, it wanders backwards during

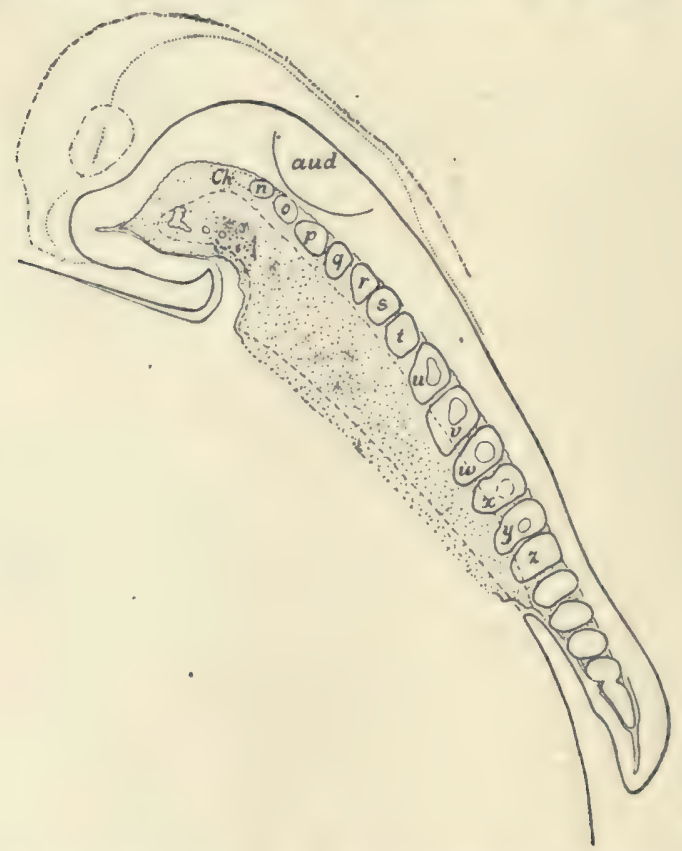

Fig. 16 Embryo of Torpedo ocellata, stage D. aud auditory vesicle, $\mathrm{Ch}$ rostral end of the notochord, $n-z$ occipital somites (after FRORIEP, 1902).

development, while at the same time the foremost somites undergo a reduction, being dissolved into mesenchyme. At the same time the originally insignificant head-mesoderm spreads over the branchial region. It occupies dorsally the place left by the dissolved somites and seizes upon the part of the notochord which was formeriy flanked by the latter and at both sides of which will appear the parachordalia, which accordingly belong to the praespinat region. The fixed point, from which to establish all these dislocations, 
is provided by the craniovertebral limit, the correct determination of which in succeeding stages he guarantees, though with the somewhat restricting addition "(Irrtum vorbehalten)".

Thus FRORIEP reaches the conclusion that a considerable part, nay, by far the greatest part, of the branchial region originally indeed exhibits segmentation, though secondarily this is destroyed and subsequently replaced by the branchiomerism, of which only the latter would have been observed by VAN WYHE and ZIEGLER, who studied stages much too far advanced in development. We get the impression, that it is no easy task for FRORIEP to demonstrate that the auditory vesicle still belongs to the unsegmented region in front of the first somite, since in his own drawings we see the series of somites clearly reaching to in front of the auditory vesicle. One would be inclined to ask if, in such Vertebrates, where no prootic somites are to be abserved, the reduction demonstrated by FRORIEP in Elasmobranchs could not have already set in in the earliest stages observed and even before the somites become evident?

Main points on which opinions differ. - At any rate we can state that the main differences between the two conceptions prevailing until the present day is reduced to a divergence of opinion on the following questions:

1. Is there a part of the head that is primarily unsegmented and is there a primarily unsegmented head mesoderm?

2. Does the auditory vesicle belong to this unsegmented head-region or to the region of the somites?

3. Does the branchiomerism correspond to the mesomerism and do the gill-slits belong to the first or to the second region mentioned under 2 ?

Unsegmented region of the head. - As regards the first question, both parties recognize the existence of an anterior part in which no segmentation can be traced. It is the evertebral region of GEGENBAUR - corresponding, together with the mandibular segment, to the acromerite of HATSCHEK $(1909,1910)$ - resp. the praespinal or cerebral region of FRORIEP, which reaches to the foramen of the vagus. The praechordal part, by the adherents to the first view, however, is generally considered as a secondary outgrowth from the first segment, their starting point being accordingly a body uniformly segmented from the tip of the nose to the end of the tail; the foremost segments having 
coalesced to form the head. HATSCHEK (1909, p. 498) assumes first the formation of a dorsal part of his acromerite by a forward outgrowing and overturning of the fore-end of the brain, as described previously (cf. p. 50), then the formation of a ventral part by the growing out of the maxillary-palatine processus of the first visceral arch. The adherents to the second view, on the contrary, consider the head region as a part of the body, which from the beginning must be opposed to the segmented trunk. DE LANGE (1913) e. g. joins HUBRECHT (1902, p. 70) in the view, that the trunk grows out from the head in the same way as the segmented soma of Annelids grows out from the trochophora-larva. Indeed among students of Annelid development we meet the same controversy: most of them, with KLEINENBERG (1886), oppose the prostomium to the segmented trunk, which has grown out secondarily; on the other side, however, we may point to the fact, that in asexual generation the prostomium is formed as an outgrowth from the first segment.

Now from the point of view of my theory FRORIEP is quite right in emphasizing, that not the whole head of Vertebrates has originated by the fusion of segments, but that there has been an anterior unsegmented nucleus to which afterwards somatic segments have been added. This unsegmented anterior part corresponds to the prostomium of Annelids, as was already anticipated by BALFOUR who in 1881 wrote: "These considerations indicate with fair probability that the part of the head containing the fore-brain is the equivalent of the praeoral lobe of many Invertebrate forms." On the other hand, as regards the backward extension of the prostomium, it seems to me to follow from my theory, that the view of GEGENBAUR, VAN WYHE etc. is nearest the truth, and that the primarily unsegmented part of the head, already so much reduced in size by FRORIEP's own researches on Elasmobranchs, does not reach any further indeed than the praechordal part, as suggested by BALFOUR. We are led to this decision especially by the answer, which my theory gives to the second of the above questions.

Is there an unsegmented head-mesoblast? - Before again considering this second question we have to deal with the second part of the first: i.e. whether there is a primarily unsegmented head mesoderm belonging to the prostomium. 
The cell-lineage investigations have taught us that, though KLEINENBERG's (1886 p. 3): "Es gibt gar kein mittleres Keimblatt" went a little too far, yet we cannot speak of a middle germinal layer homologous throughout the whole group of three layered animals. In the Zygoneura, mesoderm from two different sources may be distinguished, the one of ectodermal and the other of entodermal origin. The latter has a bilateral character and gives rise in Arnelids to the double series of cœlomic segments. The former has a more or less radial ${ }^{1}$ ) origin and a meser chymal character. It is also known as the larval mesoblast and was compared by MEYER (1890), as we have seen, to the mesenchyme of Turbellarians, while he derived the cœlomic pouches from the genital follicles of the latter (cf. p. 25). Thus the ectomesoblast, representing in the larvae of such Cœlomata as Annelids and Molluscs the mesenchyme of mesenchymal worms and Ctenophores, in the same way as the so-called head-kidney of these larvae may be compared to the protonephridia of the flatworms, is phylogenetically older than the ento- or cœlomesoderm and therefore has been termed by CONKLIN (1897, p. 151) primary or radial mesoblast, in distinction to the latter which he defined as secondary or bilateral mesoblast. While the secondary mesoblast is restricted to the segmented soma, the primary mesoblast does not belong exclusively to the prostomium. It even originates from the ectoderm of the hyposphere ( $3 r d$ quartett of micromeres), from which the soma is formed. It represents the mesoblast of the whole larva and of the primary body cavity, to which belongs part of the cavity of the prostomium in the adult form (cf. p. 26).

Can such an unsegmented mesoblast be recognized also in Vertebrates, is this the "head-mesoderm" of FRORIEP ? HUBRECHT $(1890,1908)$, MARCUS $(1910$, p. 111) and DE LANGE (1913) think they can demonstrate for the latter an origin different from that of the coelomic mesoderm, the former being split off from the entoderm, the latter being of "animal" or ectodermal origin. This assumption, however, is wholly based on the supposition that LWOFF (1894) was right in considering the roof of the archenteron of the Vertebrate gastrula as being composed of invaginated ectoderm cells, a view which has found far from general

$\left.{ }^{1}\right)$ In Annelids this has been only definitely observed in Scoloplos (DELSMAN, 1916), 
acceptance. We shall refer to this theory again in due time (cf. chapter III), I can only say here that to me also it seems untenable, the roof of the archenteron being in my opinion wholly entodermal. Further, the three authors mentioned think they can distinguish very sharply in the roof of the archenteron the invaginated ectodermal cells (the "protochordal wedge" of HUBRECHT) from the entodermal cells (the "protochordal plate", H.), and to be able thus to trace exactly the limit of the two. It is subject, however, to serious doubt, whether the histological character of cells, in this case the yolk-richness, thus permits us to trace their origin from the outer or the inner germinal layer with equal certainty as e.g. cell-lineage investigations allow us to do in Annelidan development. But assuming the above authors were right as far as concerns the facts, then, as stated above, we still would reach the conclusion, that in Vertebrates the headmesoderm ("Urmesoderm" of DE LANGE) would be of entodermal and the coelomesoderm of ectodermal origin, while in Annelids the reverse is true, the primary or larval mesoderm being of ectodermal, the secondary or coelomesoderm of entodermal origin.

If indeed in the head of Vertebrates a headmesoderm, comparable to the primary or larval mesoblast of Annelids and Molluscs, were present, it should be of ectodermal origin, whereas the coelomic mesoderm, in accordance with what is found in Annelids, is wholly of entodermal origin. Now it has been held by several authors, who follow in this Miss PLATT (1897), that ectodermal mesenchyme is proliferated from the lateral placodes which contribute to the formation of the head-ganglia. Yet it seems to me hardly probable that, if these statements are right (others have opposed to them, cf. BUCHS, 1902, p. 605), we have to do here with primary head-mesoderm comparable to that of Annelids and to the mesenchyme of their. non-segmented ancestors, the stage of development in which it appears being much too late. It seems to me improbable that traces of the primary ectomesoderm should be still found in Vertebrates. In Amphioxus we stated already that in the prostomium (fig. 5) no mesoderm is found, that all the mesoderm of the embryo is coelomesoblast and is of entodermal origin and belongs to the trunk. Only later, according to HATSCHEK (1882), a forward prolongation of the first somite provides the snout with mesoblast, in the 
same way as in Annelids prolongations of the trunk mesoblast secondarily penetrate into the prostomium (p. 26). Evidently no primary phylogenetic significance can be attributed to this mesoblast of the dorsal part of the snout of Amphioxus (the ventral half is filled up by the right anterior head cavity). And when RABL (1889) compares FRORIEP's unsegmented head-mesoderm of Craniates to this prolongation of the first somite in Amphioxus, this comparison can only lead to a negation of the fundamental significance attributed to this head mesoderm by FRORIEP.

Proamnion. - The conception, that the prostomium in Vertebrates does not contain any primary head mesoderm, seems to me to be supported also by the presence of the so-called "proamnion" (VAN BENEDEN and JULIN, 1884b) in Amniotes. The absence of mesoblast in the prostomium marifests itself also in the extra-embryonic area: the extraembryonic mesoderm, being the continuation of the somatic or coelomesoblast, ends abruptly anteriorly at both sides of the embryo with a straight line perpendicular to the body axis and intersecting the latter at the limit of prostomium and soma. In front of this line no mesoderm is present and the amnion-folds consist only of ectoderm and entoderm ("pro-amnion"). Only afterwards is the anterior part of the extra-embryonic area, corresponding to the prostomium, invaded by the mesoblast.

I am inclined to the view that the mesenchyme of Ctenophores, Plathelminths and Nemerteans, of which the primary or larval mesoblast in Annelids and Molluscs represents a last vestige, has wholly disappeared in Vertebrates, where only the coelomesoblast, so strongly developed already in Annelids and perhaps to be traced back to the genital follicles of mesenchymatous ancestors, has remained. To the prostomium of Chordates, accordingly, no primary mesoderm belongs; the unsegmented head-mesoderm of FRORIEP is to be considered as the anterior part of the somatic or coelomesoblast in which segmentation has been suppressed, as we see it pass before our eyes in the branchial region of Elasmobranchs. The gill-slits pierce through that part of the lateral plate, that belongs to the head-region and from which, as VAN WYHE (1882) first emphasized, the primordial gill-muscles are derived. The unsegmented mass of mesoderm, observed by DE LANGE in Megalobatrachus ("Urmesoderm", 1913, p. 250) and which only secondarily 
is cut into segments by the gill-slits, is, I think, nothing but this anterior part of the unsegmented lateral flate.

Diagrams of VAN WYHE and ZIEGLER.-Before proceeding now to the second of the above questions, viz: whether the auditory vesicle belongs to this unsegmented head region or to the region of the somites, we will first turn a moment to the diagrams of the metameric structure of the head drawn by the adherents of the views of GE jENBAUR and VAN WYHE. As mentioned before, the scheme lastly given by ZIEGLER (1908, 1915), and based on the researches of his disciples KLINKHARDT (1905), GUTHKE (1906) and BROHMER (1909), is one of the simplest. On the whole it agrees with that of VAN WYHE (1882), but the hyoidsegment is not considered by him as a double segment, and also ZIEGLER's conception of the polymerism of the vagus differs somewhat from that of VAN WYHE.

Myomerism, neuromerism ${ }^{1}$ ) and brartchiomerism correspond; each gill-slit has pierced through the lateral pla!e between two somites, thus causing the stalks connecting each myotom with the unsegmented lateral plate to appear much longer than in the trunk. They each run through a branchial bar and communicate at their inferior end with the pericard, in the same way as the somites of the trunk with the general coelome. Only in the occipital region are myotoms distinctly developed at their superior ends. The spiraculum is the first gili-slit, it originally resembles completely the gill-slits in shape and situation and forms witn the latter a series of which the mouth seems to be again the forward continuation. To each branchial bar a segment corresponds; that between the spiraculum and the first gill-slit represents the hyoid-segment, that between the spiraculum and the mouth the mandibular segment, from which the mandibula is formed and which at its upper end dilates into a vesicle which, projecting far forward, provides nearly all the mesenchyme of the anterior part of the head. Anterior to the mouth we then have a last couple of mesoderm segments, situated in front of the anterior end

1) This is not to be confounded with the attempts to claim a segmental structure for the medullary tube and the brain, of which the beginning has been found even in the still open medullary and cerebral plate. Most authors now recognize that this can only be a secondary phenomenon, caused by the segmentation of the mesoderm and the segmental arrangement of the nerves and their ganglia. 
of the notochord, close to the eye-balls. They are distinguished by their minute size and the absence of ventral parts. These are BALFOUR's præmandibular cavities, which VAN WYHE and ZIEGLER consider to be the first pair of mesoderm segments. According to this view the mouth is enclosed on both sides between two mesoderm segments in the same way as the gill-slits.

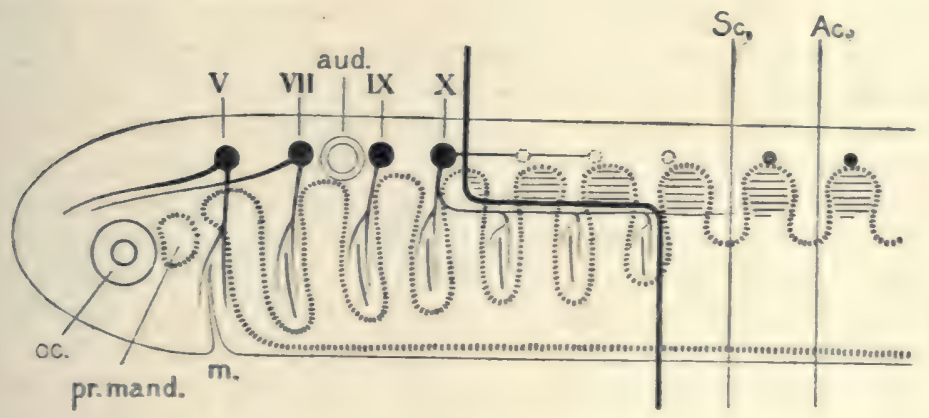

Fig, 17 Diagram of the head of a Selachian. The heavy line indicates the limit between the cerebral and the spinal part of the head after FRORIEP. $A C, S c$ cranio-vertebral limit in Acanthias and Scyllium, au auditory vesicle, $m$ mouth, oc eye, pr. mand. prae-mandibular cavity.

With the arrangement of the mesoderm segments that of the head ganglia corresponds; after VAN WYHE's (1882) example the four cranial nerves of mixed function are compared to the dorsal roots of the spinal nerves of the trunk. Above the hyoid arch lies the ganglion of the facialis-acusticus, above the first interbranchial gill-arch the ganglion of the glossopharyngeus, above the next gill-arches that of the vagus. The vagus ganglion after GEGENBAUR's (1872, p. 269) example has been originally considered as a complex ganglion corresponding to as many segments as gill-slits are innervated by the vagus. "Wenn wir für den ersten bis dritten Kiemenbogen je einen diskreten Kopfnerven bestimmt sehen," GEGENBAUR (1887, p. 103) says, "für die letzten Kiemenbogen aber einen gemeinsamen Stamm, so liegt es nahe genug, diesen aus einer Summe von Nerven entstanden zu betrachten, aus derselben Anzahl, welche jener der von ihm versorgten Kiemenbogen entspricht." Yet, in ontogeny, the number 
of ganglia fused to form the vagus-ganglion appears not to correspond to the number of gill-arches innervated by the ventral branches of the vaous, being four in pentanch Elasmobranchs. According to GUTHKE (1906), the complex vagus ganglion sends three roots into the medulla and also three branches into the last three interbranchial gill-archs. Thus ZIEGLER (1908) and his disciples consider the vagus ganglion as formed by the fusion of three ganglia, the ganglion of the fourth branch, which runs behind the last gill-slit, (cf. fig. 17) or of the last branches in hexanch and heptanch forms, having been lost and these branches themselves having united with the fore-going, so that the third or last branch coming from the ganglion sends nerves to two, three or four gill-slits. VAN WYHE, who originally (1882) considered the vagus as a quadruple nerve, afterwards (1889, p. 562), on the discovery of rudimentary dorsal ganglia to the last two head-myotomes (VAN WYHE, 1886, OSTROUMOFF, 1889), recognizes only two vagus-roots. The results of embryological and anatomical researches on Petromyzon point to the conception, advocated by HATSCHEK (1892, p. 157), that the primary vagus is here a single nerve only, which in Gnathostomes probably fuses with one spinal nerve and its ganglion, which are still independent in Petromyzon, and further "collects" the ventral part (rami prae- and posttrematici) of the dorsal roots of as many subsequent spinal nerves as there are gill-slits supplied by it ("partial polymerism" of the vagus, HATSCHEK, 1892, p. 152). Thus the ramus branchio-intestinalis of the vagus would be a collector in the same way as the ramus lateralis of that nerve according to EISIG and others.

The main ganglion of the trigeminus lies over the mandibular arch, and the first ganglion of the trigeminus, the ganglion ciliare with the ramus ophthalmicus profundus, is considered to belong to the praemandibular segment. Thus the trigeminus is considered by VAN WYHE and ZIEGLER to represent a double segmental nerve.

Neural crest of head and trunk. - Another question which has occasioned controversy is, whether the neural crest, which gives rise to the centrogenetic part of the head ganglia, is to be considered as the direct continuation of the neural crest of the trunk. In fact there is this difference between the spinal and the head ganglia, besides the mixed character of the latter, that the former are found on the inner side of the somites, the latter on the 
contrary on the outer side. After FRORIEP (1901), who, as we have seen, is inclined to emphasize the contrast between the "praespinal" or "cerebral" part of the head and the rest of the body, we have to do here with two different neural crests, which in the occipital region run along each other for some distance. DOHRN (1902) however does not admit this contrast and GUTHKE (1906) finds that the spinal ganglion crest behind the last gill-slit crosses the eighth segment, thus passing from the inner side of the somites to the outer side, where the head ganglia are found. According to ZIEGLER (1908) the lateral situation of the head ganglia stands "wahrscheinlich in Beziehung zu der Placodenbildung und ist demnach die Folge der Ausbildung der eigenartigen Sinnesorgane, als deren palingenetische Reste jetzt die Placoden auftreten". Finally GAST (1909, p. $375)$ believes, that a double ridge is found not only in the region where cephalic and trunk neural crest, according to FRORIEP, run for some distance parallel to each other, but that this double nature is characteristic of the whole head and trunk. According to the conclusions arrived at by us regarding the relations between spinal and lateral ganglia, the lateral situation, if ZIEGLER's view were right, would have been the primitive one also for the spinal ganglia, and the present situation, on the inner side of the somites, ought to be considered as secondarily acquired after the loss of the segmental communications of the spinal with the lateral ganglia. A last trace of this might be found in GAST's observation of the double nature of the trunk neural crest. But here we may stop our speculations in this direction, in which we may, perhaps, have gone too far already.

Eye-muscle nerves. - Finally the oculomotorius, trochlearis and abducens have been compared by VAN WYHE (1882) to the ventral roots in the trunk region. The oculomotorius is considered as the ventral root of the first or praemandibular segment and innervates the eye-muscles derived from it, the trochlearis as the ventral root belonging to the second or mandibular segment, while the abducens in counted as belonging to the third or hyoid segment.

We will revert later to the question whether a ventral root belongs to the following segments (ventral vagus roots of GEGENBAUR, hypoglossus in Amniotes!). Thus the number 
of head segments in such Selachians as Scyllium according to ZIEGLER is one (the praemandibular segment) more than the number of visceral archs, being accordingly eight. According to VAN WYHE, who considers the hyoid segment as a double segment, it amounts to nine, the same number as reached originally by GEGENBAUR, though their segments do not fully coincide.

Auditory vesicle in second segment. - If now in this scheme we look at the situation of the auditory vesicle, it is evident that there can be no doubt, that it belongs to the segmented region of the body and lies over the third or hyoid segment, if we count the praemandibular cavities as the first pair of segments. Now, as I will explain below, I do not feel convinced that the praemandibular cavities indeed represent a first pair of mesoderm segments, and I will give some reasons, which seem to me to plead for the view that the mandibular segment is to be considered as the first. If this view be right, we come to the conclusion that the auditory vesicle belongs to the second body segment.

On the other hand, if, with FRORIEP, we assume that the segmentation of the head observed by VAN WYHE and ZIEGLER were simply branchiomerism, that has nothing to do with mesomerism, then again, in studying FRORIEP's figures of early stages of development of Elasmobranchs (cf. fig. 16), in which true somites are found also in the branchial region, an unprejudiced observer must, I think, come to the conclusion, that the auditory vesicle (placode) lies over the second segment.

In Annelids also, where they occur, the statocysts belong to one of the first somatic segments, not to the prostomium or to the head, as first suggested by HATSCHEK (cf. fig. 14). As we have seen, there are often several pairs in more primitive forms, while in more differentiated forms they are restricted to one segment only, which in the majority of cases is equally the second segment (cf. p. 41)

Thus we must reject FRORIEP's view that the auditory organs in Vertebrates, just as the optic and olfactory organs, belong to the primarily unsegmented anterior part of the head.

Branchiomerism and mesomerism. - We now come to the third question: does the branchiomerism correspond to the mesomerism and do the gill-slits belong to the first or to the second region mentioned sub 2 on p. 69 ? The mesomerism observed by FRORIEP in nearly the whole chordal part of the 
head in Elasmobranchs disappears soon afterwards and the mesoderm segments are dissolved and replaced by an unsegmented mass of mesenchyme, as is observed in this region from the beginning in Amniotes. This mesenchyme, however, according to FRORIEP, is not, as one might suppose, a product of the dissolution of the somites. The latter do not contribute at all to its formation, it is exclusively the little area of unsegmented mesoblast lying originally in front of the first somite that grows out backwards and pushes below the scattered mesenchyme that has resulted from the dissolution of the somites. In this way things happen according to FRORIEP (1902, p. 44), but it seems to me very difficult to conclude from sections, that this view is the right one, and that it is not the dissolution of the somites which is the source of the unsegmented mesenchyme mass. FRORIEP himself has been long in doubt, as he admits, and I cannot feel convinced by his argumentation, which is based on a slight difference in density of the supposed two kinds of mesenchyme.

Now the question is, whether the branchiomerism, which soon after makes its appearance in this region, is quite independent from the original mesomerism or if it corresponds to it. In studying the work of the above cited authors, one cannot avoid the impression that the adherents of the first view place themselves on a too restricted stand-point and that, to quote once more the words of EISIG (cf. p. 58), they are inclined to translate "eine ontogenetische Thatsache wil!kürlich ins Phylogenetische." Truly, the correspondence of branchiomerism to mesomerism is often, especially in somewhat further advanced stages of development, far from evident. As a rule, especially in higher Chordates, mesodermic segmentation is no longer to be observed in the branchial region when the gill-slits have broken through. The fact, however, that one gets the impression, that in ontogeny the seriality of the gill-pouches originating from the entoderm is the cause of the segmentation of the head-mesoderm, seems to me not at all to exclude the possibility, that in phylogeny the reverse may have been the case and that also in ontogeny the place where the gill-pouches will arise has been determined in an earlier stage by some influence from the mesoderm, in Elasmobranchs e.g. by the somites observed also by FRORIEP in the branchial region. One of the strongest arguments for the latter view seems to 
me to be the metamerical arrangement of the head nerves. If FRORIEP's views were right, we ought to assume that, simultaneously with the dissolution of the original head somites, the spinal nerves which originally belonged to them had disappeared also, and that afterwards the influence of the branchiomerism had caused the production of a quite new series of nerves, corresponding in their arrangement to the gill-slits but at the same time showing unmistakable traces of resemblance to the spinal nerves of the trunk. The neuromerism is considered as of quite secondary significance and as immediately dependent upon meso- or branchiomeri sm. As GEGENBAUR (1887, p. 93) observes in a polemic against AHLBORN: "Um die Branchiomerie zu retten, stellt er die Bedeutung der Nerven in Abrede, auch ihren metameren Charakter." It seems hardly doubtful, that in phylogeny the neuromerism has been engendered by the myomerism, but it is less probable that this primary neuromerism, once established, would so easily give way to a secondary neuromerism, caused by the branchiomerism. We might rather expect, placing ourselves on FRORIEP's standpoint, that the original headnerves, after mesomerism had been replaced by branchiomerism, had inclined to adapt themselves to the new conditions, and that in the new arrangement, resulting in this way, we should be able to find traces of the old. If then branchiomerism did not correspond to the original mesomerism, we might expect to find e.g. two or three segmental nerves in some gill-bars, or on the contrary, none at all, or one segmental nerve sending branches to two or three gill-bars. But applying this principle to the facts, we can only come to the conclusion that, on the whole, the branchiomerism corresponds to the mesomerism. Only with reference to the posterior gill-slits, innervated by the vagus, is there room for some doubt, since here indeed we have the case, that more than one gill-slit is supplied by the branches of a single nerve. ZIEGLER (1915 p.462) assumes that originally there were only four post-spiracular gill-slits, situated intersegmentally, while the last gill-slit in pentanch and the last two or three in hexanch and heptanch Elasmobranchs are phylogenetically younger, and if VAN WYHE's and HATSCHEK's view of the double nature of the vagus were combined with ZIEGLER's suggestion, their number might appear to be still greater. Of these 
secondary gill-slits it could be imagined that their arrangement did not correspond any longer to the mesomerism.

Branchiomerism and mesomerism in lower Chordata. - Until now we nave left out of consideration the two lowest groups of Chordates, Amphioxus and the Cyclostomes. A comparison of these forms with the Gnathostomes, however, proves to be decisive and truly fatal to FRORIEP's views. In Amphioxus, as shown most clearly by WILLEY's 1891) figures and by HATSCHEK (1892), the arrangement of the gill-slits originally corresponds to that of the somites, which from the foremost to the last develop regular myotomes. Only secondarily the backward extension of the branchial basket causes in this case also the series of gill-slits to extend under myotomes originally situated behind them, while, after the "critical stage". (WILLEY, 1891, p. 202) has been passed, the number of gillslits, partly also by bipartition of the first formed, on the contrary so much increases that it finally considerably exceeds the number of myotomes of the branchial region. Thus both the adherents to the view of GEGENBAUR - VAN WYHE and those who follow FRORIEP can adduce the evidence from Amphioxus as a support to their theory, the branchiomerism here partly corresponding to the mesomerism and partly being independent of it. There is no doubt, however, that these conditions in the larva must be considered as more primitive those that in the adult form.

In Petromyzon, as demonstrated by NEAL (1897, p. 447) and KOLTZOFF (1901, p. 432), there is originally a complete numerical (though not always strictly individual) correspondence of the gill-slits and the somites. The eight gill-pouches, of whi-h the foremost, the spiracular one, does not break through, originate under the boundaries between nine somites. These are here also well developed from the foremost onwards, though only the post-otic ones, from the glossopharyngeus-segment onwards, produce regular myotomes, while from the pro-otic somites the eye-muscles are derived. Again secondarily only does the backward extension of the branchial basket cause myotomes of postbranchial origin to be found above the gill-slits in the adult. As NEAL has emphasized, a comparison of embryos of $5 \mathrm{~mm}$, and of $5 \mathrm{~cm}$, shows that the dorsal portion of the post-otic myotomes $7-12$, which in the earlier stage lay behind the last visceral cleft, in the later stage lie anterior to this. Thus in the adult the 
number of myotomes exceeds that of the gill-slit-, but this is only a secondary phenomenon again.

In Necturus Miss PLATT $(1894,1897)$ found a complete accordance of mesomerism and branchiomerism, the second gill-slit is situated beneath the auditory invagination, in front of the first meta-otic somite, the third one between the first and the second post otic somite, etc. The same seems to hold for Gymnophiones, to judge from MARCUS' (1910) figures and description, though certain corrections in his interpretation of the somites seem necessary. Of the post-otic head-somites the last one still produces muscles of a permanent nature, while also the last but one still produces a few fibres. GOODRICH $(1911$, p. 116), working on the axolotl, fully confirms Miss PLATT's conclusions regarding Necturus.

If now in lower Vertebrates we find such an undeniable correspondence between branchio- and mesomerism, it is hard to deny or doubt such a correspondence in higher groups where the mesomerism in this region has become less distinct when the gill-slits appear.

Paired intestinal dive, ticula among Protostomia. - For the solution of the problem of the relation of the branchiomerism to the mesomerism we look in vain to the Annelids. Neither here, nor in other Protostomia, do gill-slits occur and it need not be further argued, that there can be any question of a direct comparison to the gill-slits of Balanoglossus. Among the parenchymatous worms, however, we often find paired diverticula of the gut which remind us of the gill-pouches of Vertebrates. They often alternate quite regularly with the equally paired genital follicles, from which MEYER (1890) derives the coelomic segments of Annelids. This is the case in several Turbellaria and in most Nemerteans. In. Polyclads the ends of these diverticula sometimes apply themselves to the ectoderm, thus giving rise e. g. to the villi of forms like Thysanozoon, which no doubt have a respiratory function. In other forms again they may: even open to the exterior (Yungia).

Something quite similar is found among Molluses in the Nudibranchs, which in several respects show such a remarkable, resemblance to Polyclads. Here also we have paired diverticula of the gut, applying themselves to the ectoderm and giving rise to the gills or cerata, which often open to the exterior. In the year 1845 NORDMANN gave a 
figure of a young Tergipes in which the gonads are shown to consist of paired follicles metamerically arranged and alternating with the paired cerata (reproduced in BRONN's Klassen und Ordnungen, Malacozoa, Plate 55). Very obvious is also the originally segmented structure of the gonads in DAVENPORT's (1893) figures. Alternating with the entodermal pouches, which here bear transverse rows of cerata, the genital follicles àre situated, one pair of ovaria and ohe pair of testes between every two rows of cerata. I myself was especially struck by the regular alternation of cerata and genital follicles, while studying a young Nudibranch from the harbour of Helder, to which my attention had been drawn by its perfect transparency. It showed very clearly that the diverticula of the gut, applying themselves to the ectoderm in the same way as gill-pouches, cause the formation of the cerata.

It seems to me not improbable that the gill-pouches of Vertebrates may be directly compared to the gut diverticula of flatworms and Nemerteans and, perhaps, of Nudibranchs. In the axolotl HOUSSAY (1893, p. 33) described and figured very distinctly a double series of lateral diverticula of the gut reaching from the mouth to beyond the anus and alternating quite regularly with the myotomes. Only the foremost break through and form the gill-slits. His observations for Siredon are confirmed by Miss PLATT $(1894$, p. 933, 961) for Necturus. These metameric outpocketings are very clearly defined and remind one vividly of the intestinal diverticula of the gut in flatworms, which alternate with the genital follicles. On the other hand, I do not think that from these observations it follows that gill-slits must have been present formerly along the whole length of the soma in Vertebrates, as assumed by BOVERI (1892). Combining then MEYER's above cited theory on the origin of metamerism (gonocoel theory), with the comparison just made, we have one more argument in favour of the view that branchiomerism originally: corresponds to mesomerism

In studying ZIEGLER's figures, one gets the impression, that it is fairly obvious, that in Elasmobranchs also the segmentation of the branchial region is simply the continuation of that of the trunk. While in the adult the series of gill-slits extends backwards considerably further than the corresponding region of the cranium, causing the glossopharyngeus and the branches of the vagus to take an 
oblique backward course, this incongruity appears to bemuch less distinct in very young stages where the gill-slits have just broken through. It is precisely the oblique course of the posterior head nerves, as argued already by GEGENBAUR (1872, p. 253, 275), which is a strong indication of the original congruence between the cranium and the series of gill-slits, however much the two may differ in backward extension in the adult. The curve in backward direction made by the ventral nerves of the cervico-brachial plexus round the last gill-slits to reach the ventral side of the body, must be considered equally as a result of the secondary backward expansion of the series of gill-slits, which in young embryos appears to be still much less pronounced. We come then to the conclusion that GEGENBAUR was not far from the truth in assuming that the posterior limit of the Elasmobranch cranium coincides with the backward extension of the gill-slits, though, as we shall see further on, we may not go so far as to assume that the number of segments incorporated into the cranium may be deduced from the number of visceral archs.

As to the second part of the third question it need not again be emphasized that the branchial region does not belong to the primarily unsegmented anterior part of the head, the prostomium, but to the segmented soma.

Thus on the whole my theory leads to a confirmation of the views of GEGENBAUR, VAN WYHE and ZIEGLER with his disciples, and to a rejection of those of FRORIEP. in so far as his conception of the branchial region as an unsegmented head region is concerned.

Significance of praemandibular cavity. - As we have seen, the praemandibular segment, at first described by BALFOUR. (1878), is considered by VAN WYHE and ZIEGLER as the first segment of the soma. To this end the $N$. trigeminus must be considered as a double nerve, the ramus ophthalmicus profundus with the ciliary ganglion representing the dorsal root to the first segment, while the oculomotorius is taken as the ventral root. As a matter of fact the latter innervates exactly those four eye-muscles which are produced by the praemandibular segment, which lies closely applied to the eye-ball. Thus everything required for a segment is present with the exception, however, of onething: the division into a dorsal and a ventral part. Only the former is present, the latter is missing, and with it the 
communication with the pericard. This, truly, need not surprise us, if we imagine with DOHRN that the mouth originated by the union of two gill-slits; in this way the communication of the praeoral somites with the pericardial cavity was of course cut off. Owing to this, and by their minute size, the praemandibular somites are distinguished from those following. When first formed in Selachians, they remain connected with each other for some time by a little stalk in front of the. notochord. Soon afterwards this connection is lost. Thus the secondary mouth of Vertebrates would have pierced between the first and the second segment of the soma, while the primary mouth, that of Annelids, the neuropore of Amphioxus, is to be found just in front of the first segment.

I must confess, however, that I do not feel convinced that the praemandibular cavities represent the first segment and that they are not to be considered as a detached part of the mandibular segment, which has applied itself to the eye vesicle, i.e. a prostomial organ. The circumstance especially, that the eyes are organs belonging to the prostomium, made me ask the questions: do not the praemandibular cavities lie in the prostomium, does not the mouth indicate ventrally the limit of the prostomium and the first segment? If the branchial diverticula of the gut made their way each in the groove between two segments, perhaps finding here places of minor resistance, or simply as a consequence of the regular alternation of gut diverticula and genital follicles present already in Plathelminthes, might it not be expected then in some degree, that the first opening to the exterior would break through in front of the first segment, which in this case would be the mandibular segment? Then in Selachians like Scyllium and Pristiurus the number of visceral archs would prove to correspond fully to the number of segments incorporated into the head. We should come to the conclusion that the new mouth of Vertebrates has broken through exactly opposite the old mouth of Annelids, like the latter between the prostomium and the first segment, and - though this of course cannot serve as an argument - the name prostomium ("in front of the mouth") might be used with equal right in Vertebrates as in Annelids.

BALFOUR (1878, p. 206), who first described the praemandibular cavities, and his disciple MARSHALL (1879) thought rindeed that they originated from an outgrowing of the 
mandibular segment, but this was denied by VAN WYHE (1882, p. : 8) and recently by ZIEGLER (1908, p. 659). GEGENBAUR (1887, p. 7) suggests that nevertheless in phylogeny the praemandibular segment may have split off from the mandibular segment. In Necturus Miss PLATT (1897, p . 443) finds that the praemandibular mesoderm in young stages is not divided from the mandibular. In Petromyzon recently HATSCHEK $(1910$, p. 481) states that here also the praemandibular and mandibular cavities originally represent one segment, the mandibular segment, which accordingly is the first mesoderm segment, to which a special significance is attributed by HATSCHEK. It is the mesoderm of his "acromerite," an anterior part of the body corresponding to my prostomium + mandibular segment, and concerning which HATSCHEK provisionally, leaves it undecided, as to whether it represents an anterior unsegmented region or an anterior, somewhat diverging, metamere. HATSCHEK thinks "dass die Vorgänge bei den Selachiern erst durch die in mancher Beziehung einfacheren und wohl auch primitiveren bei Petromyzon besser verständlich werden," and thus seems to be inclined to join GEGENBAUR's opinion. In Amphioxus also we see the first pair of segments, homologized by VAN WYHE to the mandibular segments of Craniates, send out each a forward prolongation into the prostomium.

That the praemandibular cavities produce muscles (Musc. rectus superior, internus and inferior, and Musc. obliquus inferior, as stated in Selachians), and in this respect resemble myotomes of the trunk, cannot well be adduced as an argument for considering them as representing a segment, since in the first place it may be doubted if the eye-muscles are to be derived directly from segmental muscles. We see the latter vanish gradually in going from the trunk to the head in an embryo. The three occipital segments in Pristiurus and Scyllium still have a distinct myotome with muscle-formation, the first vagus-somite has only a rudimentary myomere, while in the segments lying in front of this, the glossopharyngeus- and the facialis-segment, no myotoms are developed. In the (hyoid-?) mandibular- and praemandibular segment we then see the eye-muscles appear, which accordingly are considered, e.g. by ZIEGLER (1908, p. 674), as relatively. young muscles, not directly comparable to segmental trunk muscles. But even if we do not share- 
this view, we still see that the "head-prolongations" (Kopffortsatz) of Amphioxus also produce muscles and, as we have seen, there can be no question about considering the latter as a distinct pair of somites, which would lie in fiont of the neuropore, i.e. the old mouth of the Annelids.

Nature of the trigeminus. - Opinions differ again as to the double nature of the trigeminus which must be assumed to furnish a dorsal root to both the præmandibular and the mandibular segment. According to VAN WYHE (1882) we must distinguish the ramus ophthalmicus profundus, together with the ganglion ciliare, from the rest of the trigeminus, together with the ganglion Gasseri, these being the dorsal roots respectively of the praemandibular and of the mandibular segment. This view, suggested already, though with some reserve, by GEGENBAUR (1872, p. 290), has found a general acceptance, ZIEGLER also, as we have seen, accepts it. Truly the ramus ophthalmicus profundus could be considered only as a very incomplete segmental nerve, which has lost its typical branches and which. in contrast to the other head nerves, has no relation to any gill-slit (as the trigeminus II has to the mouth). Both ganglia, moreover, arise in close connection with each other and at their first appearance the double nature is as a rule far from obvious. In higher Vertebrates there is little doubt that the insignificant ciliary ganglion, situated over the eye, is nothing but a portion detached from the ganglion Gasseri, but it is questionable, if here it may be compared to the ciliary ganglion of Anamnia.

BALFOUR $(1878$, p. 214), pointing to the striking similarity in the arrangement of the branches of the trigeminus to the facialis, writes: "I was at first inclined to regard the anterior branch of the fifth (ophthalmic) as representing a separate nerve, and was supported in this view by its relation to the most anterior of the head-cavities, but the unexpected discovery of an exactly similar branch in the seventh nerve has induced me to modify this view, and I am now constrained to view the fifth as a single nerve, whose branches exactly correspond with those of the seventh". In the same way GEGENBAUR, who was originally $(1872, p$. 290) inclined to consider the trigeminus as a double nerve, though he remarks: "doch darf auch die Annahme einer mächtigeren Entfaltung eines einzigen Spinalnerven nicht ausgeschlossen werden", afterwards (1887, p, 51) 
changed his opinion. That part of a dorsal nerve may acquire a certain independence, may be wholly split off, as it were, from the main stem, is shown by the acusticus which is very generally considered as belonging to the facialis. That such a splitting occurred in the trigeminus may be easily accounted for by the fact that it innervates the prostomium as well as its own segment, and by the strong and special development of the first pair of visceral archs (the jaws) and the first pair of gill-slits (the mouth).

Both the trigeminus and the facialis, the first two segmental nerves, as I am inclined to consider them, send strong sensory branches (rami ophthalmici trigemini et facialis, ramus buccalis facialis) into the prostomium which, having no ganglion of its own, must be innervated from the anterior segments of the soma as far as its dermal sense-organs are concerned. This evidently has caused the strong development of these first two nerves and their ganglia, especially of the trigeminus. In Amphioxus also we find (cf. fig. 26) that the first segmental nerve, in front of the first somite, has a double nature.

Oculomotorius. - Finally we have the oculomotorius as the ventral root belonging to the praemandibular segment and innervating the eye-muscles that arise from it. If it can be doubted whether the eye-muscles can be derived directly from segmental trunk muscles, then it also seems questionable whether the oculomotorius, trochlearis and abducens can be directly compared to the ventral roots of spinal nerves. In going from the trunk to the head in an embryo we see the ventral roots disappear in the same way as the myotoms when we approach the auditory vesicle. A comparison with Petromyzon and Amphioxus, however, renders it probable that the myotomes and ventral roots of this region have atrophied only secondarily, and that at least the $M$. rectus externus with the $N$. abducens may be homologized to a regular myotome with its ventral root. Oculomotorius and trochlearis, however, afford more difficulties. I need only recall here the anomaly of the dorsal origin of the trochlearis, while the oculomotorius springs from the mid-brain which lies in front of the isthmus and accordingly does not belong to the epichordal part of the neural tube, the former stomodaeum. HATSCHEK (1892, p. 158), in Petromyzon, recognizes only the abducens as a segmental ventral nerve and derives the oculomotorius 
and trochlearis from the visceral branches of the trigeminus. - Similar views have been put forward by several authors.

I feel most inclined to the following view. In the -first chapter I made the supposition that the ventral spinal roots are to be derived from a similar diffuse plexus as - observed by FRAIPONT $(1887$, p. 36$)$ in Polygordius, innervating the longitudinal musculature and directly connected to the epidermis. Such a plexus evidently owes its existence to the close application of the rudiment of the longitudinal musculature to the epidermis in the Anneiid, or to the nervous tube in Chordates. Afterwards a concentration has caused the nerve fibres of the plexus, which has still a diffuse character in Amphioxus, to unite into more distinct nerves. Thus evidently the close application of the myotomes to the epithelium of the medullary tube in young stages, shas been the cause of the growing out of the cells of the latter into nerve fibres We cannot wonder then that also the praemandibular "somite", developing muscle fibres, has as a consequence acquired its own nerve. It will be evident from the above considerations, that to the ventral spinal nerves and tne eye-muscle nerves no primary value - can be attributed in judging the metameric structure of the Vertebrate body. They play only a passive rôle.

Thus after all we see that the arguments in favour of the view that the praemandibular cavities represent the first segment, are not so conclusive as they might appear at first sight. GEGENBAUR (1887. p. 103) states: "dieses Kopfmetamer ist etwas von allen Uebrigen Verschiedenes, da es eines ventralen Abschnittes entbehrt" and concludes: "das nach meiner Auffassung erste Metamer wird - durch das zweite Somit, den ersten primitiven Kiemenbogen oder den Kieferbogen gebildet", and to a similar conclusion HIS (1887, p. 446) was led in the same year: "dem vorderen Kopfmetamer gehören eigentümlich zu: der Complex der Trigeminusganglien und von motorischen Nerven die Nn. -oculomotorius, trochlearis und die Portio minor Trigemini."

It may be rendered probable by the application of the principles of my theory, that part of the ectodermal investment of the oral cavity is derived from the praecerebral part of the apical plate, i. c. that part of the original apical plate of Annelids which is not infolded by the formation of the brain and lies accordingly in front of the transverse cerebral fold and the animal pole. Thus part of 
the ectoderm of the prostomium would have invaginated into the mouth to invest the palate. This circumstance seems to me especially to plead for the view that it is between the prostomium and the first segment, u hich in this case would be the mandibular segment, that the mouth in Craniates has broken through. One of the facts that may be adduced in favour of this view is the mode of origin of the hypopliysis cerebri, of which STENDELL (1914), some years ago gave a short review.

Relation of hypophysis and olfactory pits to the mouth In Rana esculenta the ectoderm not only of the medullary and the cerebral plate but also in front of the latter and of the animal pole $i$. e. in the region which represents. the extra-cerebral part of the apical plate, shows a considerable thickening and a distinct demarcation of a thin superficial and a thick basal layer (fig: 1 and 2 of the plate). While now in the cerebral and medullary plate, as observed by ASSHETON (1909), this demarcation soon becomes less evident, the superficial layer fusing with the basal one and, after the folding in of the plate, evidently giving rise tothe ependyme of the neural tube, an entirely different process. takes place in the prae-cerebral part of the apical plate. Here the demarcation of the superficial and the basal layer becomes more and more evident, the basal layer detaches. itself more and more from the superficial one which now alone acts as ectoderm, overgrowing the closing cerebral folds (figs. 3 and 4 of the plate). The detached basal layer forms a lump of cells which, according to V. KUPFFER's ( 905 ) pictures of further advariced stages, gives rise to the rudiment of the hypophysis, which moves under the cerebral vesicle and applies itself to the infundibulum. Thus the hypophysis. appears to be of prostomial origin and is derived from the piæ-cerebral region of the apical plate, which also gives. rise to the olfactory grooves. In other groups of Ichthyopsids the same holds true, sometimes the first rudiment is not solid, as in Amphibians, but has the form of an invagination of the ectoderm just in front of the neuropore, as, judging from V. KUPFFER's (1905) figures, seems to be the case e.g. in Acipenser sturio. This is particularly obvious in the wellknown case of Petromyzon, where the olfactory groove takes: its origin from the same invagination. Thus it is evident that in lower Vertebrates the hypophysis is of prostomial origin, just as the olfactory grooves. A possible relation. 
of the hypophysis to the animal pole would no doubt beworth of a closer investigation. HATSCHEK (1909, p. 511), in Petromyzon, comes to the conclusion: "Die Hypophysenecke liegt unmittelbar an dem (oder "bezeichnet den") primitiven vorderen Pol des Craniotenkörpers. Dieser morphologisch ungemein wichtige Fundamentalsatz, betreffend den vorderen Körperpol der Cranioten ist aus dem Verhalten des Petromyzontenembryo ohne weiteres abzuleiten". I do not, however, think it probable that the animal pole itself is the point from which the hypophysis originates, since the latter appears to arise always behind the olfactory grooves, not in front of them as might be expected in this case. It seems evident, however, that it is a prostomial organ.

In Selachians, Teleosteans, Sauropsida and Mammals, however, we see the hypophysis originate from the roof of the mouth involution, in the same way as, in higher Vertebrates, the olfactory organ also acquires relations to the palate. This makes us infer that the praecerebral region of the apical plate, or part of it, has moved into the mouth, investing the palate. One would be inclined to connect this curious phenomenon with the circumstance that the mouth itself in higher Vertebrates has moved forward and has acquired a more terminal position, but this is already the case in Amphibians, while in the Elasmobranchs, with their ventral mouth, the hypophysis originates from the mouth involution. It is also possible, that we have to do here only with the displacement of a differentiation and not with that of the cells themselves which produce the rudiment of the pituitary body. However this may be, the relations of the palate with such prostomial organs as the hypophysis and the olfactory grooves may be adduced as a valuable argument in favour of the view that the secondary mouth of Craniates has broken through, not between the first and the second segment, but at the limit of the prostomium and the first segment, and that accordingly the latter is represented by the mandibular segment. I shall further indicate the hyoid segment as the second, the glossopharyngeus segment as the third (after VAN WYHE the fifth), the segment of the primary vagus as the fourth (VAN WYHE's sixth), etc.

Derivation of mouth from gill-slits. - It can not be said that DOHRN's (1875) hypothesis of the derivation of the mouth of Craniates from two fused gill-slits is supported buite convincingly by ontogeny. DOHRN (1881) himself 
showed in different Teleosteans(Gobius, Hippocampus, Belone), that the oral aperture at first opens at both its lateral extremities, remaining closed in the middle for some time. Afterwards the two openings fuse. The same was found in Batrachus tau by Miss PLATT (1891), and by BOEKE (1904) - in Muraenoids. In other Teleosteans, however, the mouth again originates as a single opening from the beginning, as is the rule in other Craniates. This however does not

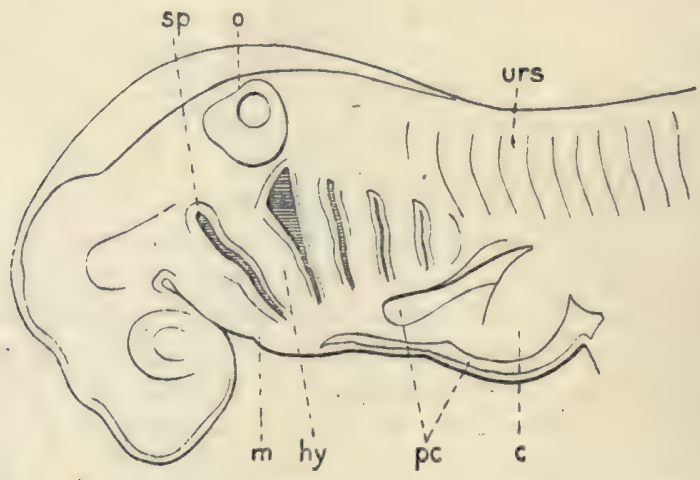

Fig. 18. Head of an embryo of Torpedo ocellata in stage $\mathrm{I}-\mathrm{K}$.

$c$. heart, hy. hyoidarch, $m$. mandibular arch, $o$. anditory vesicle, $p$. pericard, $s p$. spiracle, urs. myotomes,

after ZIEGLER 1908, p. 657.

rpreclude the possibility that phylogenetically the mouth may have arisen from the fusion of two gill-clefts. In young embryos of Elasmobranchs, as shown by fig. 18 (after ZIEGLER, 1908), the spiracle and mouth form the natural iforward continuation of the series of gill-slits. The same holds for Amphibians. Miss PLATT (1896b, p. 560) writes: "The development of the mouth in Necturus seems to me to furnish as striking an argument in favour of its branchial - origin as the paired oral invaginations found in the Teleostei. The hyobranchial clefts are primarily inclined to the transverse plane as above described, the hyomandibular are -still more inclined, and the oral clefts appear to be absolutely fused in a horizontal plane in consequence of the horizontal position in which the mandibular arches first ilie. Such a supposition readily explains the shape of the 
oral fusion outlined in fig. 1" (reproduced here in fig. 19). Miss PLATT points to the circumstance that in Necturus the rudimentary hyomandibular pockets and the hyobranchial clefts also fuse with one another ventrally. The definitive shape of the mouth is established by the elongation of the lateral extension of the oral fusion, while the longitudinal part of the latter becomes obliterated.

The relation of the trigeminus to the mouth closely corresponds to that of the facialis to the spiraculum and that

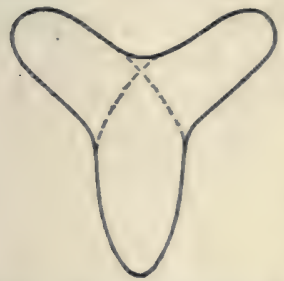

Fig. 19. Formation of

the mouth in Necturus after Miss PlatT, 1895, p. 559. of the glossopharyngeus and the vagus to the following gill-slits. If indeed the mandibular segment is to be considered as the first segment of the soma, the above cited objection of ZIEGLER against the derivation of the mouth from two gill-clefts wholly looses it validity. It is especially the conclusions we shall reach in regard to Amphioxus (cf. anon) which plead for the assumption that the gill-slits are indeed older than the mouth and that the latter is to be derived from them.

The nerve belonging to the first pair of gill-slits, represented by the mouth, would be then the trigeminus, which thus ought to be considered as a single segmental nerve and not as a double one, which would imply the falling out or failing of a pair of prae-oral gill-slits, of which in Craniates there is no indication. The scheme we arrive at in this way is still simpler than that of ZIEGLER and closely approaches that of GEGENBAUR after he had discarded his view that the labial cartilages represent two praeoral visceral archs $(1887$, p. 79$)$. The visceral archs appear now indeed to correspond to the segments incorporated into the head, the mandibular arch representing the first or trigeminus-segment, the hyoid arch the second or facialis-acusticus segment, the first branchial arch the third or glossopharyngeus segment, etc. With HATSCHEK $(1892$, p. 159, 160) we reach the conclusion that the palaeocranium of Ammocoetes, into which the glossopharyngeus and the vagus have not yet been incorporated, comprises only two segments, viz: the trigeminusand the facialis-segment, besides the prostomium, which by HATSCHEK is not distinguished from the first segment, his "acromerite". 
Head of Arthropods:- Just as in Vertebrates, the head of Arthropods is composed of a terminal part, the acron, which is to be compared with the prostomium of Annelids, and -a number of segments fused with it. As with Vertebrates, opinions differ as to the number of segments incorporated into the head and as to the question, which is to be considered as the first segment. HEIDER (1914, p. 504) comes in this respect to conclusions diverging from those of GOODRICH (1897, p. 247) who first set about the question in a general way. Probably others after HEIDER will arrive again at other conclusions in which still less rudimentary - or intercalary segments without corresponding extremities are to be assumed, and in which still more supposed segments will prove to belong to the prostomium. More than one pair of ganglia have fused to form the brain in the prostomium of Annelids (cf. p. 48) and the same is probably the case in Arthropods. These ganglia, however, have not the value of segmental ganglia and do not represent as many segments. Thus the last word concerning the segmentation of the Arthropod as well as of the Vertebrate head has no doubt not yet been said, but it seems to me to be a valuable result of our deductions, and a firm base for further researches, that we have recognized that in the Vertebrate as well as in the Arthropod head a praeoral lobe (prostomium, acron) must be distinguished from a number of segments.

Primitive features of the branchial region. - In several respects the branchial region of the Vertebrate soma seems to exhibit more primitive features than the segments of the trunk, though on closer examination it often appears doubtful whether we have not to do with secondary modifications. In this respect may be mentioned:

1. The dorsal nerve-roots are of mixed character, being both sensory and motor. BALFOUR (1878, p. 193) tried to account for this peculiarity by the assumption: "that primitively the cranio-spinal nerves of Vertebrates were nerves of mixed function with one root only, and that root a dorsal one, and that the present anterior or ventral root is a secondary acquisition". This deduction was based on the view that, in the head, only dorsal but no ventral roots are found, while in Amphioxus also no ventral roots had as yet been discovered. As we shall see further on there is every reason to consider the "occipital nerves" as ventral 
roots belonging to the head region and not, as first suggested by BALFUUR (1878, p. 205) and afterwards worked out especially by FRORIEP and FüRBRINGER, as elements of post-cephalic origin that have only secondarily shifted forwards into the occipital region, losing their dorsal roots. Moreover. ventral roots have since been discovered in Amphioxus also (SCHNEIDER, 1879, p. 15), and here evidently occur also in the anterior segments which in Craniates belong to the head. This renders it probable that in the head of the latter ventral roots have been present once and have only secondarily been lost when the myotomes degenerated. Nevertheless, though BALFOUR's arguments appear not to hold water, his opinion quoted above is in perfect accordance with the conclusions resulting from my theory, as follows from what has been said on the ventral roots in the first chapter. BALFOUR, evidently imagined the ventral roots to have originated by a process of splitting off from the dorsal roots, which, however, seems to me to be improbable.

VAN WYHE (1882) has emphasized that the muscles innervated by the doisal motor branches of the cranial nerves. the constrictores of the gills, though striated and voluntary, must yet be considered as visceral muscles, originating from the lateral plate and situated in the wall of the gut. The nerves supplying them accordingly are to be compared to the nerves of the sympathetic system in the trunk. The latter come from the sympathetic ganglia which ontogenetically are derived from the spinal ganglia. Thus the contrast of the cranial ganglia with the latter would be less abrupt than might appear at first sight. Only the splitting off of a sympathetic ganglion has not occurred. This, however, can also be considered as a primitive feature. In Amphioxus the separation of a visceral portion from the spinal nerves equally fails to find place, the dorsal roots being of mixed character. The mixed character of the dorsal roots of the head then is no doubt to be considered as a primitive feature.

2. There are segmental communications with the lateral organs and, as in Amphioxus, the dorsal roots take their path outside the myotomes. Besides the sympathetic elements the head ganglia thus also contain the lateral line elements which the trunk ganglia have lost, if the conception of the ramus lateralis vagi as a collector is right. 
The spinal nerves lack the lateral and dorsal cutaneous:

- branches, owing to the usurpation of the long trunk-branches of the cranial nerves. A third component present in the head ganglia but absent in those of the trunk is that derived from the epibranchial placodes. The latter circumstancecan not well be considered as primitive, since the gill-slits are formations of which it may be doubted if they ever have been present along the whole length of the body; the same holds for the epibranchial placodes.

3. The dorsal roots are very strong, the ventral roots either fail or are feebly developed. It is rendered probable, however, by the comparison of Gnathostomes with Amphi-. oxus and Cyclostomes that the absence of ventral roots is secondary and caused by the disappearance of the myotomes which have been crushed out of existence by thedevelopment of the skull.

4. There is no union of dorsal and ventral roots, as is: the case in the whole trunk in Amphioxus and Petromyzon. This too, however, is a somewhat doubtful point, since we are not sure if the eye muscle nerves are to be compared directly to ventral spinal nerves, while the so-called occi-. pital nerves have no dorsal roots, as we shall see below.

The third segment the simplest head-segment. - The segment of the glossopharyngeus must be considered, no doubt, as the most characteristic head segment. Here we have a typical gill-slit with a prae- and post-trematic branch of the segmental nerve, no myotome and no ventral root. All the other segments show deviations from this simple scheme. In the vagus region several nerves have fused or have been at least partly "collected" by another nerve in front of them, the primary vagus. In the first or mandibular segment, the fusion of both the gill-slits belonging to it, to form the mouth, and the innervation of the dermal sense-organs of the prostomium by the rami ophthalmici, have caused a very strong development of the trigeminus. The latter circumstance has exerted its influence upon the facialis also, which innervates the prostomial continuation of the lateral line system. In this and in the development of the eye-muscles and their nerves we have all secondary modifications imprinted upon the first (mandibular) and the second (hyoid) segment by the neighbourhood of the prostomium. The second segment moreover is distinguished by the presence of the auditory vesicle. Part of the second segmental nerve: 
has become emancipated from the main stem as the acusticus, which is generally considered as a branch of the facialis. The gill-slit belonging to this segment shows from the beginning differences to the other gill-slits. In Elasmobranchs it is the spiracle, in Cyclostomes, Amphibians and Teleostei it does not open to the exterior; while in terrestrial Vertebrates the auditory vesicle enters into close connection with its rudiment which widens to the tympanic cavity in which, in Mammals, ossified parts detached from the first or mandibular arch, the malleus and incus, transfer the vibratiops from the tympanic membrane to the labyrinth. Backward extension of the skull. - A very difficult problem which has given rise to much controversy is that of the backward extension of the skull, in which especially the appreciation of the spino-occipital nerves (FüRBRINGER) has played an imporlant role in later years.

According to the views of GEGENBAUR and VAN WYHE the number of segments incorporated in the vertebral part of the skull is indicated by that of the visceral arches. The last branchial bar, e.g in Scyllium and Pristiurus on which VAN WYHE worked, corresponds to the last segment of the neurocranium and, since this fifth branchial arch lies behind the last gill-slit, there is only one post-branchial segment incorporated into the skull, while the others are epibranchial. According to VAN WYHE (1882) there are in these forms nine head segments, a number which is reduced to seven, the number of the visceral arches, if we do not recognize the praemandibular cavity as a somite and reject the idea of a double niture of the hyoid-segment, for which, as has been recently emphasized by GOODRICH $(1918$, p. 5), no serious evidence has ever been found. Of these seven segments there are two pro-otic, four post-otic and epibranchial and one post-otic and post-branchial.

Ventral occipitcil nerves. - In Elasmobranchs a number of ventral roots leave the skull in the occipital region, under and behind the vagus. Formerly, according to GEGENBAUR's (1871, p. 530) example, they were generally compared to the hypoglossus of Amniotes, and GEGENBAUR (1871, p. 521, 1872 p. 268) who considered the vagus as a quadrivalent dorsal nerve originally called them the ventral vagus roots. Indeed, as shown first by VAN WYHE (1882, p. 36), their situation in ontogeny corresponds to that of the occipital somites, generally considered as the region of the vagus, and so do 
the roots of the hypoglossus nerve in Amniotes. Several authors have adhered to the view expressed by this double nomenclature (hypoglossus, ventral vagus roots) but abandoned aftel wards by GEGENBAUR (1887, p 65) himself.

FRORIEP's und FüRBRINGER's views, - Others, however, considered these nerves as ventral spinal nerves of which the dorsal roots have been lost, a possibility alluded to already by BALFOUR (1878, p. 205). This idea was worked out for the hypoglossus of Amniotes by FRORIEP (1882, p. 296) who demonstrated the presence of rudimentary dorsal ganglia in the posterior roots of the hypoglossus in embryos. From this, and also from the discovery of well-developed myotomes in the occipital region, he concluded that this region must have belonged $t u$ the trunk, not to the primarily. unsegmented head region (cf. p. 65) to which region FRORIEP also considers to belong the gill-slits and the vagus. According to him in Amniotes an assimilation of vertebrae into the cranium and a progressive backward extension of the latter, as first suggested by STöHR ("der Schädel ist in stetem kaudalen Vorrücken begriffen", 1881, p. 99), has occurred, by which originally post-branchial (i.e. not-cerebral, but) spinal nerves were incorporated into the skull after having lost their dorsal roots and ganglia, of which however vestiges may be noted still in ontogeny especially above the posterior roots.

The same idea has been applied again, some time afterwards, by FüRBRINGER (1897) - and before him alseady by others, as e.g. by GEGENBAUR (1887, p. 65) himself - to GEGENBAUR's ventral vagus roots in Elasmobranchs, in which accordingly the skull has already assimilated a number of vertebræ. The ventral vagus roots are considered as spinal nerves that only secondarily have shifted forward into the occipital region and under the vagus (vago-accessorius), at the same time being incorporated into the cranium. This view is based mainly on the circumstance that these ventral roots, though anastomosing with the vagus, yet on the whole join the ventral spinal roots behisd them, thus contributing to the formation of the cervico-brachial plexus, and further on the fact, that here too more or less vestigial dorsal roots to the posterior branches have been described (VAN WYHE, 1886, p. 681, OSTROUMOFF, 1889, p. 364, DOHRN, 1890, p. 82). The ventral vagus roots or hypoglossus (as formerly they were often dęsignated) of Elasmo- 
branchs (as suggested already by GEGENBAUR, 1887, p. 68, again) according to FüRBRINGER, however, do not correspond to the hypoglossus of Amniotes. The latter is represented by the ventral roots of the anterior free spinal nerves of Elasmobranchs. Thus there has been in Elasmobranchs a primary, and in Amniotes a secondary incorporation of vertebrae and nerves into the skull, accompanied each time by a loss of the dorsal roots of these nerves.

This conclusion is based mainly on FüRBRINGER's conception of the Amphibian skull. Here no ventral roots were found to leave the cranium behind the vagus, the anterior spinal nerves supply the musculature which corresponds to the hypobranchial muscles in Elasmobranchs, supplied by GEGENBAUR's ventral vagus roots, and to the tonguemusculature in Amniotes, innervated by the hypoglossus. Ontogeny gives evidence of only one skeletal element in the occipital region, represented by the "occipital arch" (STöHR, 1879, 1881, GAUPP, 1893, SEWERTZOFF, 1895, PlatT, 1898, GOODRICH, 1911). This is situated, in the same way as the neural archs of the trunk, in the myocomma between two myotomes, a little distance behind the auditory capsule (fig. 21 ), and is compared by SEWERTZOFF (1895, p. 260, 262) to the first free neural arch of Petromyzon and to the anterior one of four similar vertebral rudiments described by HOFFMANN (1894) in the occipital region of Acanthias. (cf fig. 31) The conclusion then seems obvious, and has been drawn by SEWERTZOFF, that the posterior occipital segments of Elasmobranchs and Amniotes and the hypoglossus roots supplying their myotomes have not yet been incorporated into the skull in Amphibians.

This, however, is deemed improbable by FüRBRINGER (1897, p. 485), as the Amphibians would thus have a more primitive position in this respect than Elasmobranchs (cf. also GEGENBAUR, 1887, p. 72). Though recognizing that ontogeny does not reveal any indication, however transitory, to support this view, he yet thinks it inevitable to assume that ventral occipital nerves, corresponding to the occipital nerves of Elasmobranchs, have once been present in Amphibians but have aborted, and that the occipital region here too represents a multiplum of primary occipital vertebrae. Thus FüRBRINGER homologizes the cranium and especially the occipital region of Amphibians to that of Selachians, both representing a protometameric neocranium 
in which a primary incorporation of vertebrae has taken place, "wenn ich auch den bisherigen ontogenetischen Untersuchungen darüber keine beweisende Kraft und namentlich den gewiss recht complicirten phylogenetischen Process zur Genüge aufhellendes Moment zuerkennen kann" (l. c. p. 485).

Then, however, we cannot avoid assuming that the hypoglossus of Amniotes does not correspond to that of Elasmobranchs, the occipital nerves of the latter being supposed to have already atrophied and disappeared in Amphibians. The hypoglossus of Amniotes can only correspond to the anterior free spinal nerves of Amphibians and Selachians and thus the conclusion is inevitable that in Amniotes an assimilation of vertebrae into the cranium. has occurred for the second time ("auximetameric neocranium').

Objections to their views. - The views of FüRBRINGER, based on his admirable investigations, have found a wide acceptance among zoologists. Yet, after having repeatedly studied his work and that of FRORIEP and others. I am not convinced of the accuracy of the conclusions of both these authors; on the contrary, my doubts have increased each time so that now, after a careful study of the results of embryological work on this subject, I feel sure that both are wrong in several respects In the first place I must object to the view of FRORIEP, that the hypoglossus in Amniotes and Selachians has no connection with the vagus and the accessorius, or, casuquo, the vago-accessorius. If, with GEGENBAUR, we consider the vagus and its ganglion as a product of the fusion of four dorsal nerves and their ganglia, then, truly, the discovery of more or less vestigial ganglia to the hindmost roots of the hypoglossus necessarily leads to the conclusion that the hypoglossusroots, after having lost their dorsal components and gar:glia, secondarily have moved forward under the vago accessorius, which in its turn has lost its ventral roots - however strange such a displacement may look at first sight! If, however, with several later investigators, we assume that the vagus has arisen by the fusion of a lesser number of dorsal roots or even was originally a single dorsal nerve (HATSCHEK, 1892 , p. 157) which has "collected" the ventral parts of the dorsal roots (rami post- and praetrematici) of a number of nerves behind it ("partial polymerism" of the vagus), 
then it becomes quite intelligible that vestiges of the spinal ganglia of these nerves should be found over the corresponding ventral roots, as is artually the case.

Another argument for FRORIEP's and FüRBRINGER's view that the hypoglossus-roots have no connection whatever with the vagus is derived, especially by the latter, from the circumstance that they do not unite with the vagus but with the ventral roots of the anterior spinal nerves to form with them the cervico-brachial plexus, a fairly thick nerve stem which supplies, besides the anterior appendages (brachial plexus), the hypobranchial musculature in Elasmobranchs and the tongue-musculature in Amniotes where, however, the hypoglossus is supposed by FüRBRINGER to have emancipated from the brachial plexus.

Branchial muscles. - In the branchial region of Selachians we can distinguish three groups of muscles. In the first place the primordial branchial muscles, known together as the Mm. constrictores, which in VAN WYHE's opinion (1882, p. 11) are to be considered as visceral muscles, taking their origin from the lateral plate. They are supplied by motor branches from the four dorsal cranial nerves which accordingly may be compared to the visceral branches of the dorsal roots of the trunk, connected with the sympathetic nervous system. Secondly we have the hypobranchial musculature (Musculi coraco-arcuales) from which the tongue-musculature of high:er Vertebrates is derived. These muscles are of post-branchial origin, they are produced by ventral outgrowths or "buds" from the anterior trunk- and the posterior head(occipital-) myotomes, similar to the myotomic buds which give rise to the musculature of the paired fins but growing out forward under the gill-slits. They are innervated by the branches of the plexus cervicalis - in Amniotes by the hypoglossus nerve-which, fused with the brachial plexus, runs backwards as a thick nerve stem from the medulla oblongata and curves round behind the last gill-slit to the hypobranchial muscles which it reaches after having separated from the brach:al plexus (cf. fig. 32). In the third place we have the epibranchial musculature (M. subspinalis and Mm. interbasales), a little group of muscles attached to the pharyngobranchialia. They are found only in sharks and Holocephali, best developed in the primitive Notidanidae; in all other Vertebrates, and even in rays, they have disappeared. According to DOHRN (1885, p. 
466) and HOFFMANN (1898, p. 265) this little group of muscles arises from the occipital somites. They are supplied by tiny branches from the cervical plexus, as we may call part of the cervico-brachial plexus which in other groups of Vertebrates is separate from the brachial plexus.

The cervical plexus in Selachians is composed of a varying number of spinal nerves, from four to twelve, the least numbers being found in the sharks, the highest in the Rajidae. This can be determined by carefully splitting the cervico-brachial plexus into its components. Evidently there is a certain relation between the total number of roots of the cervico-brachial plexus and the depth to which secondarily the series of gill-slits has extended backwards into the trunk region, as indicated by the distance of the shoulder-girdle from the head. The number of occipital nerves in different Elasmobranchs may vary trom 1, or even 0 , to 5 , the highest number being met with in the most primitive forms (Notidanidae), the lowest in the more differentiated, such as the rays. They are designated by FüRBRINGER with the final letters of the alphabet: $v, w$, $x, y, z$, of which then the most anterior ones show a tendency to disappear. The spinal nerves following behind them and forming together with them the cervico-brachial plexus are numbered: 1, 2, 3 etc., or, as far as in Teleosteans and Amniotes they are assumed to have been incorporated into the skull (FüRBRINGER's occipito-spinal nerves, the hypoglossus of Amniotes): $a, b, c$, etc.

The circumstance that the occipital nerves, though passing through the cranium, yet in Selachians join the cervicobrachial plexus, which takes a wide curve round behind the last gill-slit to the hypobranchial musculature, indeed seems to plead strongly for the post-branchial origin of the corresponding occipital somites. For if the occipital nerves did $a b$ origine belong to the branchial region, we might expect them to pass between the gill-slits and not behind them to the ventral side. The same holds good for the ventral muscle-buds from the occipital myotomes which grow out equally round behind the last gill-slit to participate at the formation of the hypobranchial or, casu quo, the tongue musculature, as has been shown e. g. by VAN WYHE (1882) for Selachians, by VAN BEMMELEN (1889) for Reptiles and by FRORIEP (1885) for Mammals. 
This result at first sight seems to be irreconciliable with the conclusions of VAN WYHE (1882) and others, that the occipital myotomes belong to the branchial region and alternate regularly with the gill-slits. A closer examination, however, seems to me to show the way to get out of this difficulty and to prove that from the above reflections the conclusion may not yet be drawn that all the myotomes of the occipital region and the corresponding ventral roots are of post-branchial origin and that the latter have only secondarily moved forward from the trunk to beneath the vago-accessorius, to which they originally would have had no relation at all . To this end we shall not restrict our considerations to the Elasmobranchs but first examine other groups of Vertebrates (cf. Plate I)

The origin of the hypobranchial musculature - In Petromyzon, where originally branchiomerism and mesomerism correspond, the hypobranchial musculature, as shown by NEAL (1897, p. 444) and KOLTZOFF (1902, p. 304।, is derived exclusively from the myotomic buds of the anterior post-

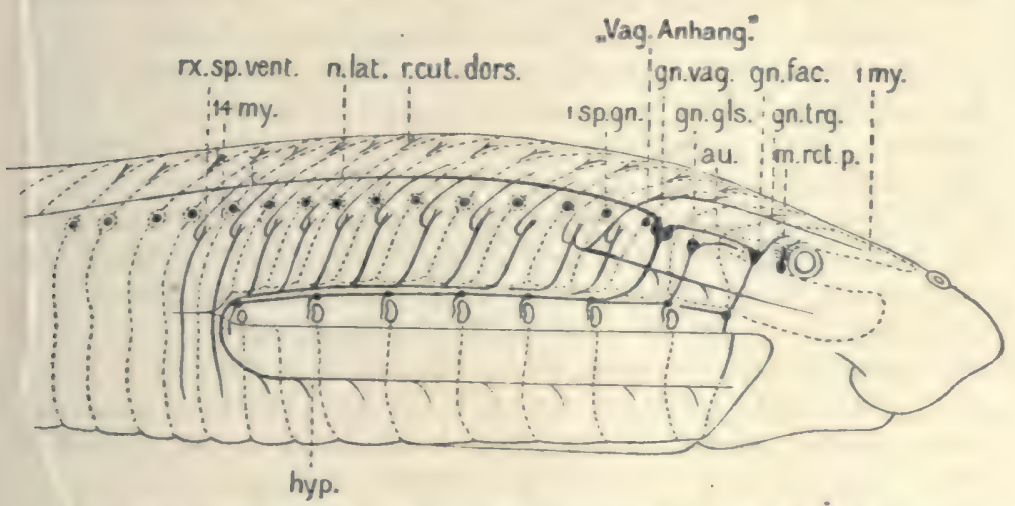

Fig. 20. Head of Ammocoetes, hypoglossus nerve (hyp.) and musculature after NEAL, 1897, p. 446.

branchial myotomes, from the $7^{\text {th }}$ post-otic (the first postbranchial) onwards. According to NEAL probably the $7^{\text {th }}-12^{\text {th }}$, according to KOLTZOFF the $7^{\text {th }}-14^{\text {th }}$, post-otic myotome contribute to its formation. This hypobranchial musculature is innervated according to NEAL by a hypoglossus nerve composed of the ventral roots of the $7^{\text {th }}-12^{\text {th }}$ post-otic myolomes and passing in a curve round behind the last gill-slit to the 
ventral side. Thus the whole hypoglossus is post-cranial and begins far behind the skull. Now a comparison of embryos of different lengths shows that the postotic myotomes-7-12, which are originally post-branchial, come to lie ultimately above the hinder part of the branchial basket, i. e. become epibranchial, by the backward extension of the branchial basket. By the same process, as NEAL was able to observe, the ventral roots of these myotomes, passing originally free behind the last gill-slit, unite one by one as the branchial basket elongates and thus form the hypoglossus. The hypobranchial musculature in Petromyzom shows a secondary (?) segmentation corresponding to the situation of the gill-slits but not to that of the epibranchial muscles to which myotomes of post-branchial origin have been added (Fig. 20).

As will be pointed out later, there is reason to consider the Amphibians next after Petromyzon and before the Selachians. We learn from the observations of Miss PLATT $(1898$, p. 452$)$ that here ventral buds from three myotomes, the last epibranchial ( $3^{\text {rd }}$ post-otic somite) and the first two post-branchial $-4^{\text {th }}$ and $5^{\text {th }}$ post-otic somites, here at the same time the first and second post-cranial, as we shall see afterwards -- produce the hypobranchial musculature. This is innervated by a post-cranial hypoglossus-nerve composed of the ventral roots of the latter two somites.

In Selachians, as may be concluded from the statements of NEAL (1897, p. 450) and HOFFMANN (1898, p. 263), the hypobranchial muscles are also produced exclusively or nearly exclusively by post-branchial myotomes. Buds from five myotomes representing in Acanthias, according to NEAL, the $4^{\text {th }}-8^{\text {th }}$ post-otic somite, form the hypobranchial musculature. Since the fifth post-otic somite, according to the conception of VAN WYHE and his followers, is here the first posf-branchial one, there is again only one epibranchial myotome that contributes to the formation of the hypobranchial musculature, while the others are post-branchial. According to HOFFMANN's $(1898$, p. 261, 263) statements it is even exclusively from the post-branchial myotomes that in Acanthias the hypoglossus musculature is produced, that of the $4^{\text {th }}$ post-otic somite not contributing to its formation. This musculature according to NEAL is innervated again by ventral roots belonging to the same myotomes from which it has originated, viz. those corresponding to 
the $4^{\text {th }}\left(5^{\text {th }}\right)-8^{\text {th }}$ post-otic somites. As we shall see below, they are partly irtra- and partly post-cranial.

Finaily, in Amriotes the relation of the occipital myotomes to the gill-slits has not been determined with equal exactness as in Anamnia by those who adhere to the view that both correspond. But, taking as an example VAN BEMMELEN's (1889, p. 254) instructive figure for Lacerta, we see that here too five myotomes contribute to the formation of the hypoglossus musculature, beginning with the first more or less rudimentary myotome to be observed in the occipital region. The most probable conception seems to me to be that this belongs to the third post-otic somite (the second being that of the primary vagus). If this be right, this somite is at the same time the last epibranchial one, since the number of gill-pouches, being five, corresponds to that of Amphibians. The hindmost of the five myotomes mentioned above is post-cranial and corresponds to the atlas. According to CoRNING $\left(1895\right.$, p. 165 , it is only from the $2^{\text {nd }}-5^{\text {th }}$ of these myotomes that the hypoglossus-musculature in Lacerta is derived, the first becoming rudimentary. In this case no epibranchial myotome would participate in its formation.

Thus on the whole we may say that the hypoglossus musculature originates from post-branchial myotomes and that, if epibranchial myotomes contribute to its formation, their number is yet not greater than one. NEAL (1897, p. 461) suggests that a temporary forward crowding of the visceral clefts which causes the last epibranchial somite to lie above and not in front of the last gill-cleft. as observed by h mself in Acanthias and by Miss PLATT (1898, p. 458) in Necturus, may permit the ventral growth of this myotome which would otherwise be prevented. Among the above investigations, however. the only statement relating to the participation of the last epibranchial myotome that has not been opposed is that of Miss PLATT for NECTURUS, and here the fact that the innervation is performed only by the first two free spinal nerves seems not whilly to exclude doubt.

The number of the myotomes producing the hypoglossus musculature may vary and we get the impression that on the whole it is greater in forms where also the number of gill-slits under which this musculature will come to lie is greater (Petromyzon), less in forms with less gill-slits (Amphibians, Amnintes). However, this is not a rule without exceptions, since e. g. in rays, to judge from the number 
of roots of the cervical plexus, the number of myotomes contributing to the formation of the hypobranchial musculature must be very considerable, whereas there are : ot more gill-slits than in sharks.

Agreement with the fin muscles. - The myotomes fo!lowing next produce in the same way muscle-buds which grow out into the rudiment of the fore-limbs and produce the musculature of the latter. Both sometimes form together a continuous series of myotomic buds, representing FRORIEP's (1885, p. 26) shoulder-tongue-string (Schulterzungenstrang), projecting externally as the shoulder-tongue-ridge, and in Selachians innervated by a single nerve-stem, the cervicobrachial plexus. This is composed of the ventral nerve-roots of the corresponding myotomes and only distally divides into two branches, a cervical one to the hypobranchial musculature and a brachial one to the pectoral fin. In other Vertebrates the cervical branch is independent of the brachial plexus and represents the hyposlossus which may be intra-cranial (Amniotes) or post-cranial (Petromyzon, Amphibians).

If with BALFOUR (1878, p. 102) we assume that the paired appendages are to be derived from a pair of longitudinal folds extending over the whole trunk, there is reason to suppose that formely a continuous series of ventral myotomic buds was present all over the trunk, as observed in some Selachians (Rajidae). Perhaps this might be compared with the growing out of myotomes inte the metapleural folds in Amphioxus, which however extend also to above the gill-slits and are found even especially marked there. Then only secondarily the formation of myotomic buds would have ceased to occur in the region between the fore- and hindlimbs and in the branchial region, while between the latter and the forelimbs the buds could have given rise to the hypobranchial musculature.

However, in Petromyzon we find the hypcbranchial musculature well-developed, but no paired limbs. If the latter have not been secondarily lost, this circumstance does not support the above considerations.

On the whole we get the impression from the statements, gathered above on different groups of Vertebrates, that the rule which also holds good for the appendages, viz. that the muscles are innervated by the ventral roots belonging to the myotomes from which they are derived, may equally 
be applied to the hypobranchial muscles, though from the observations at hand we cannot yet conclude that there is a complete correspondance. Thus we reach the conclusion that in Selachians the number of occipital nerves must be approximately indicative of the number of post-branchial segments incorporated into the skull; approximately, since we have seen that the last epi-branchial myotome also may perhaps contribute to the hypobranchial musculature. Moreover we may take into account only those occipital nerves that join the cervical plexus and thus pass behind the gill-slits to the hypobranchial muscles, for this is not the case with all.

Not all occipit.ll nerves hypoglossus roots.- In some Elasmobranchs, especially in those formas where the number of occipital nerves is relatively great (Hexanchus, Heptanchus), the anterior one or two occipital nerves do not participate at the formation of the plexus but remain independent and directly run to the epibranchial muscles that are supplied by them (cf. fig. 32). This seems to me a circumstance of special interest. FüRBRINGER (1. c. p. 394) considers it as a secondary emancipation from the plexus. Since, however, it is just in primitive forms, as Hexanchus and Heptanchus where the nerves designated as $v$ and $w$ are independent, that this phenomenon is met with, it appears much more probable that we have to do here with a primitive feature and that these nerves $v$ and $w$ are to be compared with the ventral roots of the anterior, primarily epibranchial, myotomes of Petromyzon, being in the latter the anterior six post-otic ones. These nerves also supply exclusively epibranchial musculature.

The maximum number of occipital nerves joining the cervico-brachial plexus in Selachians is only three, being $x . y, z$, according to FüRBRINGER. Treir branches partly leave the plexus again to suppiy epibranchial musculature, and they partly innervate the hypobranchial muscles. By carefully splitting the plexus into its components FüRBRINGER could demonstrate that it is even subject to serious doubt whether the nerve $x$ ever partakes in the innervation of the hypobranchial musculature. In a table given by him (I.c.p.404) of the oxcipital and spinal nerves contribuing to the innervation of the hypobranchial muscles in different Selachians we find $x$, with a query, mentioned only for Hexanchus and Heptanchus, while at another place in this table only $y$ and $z$ 
are mentioned for these same forms. In all other species only 2,1 or 0 occipital roots of the hypoglossus are present. Thus the number of occipital hypoglossus roots in Selachians, as far as stated with certairty, never exceeds 2 .

We have seen already that according to the researches of VAN WYHE and others the skull in Scyllium and Pristiurus compiises one post-branchial segment. In Acanthias, according to HOFFMANN (1894, p. 638) and SEWERTZOFF (1899, p. 302), there is one segment more incorporated into the nead, the number of post-branchial somites accordingly being two, corresponding to the $5^{\text {th }}$ and $6^{\text {th }}$ post-otic somite (cf. Plate I). Now according to NEAL, as we have seen, the hypobranchial musculature in Acanthias originates from the $4^{\text {th }}-8^{\text {th }}$ post-otic somite, of which consequently the three anterior belong to the skull, while in HOFFMANN's opinion the $4^{\text {th }}$ post-otic somite does not participate. Thus according to NEAL we might expect three, according to HOFFMANN two, occipital hypoglossus-rocts. In Acanthias there are only two (FüRBRINGER, 1.c.p. 362) in the adult form, which is in fair accordance with our conclusions. In Scyllium where, as we have sean, there is only one postbranchial occipital segment FüRBRINGER found two occipital nerves joining the brachio-cervical plexus, and in young stages three, of which, however, the anterior one only supplies epibranchial muscles. Evidently we must assume either that in Scyllium the last epibranchial somite contributes to the formation of the hypobranchial musculature, to account for the presence of two occipilal hypoglossus-roots, or that FüRBRINGER's statement needs confirmation. VAN WYHE's (1882, p 16) observations do not give evidence on this point.

Variation in length of the Selachian skull. - If our conclusions until now are right, we may, as stated above, derive the approximate number of post-branchial segments incorporated into the skull in Selachians from the number of occipital hypoglnssus-roots, which may vary from 0 to 2 . The less this number is, the greater is as a rule the number of postcranial, spinal, hypoglossus-roots (rays!). Now in heptanch and hexanch Selachians the number of occipital hypoglossusroots is never less than 2 , and since the number of gillslits is 1 or 2 more than in pentanch sharks we can only conclude that the skull contains more segments than in the latter. This conclusion is supported by another circumstance. The strong development of the vagus evidently exerts a 
certain influence on the next following spinal nerves, which causes the ganglia of the latter to atrophy. In such groups where the occipital region of the skull is composed of a restricted number of segments, as we shall show below to be probable for Amphibians, this sphere of influence may extend beyond the cranio-vertebral limit and cause the anterior spinal nerves to lose their gar glia and dorsal roots, as is the case in Amphibians. In pentanch Selachians the intluence of the vagus reaches also a little beyond the cranio-vertebral limit, but in Acanthias. where the skull contains one segment more than in Scylitum etc., we find in the last segment a well developed spinal ganglion (cf fig. 31) which, however, does not produce a regular dorsal root. In hexanch and heptanch Selachians, however, a spinal ganglion and a dorsal nerve-root is found over the last occipital nerve, fusing with this ventral root in the same way as is the case with the spinal nerves of the trunk. This indicates that these forms probably have one or two segments more incorporated into the skull than Acanthias, the influence of the vagus no longer reaching as far as the cranio-vertebral limit.

From these considerations, however, it follows that FüRBRINGER is wrong in designating the occipital nerves of Hexanchus and Heptanchus as $v, w, x, y, z$, since, e. g., $z$ is not the same nerve as $z$ in pentanch forms like Scyllium. FürRBRINGER himself (1. c. p 362) designates the last occipital myotome in Acanthius as a. Following this nomenclature I think it probable that the last head segment in Hexanchus and Heptanchus must be called $b$, or perhaps even $c$. The nomenclature of the occipital nerves in these forms must be changed accordingly. Already GEGENBAUR (1872, p. 30) had pointed out that the skull in these sharks passes more or less gradually into the vertebral column and that during life an emancipation of vertebral elements from the skull may occur. Thus the backward extension of the skull is not constant in different Selachians and the shortest skull seems by no means invariably to be found with the most primitive forms.

It was only after I had written down the above conclusion resulting from our conception of the hypoglossus-roots that I found to my great satisfaction that VAN WYHE (1905, p. 320), in a preliminary note on an investigation which until now has not been published in full, had reached 
exactly the same conclusion regarding the length of the head of Heptanchus on embryological grounds. After having treated of the development of the skull of Acanthias he writes concerning that of Heptanchus: "Es sind aber deutliche Zeichen vorhanden, welche darauf hinweisen, dass die Flemente zweier Wirbel mit dem Schädel verschmolzen sind, so dass die beiden letzten Occipitalnerven dieses Tieres, welche FüRBRINGER mit $y$ und $z$ bezeichnet, eigentlich Spinalnerven (Occipitospinalnerven) sind. Erst der Nerv $x$ muss mit dem oben mit $z$ bezeichneten Nerven, der bei Acanthias den primitiven Occipitalbogen durchbohrt, homologisiert werden."1) A better confirmation of our conclusions concerning the nature of the hypoglossus and its relation to the gill-slits could not be given.

Primarily and secondarily epibranchial somites and nerves. - FüRBRINGER, though at another place (1. c. p. 682, 685-686) recognizing the general homology of cranial and spinal ganglia and rejecting emphatically the idea of an incongruency between branchiomerism and mesomerism, yet accepts FRORIEP's distinction of a cerebral and a spinal region in the head and the idea that all the myotomes belong to the latter, that is to the trunk. Thus he considers the epibranchial muscles, which are to be derived from the occipital myotomes, as muscles of "spinal", that is primarily post-branchial, origin just as the hypobranchial muscles but in opposition to the primordial branchial muscles; the constrictores, which he calls "cerebral" muscles and which accordingly are considered as belonging to FRORIEP's primarily unsegmented head-region. In the same way the occipital nerves must then be considered as spinal nerves.

In this we can not altogether agree with him. Just as in Petromyzon where it has been proved by the study of ontogeny, part of the epibranchial musculature of the adult is no doubt of post-branchial origin and has become epibranchial only by the secondary extension of the branchial basket. VAN WYHE (1889, p. 558) demonstrated the latter phenomenon in Selachians by determining the segment in which in successive stages the biliary duct was found; the latter was shown to recede into segments situated progressively further backwards. In Pristiurus, embryonic

1) The last occipital nerve of Acanthias, however, has already been designated by FüRBRINGER as $a$, in forms like Scyllium only it is $z$. 
stage I, it was found in the fourth and in an embryo in stage $O$ in the severteenth trunksegmenl. This shows that the growth of the anterior region of the gut surpasses that of the rest of the body, a process which causes the hindmost gill-slits to be four:d finally under myotomes which were originally situated behind them. B ut this does not mean to say that all the myotomes found above the gill-slits have only secondarily a cquired this position. That myotomes behind the auditory capsule have been, so to speak, crushed out of existence by the strong development of this capsule can not be doubted. FüRBRINGER (1897, p. 440), however, assumes a "stetiges Vorrücken" and dissolution of somites in the occipital region, for which embryology has not yi lded serious evidence. On the contrary, no embryologist, with the exception of BRAUS (1899), has assumed such a process, and GOODRICH $(1918$, p. 13), the last to have worked on the subject, asks: what definite evidence is there that such a procession of myotomes which plunge one after the other below the capsule and vanish in a cloud of mesenctyme really occurs? I think with GOODRICH that there is good reason to believe that for the must part myotomes once laid down persist.

We have seen that in Petromyzon, as a consequence of the backward extension of the branchial basket, the postotic myotomes $7-12$ become secondarily epibranchial; in the same way this occurs with a cunsiderable number of myotomes in Selachians but of these only the anterior one or two, as we have seen, belong to the skull. The other occipital myotomes, in front of these, and their nerves belong from the beginning to th: branchial region, just like the anterior epibranchial mvotomes in Petromyzon. In Selachians, however, this epibranchial musculature is much less developed than in the latter, though in the more primitive froms with the greatest number of gill slits it is more developed. In other groups of Vertebrates, and even in rays, it is no longer found.

FüRBRINGER s rule applied to the hypoglossus. - Petromyzon shows us that the opinion that the hypoglossus $a b$ origine has nothing to do with the vagus (vago-accessorius) is not incorrect. If we compare the situation of the hypoglossusroots in the main groups of Vertebrates (cf. Plate 1), we see that there can be no question about an individual homology of the segments to which they belong in the 
different groups; just as much can this be the case with the segments to which the branchial and the lumbal plexus bclung. In the year 1879 FüRBRINGER (p. 389), as a result of his researches on the plexus brachialis and lumbosacralis, came to the conclusion that these plexus are not bound to definite myotomes, but that their situation and extent depend on the situation and development of the limbs they innervate. If the limb be strongly developed the number of segments participating in supplying this with muscles and nerves may increase and, in the opposite case, it may decrease, though no intercalation of new segments, or falling out of segments formerly present, can be assumed to account for this. In the same way the shifting forwards or backuards of the limbs is not the result of a moving of corresponding segments but adjoining segments take over the task of the old ones which now come free. GOODRICH (1914) has recently contributed a very interesting articlt on this subject and has shown plainly that there is no primary relation between homology and metamerism. We can speak only of a regional homology, the homology of a region or segmental level which may move caudad and rostrad and may extend over a greater or lesser number of segments.

The anterior limit of the hypoglossus-level is determined by the situation of the last gill-slit, i. e. by the number of gill-slits or the extent of the branchial level. From this and from the backward extent of the skull depends whether the hypoglossus will lie far behind the cranio-vertebral limit (Petromyzon,) whether its anterior limit will nearly coincide with it (Amphbians and several Elasmobranchs), or whether the hypoglossus will be for a lesser or greater part intracranial (other Selachians, Amniotes). It also depends on the situation of the last gill-slit whether the hypoglussus-region will be found far behind the vagus and beyond its sphere of influence which causes the dorsal roots and spinal ganglia behind it to atrophy (Petromyzon) or whether it will reach with its anterior end into the sphere of influence of the vagus (Selachians, Amniotes).

If then at least part of the occipital myotomes and their nerves are to be considered as belonging primarily to the branchial region and, as argued before, FRORIEP's distinction between a cerebral unsegmented and a spinal region of the cranium must be rejected, then our conception of the occipital region becomes 
much simplified. The antagonism between head and trunk, the invasion of the trunk-myotomes into the occipital region, the "stetiges Vorrücken" of the former (FüRBRINGER, 1897, p. 440), the struggle between the neural crest of the head and that of the trunk, the hand to hand contest between the dorsal and ventral roots of the two enemy regions, all painted to us by FRORIEP (1901, p. 372) as the "heiszen Kampf der Theile", fade away like a fata morgana: peace and rest appear to reign in the occipital region.

Hypoglossus of Amniotes. - The question has been partly answered already as to whether in the case of the hypoglossus in Amniotes, the "occipito-spinal" narves of FüRBRINGER, there is more reason to assume all these complicated displacements than in that of the occipital roots in Elasmobranchs, to which the hypoglossus shows such an undeniable resemblance. Is the distinction between a protometameric and an auximetameric neocranium a firmly founded one? These terms, introduced by FüRBRINGER, are found in every text-book, every student knows them (and if he does not, he will have a bad chance in his examination) and their general acceptance seems to allow hardly any doubt as to the correctness of this distinction. According to it, three of the anterior spinal nerves of Elasmobranchs and Amphibians, 1,2, and 3 - at least their ventral roots, the dorsal ones having again atrophied - have been incorporated in Amniotes as $a, b$ and $c$ (occipito-spinal nerves) into the cranium to which accordingly once more a corresponding number of vertebrae has been assimilated. These three ventral roots form the hypoglossus which, together with the anterior spinal nerves, innervates the tongue-musculature which is to be derived from the hypobranchial muscles of Elasmobranchs. At exactly the same place where in the latter the "ventral vagus roots" are found, that is right under the vagus and its derivative the accessorius, which, as shown e. g. by VAN BEMMELEN (1889), arises in close connection to the rudimentary dorsal ganglia behind the vagus, we find in Amniotes the hypoglossus-roots. Once more, according to FüRBRINGER, we must assume such an improbable moving of ventral roots (and corresponding myotomes) in forward direction over a distance of several segments till they have arrived right under the dorsal roots of segments far in front of them, a displacement for which not a single reason can be given. On the contrary, 
we might rather expect that the backward extension of the branchial basket into the trunk region, which pushes the anterior nerves aside and thus favours the formation of the cervico-brachial plexus in Elasmobranchs, would pull the roots of these nerves somewhat in a backward direction. Would not then rather the old conception, defended by HIS (1887, p. 401, 414, 423) against FRORIEP, be the right one : that the three hypoglossus-roots of Amniotes, being indeed nothing else than the ventral occipital nerves of Elasmobranchs, may be termed, like the latter, ventral vagus roots, not $a$, $b, c$ but something like $x, y, z$, which already in Elasmobranchs contribute to the innervation of the hypobranchial musculature and to which they show such an undeniable resemblance in their situation, their peripheral distribution and in the reduction of their dorsal roots in rostro-caudal direction? "Die Trennung des Hypoglossusgebietes vom Accessorius- und Vagusgebiet", says HIS (1887), "halte ich für eine durchaus künstliche und ich berufe mich in der Hinsicht auf die Beobachtung, wonach der Hypoglossuskern auf eine lange Strecke den motorischen Kernen von Accessorius, Vagus und selbst Glossopharyngeus parallel laufen". (p. 401). "Ein einziger Blick auf die Disposition der Ursprungsherde genügt, um erkennen zu lassen, wie willkürlich es ist, das Hypoglossusgebiet vom Vagusgebiete trennen zu wollen und jenes dem Rumpfe, dieses dem Kopfe zuzutheilen" (p. 414).

FRORIEP (1905, p. 120) himself does not join FüRBRINGER in his deductions concerning the hypoglossus but feels inclined to homologize the occipital somites of Amniotes to those of Selachians with which they agree in so many points. In this connection he still mentions the fact that the anterior end of the pronephros in Amniotes as well as in Selachians is found as a rule in the third somite behind the cranio-vertebral limit. Truly, too great weight should not be attached to this circumstance, since the situation of the first pronephric funnel is no more bound to a definite segment than that of the plexus of the limbs.

Amphibian and Selachian skull. - As we have seen, the whole distinction of a proto-and an auximetameric neocranium and of occipital and occipito-spinal nerves, as far as concerns Amniotes, is based on FüRBRINGER's assumption that the skull of the Amphibians is equal in length to that of Elasmobranchs and that it is a protometameric neocra- 
nium in which the occipital region represents a multiplum of vertebrae, not one vertebra as is rendered probable by ontogeny, by the absence of occipital nerves and by the fact that the anterior spinal nerves innervate the hypobranchial musculature. FüRBRINGER himself, as we have seen (cf. p. 100), recognizes that no facts can be adduced in favour of this supposition. He only mentions (1.c. p. 486) that once, in a young Megalobatrachus, he believes he has found an extremely fine nerve-thread in the occipital region. He considers it as a last remnant of more such nerves and calls it $z$ but does not feel quite sure of his observation which, however, has been afterwards confirmed for embryonal stages of different Amphibia. OSAWA (1902) found it in

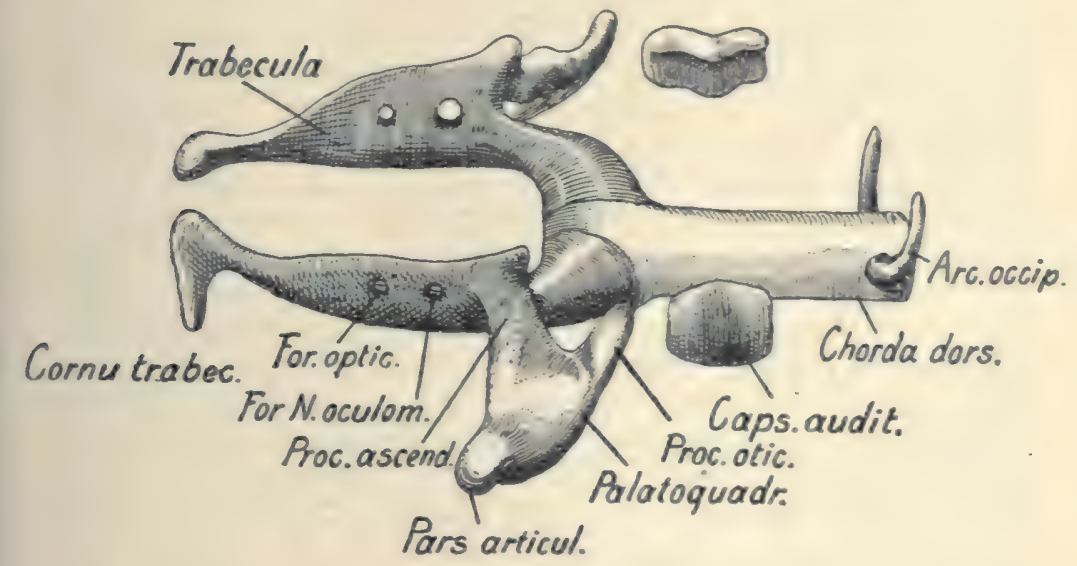

Fig. 21. Rudiment of the skull of Siredon pisciformis. Arc. occ. occipital arch, Caps. audit. auditory capsule, after STöHR, 1879.

Megalobatrachus, DRüNER $(1901,1904)$ in larvae of Triton and Salamandra, PETER (1898, p. 42) and MARCUS (1910, p. 376) in Gymnophiones and GOODRICH (1911) in Siredon. At the end of this chapter we shall revert to this nerve and show that it evidently represents the ventral root of the spinal nerve of which the ganglion has fused with that of the primary vagus (the "spinalartiger Vagusanhang" of HATSCHEK, 1892) and corresponds to FüRBRINGER's occipital nerve $x$ in Selachians like Scyllium. 
Ontogeny teaches us that the occipital arch behaves at first exactly like a vertebral arch, originating in the myocomma between two of the post-otic myotomes and differing only from the neural archs following behind it in that it afterwards fuses with the auditory capsule, leaving the foramen vagi between the latter and itself. Much better founded, therefore, seems to me to be the view of STöHR $(1879,1881)$ and SEWERTZOFF $(1895$, p. 252) that the occipital arch in Amphibians actually represents the neural arch of only one vertebra which according to SEWERTZOFF corresponds to the first free neural arch of Petromyzon. Truly, we must then assume with SEWERTZOFF (1897, p. 410): "Bei Amphibien, wie ich hierbei hervorheben möchte, entspricht der ganze Occipitalabschnitt einem einzigen S e $g$ m e $n t$ e $n$, dem einfachen Occipitalbogen, so dass die Amphibien in dieser Hinsicht unter allen Cranioten, mit Ausnahme der Petromyzonten, die einfachsten Zustände zeigen." While the skull of Petromyzon, as stated above, comprises, besides the prostomium, only two segments, the trigeminus- and the facialis-segment, this number evidently amounts to five in Amphibians, the meta-otic glossopharyngeus-segment and those of the primary vayus and of the "spinalartiger Vagusanhang" having been added to the cranium. This conception of the Amphibian cranium is strongly supported by the recent researches of Miss PlaTT (1897) on Necturus and of GOODRICH (1911) on Siredon. In Elasmobranchs and Amniotes some two or three, sometimes even a few more, segments have been incorporated into the occipital region. We shall revert to this at the end of the chapter.

The halo of primitiveness which since GEGENBAUR, BALFOUR and VAN WYHE surrounds the head of the Elasmobranch thus looses part of its glory. If, however, we call to mind that in no other group of Vertebrates do the structure of the egg and the early stages of development show so close an agreement with those of Cyclostomes as is the case in Amphibians, that especially in Urodelans the similarity is truly striking and that on the other hand the Elasmobranchs in these respects show a deviation from this simple type which nearly equals that found in Sauropsids, we shall have less difficulty in accepting the view expressed by SEWERTZOFF $(1897$, p. 410) in two articles $(1895,1897)$ of which the influence has been greatly ob- 
scured by FüRBRINGER's voluminous work of the latter year: "Nimmt man an, dass es eine Stammform gegeben hat, die in Bezug auf den Occipitalteil des Schädels sich wie die Amphibien verhielt, so würde sich weiterhin die Entwickelung in zwei getrennten Bahnen bei Fischen und Landwirbeltieren bewegt haben". Few, I think, will follow RABL (1888, p. 656) in supposing that first in the Elasmobranch egg an accumulation of yolk has occurred which, however, in the Amphibian egg has been lost again for some unknown reason, has been reacquired in Sauropsids and lost for the second time in viviparous Mammals. Especially if we compare the early stages of development of Petromyzon, Elasmobranchs and Amphibia, it will be evident at once that in this respect also the Elasmobranchs represent a sidebranch, however primitive they may be in other characters. In the structure of the brain also the Amphibia stand the nearer to Petromyzon, a metencephalon having developed in neither of them, unlike Selachians and Amniotes. In the former two the hypophysis originates from the ectoderm in front of the mouth, in the latter two from the roof of the mouth-involution. Concerning the development of the cranial muscles also, EDGEWORTH (1911) finds that the Amphibians exhibit more primitive features than the Selachians.

We could no doubt keep to the names proto- and auximetameric neocranium to express the difference in length of the Amphibian skull on the one hand and the skull of Amniotes on the other. However, we should then be using these terms in a quite different sense from that attributed to them by FüRRRINGER, for in the protometameric neocranium have now been incorporated only the glossopharyngeus and the vagus and in the auximetameric neocranium only the nerves $y, z$, while the nerves $a, b, c$, the occipito-spinal nerves, at least in Amniotes, do not exist as such. Only if with FüRBRINGER (1897, p. 362) we designate the last occipital nerve in Acanthias as $a$, have we probably to do so in Amniotes also, as will be shown at the end of this chapter. According to FüRBRINGER a protometameric neocranium is found e. g. in Scyllium. If, however, we use his terms in the sense mentioned above, Scyllium has an auximetameric cranium. A somewhat different terminology will be proposed at the end of this chapter.

Before combining the results of the above considerations into a general survey of the history of the head of 
Vertebrates we must first consider yet another question, viz. that of the relation of the head of Craniates to that of Amphioxus.

Head of Amphioxus - Attempts to derive the general structure of de Craniate head from what is found in Amphioxus have not been wanting. GEGENBAUR (1872, p. 300, 1887, p. 98) was the first to point to Amphioxus as the form in which we see the metameric structure of the trunk directly and uniformly continued into the head. He considers the whole branchial region of Amphioxus as the region corresponding to the head of Craniates, the extension of which, according to GEGENBAUR, has been determined by that of the gill-slits. The latter conclusion is objected to by VAN WYHE (1889, p. 558) who points to the fact that in Amphioxus as well as in Elasmobranchs the growth of the branchial basket surpasses that of the rest of the body, which causes it to extend with increasing age far into the trunk-region. Thus we see e. g. in Elasmobranchs as well as in Amphioxus the biliary duct in older embryos recede into progressively further backwards situated trunk segments, as can be determined by counting. (cf. p. 111) Taking into consideration this secondary process, VAN WYHE tries to determine the original extension of the branchial basket and thus arrives at a number of not much more than nine segments, the same number as assumed by him to be contained in the Elasmobranch skull. By the inequality of growth of the branchial basket and the rest of the body, the series of gill-slits afterwards extends progressively further into the trunk-region, as far as the $27^{\text {th }}$ myotom and perhaps still further in the adult animal.

In the anterior region of the body the branchiomerism originally corresponds to the mesomerism, as shown by HATSCHEK (1892, p. 145) and the figures of WILLEY (1891). During further growth, however, a "hypermetamerism" of the gill-slits is established, the number of the latter surpassing by far that of the myotomes and increasing still by splitting, until in the adult form it amounts to more than 100. It is by no means easy to determine how far the eumetamerism reaches and this is rendered still more difficult by the asymmetry prevailing in early stages in this region. Originally there are formed 14 gill-slits of the left and 6 of the right side, all situated at the beginning on the right side. Afterwards several of the former atrophy, leaving only 8 (nrs. 2-9), while those of the right side increase to the same number (sometimes 7 or 9 ). At this 
moment the "critical stage" (WILLEY, 1891, p. 202) is reached, the larva sinks to the bottom and gives up pelagic life. Thus WILLEY (1894, p. 174) concludes that the common ancestor of Acrania and Craniates has had some 9-14 gill-slits, a somewhat higher number than found by VAN WYHE for the number of segments representing the cranial region in Amphioxus.

First pair of Somites. - Opinions differ very much as to which segments and which gill-slits are to be regarded as the first pair. In a stage like that represented in fig. 5 (p. 25) it seems fairly evident which pair of mesodermic segments is the first. Afterwards, however, these two anterior somites each send out a prolongation into the snout, the "rostral prolongations" which also form muscles and supply the mesoderm to the dorsal part of the snout, which is situated over the notochord. At the same time the entoderm just in front of the first pair of mesodermic segments produces two diverticula (Fig. 7 and 23, br. 1) which have

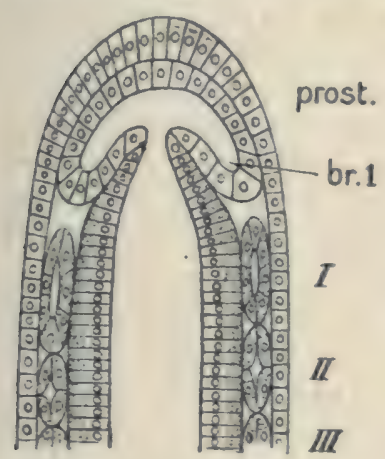

Fig. 23. Anterior end of a young stage of Amphioxus, seen from the ventral side and showing the formation of the first pair of gillpouches ("anterior entoderm pockets", br. I), after HATSCHEK, 1882, fig. 53. an entirely different fate. Both become detached from the entoderm. The right one enlarges forwards and downwards so as to give rise to the head cavity of the larva. The left one remains much smaller, it aequires an opening to the exterior and is known henceforth as the groove of HATSCHEK or praeoral pit ${ }^{1}$ ) which after the formation of the mouth involution opens into the latter.

Now HATSCHEK (1892, p. 144) considered both these "anterior intestinal diverticula" as representing the first pair of gill-slits and the two "rostral prolongations" as the first pair of somites, lying in front of them (I. c. p. 136-137).

$\left.{ }^{1}\right)$ The rightness of this statement, made originally by himself (1881, p. 73) and confirmed by MACBRIDE (1900, p. 363), has been doubted by HATSCHEK $(1906$, p. 5) in a later article, evidently under the influence of theoretical considerations. 
The second pair of gill-slits would have atrophied, they are to be found again in the left and the right pseudobranchial groove or "vorderer Wimperbogen" and correspond to the spiracle of fishes. The first permanent pair of gill-slits accordingly represents in reality the third pair. Recently HATSCHEK (1909, p. 508) seems to have changed his opinion and offers a prospect of a different interpretation and a homologization of both the "anterior entoderm pockets" and the "rostral prolongations" to the praemandibular and mandibular segments, "und zwar in einer Weise, die zu der herrschenden Anschauung im Gegensatze steht". Evidently he $(1906$, p. 6) now wants to consider the head cavities as the ventral part (hyposomite) of his anterior pair of somites of which the head-prolongations represent the dorsal part (episomite).

Similar interpretations have been given already by VAN WYHE (1893, p. 157) and WILLEY (1894, p. 126). WILLEY compares both the "anterior entoderm pockets" (HATSCHEK) or "praeoral head cavities" (WILLEY) with the praemandibular segments of Craniates and the anterior pair of somites of fig. 5 with the mandibular segment of the latter. VAN WYHE agrees with him in the latter assumption but not in the former. In the two anterior entoderm pockets he cannot see antimers, they are in reality median structures and the pocket that only secondarily, in consequence of the rotatory growth of the anterior part of the alimentary tract, has become the left one, and that passes into the praeoral pit, represents the old mouth of Amphioxus, the "autostoma", comparable to the mouth of Craniates. According to VAN WYHE the right one, passing into the praeoral head coelom, may be homologous to both the praemandibular cavities of Craniotes. As to the first pair of gill-slits VAN WYHE came to very remarkable and noteworthy conclusions. HIS (1887, p. 429) had observed already that the mouth in Amphioxus "lässt sich seiner Stellung nach eher einer Kiemenspalte vergleichen. An der entsprechenden Stelle der anderen Seite bildet sich die sogenannte kolbenförmige Drüse." VAN WYHE (1893, p. 153) now found that the musculature and the innervation show that the mouth of Amphioxus is not a median structure but one that wholly belongs to the left side. It is situated behind the mandibular segment, as VAN WYHE calls the first segment of fig. 5, and is therefore compared by him to the first left 
visceral cleft, the spiracle of fishes, and called the "tremostoma". Even a nephridium has been found to belong to it, just as to the other gill-slits, viz. the unpaired HATSCHEK's nephridium (VAN WYHE, 1914, p. 67). The antimer of the mouth is found then in the club-shaped gland which originates as an entodermal pouch at the right side of the body, in front of the series of gill-slits of that side, and afterwards acquires an opening to the exterior. A few years before WILLEY (1891, p. 225) had shown reason for considering the club-shaped gland as a gill slit belonging to the right side. During further development the whole organ disappears. Thus VAN WYHE (1906) concludes: "Amphioxus kann nicht hören; er frisst mit dem linken Ohre und hat infolgedessen den Mund verloren."

Trimerism - MACBRIDE (1898), finally, in agreement with BATESON's (1885) and MASTERMAN's (1897) attempts to explain the structure of the Chordates by a derivation from forms like Balanoglossus and the so-called "Diplochorda" (MASTERMAN), tries to find traces of an original trimeric arrangement of the coelomic cavities. These arise in the larva of Balanoglossus as one anterior unpaired and two posterior paired entoderm pouches or, if this be not strictly the case, yet soon after show a similar arrangement. In the same way, according to MACBRIDE (1.c. p. 606), "the mesoderm originates in Amphioxus as a series of true gut pouches, viz. one anterior unpaired pouch and two pairs of lateral pouches." Of these the first divides to form the two head cavities; the anterior $\mathrm{p}$ a i $\mathrm{r}$ give rise to the first pair of myotomes, and, in addition, to two long canals extending back ventrally (VAN WYHE's pterygocoel, in the metapleural folds, D.) ; the posterior pair is gradually separated from the gut and, pari passu, devided into a double series of myotomes.

Thus the anterior unpaired pouch is represented by the head-cavities, - according to VAN WYHE only by the right one, compared by him to the præmandibular cavities of Craniates - which are homologized by MACBRIDE to the proboscis-cavity of Balanoglossus. The first pair of paired pouches is represented by VAN WYHE's mandibular segments which, according to MACBRIDE, show a certain independence from the following segments in the way in which they are separated from the gut and in their prolonged communication with the latter. They are called by MACBRIDE 
(1.c. p. 599) the "collar-cavities" of Amphioxus and thus homologized to the homonymous cavities of Balanoglossus. The other mesodermic segments, according to him, are all separated from in front backwards from a pair of "coelomic grooves" which after their separation from the entoderm communicate with the gut only at their posterior $\mathrm{er}_{\perp} \mathrm{d}$. They are compared with the trunk coelom of Balanoglossus.

VAN WYHE (1902, p. 176) joins MACBRIDE in his derivation of the metamerism of Amphioxus from an original trimerism as in Balanoglossus and Echinoderm-larvae and tries to extend the comparison also to Craniates. Protocoel, mesocoel and metacoel, proto-, meso- and metasoma according to this conception may be distinguished in Chordates as well as in Balanoglossus and other deuterostomian "Prochordates". The opening of HATSCHEK's pit is compared by BATESON (1885) with the proboscis-pore of Balanoglossus and the water-pore of Echinoderms. GOODRICH (1917) tries to extend this comparison to the so-called premandibular somites of Craniata. He claims that in Selachii these acquire an opening into the hypophysis which he homologizes with the preoral pit of Amphioxus. In this direction then the connection of the Chordates with Evertebrates has been sought in recent times.

From the point of view of my theory, however, these recent attempts to solve the old question cannot lead to any good. In my opinion the metamerism of Vertebrates has been directly inherited from the Annelids and has nothing to do with the trimerism of the so-called "Hemi- and Diplochordates" of BATESON and MASTERMAN. Truly, in the Annelid body also, we can, if we wish, distinguish three regions, the prostomium, the peristomium and the rest of the segmented body. The situation of the mouth agrees with that of Balanoglossus in that it lies in front of the peristomium and the collar respectively. Whether a deeper significance is to be attributed to this agreement (cf. SPENGEL, 1893) is a question as obscure as that of the relation of Proto-and Deuterostomia to one another. Probably, however, they have nothing to do with each other.

Brain vesicle of Amphioxus - Another question raised by the comparison of the anterior end of the body in Acrania and Craniata is that of the relation of the brain vesicle of the former to the brain of the latter. Several attempts have 
been made to derive the brain of Craniates and its main peculiarities from the brain vesicle of Amphioxus. One of the best known is that of V. KUPFFER (1906, II, 3, p. 13) who homologizes especially the archencephalon to the brain vesicle of Amphioxus, while the deuterencephalon is compared with the anterior end of the neural tube. The tuberculum posterius, a thickening of the floor of the Craniate brain over the plica ventralis which indicates the limit of arch-and deuterencephalon, is found again by V. KUPFFER as a group of ciliated cells in the floor of the brain vesicle of Amphioxus. These cells were first described by BOEKE (1902, p. 411) and termed by him the "infundibular organ". In front of it KUPFFER (1. c. fig. 5, p. 7) even thinks he finds an infundibular depression comparable to the infundibulum of Craniates. BOEKE (1908), however, afterwards showed that such a depression does not exist. He sees the homologon of the infundibular organ in the sensory epithelium of the saccus vasculosus of fishes. A comparison of what WIEDERSHEIM says in the successive editions of his Comparative Anatomy about the homology of the brain of Craniates and the brain vesicle of Amphioxus shows clearly how opinions on this subject have altered. In the first edition (1883, p. 275) we read: "Durch die Lage und Ausdehnung der Chorda dorsalis im Schädelgrund kann man a priori einen praechordalen und chordalen Hirnabschnitt unterscheiden. Jener sowie auch die zugehörige Schädelregion ist als ein späterer Erwerb und daher nicht einfach als transformirtes Rückenmark zu betrachten (GEGENBAUR). Daraus ergeben sich wichtige Consequenzen für das Gehirn von Amphioxus, wo ein praevertebraler Kopfabschnitt gar nicht zur Entwickelung kommt", and p. 282-283: "Da die Chorda des Amphioxus sich bis zum vordersten Leibesende erstreckt, so kann auch, wie wir schon oben hervorgehoben haben, der darüber liegende Hirntheil nur dem chordalen Gehirnabschnitt der übrigen Vertebraten . . . entsprechen."

It is especially the comparison of the neuropore in Craniates and Amphioxus, one of the main arguments also of $\mathrm{v}$. KUPFFER, which in the 2nd and 3rd edition induces WIEDERSHEIM to homologize the brain vesicle of the latter to the fore-, perhaps also to the mid-brain of Craniates, while in later editions he leaves the question undecided, saying: "Welchen Abschnitten des Gehirnes der Cranioten das Amphioxushirn entspricht, lässt sich nicht mit Sicherheit 
bestimmen, da eine Abgrenzung des Gehirnes vom Rücken mark auf Schwierigkeiten stösst $\left(4^{\text {th }}\right.$ ed. 1898, p. 171).

While KUPFFER (1906, p. 14) and HATSCHEK (1892, p. 138) who also homologizes the brain of Craniates to that of Amphioxus cannot see any relation between the pigment spot of the latter and the eyes of the former, others, like AYERS (1890), try to derive the one from the other (cf. p. 29).

As shown by all this, the points of divergence among the authors are numerous.

It cannot be denied that in several respects Amphioxus shows very primitive features, so much so, that in text-books of comparative anatomy as well as of embryology, it is very generally taken as a starting point in exposing the structure and development of Vertebrates. It has even been argued that, if Amphioxus did not exist, it ought to be invented. On the other hand those who considered the Annelids as the ancestors of Vertebrates have always been embarrassed more or less by the difficulty of fitting Amphioxus and the Ascidians into their system, and generally considered them, with DOHRN (1875, p. 32), as a degenerated branch of the Vertebrate phylum. This view, however, also fails to remove all the difficulties and in the first exposition of my theory (1913, p. 705) I did not see any solution other than to assume that the Acrania have had a quite separate origin, and are perhaps to be derived from other Protostomia in a similar way as the Vertebrates from the Annelids. None of the sense-organs which according to my theory were inherited by the Vertebrates directly from the Annelids are present here, and apparently no such significance as in Craniates can be attributed to the tip of the notochord which reaches far in front of the brain vesicle. For Ascidian larvae and Appendicularians these difficulties are no less. Amphioxus in the light of my theory. - Afterwards, however, in reëxamining the question (DELSMAN, 1913), it appeared to me that Amphioxus at least, far from being an obstacle to my theory, fits perfectly well into it, nay, in a certain way proved to be the very missing link between Annelids and Craniates which, if it did not exist, I should have had to construct. For, if we assume that Craniates are to be derived from Annelid-like ancestors by the conversion of the stomodaeum into the neural tube and by the folding in of part of the apical plate which thus forms the brain vesicle, we may expect the existence of an intermediate 
form in which the first transformation has been accomplished while the latter has not yet occurred. In this form we ought to find no brain vesicle, at least no praechordal part of the brain; the neuropore, corresponding to the mouth of Annelids, ought to be found right over the anterior end of the notochord. just in front of the first pair of somites which correspond to the peristomium of Annelids. This now is exactly what is found originally in Amphioxus, as figs. 5 and 6 , after HATSCHEK, teach us. In front of the first pair of somites there is a well-developed prae-oral lobe, and the place of the neuropore, at the limit of this praeoral lobe and the first pair of somites, corresponds exactly to that of the mouth of Annelids. It does not correspond, however, to the neuropore of Craniates but to the isthmus of the latter, the "provisional neuropore" of certain Vertebrates in which the medullary tube has already closed when the cerebral plate is still open. This provisional neuropore, the future isthmus, in the same way lies right over the end of the notochord and over the first pair of somites on both sides of the latter. On the other hand this disposition leaves no room for any other view than that the first pair of mesodermic segments of fig. 5 is indeed the first and not the second pair as assumed by HATSCHEK ${ }^{1}$ ), VAN WYHE and WILLEY, and that accordingly neither the "head prolongations" (Kopffortsätze) nor the praeoral cavities represent mesodermic segments. The spinal nerves, restricted in Craniates to the epichordal part of the brain, in Amphioxus reach forward just as far as the somites. Only secondarily does the end of the notochord grow out into the prostomium, evidently to provide a support for the snout which is used by the animal for diving into the sand. In the same way the first pair of somites sends out a prolongation into the prostomium which, just as in Annelids, does not itself contain a division of the coelom. I feel inclined to compare these prolongations with the so called praemandibular somites in Craniates. Then VAN WYHE's mandibular somites, MAC BRIDE's collar-cavities, being the first pair of fig. 5 , would represent the first somatic segment. The homologization of

1) In a note HATSCHEK $(1892$, p. 137) remarks: "Wollte man den rostralen Fortsatz als einen Teil des ersten Ursegmentes betrachten, so würden sich Änderungen in der Darstellung ergeben, die jeder leicht durchführen kann". 
the mandibular cavities of Craniates to this first pair of normally developed somites in Amphioxus is supported by VAN WYHE (1907, p. 75) by the argument that the endostyle of Amphioxus and the thyreoid-gland in Craniates both originate from the ventral wall of the gut under this segment.

The mouth of Amphioxus. - The question of this homologization is of great importance in regard to another question, viz: the relation of the Craniate mouth to that of Amphioxus. The mouth of Craniates is situated as a median structure in front of the marıdibular segment, that of Amphioxus originates as a structure belonging to the left side, as stated bij VAN WYHE $(1914$, p. 64) and as may be seen also from HATSCHEK's figures, and behind the mandibular segment. Afterwards the left mandibular cavity grows out as a ring. round the mouth. Thus the mouth of Amphioxus must be compared with the left spiraculum of fishes, and the mouth of the latter, according to VAN WYHE, with the praeoral pit of Amphioxus. In a former article (1913) I argued that VAN WYHE's mandibular segment of Amphioxus is to be considered not as the second but as the first segment of the soma. Viewing with VAN WYHE the praemandibular segment as the first segment of Craniates, I was thus led to homologize the latter to VAN WYHE's mandibular segment in Amphioxus. If this view were right, the mouth of Amphioxus would not correspond to the spiracle of fishes but to the left half of the mouth. NEAL (1898, p. 267) was led to a similar conclusion: "I regard the mouth of Amphioxus as homologous with the left half of the mouth of Craniata and the club-shaped gland as its antimere. That the mouth of Amphioxus as an organ of the left side is exactly homologous with the left half of the mouth of Squalus appears to me probable on the a priori ground that it is improbable that an organ of the same function should be twice acquired in the Vertebrate series".

However, we have seen that arguments may be adduced as well for another view, viz: that BALFOUR's praemandibular cavities do not represent a segment and that the first segment in Craniates is that of the mandibula. Then VAN WYHE's homologization would prove to be the right one with this restriction, that in Amphioxus as well as in Craniates we should have to do not with the second but with the first body segment. The comparison also of the mouth of Amphioxus with the left spiracle of Craniates 
then proves to be right. It seems to me less probable, however, that this mouth should be a secondary one in regard to that of Craniates. The latter is found again by VAN WYHE in the praeoral or HATSCHEK's pit. He was led to this conclusion on the same a priori ground as is adduced by NEAL (see above). According to VAN WYHE (1907, p. 69) this change, not of function but, of organ would find its cause in the spiral movement of the larva during its pelagic life. However plausible this may be rendered by VAN WYHE, from the point of view of my theory it seems unnecessary to look for any other forerunner of the present mouth than ..... the neuropore. After the loss of the neuropore, which in young stages still perhaps acts as a mouth, one of the gillslits has taken over its function, as expressed by a modification of VAN WYHE's sentence, proposed by me (1913) in a former paper: "er hat den Mund (den Neuroporus!) verloren und frisst infolgedessen mit einer Kiemenspalte".

First pair of gill-pouches. - If, however, as argued on page 85 of this treatise, it may a priori be expected more or less that the first pair of gillslits would have broken through at the limit of the prostomium and the first segment, then we might expect to find a pair of gill-pouches in front of the mouth and the club-shaped gland and in front of the mandibular segment. As such, I believe, must we consider, as HATSCHEK (1892, p. 144) originally did, both the anterior entodermal diverticula. In figs. 23 and 24 , after HATSCHEK, we see them originate in a strictly bilateral way as evaginations

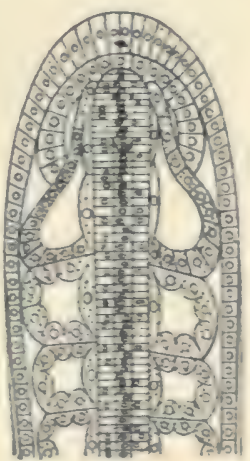

Fig. 24. Anterior end of the same stage of Amphioxus as fig. 23, seen from the dorsal side and showing, besides the first pair of gill-pouches ("anterior entoderm pockets"), the rostral prolongations of the first pair of somites. after HA TSCHEK, 1882 , fig. 52.

of the entoderm just in front of the mandibular somites, exactly where and as we should expect a first pair of gill-pouches. One of them, the left, still acquires an opening to the exterior, the praeoral pit which, according to HATSCHEK (1892, p. 144), is innervated in a similar way as the mouth 
and the other gill-slits, viz: by a visceral branch from a spinal nerve (a statement which has not been confirmed by VAN WYHE, 1893, p. 160). The development of the other, which passes into the praeoral coelome, takes a quite different course. That, however, gill-pouches may give rise to very singular structures is rendered probable by SPENGEL's (1904) and GOETTE's (1905) derivation of the lungs of Amphibia from a posterior pair of gill-pouches. This idea was rejected by GREIL (1906), but MARKUSCHOK $(1911,1912)$ has confirmed the agreement of the first rudiment of the lungs in Amphibians with a hindmost pair of gill-pouches.

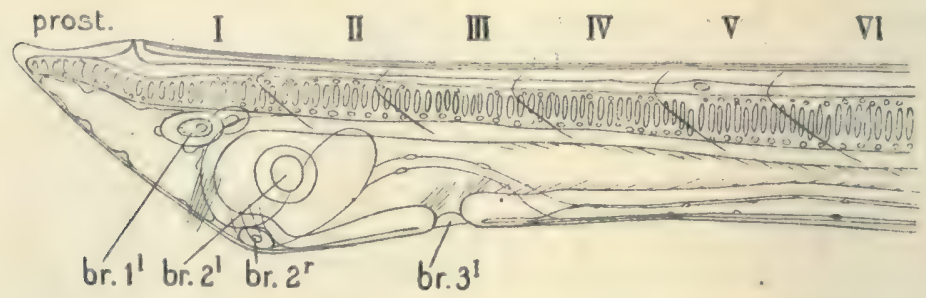

Fig. 25. Left-sided view of a young larva of Amphioxus, showing the first (br. 11, HATSCHEK's groove), the second (br. 21, mouth) and the third (br. 31) gill-opening of the left side and the second (br. $2 r$, club-shaped gland) of the right side. prost. prostomium.

(after HATSCHEK, 1882, fig. 63 A).

Thus in fig. 25 (HATSCHEK, 1881, fig. 63 A) three gill slits of the left side have broken through: HATSCHEK's pit, the mouth and the first proper gill-slit, all three of which may be united by a straight line which, prolonged on the right side, would indicate the situation of the subsequent gill-slits of the left side. The HATSCHEK's pit originally lies right under the neuropore, i:e. exactly at the limit of soma and prostomium where, according to the above considerations, it might be expected.

If then our conclusions are right, both the anterior entoderm pockets situated in front of the first pair of somites are to be compared with the mouth of Craniates. This is a partial confirmation of the opinion of VAN WYHE who considered the latter as the left one of the two pockets and, by his desire to find the unpaired Craniate mouth, was induced to doubt the paired 
nature of the entoderm pockets. I differ from VAN WYHE, however, in that I do not believe that the praeoral pit has ever functioned as a mouth. The most probable view seems to me to be that in a remote ancestor where the old mouth and the old stomodaeum (medullary tube) still functioned, a number of gill-slits, metamerically arranged, arose which soon began to act as ingestion-openings. When the old stomodaeum had changed its function, the first pair of gill-slits in Craniates fused to form a new mouth, the second pair being the spiracles. In Amphioxus, however, it was the left one of the second pair of gill-slits that developed into the secondary mouth. With this view the circumstance also agrees that, as pointed out by VAN WYHE (1907, p. 75), the thyroid gland in Craniates originates behind the mouth, the endostyle of Amphioxus in $f_{1}$ ont of it; in both cases the origin lies under the mandibular segment. I do not venture to explain what has caused this difference in the formation of the neostoma in Craniates and Amphioxus - and in Ascidians, as we shall see, the mouth is again a different structure - but it practically proves that the gill-slits are older than the mouth.

We have reached the conclusion that the so-called brain vesicle of Amphioxus is not homologous to the brain of Craniates but only to the epichordal part of the latter, the deutencephalon. In accordance with this view we do not find any trace of a cranial flexure, so characteristic in Craniates. As we have seen, the place of the animal pole in Craniates and Amphioxus confirms our conclusion (cf. p. 35).

Anterior spinal nerves. - A final question to be discussed is whether it is possible to recognize the four dorsal spinal nerves of the Craniate head, viz: the $N$. trigeminus, facialis, glossopharyngeus and vayus, among the anterior spinal nerves of Amphioxus and thus to determine in Amphioxus the region corresponding to the head of Craniates. Several authors have attempted to solve this problem but their conclusions are so divergent that I shall not treat them here at length but refer the reader to the short review given by FüRBRINGER (1897, p. 637). VAN WYHE (1894), who believes he can find the nine head segments distinguished by him in Elasmobranchs again as the first nine pairs of somites of Amphioxus, tries to homologize the nerves of this region to the cranial nerves of the former. 
As shown also by HATSCHEK's instructive figure of the head of Amphioxus, reproduced here as fig. 26, there is a dorsal spinal nerve between every two myotomes. It belongs

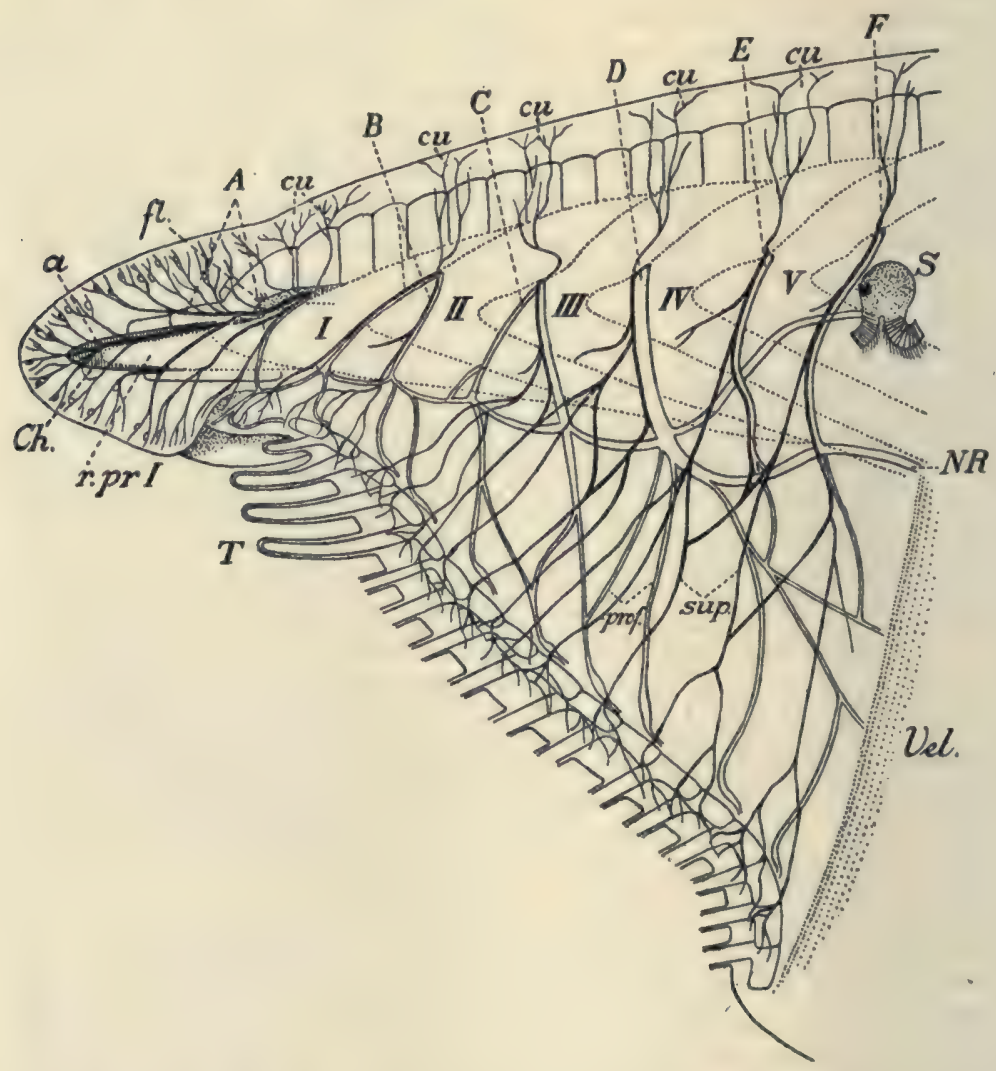

Fig. 26. Head of Amphioxus, from the left side, after HATSCHEK 1892, p. 143 (nomenclature altered).

$A, B, C$, etc. segmental nerves belonging to segments I, II, III, etc. $a$, anterior branch of the first segmental nerve ("N. ophthalmicus profunaus"), $C h$. notochord, $c u$, prof, sup. branches of the segmental nerves, $f l$. rest of the neuropore, $N R$. nervus recurrens to the branchial plexus, $r$. pr. I rostral prolongation of the first somite, $S$. HATSCHEK's groove, $T$. tentacles (cirri), Vel. velum, I, II, III etc. myotomes. 
to the myotome behind it, as is the case in Craniates ${ }^{1}$ ). In front of the mandibular somite, however, there are two pairs of nerves which mainly contribute to the innervation of the snout, a weaker anterior pair and a stronger second pair, the former situated more ventrally, the latter more dorsally. They are compared by HATSCHEK (1892) with the two portions of the trigeminus of Craniates which as a rule is corsidered as a double nerve but which we view as a single one. part of which has acquired a certain independence (fig. 17) (cf. p. 87). Indeed, on looking at fig. 5 it becomes at once apparent that in front of the mandibular somite there is room for but one single 1.erve. If we accept the view of HATSCHEK, to which also the application of my theory leads, then the dorsal parts of the next three segmental nerves in Amphioxus can only represent the facialis, the glossopharyngeus and the primary vagus (fig $26, \mathrm{~B}, \mathrm{C}, \mathrm{D}$ ), while the next three would be the dorsal roots of the hypoglossus, from which in higher Craniates the accessorius is to be derived. Is it by chance that in the figure of HATSCHEK the fourth nerve (the fifth of the authors', which would then represent the vagus (fig $26, D$ ), is so considerably thicker than the ones in front of and behind it? Is there any relation between it and the longitudinal plexus supplying the gill-slits? According to HATSCHEK a strong visceral nerve branch (fig. $26 \mathrm{NR}$ ) goes from this fifth nerve to the branchial plexus, according to VAN WYHE (1893, p. 162), however, it only supplies the velum. These questions must evidently await further investigation. Neuropore and praeoral lobe in Ascidians. - Until now we have left the Ascidians out of consideration. While we must assume that Amphioxus has undergone considerable reduction, the structure of the Ascidian-larvae and Appendicularia evidently shows so great deviations from the original plan, which is so easily recognizable in early stages of development in Amphioxus, that it is hardly possible to reconstruct the common ancestor of the Urochordates and Cephalochordates from the structure or development of the former. Does the neuropore and the brain-vesicle of

1) The four dorsal head-nerves in Craniates e.g., the trigeminus, facialis, glossopharyngeus and vagus, innervate the gill-slit in front of their segment, not the one behind it (cf. fig. 17), and in higher Craniates every dorsal spinal root unites with the ventral root following behind it (cf. HATSCHEK, 1893, p. 9J). 
Tunicates correspond to those of Amphioxus or to those of Craniates? The anterior end of the notochord evidently cannot help us to answer this question. The restriction of the musculature to the tail of Ascidian-larvae and Appendicularia evidently has engendered a corresponding reduction of the anterior end of the notochord. In the "trunk", the mesodermbands no longer produce muscles but only mesenchyme, and as a consequence the notochord is no longer required here. In Ascidian-larvae (KowALEWSKY, 1871) and newly or unhatched Appendicularia (DELSMAN, 1910) it is seen still to reach a little distance into the trunk, though not as 'far as under the neuropore, is is the case in Amphioxus; soon afterwards, however, it is exclusively restricted to the tail. In a very early stage, however, VAN BENEDEN and JULIN $(1887$, p. 269$)$ remark: ${ }_{n} \mathrm{Au}$ début la plaque médullaire ne dépassait guère en avant l'ébauche de la notocorde".

The distinctly dorsal, not terminal, situation of the neuropore makes us infer that it corresponds to that of Amphioxus and to the mouth of the Invertebrate ancestors. If this be right, the part of the body in front of it may be compared with the praeoral lobe of Amphioxus and Annelids. This name was already used by WILLEY $(1893$, p. 328 , 1894, p. 329) for the part of the body lying in front of the neuropore and of the mouth. He also compared it with the corresponding structure, the snout, of Amphioxus (1893, p. 333). Just as in Amphioxus (and in many Annelid larvae), the entoderm here is originally in contact with the ectoderm but afterwards a space is left between the two representing a part of the primary body-cavity. Just as in Annelids and, partly at least, in Amphioxus, the mesoderm-cells in this cavity proceed from the two mesodermic plates of the trunk (while in Amphioxus, the right anterior intestinal diverticulum also provides part of them). We must bear in mind, however, that, in giving the name praeoral lobe to this anterior body region of Ascidian larvae, WILLEY thinks in the first place of the "praeoral lobe" of Balanoglossus from which in recent times the English speaking zoologists are particularly inclined to derive the Vertebrates. However, he mentions in this connection the Annelids, Molluscs and Arthropods also, to which we of course direct our attention in the first place In either case the position of the adhering papillae in Ascidian larvae must correspond to the animal 
pole and indeed, the Ascidians would not be the only sessile animals which attach themselves to their substratum with the animal pole. The same can be said of the sessile Coelenterata, Cirripedia and Echinoderm-larvae. perhaps of more forms also. At the fixation of the Ascidian larva the praeoral
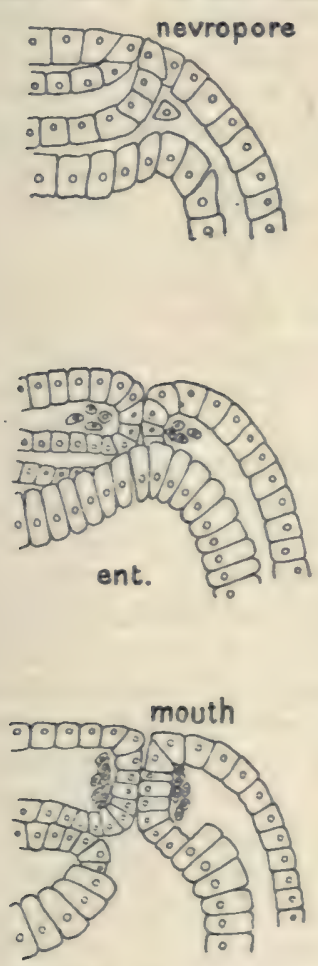

Fig. 27. Diagrammatic sagittal sections hrough antero-dorsal part of Ascidian embryos shcwing transformation of neural tube into wall of oral siphon (after HUNTSMAN, 1913).

is a secondary formation, a consequence of the loss of the primary mouth, of which process my theory gives such a simple explanation.

Segmentation in Ascidians. - If now we try to account for the further structure of the Ascidian larva and the 
Appendicularians, the first point that strikes us is the total loss of segmentation in the "trunk." The question as to whether the regular arrangement of the muscle-cells in the tail is to be considered as a last remnant of former segmentation or not, has been a point of controversy, especially recentiy between MARTINI (1909) and IHLE (1910). As to the latter question, the facts do not give convincing evidence for either alternative. From the point of view of my theory it appears to be not improbable that traces of former segmentation might be recognizable in the tail, since no doubt we must assume a segmented ancestor. In the trunk, however, no traces of segmentation of the mesoderm are to be noted anymore, nor is there a question of a secondary body cavity or a coelome.

The only starting point for a further comparison with the segmented Chordates is afforded by the first, and in Appendicularia the only, pair of gill-slits. These still might indicate the limit of two former segments. Are they, if this be the case, situated at the limit of the praeoral lobe and the first segment, as is the mouth of Craniates and the two anterior entoderm diverticula of Amphioxus? In this case they ought to be found directly under the neuro ore or the definitive mouth. Alternatively, are they situated at the limit of the first and the second segment? In the latter alternative the question is answered by VAN WYHE (1893, p. 155): the first pair of gill-slits of Ascidian larvae is situated behind the brain vesicle, as is the mouth and the club-shaped gland in Amphioxus. To both of these, therefore, they correspond and this conclusion is confirmed by the circumstance that the endostyle both in Amphioxus and in Ascidian larvae originates in front of them, while the rudiment of the thyroid gland in Craniates, which has been compared by MüLLER 11873, p. 327) and DOHRN (1885, p. 49) 10 the endostyle, is situated between the mouth and the first pair of gill-slits (VAN WYHE, 1902, p. 141), just as in Amphioxus under the mandibular segment which I consider as the first segment of the soma Thus our conclusion can only be, that the first pair of gill-slits in Ascidian larvae, the only pair in Appendicularia, indicates the limit of the first and the second body segment. While, according to VAN BENEDEN and JULIN (1884, p. 360), the Ascidians, in the same way as the Appendicularia, have only one pair of primary gill-slits, WILLEY (1893, p. 336) derives the numerous 
stigmata in the branchial sac of the former from three pairs of primary gill-clefts. The question whether these gill-slits by their situation indicate perhaps the limits of still more original trunk segments must be left open.

It needs hardly be repeated once more that I cannot agree with VAN WYHE's (1893, p. 155) opinion that the mouth of Ascidians is to be fourd again in Amphioxus as the left anterior intestinal diverticulum and that its opening would represent the former mouth ("autostoma") of Amphioxus; neither dces VAN WYHE's comparison of the anus of Ascidian larvae $w^{\text {th th }}$ the gill-slit of the left side following behind the mouth in Amphioxus seem to me very acceptable. I feel more inclired to support WILLEY $(1893$, p. 349 , in his view that the $U$ shaped alimentary caral is a consequence of the sessile habit of life, which may even have been the original condition of Arpendicularia also.

A question, the discussion of which I will also leave to those wro make a special study of these forms is, whether the tail of Ascidian larvae and Appendicularia corresponds to the tail of Vertebrates generally (WILLEY, 1893, p. 346) or whether it comprises part of the trunk of the latter (VAN BENEDEN and JULIN, 1887, p. 387).

History of the Vertebrate head. - We shall finish this chapter with an at:empt to give a short summary of the history of the Vertebrate head, drawn from the results of the numerous authors who have worked on the subject. These results, however, will be arranged and combined after the principles put forward in the preceding pages.

Animal pole of egg and blastula. - The history of the Vertebrate head is closely connected with that of the animal pole of the egg and of the blastula. The latter stage of development, through which all Metazoa pass, was termed by HUXLEY (1877, p. 678) the "animal Volvox" and, indeed, in tracing the history of the ar.imal pole, I believe we must go back to this colony of Flagellates which may be considered with equal right to be a lowly organized individual (BüTSCHLI, 1883, p. 775). As put forward by JANET (1912) in an interesting article to which I refer for the literature relating to this subject, it represents by no means a homaxonous sphere, for a main axis can indeed be distinguished. The shape of the colony is not spherical but somewhat elongated in the direction of the main axis round which the colony rotates and which indicates the 
direction in which it moves forward. Already during the egg cleavage, which exhibits certain points of resemblance with the spiral type of Polyclads, Nemertines, Annelids and Molluscs (DELSMAN, 1918), the polarity becomes evident. The opposition of an animal pole at the anterior side of the swimming colony and a vegetative pole at the opposite end of the main axis is also pronounced in the different structure of the cells of both sides, the red stigmat I characteristic for light-sensitive Flagellates being best developed in those of the animal half, less developed near the equator and absent in the neighbourhood of the vegetative pole. Here, on the contrary, the cells communicate with each other by a greater number of plasmatic connections, plasmodesms, serving for the transport of food.

In the blastula and already in the egg we find this same contrast, expressed by the names animal and vegetative. In cases where a free-swimming blastula is found it moves as well with the animal pole forwards and rotating round the main axis. The same holds good for the planula of Coelen terates and other pelagic larvae, inclusive that of Amphioxus (HATSCHEK, 1882, p. 37). The region round the animal pole genera'ly develops into a sensory and, as a consequence, a nervous centre. One of the oldest sense-organs is the tuft of long cilia at the animal pole, known as the apical organ, which we find in the larvae of Polyclads, Nemertines, Annelids, Bryozoa and Molluscs and, in a very specialized form, in Ctenophores. Though it is less distinct here, such an organ is to be found also in Echinoderm- and Balanoglossus-larvae (Deuterostomia).

Of other sense-organs in the neighbourhood of the animal pole must be mentioned in the first place that of the optic sense which already in Volvox begins to concentrate here. It may be observed that also in the Deuterostomian Balanoglossus two pigment-spots are found c'ose to the animal pole in the larva. Finally, the olfactory grooves and the tentacles in Protostomia are found on the prostomium or praeoral lobe. This region ruund the animal pole, the apical plate of the larva, evidently corresponds to the anterior half of the blastula and of Volvox, as in animals with the spiral cleavage type it originates from the four superior cells of the eight-celled stage (first quartet of ectomeres), i. e. from the animal half of the blastula.

The ultimate fate of the praeoral lobe in the animal kingdom may be very different. In most groups it develops into 
the sensory and nervous centre of the animal, directed forwards during movement, as is already the case in Volvox, and constituting or forming part of the head, as in most Annelids, MJlluscs, Arthropods and Vertebrates, and also in Balanoglossus. Sessile animals, however, often attach themselves to their substratum with the animal pole which then loses its significance as a sensory and nervous centre. This is the case in Coelenterata, Echinodermata and Ascidia. In other forms again the same phenomenon is the consequence of the use of the prae-oral lobe as an organ to bore through the earth or the sand, as e.g. in earthworms, Gephyrea, Balanoglossus, where we also can speak of a praeoral lobe, and Amphioxus.

In free-living forms, including Vertebrates, the animal pole as a rule indicates the ante:ior end of the body, as it already does in Volvox and in pelagic blastulae and larvae. While the four animal cells of the eight-celled stage, i e. the animal half of the blastula. give rise to the prostomium, the whole segmented som t of Annelids, ecto-, ento- and mesoderm, grows out from the vegetative half of the blastula, the nyposphere or sub-umbrella of the larva. In Annelids, in Arthropods and in Vertebrate, one or a number of segments of the soma form, together with the prostomium, the head.

Head of Amphioxus. - In Amphioxus ${ }^{1}$ ) there is hardly any question of a similar process. Though in the adult stage as well as during development secondary modifications play a very great rôle, yet the original structure of the most primitive Chordate - the link between Annelids and $\mathrm{C}_{\mathrm{r}}$ aniates, still missing in the first edition of this theory (1913) - may be clearly recognized in certain early stages of development. The stomodaeum of the Annelid has grown out in a backward direction and has become the medullary tube. The mouth of the Annelid, situated ventrally just behind the limit of prostomium and first segment (peristomium), is found again as the neuropore of Amphioxus on the corresponding place, viz: dorsally, at the boundary of prostomium and soma, just in front of the first or "mandibular" mesodermic segment. In consequence of the burrowing mode of life the prae-oral lobe has an equally dull appearance as e. $\mathrm{g}$ in Lumbricus. The eyes, formerly situated

1) The reader is invited to compare the following descriptions with plate I. 
no doubt on its surface, and the olfactory pits, have been lost, together with the cerebral ganglia. Directly urder the neuropore lies the anterior end of the notochord and at the left and the right of the latter the first pair of somites (the "mandibular" somites of VAN WYHE, the "collarcavities" of MACBRIDE), corresponding to the coelomesoblast of the first segment, or peristomium, of Annelids. All the somites develop. regular and permanent myotomes, from the first onwards. The first pair sends out a prolongation into the prostomium which itself has no primordial mesoderm, while at the same time the fore-end of the notochord secondarily grows out into the snout These "head-or rostral prolongations" of the first pair of somites correspond to the praemandibular cavities of Craniates. Paired gillpouches are formed each between tuo somites. The first pair appears in front of the first pair of somites, under the neuropore. The lef $\mathrm{f}$ of them acquires an opening, known as HATSCHEK's pit, to the exterior, the tight one gives rise to the praeoral head cavity. Of the second pair, between the first and the second pair of somites, the left one becomes the larval mouh (afterwards the velar opening), the right one the so-called club-shaped gland which also opens to the exterior but afterwards disappears. Only secondarily, after the "critical stage", does the eumetamerism of gill-slits and somites get lost. The endostyle oric inates under the mandibular segment, in front of the mouth.

Spinal gang ia and also head ganglia are not clearly recognizable, auditory vesicles are ahsent. Dorsal and ventral spinal nerves do not unite. There is no distinct difference between the nerves of the anterior segments (corresponding to the head segments of Craniates) and those of the trunk, both being of mixed character. In the region of the former the dorsal roots show a strong plexus-formation and a longitudinal plexus also supplies the gills. It is especially by the strong fourth nerve, evidently comparable to the vagus in Craniates, that this branchial plexus communicates with the medulla and the insignificant brain-vesicle which corresponds to the epichordal deuterencephalon of Craniates.

The asymmetrical origin of the mouth no doubt gives us the key to the interpretation of the larval asymmetry, although we shall not indulge now in speculations in this direction.

Head of Petromyzon. - In Petromyzon part of the surface of the prostomium has been annexed by the medullary tube, 
it has been enfolded and has given rise to the praechordal part of the brain. The eyes, formerly situated on the surface of the prostomium, have been closed over at the same time and, striving to regain the light, have given rise to the eyes of the inverted type characteristic for Vertebrates.

In three respects Petromyzon distinguishes itself from all other Craniates and at the same time stands nearer to Amphioxus: the segmentation of the mesoderm into somites is complete (HATSCHEK, 1910), the dorsal and ventral spiı.al nerves remain separate (RANSOM and THOMPSON, 1886) and the series of somites continues in a very distinct way in the head as far as the prostomium. The four anterior somites, being the trigeminus- or mandibular somite, the facialisacust cus- or hyoid-somite, the glossopharyngeus- and the vagus-somite, in the beginning do not differ in any fundamental respect from the subsequent ones. The first two may be termed pro-otic, the latter two are post-otic; the auditory vesicles belong to the second head-segment, as is the case $i_{1}$ all other Craniates and in the majority of the Annelids provided with orga:ıs of equilibrium. Just as in Amphioxus the first or mandibular somite sends out a prolongation into the prostomium, which afierwards sepaiates from it as the "praemandibular somite" (HATSCHEK, 1910, p. 481), comparable accordingly to the "head-prolongation" (Kopffortsatz) of the first somite of Amphioxus.

The first somite to be differentiated in ontogeny is in this case not the mandibular somite, as in Amphioxus, but the third, being the first post-otic one, and, as we shall see, the first one to produce a permanent myotome (KOLTZOFF, 1902 , p. 286, 318). The second and first are formed somewhat later, in the same way as the fourth, fifth, etc.

While in Amphioxus the endostyle arises as a ventral bulging out of the gut just in front of :he mouth, in the first somatic segment, it originates in Ammocoetes, similarly to the rudiment of the thyroid gland in Craniates, in the same segment but consequently just behind the mouth (VAN WYHE, 1907, p. 75)

The ultimate fate of the anterior somites is somewhat different from that in Amphioxus where they all produce regular myotomes. In Petromyzon this is only the case in the post-otic somites while the two pro-otic ones, together with the so-called "praemandibular somites", give rise to the eye-muscies (KOLTZOFF, 1902, p. 343, 350, 371). From the post-otic somites a uniform and continuous series of 
myotomes develops, those produced by the glossopharyngeusand vagus-somite differing externally in no way from the next ones. The only indication of the beginning of the process of reduction of the two anterior post-otic myotomes, which we see atrophy in higher Craniates, is the disappearance in the course of development of their deeper parts (KOLTZOFF, 1902, p. 329). This fact evidently is accounted for by the circumstance that the auditory capsule by its increazing size no longer finds sufficient room in one segment but reaches (and the cranium with it!) into the first and second post otic segment, the corresponding myocommata being attached to it, as shown by fig. 29 , after GOODRICH (1907, p. 40). According to NEAL $(1897$, p. 446) the ventral roots of the anterior post-otic myotomes also get lost, these myotomes being supplied by branches from the ventral roots of the $4^{\text {th }}$ and $5^{\text {th }}$ post-otic myotomes (cf. fig 20).

Just as in Amphioxus there is a numerical, though not strictly individual, correspondence between the gill-slits and the somites (NEAL, 1897, p. 447, KOLTZOFF, 1902, p. 432), the eight gill-pouches, of which the first, the spiracular one, does notbreak through, being situated originally between the first and the ninth somite (the second

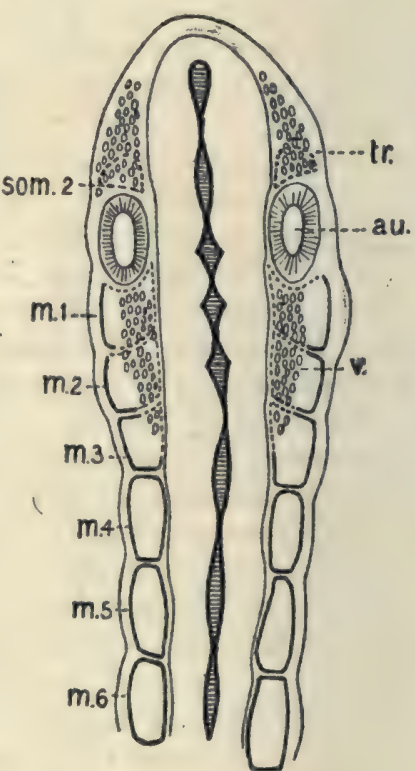

Fig. 28 Reconstruction from a series of horizontal sections through the head of Ammocoetes at the time of hatching, after KoltzofF, 1902, p. 556.

$a u$ auditory vesicle, $m .{ }^{1}, m^{2}$ etc. post-otic myotomes, som. ${ }^{2}$ second Somite, $t r$. ganglion of the trigeminus, $v$. internal part of anterior post-otic somites breaking duwn. and the tenth of those authors who count the "praemandibular somite" as the first). In front of the first somite a median mouth is found which accordingly does not correspond to that of Amphioxus (the left-sided gill-slit between the first and second somite) but evidently to a pair of fused gill-slits in front of the first or mandibular somite. 
The anterior ones of the post-branchial myotomes, from the ninth (seventh post-otic) onwards (NEAL, 1897, p. 444, KOLTZOFF, 1902, p. 304), produce myotomic buds which grow out behind and under the gill-slits and produce the

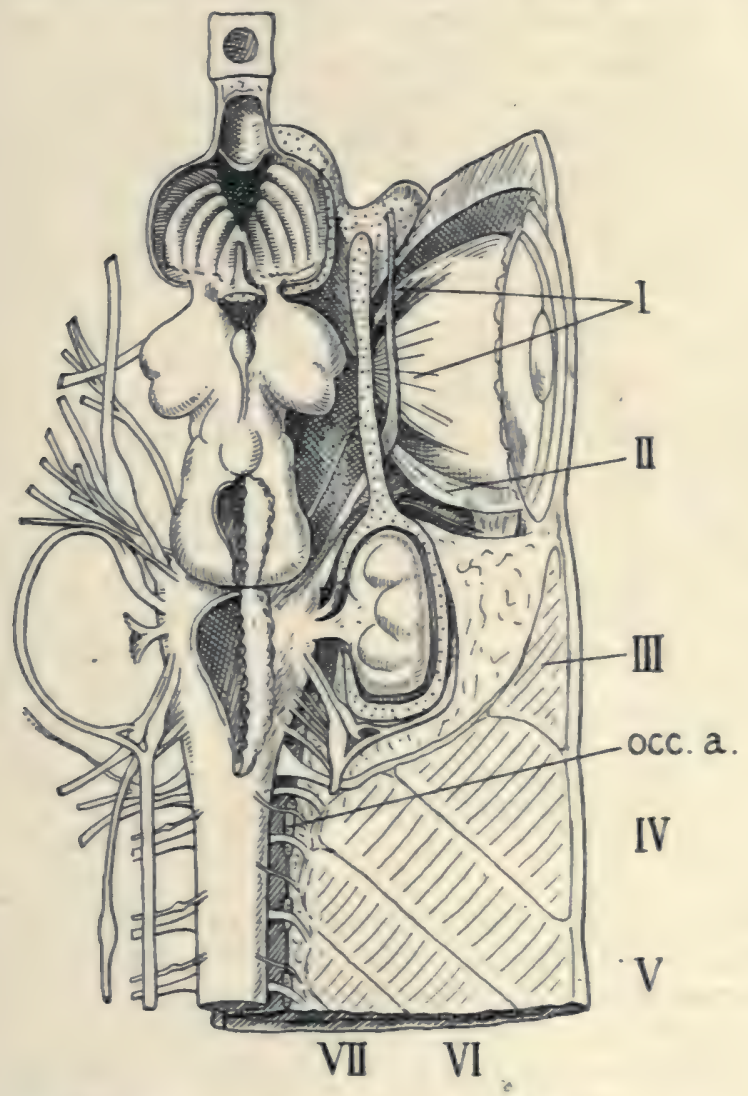

Fig. 29. Head of Fetromyzon fluviatilis, dissected, after GOODRICH, 1909, p. 40.

$I, I l$, eye-muscles derived from the two prc-otic somites.

$I I I, I V, V$, etc. myotomes.

occ. a. occipital arch.

hypobranchial musculature which afterwards exhibits a secondary segmentation corresponding to the situation of the gill-slits. It is innervated by ventral roots of the myo- 
tomes from which the hypobranchial muscles are derived ( $7^{\text {th }}-14^{\text {th }}$ post-otic, according to NEAL), afterwards constituting the hypoglossus.

Afterwards the backward extension of the branchial basket causes a secondary dysmetamerism between the gill-slits and the myotomes situated above them, the number of the latter surpassing that of the former. The hypoglossus by this process is caused to run in a backward directed curve round behind the last gill-slit to the hypobranchial $\mathrm{mis}$ culature. It is just in being pushed backwards by this process that it collects one by one the originally post-branchial ventral roots of which it is composed. In the hypobranchial

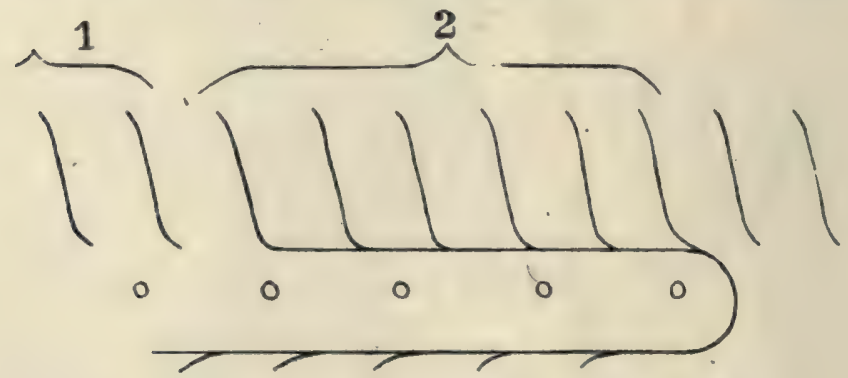

Fig. 30. The hypoglossus of Petromyzon, according to NEAL, 1897.

1 primarily epibranchial ventral roots

2 secondarily,

(hypoglossus)

musculature, however, the correspondence of the secondarily established metamerism with the arrangement of the gillslits is preserved also after the extension of the branchial basket. Thus the number of muscular segments above the gill slits is greater than that beneath the gill-slits (HATSCHEK, 1892, p. 148, cf. also fig. 20). The ventral roots in front of the hypoglossus-roots innervate the epibranchial musculature formed from the primarily epibranchial myotomes.

The opposition of the four anterior segmental nerves, of which the trigeminus, facialis-acusticus, glossopharyngeus and vagus represent the corsal ronts, and the remaining spinal nerves, has accentuated itself. Only in the former do we find in most Craniates a contribution to their ganglia from the lateral line system, only in the latter do we find 
as a rule a separation of the (visceral) motor part from the ganglion in the form of the sympathetic gangiia. Thus the four head ganglia contain two elements which are absent in the spinal gangia, probably even three, if we count the epibranchial placodes as a third system. The first segmental nerve, the trigeminus, just as in Amphioxus, has a double character and supplies, besides its own segment, also the prostomium or snout with sensory branches. Something similar is the case with the second pro-otic nerve, the facialis acusticus, which supplies the cephalic part of the lateral line (including the prostomial part) The main part of the lateral line extending along the trunk is supplied by the ramus lateralis vagi which probably may be considered as a collector which, according to EISIG (1887) and HATSCHEK (1892, p. 151-152), has collected the lateral part of the dorsal branches of the dorsal spinal nerves.

While in Amphioxus the longitudinal epibranchial plexus, connecting the ventral part of the spinal nerves above the gill-slits and supplying the latter with its branches, communicates, according to HATSCHEK (1892, p. 144), with the medulla mainly by means of the third and, especially, the strong fourth segmental nerve (his fourth and fifth), we find in Petromyzon a similar horizontal nerve-stem connecting the epibranchial placodes and supplying the gill-slits with rami post- and praetrematici. The communication between this collector, the ramus branchio-intestinalis vagi, and the brain in Petromyzon and other gill-breathing Craniates, however, is wholly established by the third (glossopharyngeus) and, especially, by the fourth nerve, the vagus (cf. fig. 20), while the connections with the spinal nerves following behind the vagus, so well developed still in Amphioxus, are represented in Petromyzon by insignificant anastomoses only of these nerves with the ramus branchio-intestinalis of the vagus, as described by RANSOM and THOMPSON (1886, p. 422) and FuRBRINGER (1897). In front of the vagus, however, the segmental communications between the anterior cranial ganglia and the epibranchial placodes have been retained. Originally the epibranchial placodes of the $7^{\text {th }}$ and the $9^{\text {th }}$ nerve also are united to those of the vagus by the horizontal plexus from which, however, they afterwards separate (KOLTZOFF, 1902, p. 531) Thus we may consider the vagus, with HATSCHEK (1892, p. 152), as a partially polymeric nerve that has collected, in its ramus branchio-intestinalis, 
the lateral part of the dorsal branches (ramus lateralis) and further the lateral and visceral part of the ventral branches (rami post-and praetrematici) of the dorsal spinal nerves behind it. Evidently under the influence of the vagus the anterior spinal ganglia behind it are not so well developed in Gnathostomes as those further back. In none of the publications on the Cyclostomes is any process of this nature referred to. The first spinal ganglion behind that of the primary vagus fuses with it ("spinalartiger Vagusanhang", HATSCHEK, 1892, p. 156).

For the first time we find in Petromyzon a cartilaginous skull, comparable to the head cartilage of Cephalopods and arising, like the latter, in close connection to the central part of the nervous system and the main sense-organs. Its extension is less than in higher Craniates and comprises, besides the prostomium, only two segments (HATSCHEK, 1892 , p. 159). This conception results from the observation that the cartilaginous skeleton does not extend further back than the auditory capsule and that the ganglion of the glossopharyngeus and the vagus is situated behind it. However, the considerable size of the auditory capsule causes the latter to extend backwards into the anterior two post-otic segments in which the internal parts of the myotomes as a consequence atrophy, while their myocommata are attached to the auditory capsule (cf. fig. 29). The first neural arch is the one situated in the myocomma between the third and the fourth post-otic somite (fig 29, occ, a.). Membranous walls connect the cartilaginous skull with the first neural arch. Through this membranous part of the skuil the glossopharyngeus and the vagus pass.

We shall call a skull as found in Petromyzon an inc o m plete (partly membranous) pala e ocra n i u m.

Finally it may be observed that the hypophysis originates from the ectoderm in front of the mouth involution.

Amphibian head. - Next to the Cyclostomes to which they show a close resemblance in their earliest development come the Amphibians in which the hypophysis still originates in front of the mouth involution, while this group stands also inearest to Petromyzon in the structure of the brain, especially of the metencephalon. The roof and the hinder, membranous, part of the Cyclostome skull, between the anterior, cartilaginous, region and the first neural arch, has 
chondrified and the neural arch itself has been incorporated into the skull. In ontogeny it appears as the occipital arch, some distance behind the auditory capsule and afterwards fusing with it, leaving the foramen vagi between itself and the capsule (cf. fig. 21). It is SEWERTZOFF (1895, p. 262) who has compared the occipital arch with the first free vertebral arch in Petromyzon.

It is not easy to determine, from the somewhat diverging statements of different authors, the number of segments incorporated into the skull by this process and situated between the auditory capsule and the occipital arch. At any rate the glossopharyngeus and the vagus have been incorporated. However, the "spinalartiger Vagusanhang", the first spinal nerve behind the primary vagus, which, according to HATSCHEK, has fused with it in Gnathostomes, represents a segment also. In Necturus Miss PLATT $(1897$, p. 448) indeed found the vagus-Anlage to have a double nature and to correspond to two somites, the second and the third post-otic ones. The anterior part of the rudiment of the ganglion extends outwards over the second somite, in the manner typical for cranial nerves, while the posterior part passes directly downwards, median to the third somite, in the manner of a typical spinal nerve, and becomes attached to the brain by the second vagus root. In Gymnophiones MARCUS (1910, p. 378) finds close to the vagus ganglion another little ganglion, sometimes fused with the former and otherwise connected with it by fibrous nervestrands, and which according to MARCUS (I. c. p. 451) must be homologized to the spinal ganglia and at the same time be counted to the vagus complex. To this little dorsal ganglion again a ventral occipital nerve, designated after FüRBRINGER's nomenclature (and thus wrongly) as $z$, shows close relations. The latter innervates the first myotome of the musculus dorsalis which is attached to the auditory capsule, in the same way as the third post-otic myotome in Petromyzon (cf. fig. 29) to which it evidently corresponds The next myotome is supplied by the first spinal nerve which has no dorsal ganglion.

As to the number of somites to be observed in early ontogeny between the occipital arch and the auditory capsule in the head of the Amphibian, the statements of different authors do not wholly agree, but from recent inves igations it becomes more and more evident that in Urodelans, as in Petro- 
myzon, there are three, as found by Miss PLATT (1897, p. 850) in Necturus. To judge from MARCUS' (1910) figures and descriptions this also holds good for Gymnophiones (the last, permanent, myotome of the head e.g. is situated here also above the space between the $4^{\text {th }}$ and the $5^{\text {th }}$ visceral cleft), although certain corrections of MARCUS' interpretations seem necessary. In the axolotl (and the sturgeon) SEWERTZOFF (1895, p. 260) observed only two post-otic somites in front of the occipital arch but, since in Selachians their number is also three, he leaves open the possibility that one has fallen out behind the auditory capsule, while Miss PLATT (1898, p. 450) suggests that SEWERTZOFF has made a mistake. This has been fully confirmed by GOODRICH (1911, p. 116) who also comes to the conclusion that there are three post-otic segments included in the skull of Siredon. This number corresponds to that found in Petromyzon between the auditory capsule and the first neural arch.

Of the three post-otic head somites the anterior two, the glossopharyngeus and the primary vagus somite, no longer develop permanent muscles, they have been crushed out of existence, so to speak, by the auditory capsule. A little transient myotome, designated by him as $y$, is found by MARCUS (1910, p. 430) close to the vagus-ganglion and also a corresponding ventral root $y$. Afterwards, however, both break down while in Necturus, according to Miss PLATT (1898, p. 447), and in Siredon, according to GOODRICH (1911), a few fibres persist, continuous with the dorsal part of the third post-otic somite. This somite, being the one of the "spinalartiger Vagusanhang", produces in Urodelans the anterior segment of the trunk musculature, attached, as recorded above, at the auditory capsule and innetvated by the ventral occipital nerve (wrongly) designated as $z$.

Recently my friend VAN SETERS (1921) has come to the interesting conclusion, that in Anurans the skull is sti!! one segment shorter than in Urodelans. Thus the first post-cranial segment would be the one corresponding to the "spinalartiger Vagusanhang." This explains why in Anurans, where the myotome belonging to this segment, together with its ventral nerve-root, atrophies, not only the first (the "spinalartiger Vagusanhang") but also the second spinal ganglion, gets lost.

We shall call the cranium of Urodelans a complete $\mathrm{p}$ a l a e-crani um, comprising the rudiment of only one 
vertebra '). Besides the prostomium it contains five segments, two pro-otic and three post-otic. No post-branchial segments, i.e. segments behind the last gill-slit, have been incorporated into the skull, the occipital arch being situated over the last (fifth) gill-slit (Miss PLATT, 1898, p. 452). As a consequence of the restricted number of post-otic head segments the sphere of influence of the vagus extends beyond the cranio-vertebral limit and causes the first (in Anurans even the second) free spinal nerve to lose its dorsal root and ganglion. The vagus never supplies more than three gill-slits and as a consequence contains the rami post- and praetrematici of only two spinal nerves behind it, being the "spinalartiger Vagusanhang" and the first free spinal nerve, to which the dorsal root is wanting.

The hypoglossus-musculature, according to Miss PLATT (1898, p. 452), is produced in Urodelans by ventral buds from the last epibranchial myotome (the third post-otic somite) and by two postbranchial ones ( $4^{\text {th }}$ and $5^{\text {th }}$ post-otic somites) and is innervated by the ventral roots belonging to the latter two, being the first two free spinal nerves which constitute the wholly postcranial cervical plexus, or hypoglossus. There is no epibranchial musculature in Amphibians.

Head of Selachians. - In Selachians and Sauropsids, finally, the first processes of development are in a corresponding way influenced by the enormous accumulation of yolk in the egg. In both, the metencephalon, in contrast with both the foregoing groups, has strongly developed, and the hypophysis no longer originates in front of the mouth involution but from its roof. In both groups new segments have been added to the skull which we shall accordingly call a neocranium. Whereas in the glossopharyngeus-somite no myotome and in the primary vagus segment only a very rudimentary myotome develops, we find in Selachians behind the primary vagus some four well-developed myotomes belonging to the head region and instead of one neural arch the rudiments of four have been described for Acanthias by HOFFMANN (1894, p. 638), of which the anterior one has been compared by SEWERTZOFF $(1895$, p. 260) with the occipital arch of Amphibians. In front of it, just as in

1) If, at least, we do not consider the rudimentary "prae-occipital arch", sometimes found in Urodelans in front of the "occipital arch", and to which the occipital arch of Anurans, according to VAN SETERS (1921), corresponds, as another vertebra. 
Urodelans, three post-otic somites are found. Evidently then three more segments have been added to the skull in Acanthias where, however, the head contains one segment more than in forms like Scyllium and Fristiurus on which VAN WYHE and others have worked and where accordingly an increase of only two segments must be assumed. In forms like Hexanchus and Heptanchus still one or two segments more must be added to the number found for Acanthias (cf. p. 109). In Acanthias we reach a total number of eight, in Pristiurus etc. of seven, head segments, the latter number corresponding to that of the arches of the visceral skeleton of the head.

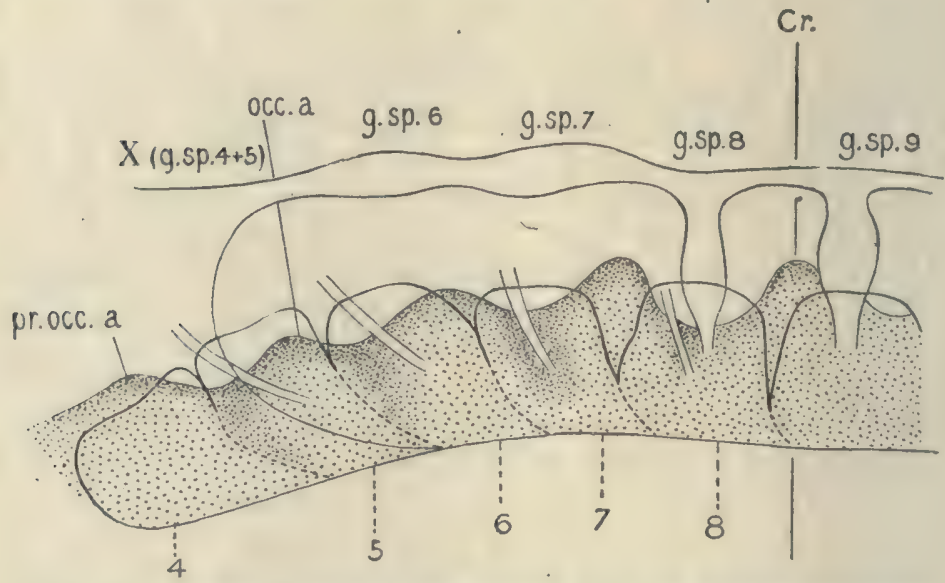

Fig. 31. Occipital region of an embryo of Acanthias, according to SEWERTZOFF, 1899, plate XXIX, fig. 4 (nomenclature altered).

Cr. cranio-vertebral limit, g. sp. spinal ganglia, occ. $a$. occipital arch, pr. occ. a. prae-occipital arch, 4, 5, 6 etc. somites.

The figure given by SEWERTZOFF (1899, fig. 4) of the occipital region of an Acanthias-embryo, reproduced here as fig. 31 , is particularly instructive. Though SEWERTZOFF could not confirm HOFFMANN's statement that true vertebrae may be distinguished here, the cartilage in the occipital region representing a continuum from the beginning, yet the segmentation of the axial skeleton is very clearly pronounced by a series of prominences corresponding to 
the myocommata, just like the rudiments of the neural arches in the trunk of which they represent the direct forward continuation. SEWERTZOFF had numbered the myotomes in his figure as 6-11, after the system of VAN WYHE who counts the "praemandibular segment" as the first and the hyoid segment as two segments. I have changed this nomenclature into $4-9$, in accordance with the conclusions arrived at in the foregoing pages. To each myotome a dorsal ganglion and a ventral root corresponds but under the vagus ganglion two myotomes are found $(4-5)$. This is in accordance with HATSCHEK's and VAN WYHE's opinion that the vagus in Gnathostomes is a bivalent nerve and that its primary ganglion has fused with the first spinal ganglion behind it ("spinalartiger Vagusanhang"). According to NEAL (1898, p. 238), SEWERTZOFF (1899, p. 287) and other investigators one more spinal ganglion (that of my segment 6 ) fuses afterwards with that of the vagus (vago-accessorius) which accordingly in the adult Selachian is trivalent (cf. GUTHKE, 1906, and ZIEGLER, 1908), being composed of the primary vagus ganglion and two rudimentary spinal ganglia following behind it.

According to HOFFMANN (1894, p. 628) and SEWERTZOFF (1899, p. 302) the cranio-vertebral limit in Acanthias lies behind my somite 8, in Scyllium and Pristiurus, according to VAN WYHE (1882) and others, behind my somite 7. The neural arch rudiment between the somites 5 and 6 corresponds to the first of the four vertebral rudiments described by HOFFMANN and has been compared by SEWERTZOFF with the occipital arch of Amphibians and with the first free arch in Petromyzon. Thus the ventral root belonging to somite 5 and to the "spinalartiger Vagusanhang" must be the one that has been observed in Urodelans (cf. p. 115). It must be called $x$ in Amphibians after FüRBRINGER's nomenclature, not $z$ which indicates the last head segment of Scyllium.

A faint neural arch rudiment in front of the somite 5 (fig. 31) evidently represents a rudimentary prae-occipital arch, as described by Miss PLATT (1898, p. 448) in Necturus and by GOODRICH (1911, p. 104) in Siredon.

As in Amphibians, the two anterior post-otic somites no longer develop myotomes, but the second post-otic somite still forms a rudimentary one. From the remaining occipital somites, however, myotomes are still developed. From these 
the epibranchial musculature is formed (DOHRN, 1885, p. 446, HOFFMANN, 1898, p. 265) which in all other Gnathostomes, and also in rays already, is absent. The greatest number of epibranchial myotomes will be found in hexanch ard heptanch Selachians where the number of gill-slits is greatest. Here indeed the epibranchial musculature is best developed (FüRBRINGER, 1897, p. 416) and so are the occipital nerves supplying them which lie in front of the hypoglossus-roots $(v, w, x$, according to FüRBRINGER).

In the development of the somites from the unsegmented mesoderm a retardation in the head region, correlated with the degree of degeneration of the corresponding myotomes, is to be noticed. The first somite to be differentiated is as a rule the first to develop a permanent myotome. This serves to explain why in the Craniata the development of the somites begins in the neck region and not, as in Amphioxus, with the foremost one (NEAL, 1898, p. 195). Thus in Acanthias the $3^{\text {rd }}$ or $4^{\text {th }}$ post-otic somite is the first to develop. As we have seen, this rule has been confirmed for Petromyzon by KOLTZOFF (1902, p. 318). Here the first post-otic somite is the first to appear.

The hypobranchial musculature (Musculi coraco-arcuales) is formed in Selachil from the ventral buds of a number of myotomes behind the last gill-slit. To judge from the number of ventral roots supplying it (cervical plexus, hypoglossus, cf. FüRBRINGER, 1897, p. 404), the number of myotomes contributing to the formation of this musculature is greater in rays where some seven or eight ventral roots participate in its innervation. In sharks this number is as a rule from four to six of which none, one or two may be intracranial, the rest being post-cranial.

The secondary backward extension of the branchial basket in Selachians is so strong that not only the cervical but also the brachial plexus is pushed backwards in a curve round behind the last gill-slit. As a consequence both unite to a cervico-brachial plexus which distally divides again into two branches, one to the hypobranchial musculature and one to the pectoral fin. This common plexus was seen by HOFFMANN (1901, p. 39) to form during development in exactly the same way as is described by NEAL for the hypoglossus of Petromyzon. In the sturgeon so great a number of vertebral elements is assimilated by the cranium that the whole brachial plexus, consisting of ventral and 
dorsal roots, is incorporated into the skull (FüRBRINGER, 1897, p. 457).

Thus among the so-called occipital nerves we must distinguish primarily epibranchial, supplying epibranchial musculature, from secondarily epibranchial or hypoglossus roots, supplying hypobranchial musculature. From the number of the latter may be determined the approximate number of post-branchial segments into which the skull reaches. Adding to this number that of the epibranchial

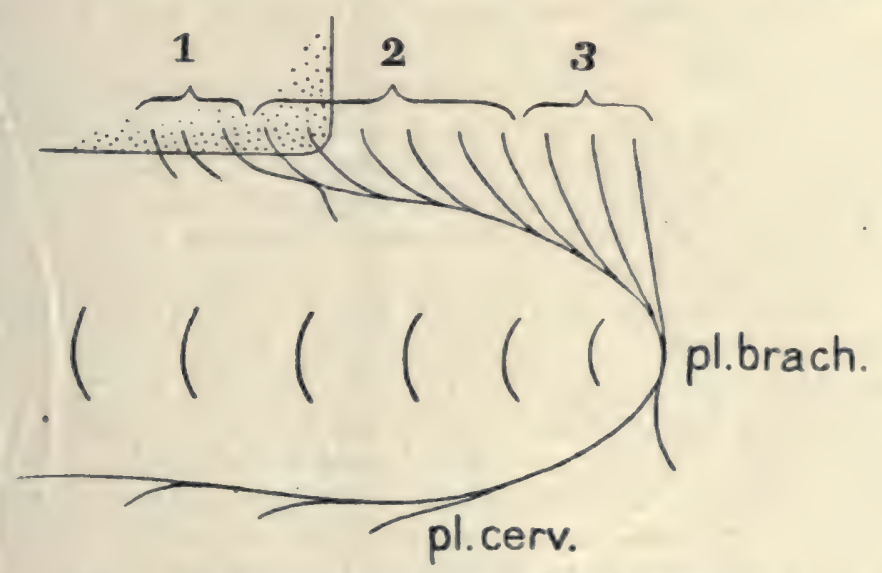

Fig. 32. Plexus cervico-brachialis of Heptanchus, after FüRBRINGER's statements, 1897.

1 primarily epibranchial ventral roots

2 cervical plexus or hypoglossus.

3 plexus brachialis.

segments we get the total length of the skull. This proves to be subject to variation among Selachians, the number of epibranchial (depending on the number of gill-slits) as well as that of post-branchial segments may vary. Thus FüRBRINGER was wrong in assuming that the skull in all Selachians has equal length and that consequently the last segment and its ventral nerve may always be indicated with the same letter $(z)$. If in Scyllium we call it $z$, we ought to call it $a$ in Acanthias and $b$ or $c$ in Hexanchus and Heptanchus. While $z$ and $a$ in the latter form are prima ily epibranchial nerves, they have become hypoglossus-roots in forms like Scyllium where the number of gill-slits has decreased. In 
general we see in Elasmobranchs rather a tendency of the skull to decrease than to increase in length, the highest number both of epibranchial and of post-branchial cephalic segments being found in the more primitive forms (Notidanids). FürRRINGER was also wrong in assuming that the skull in Amphibians is equal in length to that of Selachians and that here also the occipital ventral nerve, sometimes observed in early stages, must be termed $z$. It is not $z$ but $x$, the skull being shorter than that of Selachians.

Head of Amniotes. - In sharks one (Scyllium, Pristiurus) or two (Acanthias) post-branchial somites belong to the region of the skull and a corresponding number of ventral occipital nerves are found to leave the latter and to participate in the innervation of the hypobranchial musculature. In Amniotes it is generally stated that the hypoglossus consists of three occipital ("occipito-spinal" after FüRBRINGER) ventral roots, that is one more than in Acanthias. Since in Amniotes the number of gill-slits is one less, we reach the conclusion that the backward extension of the Amniote skull corresponds to that of Acanthias and that, as in the latter form, the skull comprises eight segments. The number also of myotomes observed in the occipital region of Amniote embryos corresponds on the whole to that found in Selachian embryos.

The hypobranchial or tongue-musculature is formed again from the post-branchial myotomes, four in number, of which one does not belong to the skull. The tongue musculature, in fact, is supplied by a hypoglossus with three occipital roots uniting with the first free ventral root to a plexus which, however, in this case does not fuse with the plexus brachialis which in Amniotes often moves backwards a fair distance from the head.

Thus the Amniote skull represents a neocranium, corresponding in length to that of the Selachians. The intracranial (occipital) hypoglossus-roots may be designated with the same letters as those in Selachians, i.e. with the last, and not the first, letters of the alphabet. Only if, with FüRBRINGER (1897, p. 362), we call the last occipital nerve of Acanthias $a$ have we probably to do the same in Amniotes. The "ganglion hypoglossi" discovered by FRORIEP (1882) in the sheep and known also as FRORIEP's ganglion, being the dorsal ganglion of the last head segment, evidently corresponds to the dorsal ganglion found in the last segment of the head in Acanthias (cf. fig. 31, sp. 8). In both cases it is 
somewhat less developed than the spinal ganglia behind it, though not so rudimentary as the ganglia in front of it. Neither in Amniotes nor in Acanthias does it produce a regular dorsal nerve.

It will be better, however, to leave now FüRBRINGER's nomenclature and to replace it by the numbering of the segments shown in plate $I$.

The pro-otic and the anterior post-otic somites are no longer to be recognized even in the earliest stages of development. The first myotome probably develops from what we may consider as the third post-otic somite. The auditory vesicle acquires certain relations to the first of the gillpouches behind the mouth.

General conclusions. - From the foregoing considerations the following conclusions result. Though in such Selachians as Scyllium and Pristiurus the number of head segments happens to correspond with that of the visceral archs, we must yet conclude, in opposition to GEGENBAUR (1872), that on the whole there is no relation between them. The number of gill-slits may be considerably greater than that of the segments of the skull, as is the case in Petromyzon, or the skull may reach just as far as the last gill-slit, as in Urodelan Amphibia, or a greater or lesser number of post-branchial segments may belong to it, as in Selachians and Amniotes. In the first case the roots of the hypoglossus lie far behind the skull, in the second case it is formed from the anterior free ventral roots, in the third case a greater or lesser number of hypoglossus-roots become intracranial or occipital. In the first case we shall speak of an incomplete palaeocranium, in the second case of a complete palaeocranium, in the third case of a neocranium. It depends on the number of gill-slits whether the hypoglossus roots will lie far behind the vagus or within the reach of its sphere of influence which causes the dorsal ganglia behind it to atrophy. That originally the hypoglossus has nothing to do with the vagus is shown by Petromyzon. When the number of gillslits decreases, the hypoglossus moves forward, i. e. its roots now belong to segments more in front. This does not mean to say, however, as FüRBRINGER (1897, p. 440) assumed, that the myotomes and their ventral roots themselves move forward. Of such a "stetiges Vorrücken" there is no question. The roots of the hypoglossus may by the process mentioned above come so close to and under the partially 
polymeric vagus that they may be termed with some right ventral vagus roots, as has been done by GEGENBAUR. Better still would it be, no doubt, to speak of ventral accessorius roots or vago-accessorius roots, for the accessorius originates in closest connection with the anterior rudimentary ganglia behind that of the primary vagus. In Selachians it still forms part of the vagus which here innervates also the Musculus trapezius, one of the muscles in the branchial region which originate from the lateral plate and are innervated by the dorsal nerves of the head. The strong development of this muscle in higher Vertebrates causes the accessorius to split off from the vagus.

Hypoglossus homologous in Vertebrates? - Is the hypoglossus homologous in the different groups of Vertebrates? I think this question must be answered in the affirmative. Truly, its roots belong to segments bearing different numbers in different groups and still more do their relations to the skull vary. The first circumstance, however, as has been argued recently exhaustively by GOODRICH (1914), is no hindrance to considering structures as homologous. On the contrary, homology is quite independent from metameric segmentation and only secondarily can there be established a more or. less fixed relation between both, especially in forms with a restricted number of segments, and at the anterior end of the body, e.g. in the anterior segments of the head and their organs in Craniates. Were we to make homology dependent upon the number of the segments from which the organs arise, then there could be no question of an homology of the paired limbs among fishes and tetrapods, as the segments from which they arise are by no means the same and subject to considerable variation both in number and in situation. The same holds good e.g. for the pronephros. In Urodelan Amphibians the first pronephric funnel is found in the second segment behind the skull (FIELD, 1891, p. 261, GOODRICH, 1911, p. 112), i.e. in segment nr. 7 which in Selachians and Amniotes belongs to the skull. In the latter groups the first funnel is found as a rule in the third segment behind the skull, i.e. in segment about nr. 11 (FRORIEP, 1905, p. 119). Nobody will doubt the homology of these organs. The "segmental level" to which they belong may move backwards and forwards, may extend over a greater or over a lesser number of segments 
Plate 1. Diagrams

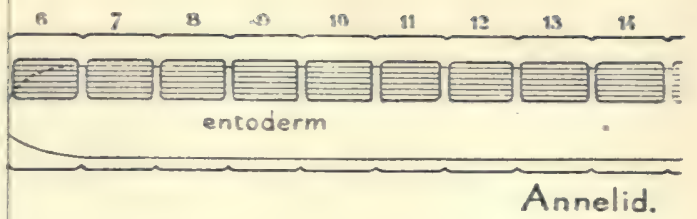

tes; the $\mathrm{b}$

Ac.

a.p.

can. med.

cr.

Amphioxus.

gr. $H$.

$m$.

m. tymp.

neur. $a$.

np.

$o c$.

occ. $a$.

olf.

pr. mand.

Sc.

$s p$.

stom.

$1,2,3$,

(According to $\mathrm{V}$ the scheme given Anura where the first myotome belo

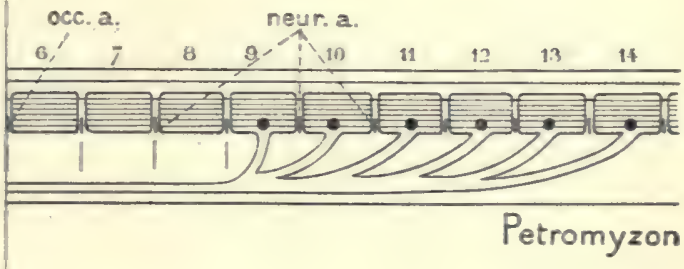

cr. occ. a.
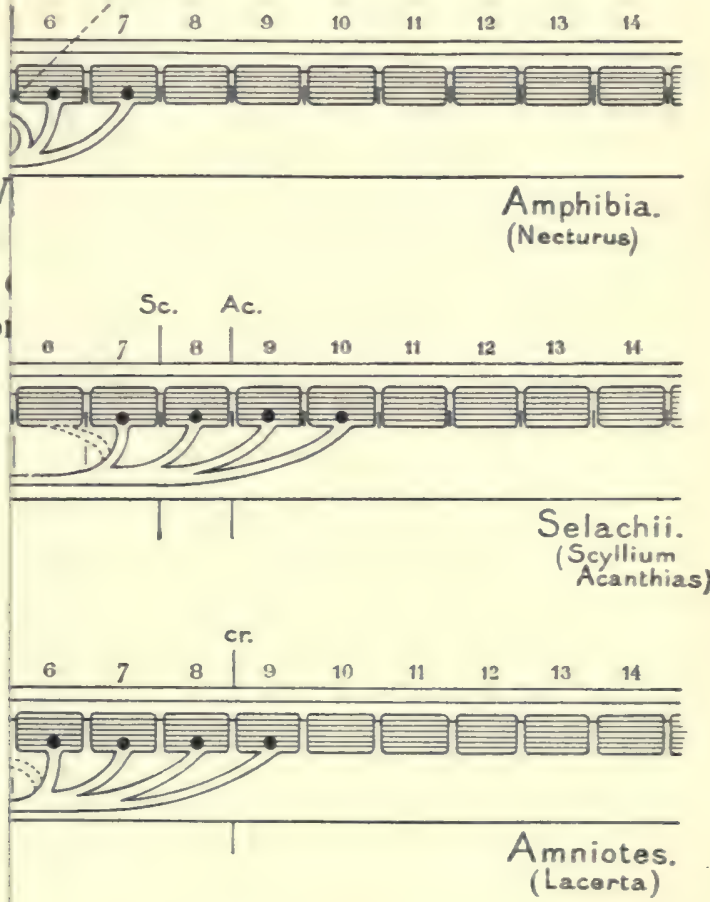

without the somites themselves moving in one direction or in the other, or fusing or being split up. We have to do simply with a displacement of differentiation and not of the cell material itself.

The hypoglossus-musculature and the hypoglossus itself, originating always from the anterior post-branchial somites and having a constant relation to the branchial basket, which also has not always the same extension, must therefore be considered as homologous throughout the whole series of Craniates, from the Cyclostomes on to the Amniotes. The length of the skull, however, being independent from the number of gill-slits, i.e. from the length of the branchial segmental level, the cranio-vertebral limit has no constant relation with the hypoglossus-roots. In the same way e.g. the paired and the unpaired fins in different groups of fishes may vary in their situation independently from each other. 


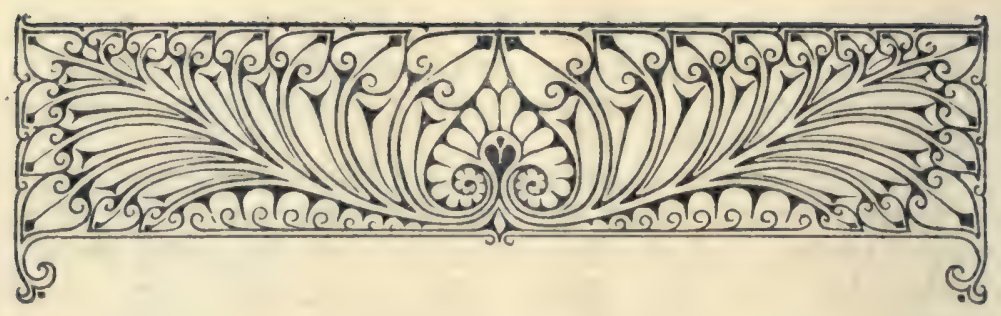

CHAPTER III.

\section{Gastrulation and earliest development.}

As the reader will have observed, the conclusions reached in the foregoing chapter are based for the greater part, not on investigations of the writer himself, who until now has worked more on Invertebrate than on Vertebrate development, but on researches made by numerous other anatomists and embryologists. Whenever I found that the views 1 was led to had been pronounced in some form or other by those who have worked on the subject themselves, independently from the theoretical considerations on which my conclusions were based, I have of course eagerly cited them. And since to my delight I found this to be often the case, the reader will perhaps have got the impression that my theory is for a great deal nothing but an anthology and compilation of thoughts more or less distinctly pronounced by others. I must therefore emphasize that the greater part of the numerous quotations have been gathered from the literature only after I had worked out the theory, though sometimes they have also indicated to me the direction in which to continue. In this last chapter, where the earliest stages of development will be dealt with, I now can give also a few of my own observations which, I believe, contribute a good deal to consolidate the foundations on which my theory rests. 
Fate of the animal pole. - In the first place they concern the problem as to what becomes of the animal pole of the egg. The importance of an answer to this question, to which until now only little attention has been paid, has already been emphasized in the foregoing chapter. In the first edition of my theory (1913, p. 685) I suggested that the cerebral plate is the homologon of the apical plate of the trochophora-larva, i e. the surface of the prostomium of the adult Annelid, and concluded that the accuracy of this supposition could be verified by determining the place of the animal pole of the egg in the foundation of the embryo. In Annelids the animal pole is found in the centre of the apical plate, in Vertebrates as a consequence it could be expected to be located on the cerebral plate. Closer examination, however, showed (1916, p. 499) that this conclusion in the present form could not be right since the apical plate or the surface of the prostomium of Annelids has to give rise not only to the cerebral plate but also to the ectodermal epiderm of the prostomium in Vertebrates. Originally this ectodermal material is situated only on the ventral side of the prostomium, the cerebral plate occupying the dorsal part, but after the latter has been folded in and has closed this ectoderm clothes the prostomium dorsally as well. Thus only part of the area corresponding to the apical plate can give rise in Vertebrates to the cerebral plate and this must be the dorsal half, in front of the former mouth which is now, as we have seen, the neuropore in Amphioxus, sometimes appearing as a provisional neuropore in Craniates. The other, ventral, half then gives rise to the epiderm of the prostomium, not only ventrally but soon after dorsally as well, over the brain. From this it follows that the animal pole may be expected to be found again not so much on the cerebral plate but either on or just in front of its anterior border, the so-called transverse headfold or brainfold. To state the general prevalence of such a relation between the animal pole arid the anterior end of the embryonic rudiment would not only be interesting in itself but it would be of great value also as a crucial test of the accuracy of our conclusions and the assumptions on which they rest.

Teleostean eggs. - The determinate cleavage and the regular arrangement of the cleavage-cells in Annelids renders it possible to trace the fate of the animal pole with great 
accuracy. In Vertebrates, however, the cleavage is much more indeterminate and the relatively equal size of the cleavage-cells and their great number, when differentiation sets in, very soon make it impossible to find out any longer the place of the animal pole, where the first two cleavagefurrows have intersected. Thus we must look for another landmark, or make it ourselves, to enable us to determine the place of the animal pole. The egg of the anchovy (Engraulis encrasicholus) presents certain advantages in this respect. It is characterized by its oblong shape in which it reminds one of the eggs of Cephalopods. It agrees
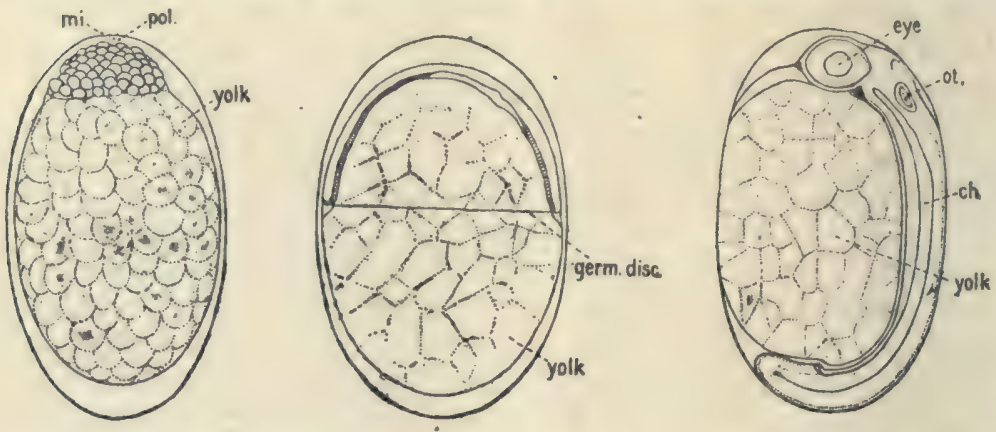

Fig. 33. Three stages of development of the egg of the anchovy (Engraulis encrasicholus), $b$ and $c$ after WENCKEBACH, 1886. $a$ morning of the 1 st day, $b$ morning of the 2 nd day, $c$ evening of the $2^{\text {nd }}$ day.

$C h$ notochord, $m$ micropyle, of auditory vesicle, pol polar bodies.

with the latter also in that after fertilization the animal pole, with the nucleus and an accumulation of protoplasm, is situated at one of the extremities of the unsegmented egg, right under a little opening in the chorion, the micropyle (WENCKEBACH, 1887). The first cleavages have not yet been studied, the spawning taking place very early in the morning or in the night. The development takes three days. The eggs fished in the morning of the first day of their development all show a little round germinal disc sitting like a little cap on the animal pole. Above the centre of this disc the micropyle and often also the polar bodies may be seen. In the course of the first day and night this germinal disc extends in a concentric way over the surface of the egg, the circular circumference during this process 
remaining parallel to itself and perpendicular to the main axis of the egg. Approaching the opposite pole it finally contracts to a ring, the so-called yolk-blastopore, nearly diametrically opposite the place where. at about the same time, the rudiment of the head is formed. This appears at one of the extremities of the oblong egg, while the blastopore closes at the opposite end. From this it is evident that the head and the fore brain are formed in the neighbourhood of the animal pole (DELSMAN, $1913 \mathrm{~b}$ ), as shown clearly by fig. 33 .

More conclusive evidence is yielded by pricking experiments. SUMNER (1904) operated on the egg of some NorthAmerican species of the Teleostean genus Fundulus. When he pricked in the centre of the still small germinal disc, which later appears to extend here also in a concentric way over the whole egg, the mark was found afterwards exactly in front of the anterior end of the rudiment of the embryo, just where we might expect it from our theoretical considerations.

Amphibian eggs. - Similar were the results of pricking experiments on several kinds of Amphibian eggs. EYCLESHYMER (1895, 1898), operating on the eggs of the axolotl and the American frog Acris, also rediscovered the mark either just in front of, or upon, or just behind the transverse brain-fold. I myself (1916) obtained the same result with the eggs of Rana fusca, Rana esculenta and Amblystoma tigrinum. The eggs when in the 4- or 8-celled stage, after having been freed from the surrounding jelly, were placed in a small glassscale with water and cotton wool and under slight microscopical enlargement were pricked with the point of the quill of a hedge-hog in such a way that only a very trifling wound was made. For with a somewhat more serious lesion a considerable extraovate protrudes at once, the size of which increases during the subsequent cleavage and which results in abnormal development. In working with the eggs of Amblystoma, where the protoplasm has a very fluid consisiency and at a little lesion already protrudes in large quantity, it appeared necessary first to sharpen the hedgehog quill on a smooth file. In this manner a very fine point could be obtained. The eggs were marked in the four- or eight-celled stage at the crossing-point of the first two cleavage-furrows and the mark was found again in all three kinds of eggs on, or just in front of, the transverse 
head-fold, opposite the place where the blastopore closes.

The results described above point to the general prevalence of a relation between the animal pole of the egg and the anterior border of the cerebral plate, as might be expected from my theory. For the sake of completeness I must mention here that HELEN DEAN KING (1902) in Bufo and EYCLESHYMER (1902) in Necturus concluded from similar pricking experiments that in these forms the animal pole is found some distance in front of the transverse brain-fold and that the latter lies even halfway. between the animal pole and the equator. However, it seems to me that the evidence yielded by these experimerts is not so conclusive as to preclude the possibility that on re-examination these forms also might turn out to conform with the rule found to be valid for such closely allied species.

Acrania and Craniata. - In the foregoing chapter we have pointed already to the fact that the relation of the animal pole to the cerebral plate in Amphioxus is a different one from that in Craniata. In Amphioxus, as shown by CERFONTAINE's (1906) figures, the place of the animal pole is often indicated until the gastrula-stage by the second polar body which remains fixed to the egg. Here also the closure of the blastopore occurs nearly opposite the animal pole, but a comparison of a gastrula where the polar body is still present, as represented in fig. 12 , with a somewhat older stage, with a neuropore but where the polar body has been lost (fig. 5), renders it quite evident that, if in the latter the polar body were still present, it would be found at a considerable distance in front of the neuropore. In both Acrania and Craniata the animal pole lies at the anterior end of the embryonic rudiment, in corresponding places with regard to the main axis of the embryo and to the place where the blastopore closes (with regard to the latter circumstance exception must be made for very yolkladen eggs). The neuropore in Craniata however lies terminally and close to the animal pole while in Acrania it is situated dorsally, a good distance away from the animal pole. This is one of the circumstances which, in the foregoing chapter, has induced me to conclude that the praechordal part of the brain of Craniates is not yet present in Acrania, In reality, however, I first made this conclusion from other reflections (1913) and only afterwards, by the 
pricking experiments, I found it to be confirmed in the way I had expected. A prediction from phylogenetic considerations was thus verified by experiment!

Gastrulation. - The pricking experiments proved to be a very valuable help also in studying the gastrulation in Chordates. Extremely divergent opinions have been held and are still held regarding this process. Hardly two authors agree on the questions as to what is the gastrulation in Vertebrates and as to how it is performed.

We shall first consider the question as to what we have to understand by the gastrulation and as to which stage is to be designated as the gastrula in Vertebrates. The gastrula in Invertebrates is the stage in which two layers may be distinguished, the primary ectoderm and the primary entoderm, which differ from each other in physiological, histological and topographical respect. Thus the gastrula is the two-layered stage while the blastula may be designated as the one-layered stage. While the latter is represented in a permanent state by Volvox (HUXLEY, 1877), the twolayered stage owes its phylogenetic significance to the comparison with the Coelenterates, first made by HUXLEY (1849) who again compared the two primary layers of the developing Vertebrate egg with the two layers of the Coelenterate, termed ecto- and entoderm by ALLMAN (1853, p. 368). The entoderm may originate by delamination or by invagination, both being forms of one and the same process of which I feel inclined to consider the latter as giving the purest expression of the phylogenetic process of which they are the recapitulation. Here the epithelial connection of the cells is preserved during the gastrulation process, whereas in the former it gets temporarily lost and is only reestablished afterwards. On this question, however, we shall not insist here.

Thus the gastrula-stage is a stage found in the development of all Metazoa - though sometimes modified into a form which makes it difficult to be recognized - in which part of the epithelium of the blastula has sunk away from the surface by a process of invagination or delamination. It now clothes as an internal epithelium the archenteron which opens to the exterior by the narrow blastopore. Many Vertebrate embryologists are accustomed to advocate their views on the gastrulation and the formation of the layers in Vertebrates - often forming their deductions after the in- 
vestigation of only one or a few forms - without ever considering the same processes in Invertebrates and evidently regarding the germinal layers as a mere histological conception.

Truly, there is often a histological or, better perhaps, a cytological difference between the cells of the primary entoderm and those of the primary ectoderm, resulting from a difference in the amount of yolk and well distinguished from the histological difference of the tissues to which they give rise in the adult form. However considerable this cytological difference may sometimes be, and however early in development it may become evident, it is yet only of secondary significance in determining what we have to call ento- and ectoderm. The first criterion in those early stages is, as the names indicate: what disappears from the surface by invagination or delamination and what remains on the outside? Though in several Evertebrates with determinate cleavage we can already determine in the blastula-stage with perfect certainty which cells will become ento- and which ectoderm (and even which mesoderm), we yet are not allowed by this circumstance to call the blastula a gastrula, as has been done by some authors in the case of Vertebrates. In the same way it is sometimes possible in the gastrula to irdicate in the two primary germlayers the cells which will become the mesoderm. This is neither a reason to deny that we have to deal in such a case with a gastrula. It is only the process of the topographical separation by which the germinal layers originate. No doubt the great cytological difference often prevailing between ecto- and entoderm has developed phylogenetically only after the topographical opposition, though in ontogeny it often becomes apparent before the latter.

This has often been lost sight of in determining what we have to understand by gastrulation and by ecto- and entoderm in Vertebrates. In the lower forms such as Acrania, Cyclostomata and Amphibians the process of invagination is easily recognized. The difference in the cytological character of ecto- and entoderm-cells is sometimes less, sometimes more, evident, though as a rule not excessive. In Amphibians it is more pronounced than in Amphioxus and, as a consequence, the process of invagination sometimes becomes less evident, especially in the more yolk-laden eggs. Nevertheless, by means of the less yolk-laden eggs of other 
species, the gastrulation in yolk-laden eggs may be easily traced back to the simple process in Amphioxus.

A peculiar feature of the gastrulation in Vertebrates which has greatly contributed to the prevailing confusion of opinions is the eccentric way in which the border of the blastopore contracts to the final narrow opening that passes into the neurenteric canal. We shall revert to this. Firstly we must consider the questions: which stage represents the gastrula, what must we understand by the gastrulation and what must we call ento- and ectoderm? If, to answer these questions, we look to the Invertebrates for a comparison, especially to the Protostomia, and keep in mind the considerations given above, our conclusion must be: the gastrulation is the sinking away from the surface of part of the cells and the contraction of the blastopore-border over them. The gastrula, as a consequence, is the stage where the blastopore-border has contracted to a very narrow, often slit-like, opening that passes into the neurenteric canal in the same way as in Protostomia it passes into the corresponding cardiac pore, as I (1917b, p. 1267) have proposed to call the passage from the ectodermal stomodaeum into the entodermal gut. The ectoderm then, is what lies at the surface in this stage and the primary entoderm what lies in the interior, lining the archenteric cavity.

Different views. - Several authors have come to other conclusions by paying more attention to the histological difference than to the topographical relation of the two primary germ-layers. The former, just as in Invertebrates, may become evident during the cleavage, long before gastrulation sets in. In the Amphibian egg e.g. we can distinguish the future ecto- and entoderm by the colour and the size of the cells in early cleavage-stages, though no sharp boundary between the two can be traced as yet. For Amphioxus the same holds good, though here the difference between the cells of both areas is less conspicuous and the transition from the one into the other equally gradual.

This circumstance, together with the above mentioned peculiarity of the eccentric blastopore-closure by which the gastrulation and the gastrula distinguish themselves from those of Invertebrates, has induced some authors to put forward the view that already in what we call the blastula-stage and during the cleavage of the egg the differentiation of ecto- and entoderm is completed and that, if we 
call the process, by which this is performed, the gastrulation, the latter has nothing to do with the invagination following soon afterwards. When the latter sets in, the separation of the two primary germinal layers has been already completed and the opposition between the two processes is, according to LWOFF's (1894) well-known conception, still more accentuated by the fact that not only the entoderm but also a part of the ectoderm would invaginate, forming especially the roof of the archenteron. To this latter view we shall revert in due time.

A somewhat similar view is held by BRACHET (1902) in his study of the gastrulation in the Amphibian egg. He too distinguishes a "clivage gastruléen", the gastrulation, i. e. the formation of the primary germ layers, being performed during cleavage. The limit between the entodermal and the ectodermal area, both still on the surface of the egg, represents a "blastopore virtuel" and, by the appearance of the true blastopore border, the "blastopore réel", gastrulation is only completed: "la formation des lèvres blastoporales, aussi bien de la lèvre dorsale que de la lèvre ventrale, ne constitue nullement le début de la gastrulation, mais en indique plutôt, a certains points de vue, l'achèvement'"(p.225). It must be added, however, that BRACHET denies an invagination of "animal" cells round the dorsal blastopore border, as postulated by LWOFF, but feels, on the other hand, more inclined to the concrescence-theory.

HUBRECHT (1890, p. 518) and KEIBEL (1889, p. 376, 1890), mainly from their studies on Amniote embryology, were led to advocate the idea of a gastrulation in two phases, a palingenetic one, to be considered as invagination, and a caenogenetic one, represented by a precocious delamination and a splitting of the entoderm-cells. Ontogenetically the latter occurs first and is followed by the former which in higher Amniotes becomes less and less evident. ASSHETON (1894), a few years later, asserts that in the development of the frog, and in that in Vertebrates in general, two processes must be distinguished: 1 . the formation of the archenteron by splitting of the endoderm cells, 2. the growing over of the blastopore border, which is no longer to be counted to the gastrulation. Since then HUBRECHT (1902, p. 67, 1905, p. 361), evidently influenced by. ASSHETON and BRACHET, has ceased to recognize the second or palingenetic phase as forming part of the gas- 
trulation which, accordingly, in Vertebrates is always performed by delamination (HUBRECHT, 1902, p. 71), though of course an exception must be made for Amphioxus. This, truly, might app zar a serious obstacle but it can easily be overcome by no longer recognizing "the holy Amphioxus" (ibid. p. 68) as the most primitive Chordate.

Thus HUBRECHT (1905), in agreement with ASSHETON and going still one step further than BRACHET, now adheres to the view: "Sobald der sogenannte Blastoporus auftritt, der als Rusconischer After eine Strecke weit um die Eioberfläche wandert, um schliesslich vielfach in den definitiven Anus verwandelt zu werden, haben wir es nicht mehr mit dem Gastrulationsprozess, sondern mit jenem der Bildung des metameren, bilateral-symmetrischen Rückens und der Chorda zu tun". This process in termed "notogenesis" by HUBRECHT.

Let us now first have a look at the process which in my opinion is the gastrulation of Vertebrates but which according to the above cited authors either indicates the end or comes only after the gastrulation and which is interpreted in entirely different ways. At the surface of the egg this stage is characterized by the formation and the contraction of the blastopore border. Though, as we shall see, hardly two authors agree in regard to the place where this border, e.g. in the Amphibian egg, first appears and how exactly it moves over the surface of the egg, there is now a fairly general agreement that the closure is performed in a rostro-caudad eccentric way and that the dorsal lip which is also the first to appear, in the shape of a crescent, moves much faster than the ventral lip which remains almost stationary. In Invertebrates RHUMBLER (1902) reached the conclusion that the entoderm cells particularly play an active rôle at the gastrulation process and in Vertebrates we get the same impression. Their tendency to sink into the interior of the egg is already evident in the blastula-stage, as is the case in Invertebrates where often the entoderm cells elongate considerably before invagination begins. It is also this phenomenon which has led BRACHET to his conception of a "clivage gastruléen." Proliferating and growing inwards under the border of the blastopore the entoderm-cells then form the archenteron, and since this process also goes on more actively under the dorsal than under the ventral lip, the part of the archenteron formed here is much more 
spacious than that formed under the ventral lip, known as the anal gut. The yolk-laden central entoderm cells, however, evidently play a very passive role; no doubt they contribute by continued divisions to the production of the smaller and more active entodermcells surrounding them, but for the rest they are sunk into the interior only by the action of these peripheral cells and, until the last moment before the closure of the blastopore, remain visible in the opening as the "yolk-plug." They are surrounded by the ring-shaped archenteron-incision which, as stated, is much deeper and wider anteriorly than under the posterior lip and is lined by smaller and more active entoderm-cells.

Theory of concrescence. - The peculiar mode of contraction of the blastopore border has given rise to divergent opinions. In the first place the concrescence-theory must be mentioned here. It was founded by HIS (1876) who was led to it especially by the study of the development of Teleosteans. According to him, the formative material for the embryo is situated originally as a ring round the border of the blastopore. The closure of the blastopore is performed by the concrescence of the lateral borders from the left and the right. This process occurs at the anteriormost point of the blastopore-border and the fusion proceeds from in front backwards. The two halves of the ring-shaped embryonal rudiment in this way unite in the middle of the anterior border of the blastopore and the embryo is formed in front of this point at the same rate as this moves backwards. This conception was extended to other Chordates, from Amphioxus onwards, where HATSCHEK (1881, p. 31, 32) assumed concrescence though recognizing that it can not be observed.

A phylogenetic interpretation has been given to this process by HUBRECHT (1902, p. 69) in the following way. In his well-known theory on the origin of metamerism SEDGWICK (1884) derives the Annelids from an Actinia-like ancestor in which the opposite borders of the mouth-slit would have coalesced, leaving an anterior and a posterior opening, the mouth and the anus of the worm, while the diverticula of the gut which are separated by the septa pass into the mesoderm segments. This same principle is applied now by LAMEERE (1891) and afterwards by HUBRECHT to the Vertebrates which by these authors are derived in the same way from an elongated Actinia. LAMEERE 
(1905) derives the medullary tube in the following way from the Actinian stomodaeum: “l'actinostome se ferme d'avant en arrière, de manière à se réduire au neuropore, l'actinopharynx se transformant en un tunnel, de sorte qu'en définitive, au lieu de communiquer avec l'extérieur sur toute sa longueur par une vaste ouverture, la cavité digestive est en rélation avec le dehors par un long canal qui lui est superposé". By HUBRECHT the concrescence of the borders of the mouth-slit is brought into relation more especially with the primitive streak found in yolk-laden eggs like those of the Amniotes and indicating the future dorsal side of the embryo. "Die noch mit dem Darm zusammenhängenden Cölomsäcke der Actinien sind wohl die Vorstufen der Somiten, der Nervenring auf der Mundscheibe jene des Rückenmarks, das Stomodaeum die Vorstufe der Chorda und der Mundschlitz der Actinie (nicht der Urmund oder Blastoporus!) jene der Primitivrinne, welche mit der Chorda (resp. Actinienstomodaeum) in so enger Beziehung steht" (HUBRECHT, 1905, p. 360).

Thus this process, according to HUBRECHT who designates it as "notogenesis", has nothing to do with the gastrulation and follows only after the latter which in Vertebrates is in his opinion always performed by delamination. "Bei Ichthyopsiden und Sauropsiden ist die Delamination, die Bildung zweier Keimblätter durch Abspaltung, leicht genug wahrzunehmen, ein Blastoporus fehlt aber und der schliesslich zum Porus sich zusammenziehende Umschlagsrand täuscht allerdings einen solchen vor, ist aber im Grunde der Sache nur der zeitweiliga Vertreter irgend eines Theiles des Stomodäalschlitzes, von welchem der allerhinterste Abschnitt auch bereits bei Actinien den Anus repräsentiert" (HUBRECHT, 1902, p. 72, 73). We are accordingly no longer allowed to speak of the blastopore but only of a "notopore" or, according to DE LANGE (1912, p. 326), of a "somatopore".

Objections. - I am sorry I must so often oppose the ideas and conclusions of embryologists who are my countrymen, especially those of the school of HUBRECHT, but here again I can only come to the conclusion that they are on the wrong track. The theory of SEDGWICK is by no means supported by the facts of embryology. In Annelids we never find a slit-like blastopore closing in the middle in such a way that its anterior end passes into the mouth and its posterior end into the anus. The latter condition 
especially is never fulfilled, the anus always arising as an independent perforation. Peripatus only could be adduced here as a support to SEDGWICK's view, the same form which also inspired SEDGWICK himself to his theory. If, however, the still insufficiently elucidated processes of the early development of Peripatus have been rightly interpreted by their investigators, we can only state that this form holds in this respect a quite exceptional position. BALFOUR's (1881, II, p. 308, 317) opinion seems to me much better founded; he views in the Pilidium the larval form which most nearly approaches the characters of the radiate larval prototype in the course of its conversion into a bilateral form, the latter being reached by the unequal elongation of the oral face, the aboral dome forming the praeoral lobe and the oral half growing out into the segmented trunk. Already in the Pilidium the archenteric pouch is directed backwards and evidently it has broken through in the trochophora, as we see in ontogeny. thus forming an anal aperture which has nothing to do with the mouth or the blastopore.

As regards the application of SEDGWICK's principle to Vertebrates, we must state in the first place that, unlike in Annelids, there is here no question of a relation of the mouth to the anterior end of the blastopore, while on the contrary the anus often shows certain connections to the posterior end. We shall see, however, at the end of this chapter that this connection is not of primary but of secondary nature.

Experiments. - The theory of concrescence has found several adherents but still more numerous opponents. According to this theory we might expect to find a little incision in the middle of the anterior blastopore-border, and a raphe together with a coherence of ecto- and entoderm at least along a little distance in front of it, as a consequence of the coherence of ecto- and entoderm at the blastoporeborder. Several authors have emphasized that of all this very little or nothing is to be recognized during the gastrulation, especially in the lower forms like Amphioxus or Amphibia. On the contrary, we get much more the impression that the blastopore closes by, truly eccentric but yet all-sided, contraction of its border over the yolk. Experiments made by MORGAN (1895), KOPSCH (1896) and SUMMER (1904) on fish eggs, the same objects which 
inspired HIS to his theory, yielded only negative results. MORGAN in cutting the germ-ring at one side near the rudiment of the embryo yet obtained a perfect embryo. According to him the embryo is "formed largely from material that has never been at the edge of the blastoderm" (p. 440). "At neither period is there sufficient material in the ring to form the sides of the embryo" (p. 463).

SUMNER (1904) pricked with a needle the yolk just under the germ-ring, close behind the embryonic rudiment. After His's theory this could be no hindrance to the further concrescence of the lateral borders beneath the puncture and we should expect to find the needle at the closure of the blastopore somewhere in the middle of the embryonic rudiment. This is not the case: the puncture is still found at the posterior end of the embryo, it has been pushed backwards by the overgrowing germ-disc.

Similar experiments led KOPSCH $(1896$, p. 117) to the same conclusion. The caudal swelling (Endknospe) is the growing centre from which the trunk of the embryo is formed and which indicates its hinder end. Only a very restricted part of the germ-ring contributes towards the formation of the embryo. The head, however, is not formed in this way, it originates in loco (p. 121).

The same conclusion is drawn by KATSCHENKO (1888, p. 456) from similar experiments on Selachians.

Spina bifida. - From a study of pathological forms HERTWIG (1892) concludes that the embryo is formed by concrescence. Eggs developing under somewhat abnormal conditions often show the phenomenon first discribed by RouX (1888) as Asyntaxia medullaris and afterwards studied by HERTWIG under the name Spina bifida. It is characterized by the peculiarity that the contraction of the blastopore border is retarded and the differentiation of the medullary plate, the mesoderm and the notochord begins while the blastopore is still wide open. The rudiments of these organs then appear to surround the blastopore and the yolk-cell mass as a ring. From this HERTWIG concluded that the whole embryo is formed in normal development by concrescence of the lateral borders of the blastopore, the transverse brainfold lying close in front of the place where the dorsal blastopore rim first appears, as had been asserted by Roux (cf. p. 177). Since the rudiment of the embryo of the frog has a length of some $180^{\circ}$ of the circumference 
of the egg, it follows that the blastopore has also originally nearly the same diameter, and in the figures given by ROUX (1888, p. 698) and HERTWIG (1892) for the eggs showing the Spina bifida-phenomenon, this indeed proves to be often the case, the blastopore-border extending round the equator of the egg. In normal eggs, however, the diameter of the blastopore, even if we measure the distance between the place where the dorsal rim first appears, and that where the ventral lip appears, never reaches $90^{\circ}$ (cf. fig. 35). As we shall see, the pricking experiments made by different authors and by myself leac to conclusions quite different from those of HERTWIG and are in no way to be reconciled with the latter. Thus, I think EYCLESHYMER (1895, p. 388) is quite right in questioning the entire evidence adduced from pathological forms and so probably is WILSON (1900) when he suggests that the spina bifida-phenomenon might have to be interpreted by a kind of rupture or rolling in of the dorsal lip. That something of the kind occurs is rendered probable by observations on eggs with a tendency to spina bifida which I shall mention further on (cf. p. 182).

As we shall see later, the study of the movement of the blastopore border with the aid of artificial marks proves, that there can be no question about the whole dorsal side of the embryo being formed by concrescencc since the greater part lies in front of the place where the dorsal border of the blastopore first appears. In Amphioxus also several authors (LWOFF, 1894, GOETTE, 1895, SOBOTTA, 1897, GARBOWSKI, 1898, KLAATSCH, 1898, MACBRIDE, 1898) have emphasized that no evidence in favour of the concrescence theory can be adduced from the observed facts.

I shall not deny that concrescence ever plays a tôle in the closure of the blastopore, especially not in the case of yolk-laden eggs, but this is only a secondary phenomenon to which no primary phylogenetic significance can be attributed. Also the formation of the primitive streak in Amniotes e. g. must be explained by concrescence of part of the blastopore border which has lost its original character.

Invagination of ectoderm cells? - LWOFF (1894) has been the principal advocate of another tendency in interpreting the process of gastrulation in Chordates. As stated above, the entoderm-cells, e. g. in Amphibians, are of unequal 
size. We may distinguish a central group of large, yolk-laden, inactive cells and a peripheral ring of smaller and more active entoderm-cells which, by their proliferation and moving inwards, contribute especially to the invagination and the formation of the archenteric cavity. The wall of this cavity in Amphioxus consists partly of the larger entoderm-cells and in Amphibians at the corresponding place it is thickened very much by the presence of the mass of yolk-cells which as a voluminous plug project into the archenteron, often filling it up for the greater part and leaving only a ring-shaped lumen. The ring of smaller entoderm-cells is best developed near the anterior border of the entoderm-area and as a consequence the archenteric cavity at the close of gastrulation is best developed under the dorsal blastopore border. This causes the plug of yolk-cells to lie not in the centre of the archenteric wall, opposite the blastopore, but more to the ventral side. The dorsal wall then is formed especially by the smaller entoderm-cells, which contain much less yolk and from which afterwards the notochord and the mesoderm are derived. In Amphioxus the difference in size of the dorsal and the ventral entoderm-cells is insignificant, in Amphibians it is already greater and it becomes very considerable in the yolk-laden eggs of Selachians and Amniotes. Here as a matter of fact the cells of the dorsal archenteron wall by their size and appearance stand much nearer to the ectoderm-cells than to the often enormous yolk-laden ventral entoderm-cells, and this will easily give rise to the impression that an invagination of ectoderm-cells has occurred round the dorsal border of the blastopore. These cells would have formed the dorsal archenteron wall from which the notochord and the mesoderm will be derived afterwards.

This view has been advocated indeed as early as 1879 by SCOTT and OSBORNE (1879) in their study on the development of the newt, and in 1882 and ' 83 O. HERTWIG came to similar conclusions. The latter identifies the pigmented animal half of the frogs egg with the ectoblast, the unpigmented vegetative half with the entoblast. During gastrulation the "animal" cells at the dorsal border invaginate in such a way that the median band of the archenteron roof, from which the notochord originates, is formed by them (p. 262-264). The mesoblast-bands are also derived from the animal cells (p. 263). 
As early as 1890 GOETTE (p. 6) had opposed this view. He emphasizes that at no time is there a definite limit between micro- and macromeres which shade quite - gradually into each other, so that it is impossible to say in the blastula-stage where the one begins and the other ends. New micromeres evidently are produced continuously by the macromeres. "Bei einigen Tieren gelingt es allerdings, die Grundlagen der Keimschichten und selbst viel späterer Bildungen schon von den jüngsten Entwickelungsstufen des Keimes an auseinanderzuhalten, aber nur deshalb, weil eine geringe Anzahl seiner Zellen oder eine ausserordentliche Grössenverschiedenheit derselben das Übergreifen aus einer Gruppe in die andre erschweren oder hindern. Für die Mehrzahl der Tiere - und dazu gehören auch die Wirbeltiere - trifft dies aber nicht zu. Ihre Embryonalzellen sind nicht von Anfang an in unveränderliche Gruppen getrennt, sondern es werden deren Grenzen und somjt das Schicksal der einzelnen Zellen in den Grenzgebieten erst durch den Verlauf der Entwickelung bestimmt.

Deshalb können in unsrem besonderen Fall die Mikro- und Makromeren der frühern Stufen keineswegs mit dem späteren Ektoderm und Entoderm oder irgend welchen andern best immte $\mathrm{Ke}$ im teilen identifiziert werden. Sie sind vielmehr nur der jeweilige Ausdruck eines fortschreitenden Entwicklungsvorganges, der Gastrulation, so dass die Mikromerenbildung allerdings nicht auf die Keimhöhlendecke beschränkt bleibt, sondern auf angrenzende Makromeren übergreift, anderseits aber doch, wie es namentlich an der Bauchseite deutlich hervortritt, von der Keimhöhlendecke aus successiv sich abwärts ausbreitet und so die sichtbare Zellenverschiebung, die Umwachsung und Einstülpung bedingt.

Dies ist also die Wirkung nicht von ursprünglich und spezifisch verschiedenen Zellen und Zellengruppen, sondern eines allgemeinen, im ganzen Keim sich abspielenden, aber bestimmt organisierten Vorgangs, dessen Fortschritt in der Ausbreitung der Micromerenbildung sichtbar wird.

Bei einer solchen Auffassung der Gastrulation kann von der wirklichen und vollkommenen Trennung der zwei primären Keimschichten, des Ectoderms und Entoderms natülich erst die Rede sein, nachdem der ganze Vorgang beendet ist." 
LWOFF's views. - Yet the conception so ably objected to by GOETTE has been formulated once more in a very definite way by LWOFF (1894), who asserts that at what hitherto was known as the gastrulation of Amphioxus not only the entoderm cells invaginate but also part of the ectoderm cells, forming the archenteron roof, the dorsal plate, from which the notochord and the mesoderm arise. Thus the resulting gastrula-like stage is by no means homologous to the gastrula of Invertebrates. In Amphioxus itself truly the difference between the cells of the supposed ectodermal part of the archenteron-wall and the endodermal part is not so very pronounced and LWOFF states that, had he been dealing with the development of Amphioxus alone, he would not have ventured to put forward the hypothesis of an ectodermal origin of the dorsal wall of the archenteron, but that, as he found in other Vertebrates that this dorsal wall was entirely used up in the formation of the notochord and mesoderm, and was in some cases apparently derived from ectoderm, he felt justified in applying this interpretation to the developmental processes of Amphioxus also.

Some have seen in LWOFF's article the inauguration of a period of better understanding of the early development of Vertebrates, others the beginning of an ever increasing confusion of thoughts. To the former e. g. HUBRECHT belongs. Among the latter may be cited MACBRIDE (1898, p. 597) who writes: "Such an attitude of mind seems to me the entire converse of the proper one to be adopted under these circumstances. Quite apart from the superior value to be attached to the significance of the processes in Amphioxus owing to the primitive nature of the adult, it is one of the best known facts of embryology that the presence of large quantities of yolk clogs and utterly distorts the developmental processes, and that we have to interpret the cases where much yolk is present in the light of those where little yolk is present, and not vice versâ. Moreover, a very simple and natural explanation can be suggested why in the Vertebrate embryo the yolk should be confined to the ventral wall of the archenteron. We know that many, if not most, developmental processes are ultimately reducible to processes of folding, such as would be rendered entirely impossible were the tissue in which they have to take place clogged with yolk. Hence in the higher Vertebrates the processes of invagination itself are profoundly modified; 
and, as explained in detail in the careful work of WILL (Zool. Jahrb. Vol. 6) (who in this confirms the ideas of BALFOUR, 1875), the bulky ventral wall of the archenteron can no longer be folded in, and the persistent invagination of the yolkless dorsal wall has the appearance of an independent ingrowth of the ectoderm".

The fact that in the blastula-stage the future ecto- and endoderm are often already recognizable by their cytological character may not induce us to deny that we have to deal with a blastula. Neither from the circumstance that in the gastrula-stage the future mesoderm cells may be already distinguished among the primary endoderm cells may we conclude that this stage is not a gastrula. As KORSCHELT and HEIDER (1910, p. 419-420) rightly remark concerning the gastrula of Amphioxus, the fact that the cells of the archenteron roof are a little (and how little!) smaller than those of the floor does not entitle us in the least to postulate a fundamental difference between Vertebrates and Invertebrates in the gastrulation. "Es liegen nicht genügende Ursachen vor, welche uns nöthigen würden, in diesen einfachen Einstülpungsprocess alles Mögliche hineinzugeheimnissen und Schwierigkeiten zu suchen, wo in Wirklichkeit keine vorliegen. Wenngleich der Gastrula von Amphioxus gewisse Eigenthümlichkeiten anhaften, so sind dieselben doch nicht so weitgehend, dass sie uns zwingen würden, an einer Homologie dieses zweischichtigen Keimes mit ähnlichen durch Invagination entstandenen Gastrulaformen vieler wirbellosen Thiere zu zweifeln."

HUBRECHT's speculations. - Yet particularly those authors who have occupied themselves principally with the embryology of higher Vertebrates, viz: the Amniotes, have tried again and again to take the gastrulation process in the latter as a base for their conception of the gastrulation of Vertebrates. Reading "the book of Nature upside down" (MACBRIDE, 1909) they tried to explain from this aspect the simpler processes in Anamnia and Acrania. Thus, as we have seen above, HUBRECHT and KEIBEL (1900) originally distinguished two phases in the gastrulation, one in which, by delamination, the endoderm is formed, and one in which the rudiment of the notochord and mesoderm invaginates. The latter process is the palingenetic one, the former is caenogenetic. As a consequence of the accumulation of 
yolk the latter process is replaced more and more by the former, especially in Amniotes.

Afterwards, however, the supposed invagination, giving rise to the rudiment of the mesoderm and the notochord, was no longer counted to the gastrulation by HUBRECHT (1902, p. 67), who in this respect supports LWOFF and consequently advocates the view that in Vertebrates the gastrulation is performed exclusively by delamination (1 c. p. 71). An exception must then of course be made for Amphioxus which can no longer be maintained as the prototype of Vertebrates. For all Craniates, however, according to HUBRECHT, the rule, cited above, holds: "Sobald der Blastoporus auftritt..... haben wir es nicht mehr mit dem Gastrulationsprocess, sondern mit jenem der Bildung des metameren, bilateral-symmetrischen Rückens und der Chorda zu thun" (HUBRECHT, 1905).

HUBRECHT (1890, p. 501) even thinks he can distinguish in Mammalia a posterior ectodermal from an anterior endodermal part of the archenteron-roof, the "protochordal wedge" and the "protochordal plate", and afterwards (1908) has tried to extend his conclusions reached in Mammalia to other groups of Vertebrates. In this MARCUS (1910, p. 171) and DE LANGE (1912) follow him in their researches on Amphibia where in the same way they distinguish an anterior endodermal from a posterior ectodermal part of the archenteron-roof. From the former, which according to HUBRECHT corresponds only to the praechordal part of the head (cf. p. 71), DE LANGE (1913, p. 250) derives the primarily unsegmented head mesoderm or "Urmesoderm" of the branchial region which, however, after the conclusions reached by us in the foregoing chapter, does not exist but probably represents nothing but the anterior part of the lateral plate. The notochord according to HUBRECHT is derived in its anterior part from the endodermal, in its posterior part from the ectodermal, cells of the archenteron-roof.

Finally TRIEPEL $(1914,1918$, p. 285) considers the archenteron-roof in Amphioxus to be composed of endodermal, that in Craniates, however, of ectodermal cells. Thus the notochord and the mesoderm have a different origin in the two and the Canalis neurentericus proves to be a "Konvergenzerscheinung".

Conception arising from my theory. - If the above survey of the conflicting views on the gastrulation and the forma- 
tion of the germinal layers in Vertebrates be not exhaustive, I think it will sufficiently illustrate the reigning confusion and uncertainty on these subjects. The cause of all this controversy is the absence of true insight as a consequence of the lack of a phylogenetic guiding thread connecting the Vertebrates with the lower groups of animals. Observations and facts alone can not help us here. My theory leads to the following conception which, I believe, also proves to be best in harmony with the facts.

In Invertebrates the blastopore, after having contracted to a narrow opening, passes into the cardiac pore as a consequence of the formation of the stomodaeum. In Vertebrates the blastopore, after having contracted to a narrow opening, passes into the neurenteric pore as a consequence of the formation of the medullary tube. In Invertebrates we call gastrula the stage in which the blastopore has contracted to a narrow opening but before the stomodaeum has formed. Thus in Vertebrates we must call gastrula the corresponding stage, being e.g. that of fig. 12 or Plate II, fig. 1. That which lies at the surface here is the primary ectoderm, that which lies in the interior is the primary endoderm, just as in Invertebrates. Thus the roof of the archenteric cavity consists of (primary) endoderm cells just as does the floor, as has been argued already by many investigators who have emphasized the fact that, e.g. in the frogs egg, the cytological character also of the cells of the roof renders it quite evident that they belong to the endoderm, not to the ectoderm.

Eccentric closure of the blastopore. - However, it cannot be denied that the gastrulation in Vertebrates exhibits certain peculiarities which call for an explanation. The blastopore does not close in a concentric way. This is the case also in Annelids. The originally wide blastopore here closes by fusion of the two opposite lateral borders, leaving open only the foremost end which passes into the cardiac pore. How the blastopore border while contracting moves over the surface of the egg is not easily to be determined in Vertebrates since we have no fixed landmark. Observing the living egg of a frog in its natural position, in which at first the animal pole is directed right upwards, gives no reliable results since during the gastrulation the centre of gravity of the egg changes its position and causes a rotation of the latter. In observing the egg in "Zwangslage" between two glass-plates and making e.g. photographs of it, for 
which purpose ZEISS has even constructed a special apparatus for HERTWIG $(1906$, p. 740$)$, we run the risk that the egg, being prevented from assuming its natural position of equilibrium, does not develop in a normal way.

Different view; on movement of blastopore border. - As a consequence, the opinions on the movement of the blastopore border have been very divergent. The oldest view is that the black hemisphere becomes the dorsal part of the embryo, so that the egg axis lies dorsoventrally. As is well known, PFLüGER (1883) first pointed out that the blastopore moves forward over more than $90^{\circ}$ from the point where the dorsal lip first appears, from which PFLüGER concluded that the foundation of the nervous system originates on the white hemisphere. He added however: "Um nicht missverstanden zu werden, möchte ich hervorheben, wie ich keineswegs bewiesen zu haben glaube, dass die ganze Uranlage des centralen Nervensystems ein Deı ivat der weissen Hemisphäre des Eies sei .... so bleibt es denkbar, dass die vorderen Teile der Markanlage, die dem Gehirn und möglicherw eise sogar dem oberen Teil des Rückenmarks entsprechen, sich in der schwarzen Hemisphäre bilden".

The controversy between ROUX (1888) and SCHULTZE (1887) is well known. The former concluded that the dorsal lip of the blastopore moves over the white half of the egg through no less than $170^{\circ}-180^{\circ}$, so that the medullary plate consequently originates entirely on the white half. SCHULTZE, on the other hand, declared all displacement of the blastopore border to be imaginary and ascribed it to the rotation of the egg, so that it would be just on the black hemisphere that the medullary canal originates (cf. fig 34). They agreed, erroneously, as we shall see later, only on the point that tise egg axis afterwards has a dorsoventral direction. The place where the dorsal lip is first noticed is according to RouX the rostial, according to SCHULTZE the caudal, end of the einbryo. HERTWIG (1892) and BERTACCHINI (1899) took the side of ROUX, LWOFF (1894) that of SCHULTZE. Among later investigators, however, the opinion begins to gain ground that neither of the two conceptions mentioned is correct but that the embryo is formed partly on the white, partly on the black, hemisphere, and that consequently the egg axis is not perpendicular to the longitudinal axis of the embryo but has more or less the same direction. This view was first put forth by ASSHETON (1894) and EYCLESHYMER 
(1895) and after them by KOPSCH (1900), according to whom the egg axis lies in the embryo from a ventral point in front to a dorsal point behind. If SCHULTZE was of opinion that the formative material of the embryo lies entirely in front of the dorsal blastopore border, and if RouX, HERTWIG, BERTACCHINI that at first it surrounds the blastopore as a ring, then according to $\mathrm{KOPSCH}$ there is some truth in both statements, the rudiment of the head being found in front of the newly formed blastopore lip, the contiguous rudiment of the dorsal parts of the trunk lying round the
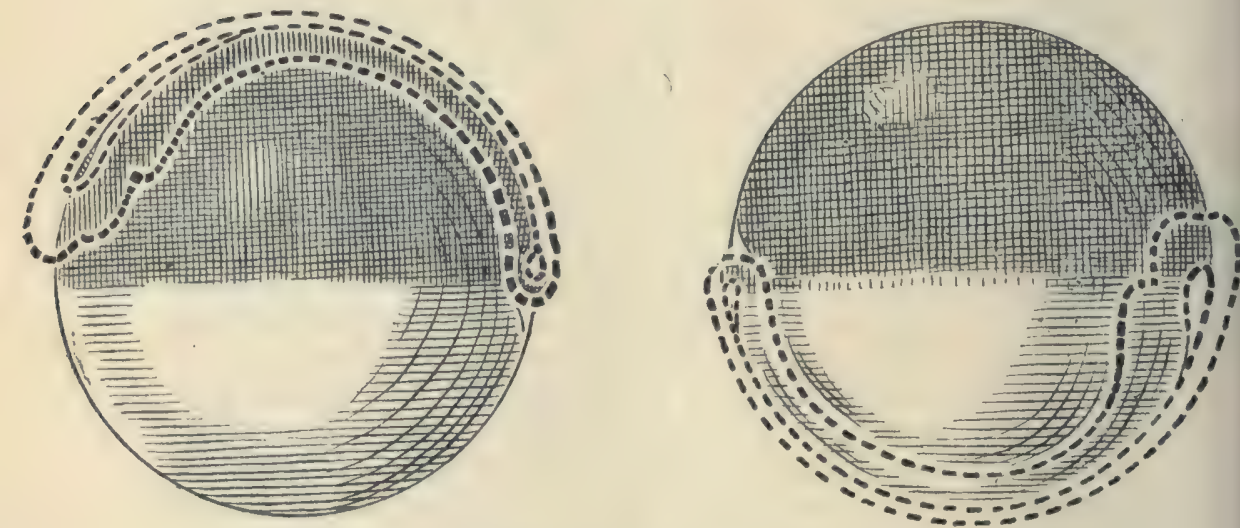

Fig. 34. Situation of the medullary plate in the frog egg according to SCHultze (a) and Roux (b). after Roux, 1888, p. 698.

blastopore border in the semilunar stage of the latter. This last view is more and more accepted by later investigators (H. V. WILSON, 1900, 1902, KING, 1902, IKEDA, 1902) and also my experiments confirm it entirely, as will be shown. The view is gaining ground that the principal axis of the egg and the longitudinal axis of the embryo more or less coincide and that consequently, when the first cleavage of the frog egg separates the left and right halves of the embryo (which is so in the majority of cases, see note on p. 181), the second cleavage will not separate rostral and caudal but dorsal and ventral parts of the embryo. Meanwhile opinions still differ widely; thus BRACHET '(1902. 1905) has recently supported the view that the transverse head fold originates exactly in front of the spot where the 
blastoporic rim first appears, i. e. about the egg equator (RouX's view), that consequently the embryo will lie entirely on the lowe $i$ hemisphere of the egg but that the caudal end does not, as RouX thinks, extend on the other side as far as the equator but no further than just beyond the vegetative pole. The egg axis " $n$ 'est en relation avec aucun des axes principaux de l'embryon" (1905).

As to the place where the dorsal lip first appears and as to the extent of its progression over the surface of the egg, opinions are also as yet rather divergent. PFLüGER and RouX see the dorsal blastopore lip originate on the egg equator, PFLürER allows it to travel through a distance of a little over $90^{\circ}$, ROUX of $170-180^{\circ}$, MORGAN and UME TSUDA (1894) sre it originate $\pm 30^{\circ}$ below the equator and travel through $120^{\circ}$. ASSHETON (1894) and KOPSCH (1900), with whom IKEDA (1902) in the main agrees, also let it appear a little below the equator (according to $\mathrm{KOPSCH}$ on an average $25^{\circ}$ ) and move through a distance of $60-70^{\circ}$ (ASSHETON) to $75^{\circ}$ (KOPSCH). BERTACCHINI (1899) again quite agrees with RouX and estimates the distance travelled through a little under $180^{\circ}$. KING (1902) finds in Bufo a displacement of $140^{\circ}$ from a point below the equator. EYCLESHYMER gives no definite data on this point, his opinon would probably be in fair accordance with the results obtained by me.

Conclusions from pricking experiments. - By carefully watching the marked eggs and by drawing them repeatedly, the above questions can of course be answered with cer. tainty. The animal pole then furnishes the landmark which most of the above cited authors did not dispose of ${ }^{1}$ ). I have investigated in this way the eggs of Rana fusca, Rana esculenta and Amblystoma tigrinum. For both the former species I have published my results in two preliminary papers (1916). Those for Rana esculenta, however, need certain corrections since further investigations have taught me that part of the eggs on whose experiments my conclusions were based did not develop in a normal way and showed a certain tendency to the "spina bifida" phenomenon.

For the sake of convenience I begin with Rana fusca for which my results are, most complete and reliable and which, moreover, holds in a certain way an intermediate position

1) For the question whether the animal pole is indeed a perfectly fixed point I refer to a remark made on p. 52 of the foregoing chapter. For Rana fusca, at any rate, this may be assumed. 
between the other forms as regards the closure of the blastopore. The results of my experiments for Rana fusca have been combined in a single figure, composed from many other figures, two drawings being each time superposed and held up to the light, the details of one figure being in this way transferred to the other.

The eggs marked at the animal pole teach us what follows (cf. fig. 35):

The dorsal blastoporic lip is formed very little below the equator (much less than $25^{\circ}$ or $30^{\circ}$, see above) and
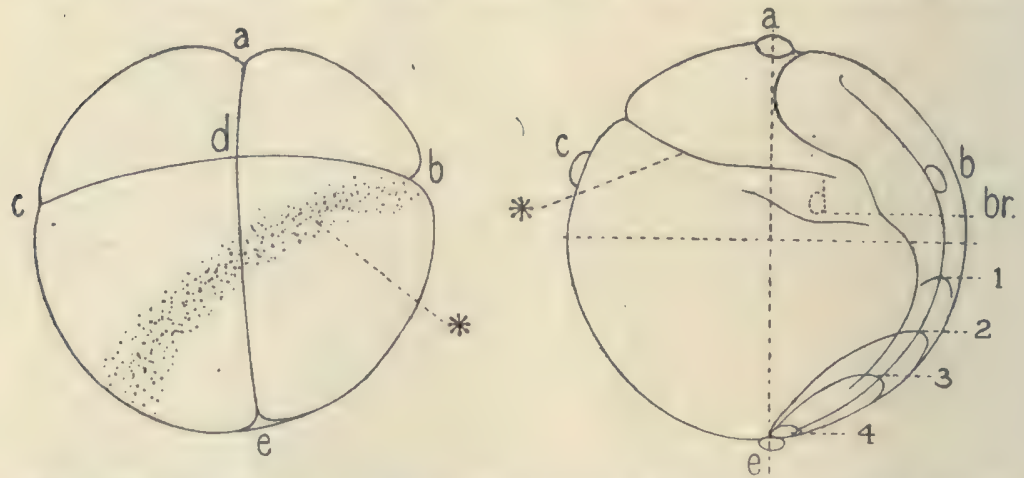

Fig. 35. Results of pricking experiments on the frog egg (Rana fusca). $a$ eight-celled stage seen from the side, $b$ stage with medullary plate.

$a, b, c, d, e$, situation of the marks at the points of intersection of the first three cleavage furrows.

$1,2,3,4$, anterior border of the blastopore in successive stages of contraction.

br. rudiment of the gills,

* (fig. a) limit of black and white area,

* (fig. b) edge of the so-called sense-plate.

immediately begins to grow over towards the vegetative side. The ventral blastopore lip is formed about diametrically opposite the animal pole, slightly more to the dorsal side. This border practically does not move, so that the closing of the blastopore finally takes place at this same point. From this it follows that the dorsal blastopore lip progresses through a little less than $90^{\circ}$ (estimated not under $80^{\circ}$ ).

When the blastopore has finally narrowed to a short slit and the medullary folds arise, this slit consequently still lies almost diametrically opposite the animal pole which is situated exactly in front of the cerebral plate. The distance 
between the two is, when measured dorsally, perhaps somewhat shorter than when measured ventrally, but the difference is very insignificant and we may safely say that the length of the dorsal embryonic rudiment is $180^{\circ}$. Although in yolk-laden eggs this arch has a somewhat smaller length, still the above relation occurs regularly in various animal groups. Besides in Amphibia, we find it e g. in Teleostei; especially in those with pelagic eggs not too yolk-laden, it is generally observed that the closure of the blastopore takes place almost diametrically opposite the animal pole, i. e. the point of the nose, so that here also the embryo extends over almost $180^{\circ}$ between the animal and vegetative poles. Also in the anchovy, as we have seen above, this is the case. Far from a fundamental difference, as MORGAN (1894) thought, we find a fundamental agreement in the position of the embryo in Amphibian and Teleostean eggs. Also for Amphioxus the same holds good. CERFONTAINE's (1906) pictures of gastrulas of Amphioxus with the polar body still attached to them show that here also the blastopore after having contracted lies approximately diametrically opposite the animal pole, while the dorsal blastopore lip is as well furmed here near the egg equator.

We clearly see from fig. $35 b$ that the place of the first appearance of the blastoporic rim lies in about the middle of the length of the embryo, that consequently the embryo is formed half on the black, half on the white surface of the egg after the latter has been overgrown by the dorsal blastopore lip, and that the main axis of the egg coincides with the longitudinal axis of the embryo, so that the second cleavage of the egg in so-called typical development $\left(\right.$ ROUX $\left.^{1}\right)$ separates the dorsal and ventral halves. Since in the 4 - or 8-celled stage the distance from the animal to the vegetative pole (upper and lower crossing point of the

1) In the fertilised but still unsegmented frog egg a bilateral symmetry is soon to be observed, caused by the white - in the form of the so-called "grey field" (ROUX) - extending on one side, the dorsal one, higher up towards the egg equator than on the other side. In the majority of cases the first cleavage plane coincides with the plane of symmetry of the unsegmented egg and the symmetryplane of the embryo is then in its turn the same as these two. This way of development was called "typical" by Roux. It has been shown (BRACHET, 1905 a, DELSMAN, 1916) that in such eggs where the first cleavage plane does not coincide with the symmetry plane of the egg, the symmetry-plane of the embryo coincides with that of the unsegmented egg, not with the first cleavage-plane. 
first two cleavage planes) is a little shorter when measured dorsally than when measured ventrally (the two ventral cells in stage 4 being slightly larger than the two dorsal ones), it follows that the closure of the blastopore takes place exactly at the vegetative pole.

If now we consider the eggs marked at $b, c$, or $d$, which are the points of intersection on the third or equatorial cleavage furrow, we find that these marks during the gastrulation process remain almost stationary. Their distance from the mark $a$ at the animal pole certainly increases, but the difference is only very slight. When the dorsal blastopore lip is formed, the mark at $b$ is found lying about just as far in front of it as in the eight-celled stage the point $b$ is distant from the egg equator. The mort the blastopore lip is then shifted backwards the greater the distance becomes. Finally the mark is found on the medullary plite exactly behind the cerebral plate. From this it is quite evident that there can be no question about the whole rudiment of the embryo being formed by concrescense of the lateral borders of the blastopore, since the greater part originates in situ in front of the dorsal rim. The rudiment of the cerebral plate is situated from the beginning between the marks $a$ and $b$. That there would be an invagination of animal cells round the dorsal blastopore border to invest the archenteron roof is rendered improbable by other pricking experiments in which marks were made slightly in front of the crescentic border as it was just appearing. In some cases truly I found this mark to approach and to reach the blastopore border, but soon the eggs on which I worked, which were of Rana esculenta, proved to develop abnormally and to show a tendency to "spina bifida," i e. a retarded closure of the blastopore. In these eggs the dorsal blastopore border, instead of moving backwards, moves forward and in this case an invagination of cells round it seems to take place. In normally developing. eggs, however, a mark, however closely it lies in front of the dorsal blastopore border, does not approach the latter, which shows that there occurs no invagination of cells from the surface, as postulated by LWOFF.

The mark at $c$ is found again some distance before the anterior end of the cerebral plate, in front of (properly speaking behind) the border of the so-called sense-plate which lies round the front part of the cerebral plate in 
the shape of a crescent and the border of which (fig. $35 b^{*}$ ), as further development shows, indicates the limit of the head as far as the gill-slits. On this plate two suckers, the mouth and the two olfactory grooves are afterwards found. Further experiments have shown me, that the mark $c$ is generally found a little distance further behind the fold which represents the border of the sense-plate than indicat.d in fig. 2 of my publication of 1916 and that as a consequence we probably can not think of a closer relation between the so-called sense-plate and the apical p'ate of a trochophore as alluded to at that time (p. 9).

The mark $d$ also does not alter its position in a marked way. It is found again in the region where afterwards the gill-slits will break through.

The above results were published by me in 1916. Since then 1 have repeated and completed these experiments and, by using specially sharpened hedgehog quills, have now succeeded in making marks not only at the animal but also at the vegetative pole, i. e. at the opposite point of intersection of the first two cleavage-furrows, where the yolk accumulated here renders marking more difficult since a little lesion causes the yolk to protrude in great quantity. During further development, during cleavage and gastrulation, the mark at the vegetative pole did not change in the least its position with regard to the one at the animal pole. After the blastopore border had appeared it was found just in front of the ventral lip within the white area and finally it was lying at the place where the blastopore closes to a short slit, still right opposite the mark at the animal pole. This shows that the white endodermic area does not change its position at all while the blastopore border is overgrowing it and while at its periphery the smaller endoderm cells are proliferating and by sinking in and splitting are forming the archenteric cavity

The results obtained with Rana esculenta and Amblystoma tigrinum agree on the whole with those on Rana fusca. The closure of the blastopore, however, does not occur exactly opposite the animal pole as in the latter form. In Rana esculenta this point lies slightly more to the dorsal side, the rudiment of the embryo as a consequence covering less than $180^{\circ}$ of the circumference of the egg, whereas in Amblystoma it is situated somewhat more to the ventral side, the base of the embryo extending here dorsally over 
more than $180^{\circ}$. The place where the dorsal blastopore lip first appears is in all three cases nearly the same, being situated a little beneath the equator of the egg. The same holds good for the place where the crescent-shaped blastopore border closes to a ring, i. e. where the ventral lip first appears. In all three cases this is close to the vegetative pole.

In Rana esculenta, however, we see the ventral lip moving forward more actively than in Rana fusca, which causes the blastopore to close at a place situated more to the dorsal side than in Rana fusca I must rectify here a statement made with some reserve in a former paper (1916). I gave a figure (fig. 8, p. 8) in which tlee border of the blastopore, at the moment it has just closed to a ring, was provisionnally indicated with a dotted line, since I had not observed it in the egg figured there but had transferred it into this figure from other eggs. Afterwards, however, repeating my experiments I could state that the latter eggs were such that had been developing abnormally and showed a tendency to the "spina bifida" phenomenon. In normal eggs the blastopore has never so large a diameter which seems to be caused by a bulging out of the yolk-plug and a temporary forward instead of backward movement of the dorsal blastopore lip, as mentioned above. Thus this dotted line must be removed from the figure. Further experiments have also given me the impression that the movement of the ventral lip has been shown a little too large in this figure and that in reality it does not move faster than the dorsal lip. Also the dorsal movement of the whole white area, to which I thought it inevitable to conclude from the observed facts, was not confirmed by the observation of eggs marked at both the vegetative and the animal pole. As far as I could state both marks remained exactly opposite each other during the cleavage and the gastrulation, just as in Rana fusca.

Thus the difference between Rana fusca and Rana esculenta appears to be much less than I first concluded from experiments on eggs, part of which afterwards proved to develop abnormally. In Rana esculenta the ventral lip moves only a little more actively than in Rana fusca, and also in longitudinal sections the ventral lip appears to be a little more strongly developed than in the latter form.

The reverse case is found in Amblystoma. Here the dorsal blastopore lip, after its first appearance a little 
beneath the equator, moves backwards over a considerable distance, while it becomes deeper only quite gradually and extends laterally into a crescent. When it finally closes to a ring it has certainly already travelled over a distance of some $60^{\circ}$. The crescent and the ring into which it passes have here only a very small diameter which I do not believe to be more than $30^{\circ}$. During its contraction the dorsal lip moves considerably faster than the ventral one and after the blastopore has reached the slit-like stage the backward movement of this slit with regard to the animal pole still continues. Thus the dorsal rudiment of the embryo covers here considerably more than $180^{\circ}$, the ventral side being much shorter.

Interpretation of the results. - What conclusions may now be drawn from the facts recorded and how are these to be interpreted? In the first place we may state that, since more than half of the base of the embryo is situated in front of the piace where the corsal blastopore lip first appears, there can be no question about the whole embryo being formed by concrescence of the laterai blastopore borders. For the assumption that concrescence would play a more or less important rôle in the closure of the blastopore which gives rise to the posterior lesser half of the embryo, there is not the slightest evidence. It is quite true that in the amphibian egg a fıne median line is often seen running from the blastopore forward, which strongly suggests a concrescence suture. Only, as ROBINSON and ASSHETON (1891) remark, this line continues to the foreend of the cerebral plate where the blastopore has never been! I shall now propose the explanation which seems to me to follow from my theory. Two circumstances give a peculiar character to the gastrulation of Vertebrates:

1. the white area indicating the future endoderm is situated not opposite the animal pole, as we have good reason to assume must have been the case in radiate ancestors, but shifted more to the future dorsal side,

2. the contraction of the blastopore border occurs in a caudad eccentric direction, so that the closure finally takes place nearly opposite the animal pole.

Comparison with Annelids. - As regards the former phenomenon, the displacement of the white endoderm area is fairly considerable, as shown e.g. by fig. 35 . This same displacement of the endoderm area, here to the ventral 
side, is seen to occur during the development of Annelids. The primary ectoderm is represented here by the three quartets of micromeres, the primary endoderm by the remaining quartet of macromeses which, however, merit this name in yolk-laden eggs only Let us first leave the case of yolk-richness out of consideration and consider the development of an egg with less or hardly any yolk, in which the macromeres scarcely, if at all, surpa-s the micromeres in size.

While the endoderm which remains after the production of the three quartets of ectomeres lies originally diametrically opposite the animal pole, we find the mouth, which is directly to be traced back to the blastopore, in the trochophora lying on the future ventral side, just under the prototroch which forms the border of the apical plate. As 1 have discussed in my article on the development of Scoloplos armiger (1916 a), the displacement is to be ascribed to three factors.

a

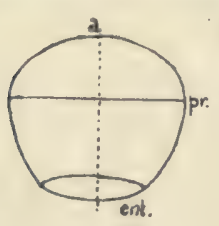

b

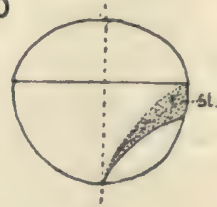

C

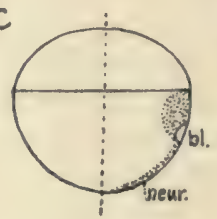

d

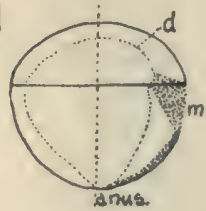

e
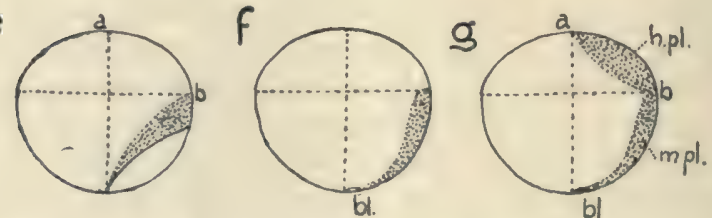

Fig. 36. Diagrammatic representation of the behaviour of the blastopore, $a, b, c, d$ in polychaetous Annelids, $e, f, g$ in Chordates.

$b l$. blastopore, $d$ gut, ent. entoderm, h. pl. cerebral plate, $m$. mouth, $m p l$. medullary plate, neur. neurotroch, $p r$. prototroch.

In the first place we observe a moving of the whole endoderm area to the ventral side (fig. $36 b$ ), a result of the active multiplication and extension of the ectoderm cells at the rear side, i.e. mainly the $d$-quadrant of the egg, whereas the cells of the anterior side, the $b$-quadrant, are backward in development. This causes the endodermarea to move to the ventral side to such an extent that 
no longer its centre but its hind border is found opposite the animal pole. In this region the anus is afterwards formed.

Secondly the blastopore does not close concentrically but eccentrically in a forward direction , fig. $36 \mathrm{c}$ ), be it with or without concrescence of the lateral borders. Evidently concrescence here occurs as a rule and the neurotroch arises at the suture where left and right blastopore borders have met.

In the third place the foundation of the stomodaeum no longer surrounds here the blastopore as a ring of uniform breadth, as in Protaxonia, but lies more in the form of a crescent round the anterior border, for of the third quartet it is only the cells of the anterior two quadrants, $3 a$ and $3 b$, and of the second quartet only $2 a, 2 b$ and $2 c$ which participate in the formation of the stomodaeum. After the sinking in of this crescentic rudiment to form the stomodaeum-tube which arises outside the final narrowed blastopore, the
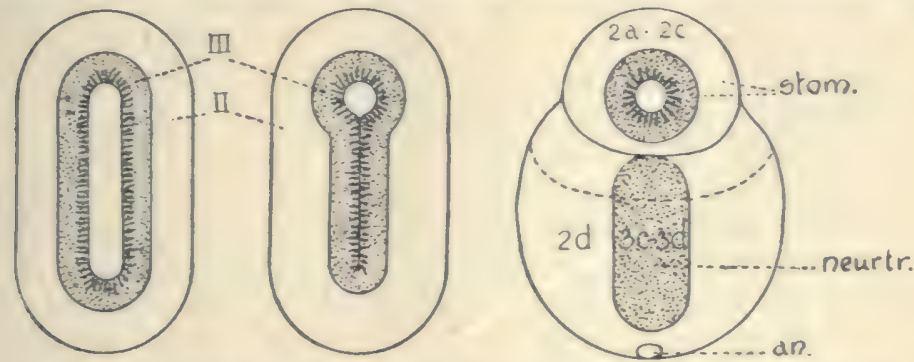

Fig. 37. Representation of the fate of the blastopore in Annelids. Dotted are the cells of the 3 rd quartet of micromeres (III), surrounding the blastopore, blank those of the $2^{\text {nd }}$ quartet (II).

an. anus, neur. tr. neurotroch, stom. stomodaeum.

mouth comes to lie just underneath the prototroch (fig $36 d$ ). The cells surrounding the posterior half of the original wide blastopore border, being the descendents of $3 c$ an $3 d$, form together the neurotroch, a ciliated band of vacuolized cells along the median ventral line. In the radially symmetrical ancestors of the Annelids, where no doubt the stomodaeum had a radial origin, these cells probably have participated at its formation. We can imagine that this original stomodaeum has partly closed by coalescence of its lateral borders and that in this way the neurotroch has originated (fig 37 ). 
Displacement of the endoderm-area. - We shall see now what we find of these phenomena in the frog egg, and take as an example the egg of Rana fusca. At once it will be evident that the first of the three above-mentioned processes, the wandering of the endoderm area to the ventral (in Chordates to the dorsal) side, is here pesformed very precociously, immediately after fertilization, and consequently is already finished in the unsegmented fertilized egg. Thus we find, as is shown by fig. 35 , that the white area here does not lie diametrically opposite the animal pole but much more to the future dorsal side which corresponds to the ventral side of the Annelid. The boundary between the ecto- and endoderm areas probably runs parallel to the demarcation of the darker and lighter areas of the egg, as may also be concluded from the place where afterwards the dorsal and ventral borders of the blastopore appear (fig. 35). The same displacement of the endoderm area which in the Annelid occurs during development is evidently already completed in Chordates in the unsegmented egg.

However, in Annelids also we often find such a structure of the egg, as may be concluded from the relative size of the cleavage cells. In my article on the development of Scoloplos (1916) I have tried to show that among the eggs of polychaetous Annelids three types are to be distinguished. In the first place we have the small, poorly yolked, eggs of Polygordius, Hydroides etc., in which the cleavage results in a very equal coeloblastula (fig. $38 a$ ). Secondly we have the larger eggs of other species in which two types of polarity may be very early recognized, which exert their influence on the very determinate cleavage. In the first place we can distinguish the polar or radially symmetrical polarity, manifesting itself in the accumulation of yolk at the vegetative pole which again causes the endoderm cells to be much larger than the cells of the three quartets of ectomeres, so that, in fact, they deserve the name macromeres. In the second place the bilateral polarity which manifests itself in the cells of the rear side ( $d$-side) being from the beginning much larger than the corresponding cells at the anterior side ( $b$-side), so that the entoderm area from the beginning does not lie diametrically opposite the animal pole. The diagrams of fig $38 b$ and $c$ may serve to illustrate this. As a rule we see in the eggs with a larger diameter both kinds of polarity exerting their influence on the cleavage at the 
same time, but in one case the first predominates and in the other the second prevails. As an example of the prevalence of polar polarity, I mentioned Nereis where the macromeres (endoderm) are particularly large in comparison with the ectomeres which lie over them in the form of a little cap, while the bilateral polarity is only slightly manifested, the cells of the rear side not being much larger than those of the anterior side. On the other hand, this last condition prevails very strongly in Scoloplos which accordingly can serve as an example of the predominance of the bilateral polarity. The cell $2 d$ especially is of extraordinary size, while the endoderm cells are not at all remarkable for

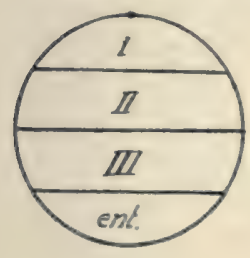

a.

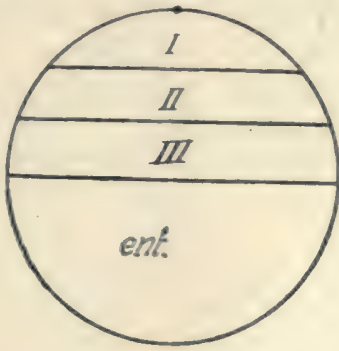

b.

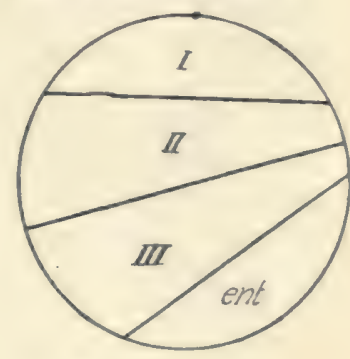

c.

Fig. 38. Diagrammatic representation of the 3 types of the eggs of polychaetous Annelids

I, II, III, 18t, 2nd, and 3 rd quartet of ectomeres.

ent. entomeres

$\boldsymbol{a}$. minute egg, $\boldsymbol{b}$. egg with pronounced radial polarity, $c$.egg with pronounced bilateral polarity.

The animal pole is indicated by a black dot.

special bulk. Thus the endoderm area, as shown by the diagram $c$ of fig. 38 , is displaced here to the ventral side from the beginning, as is found in the same way in the egg of the frog where, however, the cleavage process is much more independent of the constitution of the egg. In this way, I believe, is the dorsad displacement of the endoderm area in the egg of lower Vertebrates to be explained 1 ).

$\left.{ }^{1}\right)$ Thus the Amphibian egg in its structure corresponds to the Scoloplos-type among Annelids. In a former article $(19 / 6 \mathrm{~b})$ I was led to compare the egg of Rana esculenta to the type of Nereis. This has not been confirmed hy further investigations which showed that there is no such greal difference between the eggs of Rana fusca and esculenta as I at first concluded from the study of more or less abnormally developing eggs of the latter species. 
Interpretation of the eccentric closure of the blastopore. The second process mentioned above, the rostrad-eccentrical c osure of the blastopore, is not found in the frog egg; on the contrary, the closure proceeds caudad-eccentrically. I see in this caudad-eccentrical closure a result of the interference of the contraction of the blastuporic border with a backward movement of the blastopore, following directly from my theory on the homology of stomodaeum and epichordal neural tube in Annelids and Vertebrates. As a result of the strong elongation, which we must assume the stomodaeum of Annelids undergoes in order to be transformed into the medullary tube of the Vertebrates, the entrance to the stomach, the cardiac pore, into which the blastopore passes, must move backwards over the whole length of the body - it moves still further, as we shall see (formation of the tail) - to tecome the neurenteric canal (also representing the former blastopore). This backward movement is performed in Chordates in anticipation of $t$ e formation of a tube and during the contraction of the blastopore border, thus interfering with the gastrulation process. In this way the final, narrowed, blastopore is carried back to the place where it was originally found in Protaxonia, viz: diametrically opposite the animal pole. Whether this caudad-eccentrical closure of the blastopore is performed by concrescence or not is here of no importance; as stated earlier, I do not believe that concrescence, in Amphibians at least, occurs to any considerable extent, and if it plays a rôle in more yolk-laden eggs, evidently no primary significance should be attributed to it. The medullary plate in stage $e$ (fig. 36), just as the rudiment of the stomodaeum in fig. $36 \mathrm{~b}$, su.rounds as a crescent the anterior border of the blastopore. This conception is reached for Amphioxus, e.g. by KORSCHELT and HEIDER in the last edition of their "Lehrbuch" (1910, p. 435), and especially for Ascidians by VAN BENEDEN and JULIN (1884, 1887), CASTLE (1896) and CONKLIN (1905) in their cell-lineage investigations. VAN BENEDEN and JULIN $(1887$, p. 259) state that the rudiment of the medullary tube surrounds the blastopore, presenting "la forme d'un anneau ou plus exactement d'une bague chevalière, l'anneau élargi en une plaque en avant du blastopore se rétrécit progressivement sur les côté's et se réduit à son minimum en arrière de cet orifice." In contradiction to CONKLIN they emphasize 
(p. 281) that "une partie importante de la plaque médullaire siège en arrière du blastopore", as follows from fig. 2 (cf. p. 9). This seal-ring or crescent is evidently to be derived by one-sided develupment from a ring of uniform breadih as represented by the stomodaeal rudiment in Protaxonia.

During the contraction of the blastopore this ring-shaped rudiment of the medullary tube undergoes a change in shape as indicated in figs. $36 f$ and 39 . We see here the backward growing out of the stomodaeum of Annel ds into the epichordal neural tube of Chordates projected as it were on a plane, this being the dorsal side of the embryo Thus in ontogeny it is not the neural tube itself that grows out but its rudiment, before the tube has been formed. This may at

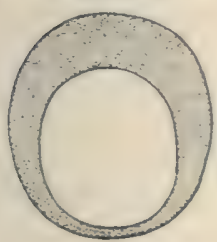

a.

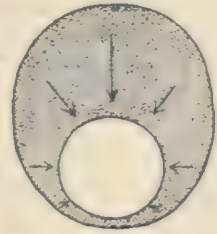

$b$.
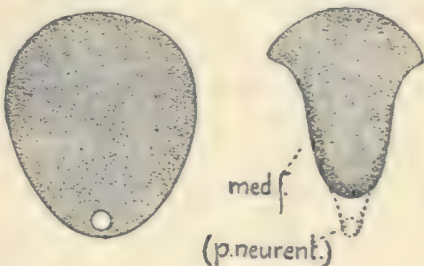

$d$.

Fig. 39. Formation of the epichordal part of the medullary tube in Chordates. In $d$ the medullary folds are closing.

first appear a little strange and it might easily be supposed that it is the neurotroch of the Annelid which has simply sunk under the surface and that in this way the ciliated neural tube has been formed. By this assumption, however, the fate of the blastopore, its backward movement and its conversion into the neurenteric canal, would not be accounted for Moreover, we sha.' find our conception confirmed when considering the relation of the anus to the blastopore and the formation of the tail.

As we have seen there is a certain genetic relation between the neurotroch and the stomodaeum in Annelids (cf. fig 37) and there is reason to consider the former as an obliterated part of the latter As both consist c $f$ ciliated and vacuolated cells, there is also a certain histological agreement. If now the blastopore moves backwards in Chordates it is quite possible, and even probable, that the cells of the neurotroch are reincorporated into the material for the stomodaeum, now the medullary tube. Then there appears to be still a certain relation between the 
neurotroch of Annelids and the medullary tube of Vertebrates, and the posterior part of the circular rudiment of the neural plate surrounding the wide open blastopore might be compared with it. In Amniotes the primitive streak, along which the blastopore moves backwards, is then distantly comparable to the neurotroch, since here too we have to deal with the coalesced lateral borders of the blastopore.

In fig. $36 g$ has been indicated now in Craniates the praechordal cerebral plate (h.pl.) is added to the epichordal neural plate $(m . p l$.$) , while in Acrania the condition shown$ in fig. $36 f$ persists.

Summary. - From the foregoing considerations on the gastrulation of Chordates the following conclusions result:

1. All that sinks beneath the surface represents the primary endoderm or hypoblast, and that which remains at the surface is the ectoderm or epiblast (contra LWOFF).

2. That which formerly has been always considered as the blastopore is indeed the blastopore, not a "notopore" (HUBRECHT) or a "somatopore" (DE LANGE) which would be only a very little part or the rest of the blastopore.

3. The phenomena occuring during the contraction of the blastopore border must be called gastrulation, not "notogenesis" (HUBRECHT) or "somatogenesis" (DE LANGE), following after the gastrulation. Truly, during gastrulation the embryo of Amphioxus assumes an oblong shape, which proves that at this moment the growing out of the segmented soma has already begun, as is shown also by the circumstance that only a little later a whole series of mesodermic segments appears. If, however, we call the growing out of the segmented soma in Annelids "somatogenesis", then we must say that in Vertebrates the "somatogenesis" interferes with the gastrulation and does not come after it In this sense I propose to use the term "somatogenesis" in future ASSHETON (1894) was right in distinguishing two growing processes of which the latter, called notogenesis by HUBRECHT and somatogenesis by DE LANGE, is connected with the longitudinal growth of the embryo, but he did not make out the correct relation between the two and the way in which they interfere mutually. 
4. The displacement of the endodermic area from opposite the animal pole to the future dorsal side in the eggs of lower Vertebrates is to be explained by a similar displacement to the ventral side during the early development of Annelids.

5. The caudad-eccentric closure of the blastopore, typical for Chordates, is a result of the interference of the contraction of the blastopore border with the backward shifting of the blastopore as a result of the elongation of the medullary tube - former stomodaeum - which in ontogeny occurs before this tube has been formed.

Relation of anus and blastopore. - We shall pass now to the question of the relation of the anus to the blastopore, yet another question of Vertebrate embryology on which the greatest uncertainty and confusion reign and which indeed, as I hope to show, could hardly have been solved without the aid of my theory.

The statements made by the numerous investigators on this subject are so divergent that it must be very difficult for any one who can not judge from personal experience to form a sound opinion. I shall try to show that the application of the principles of my theory on the origin of Vertebrates will once more serve to furnish us with the solution of an old problem which has been resuscitated, especially, by GROBBEN's (1900) classification of the animal kingdom. In the first place the different views and results of former investigators may be briefly reviewed. We shall confine ourselves mainly to the Amphibian egg, in which a relation between anus and blastopore was noticed for the first time. Anurans and Urodelans will be treated separately because, as I can confirm from my own investigations on Rana esiulenta and Amblystoma tigrinum, these two groups exhibit a notable difference in the relation of the anus to the blastopore. We shall begin with that group on which the first observations were made, the Anurans.

Different views on Anurans. - BALFOUR (1881), in his Text-book, gives a description of the origin of the anus, based mainly on the figures of GOETTE (1875) for Bombinator igreus and his own investigations on Rana temporaria where the anus breaks thı ough somewhat earlier than appears to be the case in toads generally. The blastopore passes into the neurenteric canal and the anus eventually arises at the bottom of a diverticulum of the 
alimentary tract which meets an invagination of the skin. Perforation, according to GOETTE's well-known representation of a longitudinal section in Bombinator, only occurs when the growth of the tail is well advanced, in Rana temporaria according to BALFOUR somewhat earlier.

HERTWIG (1883, p. 285) also sees the anus in Rana temporaria arise behind and independently from the slitlike blastopore. He emphasizes the different behaviour of the germinal layers at the border of the two structures. At the blastopore border ecto- and entoderm are continuous with the mesoblast and are separated from each other by the latter. At the anus, on the contrary, ecto- and entoderm pass directly into each other, forming a passage which pierces the mesoderm at that place.

SPENCER (1885), on the contrary, comes to the conclusion that the blastopore in Rana temporaria remains open and passes directly into the anus The blastopore is not enclosed by the medullary folds and thus there is no neurenteric canal. The former conclusion is shared by DURHAM (1886) in a short note, but according to the latter, a neurenteric canal is formed independently from the blastopore. In one series, truly, DURHAM finds no blastoporal opening whatever but considers this as a pathological case. KUPFFER (1887), dealing with the same object, comes to the conclusion that the blastopore remains open as the anus; so, also PERENYI (1888).

SCHANZ (1887) also operated on Rana temporaria, together with Triton. In Rana he concludes that the medullary folds rather close over the blastopore, that there is indeed a neurenteric canal, though the lumen is not evident, and that the anus arises by perforation at the bottom of a little groove behind it.

As regards the facts SIDEBOTHAM (1888) quite agrees with him. According to him BALFOUR's description is the right one, he too sees in sections the "diverticulum from the hind end of the mesenteron, dipping down towards a distinct pit in the epiblast below the blastopore and quite separate from it." Eventually perforation ensues. Similarly by MORGAN (1890, in Rana halecina and Bufo lentiginosus the anus is seen to arise at the bottom of a little groove in the ectoderm behind the blastopore

GOETTE (1890), after a renewed investigation on Bombinator igneus and some other Anurans reaches the con- 
clusion that the anterior half of the slit-like blastopore is transformed into the neurenteric canal, the posterior half into the anus. Yet in Pelobates he claims that this posterior half first closes and that the anus forms only later.

As is apparent from the foregoing, during this period nearly every year brought forth a new investigation on this subject. In 1890 that of ERLANGER on Rana esculenta appeared; in 1891 that of ROBINSON and ASSHETON on Rana temporaria; in the same year a small treatise by ERLANGER in reply to some observations made by the two English authors on his work All three authors agree, however, that in both cases the anus arises by perforation.

In later years the fate of the blastopore is alluded to only in a few invesigations, e g by BLES (1905) who for Xenopus laevis, and by SEEMANN (1907) who for Alytes obstetricans finds that the blastopore is not enclosed by the medullary folds and passes directly ir to the anus, there being accordingly no neurenteric canal.

Rana esculenta - Most of the investigators who have paid special attention to the question thus come to the conclusion (which after my own examination of Rana esculenta I can support without reservation) that the anus arises by perforation a little distance behind the blastopore which is transformed into the neurenteric canal. A short description may be given here in addition to the figures for Rana esculenta.

After the yolk-plug has disappeared from the surface the blastopore presents itself as a short longitudinal slit (fig. 40 a) A median section through this egg is reproduced in fig. I of the plate II. In a similar longitudinal series one succeeds better than might be expected in getting the blastopore as an opening $(b l)$, though of course this is only the crse in one or two sections. The ventral blastopore lip is well developed and includes between itself and the yolk cell mass in the archenteron the so-called anal diverticulum (Afterdarm, a. d.) which, however, is nothing but the intersection of the circular incision surrounding the mass of yolk-cells.

In a somewhat advanced stage a shallow impression in the ectoderm (a) appears on the surface of the egg (fig. 40 $b$ ) behind the slit-like blastopore. This impression is clearly visible in a longitudinal section, as in fig. 2 of the plate. Underneath this impression a thickening of the ectoderm 
occurs, the beginning of which is already visible in fig. $1\left(^{*}\right)$. Opposite the depression of the ectoderm a similar one is found in the entoderm at the bottom of the anal diverticulum.

In an egg as represented in fig. $40 \mathrm{c}$ we see, at the bottom of the shallow invagination of the ectoderm mentioned above, a little pit, as yet not very deep, from
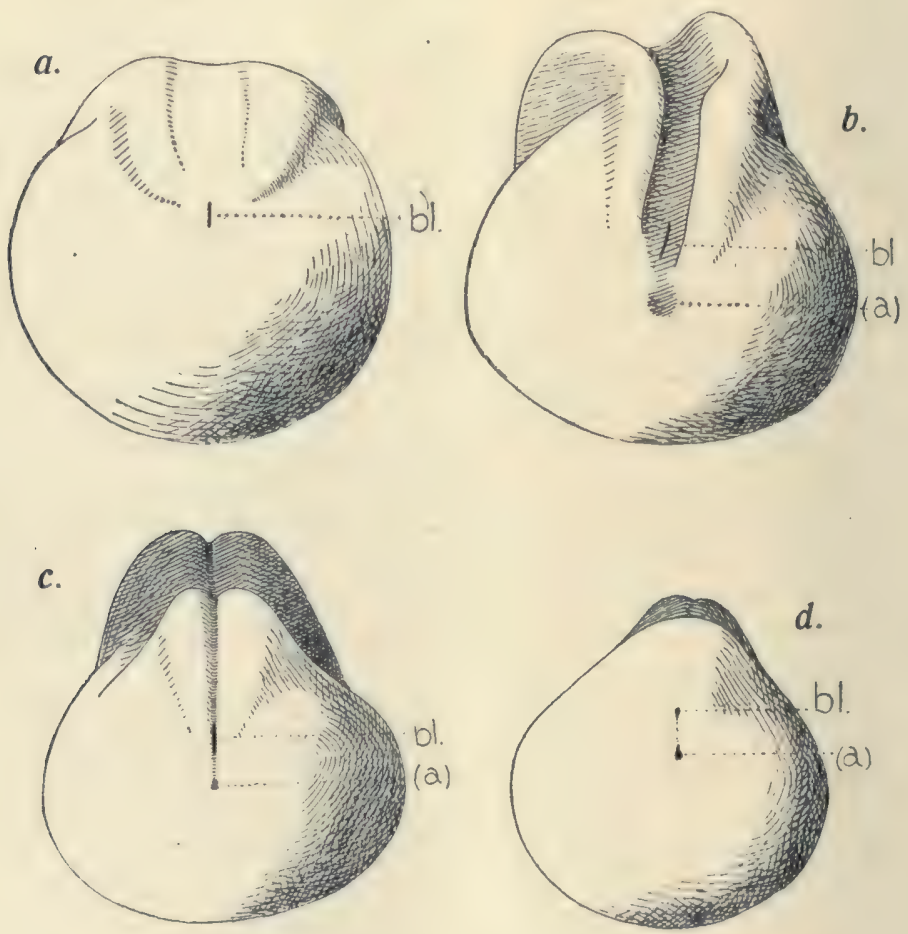

Fig. 40. Four eggs of Rana esculenta during the closure of the medullary folds.

(a) anal pit, bl blastopore.

which a still more shallow groove, the anal groove, runs forward to the blastopore-slit. The longitudinal section of the egg is given in fig. 3 of the plate. It bears a close relation to fig. 2 ; the anal membrane has, however, become thinner. 
In a slightly further advanced stage (fig. $40 d$ ) the greater part of the slit-like blastopore has been overgrown by the medullary folds, only at the hindmost extremity is there still a little opening ( $b l$.) from which the anal groove runs to the anal pit $(a)$. This anal groove, with a deeper impression at its anterior (rest blastupore) and at its posterior end (anal pit) appears to have been confused by several authors with the slit-like blastopore of a somewhat earlier stage (fig. $40 a$ and $b$ ). They accordingly imagine this slit to have closed in the middle by coalescence of the opposite borders, leaving only a passage at the anterior and at the rear end, these being the future neurenteric canal and the anus. The rudiment of the tail is claimed to arise as a double knob at the right and the left side of the line of coalescence, these knobs fusing afterwards over the middle of the blastopore. Thus ZIEGLER (1892), in his note on the surface views of Rana-embryos, writes: "Etwas später sieht man an Stelle des Spaltes eine Rinne, welche vorn in den Canalis neurentericus, hinten in die Aftergrube ủbergeht; es sind nämlich jetzt die seitlichen Blastoporuslippen median zur Vereinigung gekommen". The same views are put forward by HERTWIG in his Lehrbuch. Even a close examination of surface views, however, teaches us that the anal groove is by no means identical with the slit-like blastopore but that its anterior end coincides with the rear end of the latter. In fig. $40 c$ we see it already running from the slit-like blastopore to the anal groove. The study of median sections precludes every possibility of doubt. These sections invariably give the condition of fig. 4 (plate) which links up with fig. 3. The anus is on the point of breaking through, the blastopore of being closed by the medullary folds. The two are quite independent.

The step to fig. 5 (plate III) is again a small one. In fig. 3 we see the cerebral plate already curving in. Especially noticable is the opposition between the praechordal cerebral plate and the epichordal medullary plate which, as a matter of fact, is in this stage no longer a flat plate but curved into a groove between the medullasy folds. Fig. 3, therefore, is realized only in one or two sections which are exactly median; to the right or the left side immediately one of the medullary folds is intersected, as indicated in fig. 3 with a dotted line. A paramedian section in this series thus offers a much 
greater resemblance to fig. 5 , where the medullary folds have coalesced, than the median one of fig. 3 .

At the bottom of the body the anus has broken through, the ventral blastopore lip as a consequence seems to have suddenly vanished. The blastopore itself has been overgrown by the medullary folds. In the hindmost part of the medullary tube these folds have applied themselves so closely one to the other that the lumen of the tube is not continued between them and only a virtual neurenteric canal can be spoken of. From figs. 4 and 5 and from the study of whole eggs it appears quite evident that the medullary folds unite over the blastopore and that the anus breaks through a little distance behind it at the bottom of the small depression indicated in fig. $40 \mathrm{c}$.

I should like to emphasize a peculiarity which has only be noted by ERLANGER (1890), especially in relation to what we shall find in Urodelans. In the short time that passes between the stages of fig. 1 and fig. 3 (plate II), the distance between blastopore and future anus diminishes slightly; in other words, if we take the place of the future anus as a fixed point, the slit-like blastopore moves a little backwards towards it. Thus the ventral blastopore lip in median sections is not only getting thinner, owing to the appearance of the groove between blastopore and anus, but also somewhat shorter. To this point we shall revert later.

Different views on Urodelans. - Let us pass now to the Urodelans. The small extension of the ventral ectoderm and the strong development of the dorsal parts is here characteristic in the early stages of development, the foundation of the embryo accordingly encircling the egg over considerably more than $180^{\circ}$. The Urodelans have this peculiarity in common with the Dipnoans and Petromyzontes of which the earlier stages of development, externally as well as in sections, exhibit a striking similarity to those of Urodelans.

According to SCOTT and OSBORNE (1879) the blastopore of Triton is overgrown by the medullary folds and becomes the neurenteric canal. SEDGWICK (1884), in his well-known article on the origin of metamerism, writes concerning Triton cristatus: "in this animal the blastopore appears not to close, but to persist as the anus" and his pupil ALICE JOHNSON (1884) verified this by sections. A neurenteric 
canal, as described by SCOTT and OSBORNE, was never observed by her. SCHANZ (1887) in Triton punctatus comes to the conclusion that the blastopore is constricted in the middle, the anterior opening becoming the neurenteric canal, the posterior opening the anus. HousSAY and BATAILLON (1880), on the contrary, find in the axolotl: "qu'il n'y a pas de canal neurentérique, que le blastopore demeure toujours ouvert et qu'il devient l'anus définitif". Next comes the accurate investigation of MORGAN $(1889,1890)$ for the axolotl. He too finds that the hindmost part of the blastopore passes into the anus, the anterior part being enclosed between the medullary folds. Since my conclusions are closely akin to those of MORGAN, I shall revert to them in detail presently.

GOETTE (1890) similarly sees in some Urodelans (Triton, Siredon) the rear end of the blastopore pass into the anus.

A few further observations of recent times as to the fate of the blastopore may be touched on: those of DE LANGE (1907, 1912) and ISHIKAWA (1908) concernıng Megalobatrachus maximus, of KUNITOMO (1911) concerning Hynobius and of SMITH (1912) concerning Cryptobranchus alleghaniensis. All agree that the hind part of the slit-like blastopore remains open as the anus, the anterior part being overgrown by the medullary folds, except ISHIKAWA who considers this course of events as an exception only, the anus as a rule springing up as an independent formation, which is denied by DE LANGE (1912).

For Petromyzon and Dipnoans most investigators hold that either the whole blastopore or its hind end passes into the anus.

Amblystoma tigrinum - My own investigations concerning the axolotl all go to confirm the conclusions reached by most of my predecessors, viz: that the rear part of the blastopore passes into the anus. If then I give a brief survey of my observations, it is with the express object of emphasizing some few circumstances which were not noticed by former investigators and see $m$ to me of importance in giving a correct interpretation.

The stage represented in fig. 41 a (text) and fig. 6 (plate III) corresponds absolutely with that of fig. $40 a$ and fig. 1 (plate II) for Rana esculenta. Here also the medullary folds begin to appear and the blastopore has contracted to a short longitudinal slit. Already in fig. 6 (plate) it is evident how much more the dorsal side is developed than 
the ventral side, the distance from the animal pole to the slit-like blastopore measured ventrally being much less than $180^{\circ}$. In accordance with this the dorsal blastopore lip, as fig. 6 (plate) compared with fig. 1 (plate) shows, and the archenteron under it are developed strongly, the
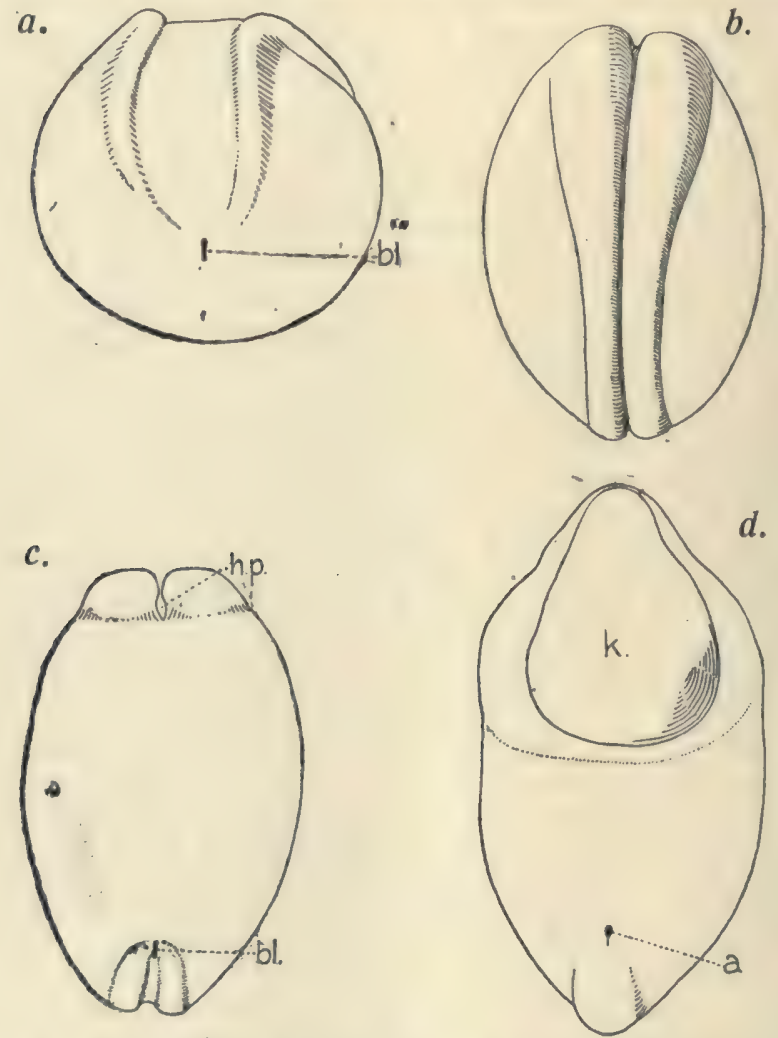

Fig. 41. Three eggs of Amblystoma tigrinum during the closure of the medullary folds.

$a$ seen from behind, $b$ dorsally, $c$ (the same as $b$ ) and $d$ ventrally.

$a$. anus, bl. blastopore, h.p. cerebral plate, $k$, head.

ventral blastopore lip and the so-called anal diverticulum very little. Yet both the latter are still quite well recognizable and on the outside of the ventral lip, a little distance behind the blastopore, may even be noted a smill depression of 
the ectoderm (a) where the future anus might be expected, if a similar state of affairs were to take place as in Anurans. Immediately behind that shallow depression we find here the same thickening of the ectoderm (*) as noted in Rana (cf figs. 1, 2, 3, plate II). Thus there is no fundamental difference, on the contrary agreement in every respect with what we found in Rana.

Now in Rana we stated that the blastopore, after becoming slit-like, continues to move backwards a small distance, approaching the future anus, which manifests itself in longitudinal sections in that the small lip which represents the ventral blastopore border becomes a little shorter. This now we see happening also in somewhat further advanced stages of the axolotl-egg: in sections the ventral lip gets shorter and soon, being here already small, it disappears altogether. In the egg shown in fig. $41 b$ and $c$ (text) the medullary folds are on the point of fusing, except at the fore and the rear end. The blastopore still appears as a slit. The longitudinal section (fig. 7) shows that the ventral blastopore lip has nearly disappeared: as a result of the backward movement the rear end of the slit-like blastopore has arrived at the spot where the anus must break through!

Particularly interesting is next the egg shown in fig. 41 $d$, where the medullary tube has just closed except at the hindmost extremity where the anterior part of the slit-like blastopore has just been overgrown by the medullary folds. Whilst in Rana the whole blastopore is in this way enclosed, in the axolotl the medullary folds leave an opening over the rear end of the blastopore, which is the anus $(a)$.

Only one egg in this stage was found by me amongst my material. This was cut into longitudinal sections. MORGAN studied a similar egg in transverse sections. I reproduce here the outline of his exce!lent figures which confirm my views in every way. Fig. $42 a$ represents a section through the medullary tube just in front of the blastopore. Under it the anal diverticulum has been intersected. The medullay folds just meet. Figs $42 b$ and $c$ show the blastopore in its anterior half, as is of course the case in many succeeding sections The medullary folds meet over the blastopore, the latter itself constituting the neurenteric canal. Figs $42 d$ and $e$ are still further back, the medullary folds are 
less developed and leave an opening, the anus. Comparing my description with that of former investigators it will be noted that, keeping strictly to the facts, 1 yet present them in a somewhat different way: I do not let the medullary folds finish halfway along the length of the blastopore slit but only in closing leave an opening over the rear end of the blastopore, the anus. Accordingly one can, retracing the medullary canal, not only pass through the neurenteric canal into the archenteron but also through the anus to the outside, this being nowhere prevented by a coalescence

a
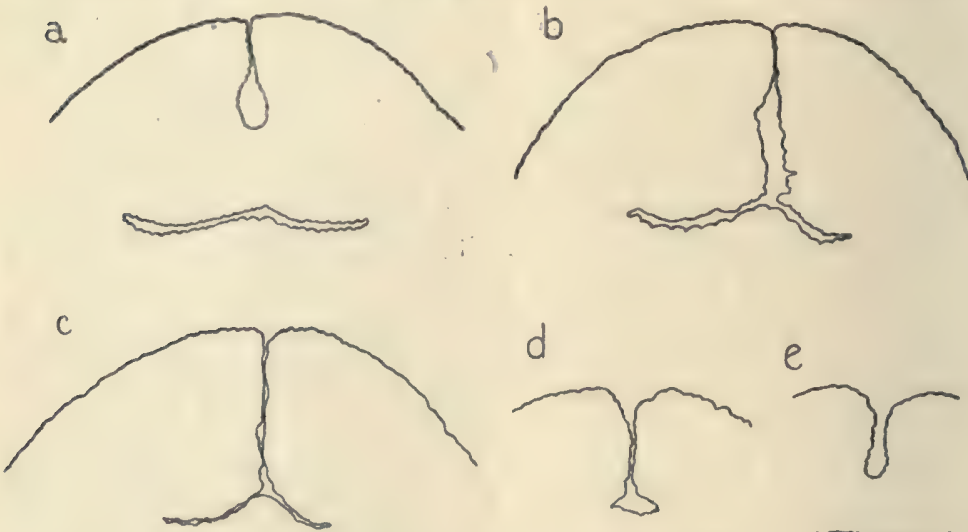

Fig. 42. Transverse sections through the blastopore of an egg of Amblystoma punctatum, where the medullary folds just close over it, after MORGAN, 1890.

$a$ in front of the blastopore, $b$ and $c$ through anterior half, $d$ and $e$ through rear end (anus).

of the two medullary folds across the middle of the blastopore, as several investigators are inclined to assume.

Now in a longitudinal section (fig. 8, plate III) the blastopore $(b l .=p$. neur.) and the anus $\mid a)$ are easily distinghuishable from one another. The blastopore becomes the neurenteric canal or, perhaps better, the neurenteric pore (porus neurentericus), as I prefer to call it henceforth. Entering the anus, one can pass through the neurenteric pore into the archenteron. The anterior part of the neurenteric pore, however, becomes - and is already in fig. 8virtual, the medullary folds applying themselves behind so closely to one another that the lumen of the medullary 
canal is not continued any further between them, as MORGAN has already remarked. Hence the opinion of many investigators that the medullary folds do not reach to the blastopore and that there is no neurenteric canal. The hindmost part of the neurenteric pore remains open as the internal opening of the anus. The result is really that the hindwall of the hindmost part of the medullary tube is perforated by the anus, which in Anurans atises closely behind it, and this is caused by the circumstance that the neurenteric pore, the former blastopore, in Urodelans has travelled back so far that its rear end has reached the place where in Anurans the anus breaks through. This is at the same time the solution of the apparent contradiction between Anurans and Urodelans in this respect.

Different interpretations - The interpretation which until now has been fairly generally accepted is that of SCHANZ (1887), MORGAN (1890!, ERLANGER (1890) and ROBINSON and ASSHETON (1891) who contend that the place where the anus in Anurans breaks through really represents the rear end of the original wide blastopore, which has narrowed cown by concrescence of the lateral borders not only at the anterior end from in front backwards, as postulated by HIS' concrescence theory, but also at the posterior lip from behind forwards. The longitudinal groove between the blastopore and the anal depression in fig. 40 seemed to be an indication of a raphe. Thus the anus in Anurans would be closed only temporari'y and would not arise as an independent formation. In this way ERLANGER assumed concrescence at the dorsal as well as at the ventral blastopore border, ROBINSON and ASSHETON only at the ventral border. The line of concrescence in both cases is compared to a primitive streak. However, a primitive streak, as ROBINSON and ASSHETON remark, can be expected only behind the blastopore They join BALFOUR when he writes $(1881$, p. 238): "The primitive streak represents the linear streak connecting the Elasmobranch embryo with the edge of the blastoderm after it has become removed from its previous peripheral position, as well as the true neurenteric part of the Elasmobranch blastopore". Wrongly enough the adherents of the doctrine of concrescence sometimes compare to the primitive streak the concrescence-seam assumed by them in front of the blastopore. To me it seems that one ought to add that a primitive streak is to be expected only in yolk-laden eggs 
with a germinal disc, or in eggs that are to be derived from yolk-laden ones, such as those of Mammals.

As stated earlier, I shall not absolutely deny that concrescence ever plays a part in Vertebrate gastrulation, particularly in yolk-laden eggs. It seems to me beyond doubt, however, that its rôle is a much more subordinate one than the wellknown doctrine of HIS assumes. For Amphibians the pricking experiments described above have shown that there can be no question of the whole dorsal side of the embryonic rudiment arising by concrescence of the blastoporic lips.

For concrescence at the hind border of the blastopore, as assumed by ROBINSON and ASSHETON, still less evidence can be adduced. The groove between the slit-like blastopore and the anal pit does not become gradually longer, as might be expected in this case, the anal pit moving away from the ventral border of the blastopore, but on the contrary it only gradually becomes more distinct ar $d$ at the same time shorter, the blastopore approaching the anal pit. Evidently it is not to be iconsidered as a concrescenceseam, perhaps it may be compared to the groove joining the two impressions made by two fingers pressed near one another into a soft cushion. When ROBINSON and ASSHETON (1891, p. 475) compare it with the primitive streak e.g. of a bird, they encounter at once the difficulty that in the latter it is formed from in front backwards, in the frog egg, according to their assumption, from behind forwards.

Three possibilities may be distinguished concerning the relation between blastopore and anus in Vertebrates:

1. there is a primary relation

2. there is no relation

3. there is a secondary relation.

Primary relation between anus and blastopore. - The first supposition mentioned above is now the one most widely accepted. Even where in Anurans 2 seems to prevail, yet it is assurred that this is to be traced back to 1 , since what is found in Urodelans may be supposed to be valid for Anurans also. Thus MAURER (1906) in HERTWIG's Handt uch tries to trace back all the results for Chordates to 1 , though the evidence adduced can not always be called convincing. Even in Amphioxus n) relation between the anus and the blastopore has as yet been established.

The possibility of 1 is in no way precluded by my theory which derives the Chordates, in opposition to GROBBEN, 
from Protostomia, as long as the possibility of a relation between the anus and the blastopore in the latter group exists. This might be expected from SEDGWICK's well-known theury (1884) which derives the mouth and the anus of Bilateria from the anterior and the posterior extremity of a slit-like Actinian mouth of which the borders coalesce in the middle. It ought then to be possible to trace the concrescence-seam joining mouth and anus, which according to this theory should run over the ventral side of Annelids, in Vertebrates also in the groove between anus and blastopore, that is in the so-called "Afterrinne," the "primitive streak" of ROBINSON and ASSHETON (see above) - not in the hypothetical concrescence-raphe in front of the blastopore, the "primitive streak" of the theory of concrescence, as LAMEERE (1891) and HUBRECHT (1905) assume in their application of SEDGWICK's theory to Vertebrates. Thus the presence of a primary relation retween the anus and the blastopore in Vertebrates would in no way compel us to derive them with GROBBEN (1908) from the Deuterostomia, as long as the possibility of a similar relation in Protostomia exists.

However, the theory of SEDGWICK finds in the development of Protostomia just as little support as I hope to show is the case in Tritostomia (Vertebrates). A process of such fundamental phylogenetic significance as assumed by SEDGWICK s theory might be expected to have left more distinct traces in the ontogenetic development than are demonstrated by the most careful research of recent investigators. Again and again we see the anus arise as a new formation, by perforation. In Annelids, where primarily we might expect to find evidence of a common origin of mouth and anus, a direct transformation of the rear end of the blastopore into the anus has never been established. Even in the primitive Polygordius, where as a matter of fact the blastopore is divided into two halves by a median constriction (WOLTERECK, 1904), the posterior opening nevertheless closes and the anus is formed by perforation behind the two teloblasts which lie at the rear end of the blastopore. To me, as stated before, the most probable conception of the origin of the anus seems to be that in a larva of the protrochula-type (MüLLER's larva of a Polyclad, pilidium of Nemertines) the entodermal pouch, which is already turned in a backward direction, has come in contact with the ventral body wall and has broken through by 
perforation, in the same way as occurs in Deuterostomia, and that thus the trochophore larva has originated.

I think the idea of a primary relation between the anus and the blastopore for Proto- as well as for Tritostomia should be abandoned. The anus in Proto- as well as in Tritostomia arises by perforation, independent of the blastopore.

Secondary relation between unus and blastopore.- Of the three above mentioned possibilities regarding the relation of the : nus to the blastopore the second then seems to me, both for Proto- and Tritostomia, the correct one. The third possibility, however, we find exemplified in Urodelans and apparently also in Dipnoans and Petromyzontes which in their early development so closely agree with the former. Let us now invoke the aid of my theory for further interpretation

Perianul and periporal growing zones. - According to this theory the Vertebrate is to be derived from the Annelid by the stomoc'aeum growing out backwards so strongly that it extends, as the medullary tube, over the whole length of the soma, and, as we shall see, even further still (forma ion of the tail!). I have proposed the name porus cardiacus for the entrance of the stomodaeum into the entodermal part of the gut. This is the former blastopore. Already during the development of Annelids we see this cardiac pore by the lengthening of the stomodaeum travelling backwards into segments situated ever further to the rear. In. Vertebrates the backward movement goes so far that finally the cardiac pore, as the neurenteric pore, comes at a certain moment to lie at the utmost extremity of the soma, just in front of the anus. This backward movement is evidently produced by a growing-zone which has entered into activity at the inner end of the stomodaeum, round the porus cardiacus, and which causes the stomodaeum to extend progressively to the rear. This growing zone I should like to call the periporal growing zone.

The longitudinal growth of the soma of Annelids, the somatogenesis, is, on the contrary, produced by a terminal, perianal, growing zone. Both these growing zones now exert their influence, as I shall try to render probable, in the earliest development of Vertebrates. A further complication is introduced by the fact that the activity of both, ontogenetically anticipated, interferes with the gastrulation. Further researches (pricking experiments, counting of the mitoses) will 
be necessary to test the accuracy of the conclusions reached by the application of the above principles. They are as follows.

Interjerence of both with the gastrulation. - The ectoderm which afterwards has to invest the whole soma - dorsally also - lies in a stage like that of figs. $40 a$ and $b$ (text) principally at the ventral and the lateral sides and ony afterwards, by the closing of the medullary tube, extends over the dorsal side as well. The production of this somatic ectoderm must now evidently be performed by the perianal growing zone, as is the case in Annelids. Thus in the neighbourhood of the future anus, a short distance behind the ventral blastopore lip. mitoses may be expected to be most frequent. When, however, the blastopore has closed (figs $40,41 a$ ), the rearward extension of this ventral ectoderm comes to an end. If now the perianal growing zone continues to be active, a ring-shaped thickening of the ecto-
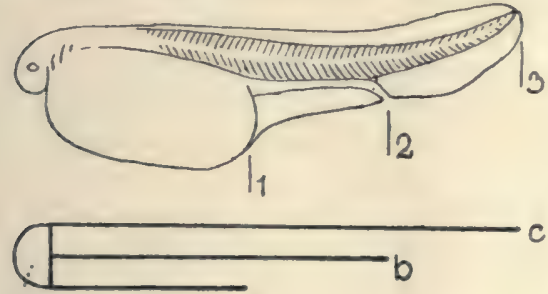

prostomium.

Fig. 43. Larva of the sturgeon, after KUPFFER from HERTWIG's Handbuch, Bd. I, 2, p. 24.

1 limit of the gastrulation, 2 limit of the somatogenesis, 3 limit of the urogenesis.

Beneath: Diagram of the interference of the gastrulation (a) with the action of the perianal (b) and the periporal (c) growing zones. is so slight, this ectodermal thickening also, though present, is yet of very little importance $\left(6^{*}\right)$. The activity of the perianal growing-zone seems to die down soon afterwards and the ectodermal thickening in the ensuing stages gradually disappears again. Somatogenesis has closed simultineously with gastrulation. Were it to continue also after the end of gastrulation the anus would eventually lie somewhere 
between the yolk-cell-mass and the extremity of the tail. In fishes this case is fairiy generally met with. As an example may be mentioned the sturgeon (fig. 43). Many Teleosteans might also be mentioned here, in whose larvae the place of the anus varies considerably, which is of importance in determining the species.

Let us now turn to the periporal growing zone which causes the growing out of the stomodaeum, the medullary tube or the medullary plate, together with the backward movement of the cardiac pore (Annelids), the neurenteric pore (Chordates) or the blastopore. Organs or processes that are of much importance for the structure of the adult animal often appear precociously in ontogeny. In Lamellibranchia, e.g., the shell-gland invaginates during gastrulation, though the gastrulation-process is no doubt phylogenetically much older Thus also the activity of the periporal growing zone and the backward movement of the cardiac pore associated with it begin very precociously, viz: during gastrulation, when the future cardiac or neurenteric pore is still the blastopore. The interference of the contraction of the blastoporic rim with the backward movement of the blastopore causes the caudad eccentric closure of the blastopore which is so typical of Chordates. The action of the periporal growing zone, as long as the tube-formation has not set in, results not in the production of a stomodaeal or medullary tube, as is afterwards the case during the urogenesis, but provisionally in the formation of the medullary plate. As I have expressed beforc (cf. p 191), the growing out of the stomodaeum into the medullary tube is thus in its first, and somatogenetic, phase to be imagined as projected on a plane, the dorsal plane of the embryo. When the blastopore has narrowed to a slit and the tube-formation begins, in the form of the appearance of the medullary folds, the caudad movement of this slit-like blastopore, as stated above, continues nevertheless, probably with undiminished speed, though only over a short distance - as indeed might be expected from the short duration of this phase. Further than the anus, however, this backward movement can not go; phylogenetically: the stomodaeum of the Annelid, growing out backwards, finally reaches the anus. If now the movement stops slightly in front of the anus, there will be no relation whatever between neurenteric pore (blastopore) and anus (fig. $44 a$ ), as we stated was the case with the frog. If the movement continues 
yet a little further (fig. 44 b), a secondary relation between neurenteric pore (blastopore) and anus results ${ }^{1}$ ) The anus now opens to the exterior through the hindmost extremity of the medullary tube. From the medullary canal there is a passage through the anus to the exterior as well as through the neurenteric pore into the archenteron, and from the archenteron through the neurenteric pore and the anus to the exterior. In ontogeny this will result in the non closing of the medullary folds over the rear end of the slit-like blastopore, and in the leaving of an opening, viz. the anus. Possibly they will develop slightly at both sides of the rear part of the blastopore under the influence of the formation of the

a.

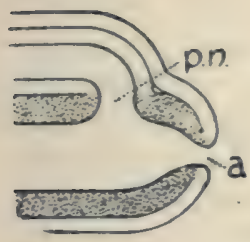

$b$.

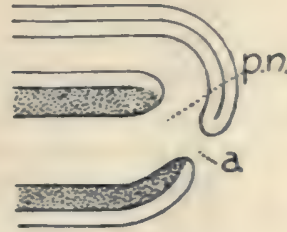

c.

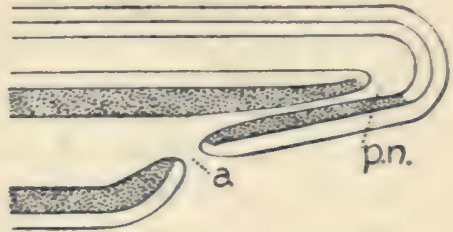

Fig. 44. (cf. fig. 11, p. 220). Diagram of the relation between anus and blastopore, and of the tail-forming (cf. p. 213). $a$ at the moment of the closure of the neural folds is Anurans, $b, n, n, n, \cdots$ Urodelans,

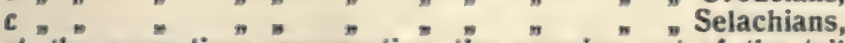
at the same time representing the growing out of the tail in Amphibians.

$a$ anus, $p . n$ neurenteric pore; the entoderm is dotted.

anus at this point, or possibly not. If we imagine things very much enlarged and if we look through the anus into the interior, we shall see the slit-like blastopore (neurenteric pore) in the background, though its rear end, under the influence of the formation of the anus, will probably be slightly widened. With this conception the facts stated by us in Urodelans so perfectly agree that it seems hardly possible to doubt the accuracy of this interpretation. We see in the Axolotl the blastopore move backwards to the place where in Anurans the anus breaks through. We see over that place, that is over the rear end of the blastopore, that the medul-

1) In a longitudinal section as in fig. 44 the conditions at first sight might appear in fig. $44 b$ radically different to those in $44 a$. In an elevation, however, the agreement between them will be evident. 
lary folds do not, as in Anurans, unite, but leave an opening. We have seen that there is a passage from the medullary tube as well through the anus to the exterior as through the neurenteric pore into the archenteron. Afterwards this is more or less obscured by the fact that the medullary folds are in such close contact caudally that there is here no lumen, no medullary canal (fig. 8, plate) - just as in the frog (fig. 5) - and that accordingly, as in the frog, the slit-like neurenteric pore would become wholly virtual if the rear part did not remain open as the anus.

Thus only the anterior part of the slit becomes virtual and hence the statement of several authors concerning Urodelans, Dipnoans and Petromyzontes, that the blastopore passes into the anus and a neurenteric canal is wanting, is to be explained. The apparent contrast between Anurans and Urodelans has thus found a solution. It would cause us no surprise if in an Anuran a similar condition were observed as appears to prevail in Urodelans, nor would the reverse case - the difference between them not being fundamental but only graduated. It would not be impossible that in one species at one time the first, at another the second case might be realized (comp. DE LANGE and ISHIKAWA on Megalobatrachus!)

Formation of the tail. - I have spoken above of the caudad movement of the neurenteric pore=blastopore stopping in front of the anus. In reality, however, there is no question of stopping. Although the anus, when it has been reached by the cardiac $=$ neurenteric pore, seems to afford an insurmountable obstacle for the further backward growth of the stomodaeum = medullary tube, the activity of the periporal growing zone has not yet come to an end when the perianal growing zone has stopped working There being no room, however, within the soma for further extension, a protuberance of the body wall in front of the anus results. Into this the stomodaeum $=$ medullary tube grows out. This protuberance is the tail-knob (fig. $44, \mathrm{c}$ ). Thus we see the tail of Vertebrates originating by the fact of the periporal growing zone continuing its activity after the perianal has stopped. In this way the position of the anus in Vertebrates is not terminal, as in Annelids, but at the root of the tail which overgrows it and which owes its origin simply to the presence of the anus. Phylogenetically we have to imagine that the longitudinal growth 
of the stomodaeum (medullary tube) exceeds that of the soma, so that the cardiac (neurenteric) pore overtakes the anus and passes it. Just as in Annelids the position of the anus in Vertebrates is terminal in regard to the soma proper, the tail being an outgrowth of the dorsal side of the latter in a backward direction. According to this conception the ventral side of the tail belongs to the dorsal side of the soma. In conformity with this the dorsal unpaired skinfold of the fish- and amphibia-larvae is continued over the tip and the underside of the tail as far as the anus. The mesoderm, originating at the blastopore-border and evidently being a product of the periporal growing zone, also takes a considerable part in the tail-formation.

Several authors have rightly emphasized the difference between somatogenesis and what we may call with DE LANGE (1912) urogenesis, i. e. the formation of the tail. From the foregoing results it appears that somatogenesis, just as the somatogenesis in Annelids, is performed by the perianal growing zone which gives rise to the ft.ture somatic (not to the neural, which is that of the medullary plate) ectoderm of the trunk which, as long as the medullary plate is open, lies mainly ventrally and at the sides of the egg. Simultaneously, however, with the gas!rulation the periporal growing zone is at work, which produces the backward movement of the blastopore and the backward extension of the originally crescentic rudiment of the medullary plate, i. e. the rudiment of the medullary tube. Both growing processes are combined with a third one, going on simultaneously: gastrulation, manifesting itself at the surface in the contraction of the blastopore border.

The urogenesis however sets in after two of these three processes have finished, viz: gastrulation and the action of the perianal or somatic growing zone. While in Anurans both these processes stop nearly at the same time, in fishes, as stated above, we frequently find hat somatogenesis continues after gastrulation has been completed, so that the anus eventually lies somewhere about halfway between the yolk-cell-mass and the tip of the tail. The urogenesis accordingly is exclusively the result of the periporal growing zone which causes an elongation of the medullary tube disproportional to the length of the soma. The difference between somatogenesis and urogenesis herein finds an explanation. 
The activity of the periporal growing zone, manifesting itself in the backward movement of the blastopore and the neurenteric pore, at first interferes with the gastrulation, which causes the backward directed eccentrical closure of the blastopore, then manifests itself in the backward movement of the slit-like blastopore as stated by us above (which stage lasts only a short time), and only finally in the urogenesis as longitudinal growth of the medullary tube in the way in which we image the stomodaeum of Annelids to have passed phylogenetically into the medullary tube of Chordates.

Difference between Urodelans, Anurans and Selachians There is then no question of the backward movement of the blastopore $=$ neurenteric pore stopping in front of the anus and the difference between Anuran and Urodelan consequently does not lie in the fact that in the former the neurenteric pore stops a little before the anus is reached and in the latter only after this has occurred, but in that in Anurans the tube-formation, i. e. the closure of the medullary folds, occurs a little before the anus is reached; in Urodelans, Dipnoans and Cyclostomes only after the neurenteric pore (blastopore) has fused with the anus. This graduated difference evidently again depends on the circumstance that in Urodelans the action of the periporal growing zone is stronger than in Anurans, the activity of the perianal relatively weaker than in the latter. This manifests itself, as stated above, in the medullary plate in Urodelans being developed very strongly, the ventral side relatively little in comparison with the Anurans. The same holds good for Dipnoi and Cyclostomes. Now, as we have seen, the perianal growing zone acts mainly ventrally and on both sides of the (future) anus for the simple reason that, as long as the medullary plate is open, the future trunk ectoderm also lies only ventrally and on both sides of the egg. But in front of the (future) anus also, there seems to be some feeble activity, directed towards the ventral blastopore lip which accordingly is developed more strongly where the perianal growing zone is mosi active (Anurans, fig. 1, plate), less so, where the perianal growing zone is less active (Urodelans etc., fig. 6, plate).

Now the action of this dorsal part of the perianal growing zone is opposed by the periporal growing zone, which pushes the blastopore backwards. It is no doubt due to 
the relative strength of the two growing zones that in Urodelans the blastopore is pushed back to the anus before the tube-formation, in Anurans on the contrary it does not reach it till atter the tube-formation. The beginning of the latter evider.tly is determined again by the end of the gastrulation, just as in Protostomia the stomodaeal tube is formed directiy after gastrulation. In Selachians, where the accomplishment of the gastrulation is so much retarded by the great yolk-wealth, urogenesis actually sets in before the tube-formation, the neurenteric canal thus originally being an open groove known as the sulcus neurentericus. Thus there are three possibilities:

1. when the gastrulation is accomplished and the tubeformation ensues, the receding blastopore has not yet reached the (future) anus. Immediately after the closure of the neural folds we then have the case of fig. $44 a$, realized in Anurans.

2. the action of the periporal growing zone being stronger than in the foregoing case, the blastopore has reached the (future) anus when the gastrulation has finished and the tube-formation occurs. Immediately after the accomplishment of the latter we then have the case of fig. $44 b$, realized in Urodelans. Of course this stage is passed through by Anurans also before the tail-formation begins.

3. the yolk has so much retarded the end of the gastrulation that the neurenteric canal has already passed the anus when it has finished and the tube-formation ensues. Immediately after the latter we get the condition of fig. $44 c$, as is found in Selachians. This figure, however, represents at the same time the tail-formation in Urodelans and Anurans.

While I feel that the application of my theory has thus thrown light on a number of obscure problems, the facts and results recorded above afford to my theory yet further support of no inconsiderable value. In contemplating fig. 44 we see, as it were, pass before our eyes the growing out of the stomodaeum and the travelling backwards of the porus cardiacus or neurentericus, which are demanded by my theory but which only after a careful analysis are to be recognized in the early ontogenetic processes which then, however, prove to be explained by them in such a surprising manner

Mesoderm of Vertebrates. - Before closing this chapter we must devote at least a few words to the question of 
the nature and origin of the mesoderm and the notochord of Vertebrates. This question has given rise to an almost hopeless divergence of opinions as well as much controversy. While some derive the mesoblast from the primary endoderm, others suppose it to originate from the primary ectoblast which they assume to have invaginated round the blastopore border, or partly from the ento-, partly from the ectoderm. According to some, the mesoderm in Craniates is formed by evagination of paired pockets from the archenteron roof, others assume a process of splitting off. Some allot the notochord to the mesoderm which accordingly has a single nature in the beginning, others consider the notochord as belonging to the endoderm and thus imagine the mesoderm as a paired band on both sides of it. Some distinguish a gastral from a peristomal mesoblast, others hold that all the mesoderm originates from the border of the blastopore, being thus peristomal. We shall not enumerate all the different views; those mentioned above will show sufficiently that the facts alone noted in Vertebrates are again insufficient to give us the solution of this problem. A comparison with Evertebrates will be the deciding factor.

The segmentation of the mesoderm in Vertebrates is one of the main points of agreement with the Annelids. The way in which the mesoderm is formed, however, is very different in the two. In Annelids we see the paired mesoderm bands originate from two large cells situated at the border of the blastopore and no doubt belonging to the primary endoderm. They produce by teloblastic proliferation the two mesoderm bands which grow inwards pari passu with the invagination of the entoderm

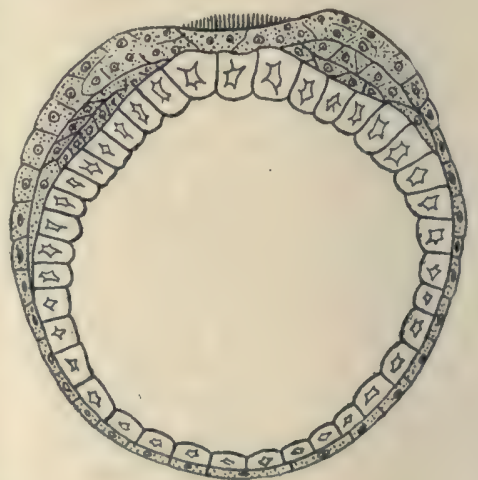

Fig. 45. Transverse section of an earthworm embryo, from BERGH. 1895, p. 154, after KOWALEWSKY, 1871.

along which they are situated. Soon afterwards they become segmented from in front backwards. When once this stage has been reached the resemblance to what we find in Vertebrates 
becomes evident. The similarity of fig. 45 representing a transverse section through an embryo of an earthworm to a similar section through a young Amphioxus embryo cannot be denied. In Vertebrates, however, the mesoderm is not produced by teloblasts but split off longitudinally from the primary endoderm, in a way on which opinions still differ but at any rate quite unlike that in which the mesoblast of Annelids is produced. Yet, however different this process in the two cases may appear, the application of my theory necessarily leads us to the conclusion that there must be a fundamental agreement between them. In both cases it is evident that the mesoderm is of entoblastic origin, that it is formed at the border of the blastopore, that the growth of the mesoderm bands is terminal and that the segmentation proceeds from in front backwards. The main difference is, that in Vertebrates the mesoderm bands for some time continue to form part of the endodermic archenteron-wall and that consequently when they separate from it they have already a certain length and the segmentation sets in at the same time. In Annelids the mesoderm bands are separate from the endoderm from the beginning and grow inwards at the same rate as the latter.

Notochord. - What are we to think of the notochord? Must it be considered as endoderm or as mesoderm? Nothing of the kind is found in Annelids, evidently the notochord is an organ that has been acquired only at the transition of the Annelid into the Chordate. Formerly (1913, p. 696) I felt inclined to share with GOETTE (1890, p. 24) in considering it as mesoderm which in other cases also produces a similar tissue of vesicular cells. Further consideration and reflection, however, has made me alter my opinion and now the following conception seems to me the most probable. The comparison with Annelids leads us to the conclusion that the mesoderm in Vertebrates also consists of two bands and thus has a paired nature. These two bands in Annelids are separated a little distance from each other and between the two a longitudinal ridge of entoderm in often squeezed in, as it were, and separates them. This is shown e.g. in the transverse section in fig. 45 and still more evident I found it to be in transverse sections of Scoloplos (DELSMAN, 1916, a, figs. $35,36,44)$. I imagine this ridge of entoderm to have split off from the roof of the archenteron and to have 
been transformed into an elastic supporting organ, the notochord. In the tentacles also of Cnidarians we see the endoderm produce large vesicular cells constituting a supporting tissue which here, truly, has not the elasticity of the notochord. Thus I think the notochord is a derivative from the endoderm in the same way as the mesoderm but of phylogenetically younger origin than the latter. In ontogeny also do we see that the development of the mesoderm bands in Chordates begins and is completed earlier than is that of the notochord. From this circumstance GOETTE (1890, p. 26) concludes: "dass die Chordabildung erworben wurde, nachdem die bilaterale Mesodermbildung bei den Vorfahren der Chordaten bereits bestand." It is difficult to say whether we should consider the notochord as mesoderm or endoderm.

Gill-slits. - As regards the gill-slits, we look once more in vain for an homologous structure in Annelids. In the chapter on the head, however, I have compared them with the paired diverticula of the gut in flatworms and nemertines. For this I refer to p. 82. It will be evident that the gill-slits of Balanoglossus, formed from the ectodermal stomodaeum, can have no connection with those of Vertebrates and can only be considered as analogous structures. The Deuterostomia can not give us the key to the solution of the problem of the origin of Vertebrates and to the explanation of the structure of their organs. 
Fig. 1 Rana esculenta, median fig. $40 a$

Fig. 2 Rana esculenta, median fig. $40 b$

Fig. 3 Rana esculenta, median fig. $40 c$ Abbreviations:

a.

(a.)

a. d. arch.

bl.

can. med.

h. $p$.

l. $b$.

mes.

n. $p$.

(n. p.)

p. neur.

pl. med.

pr. cer.

ventr. mes. anus

anal pit

anal div

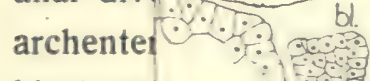

blastopor

medullar

cerebral

liver cov

mesoder

neuropor

place of

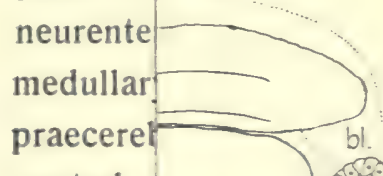

ventral $n$ 



\section{Fig. 4 Rana esculenta,} (Abbreviations ig. 5.

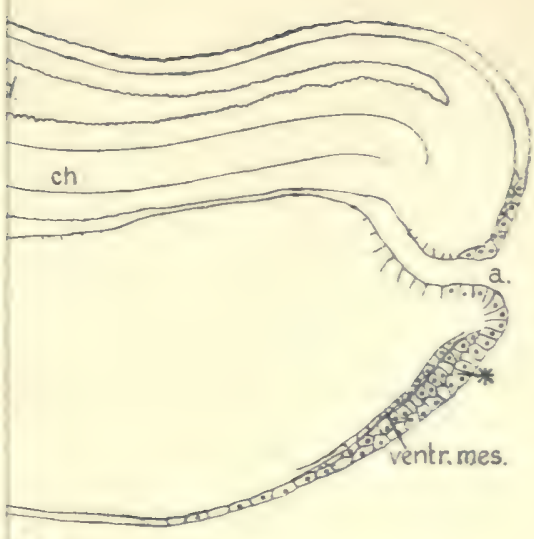

\section{Fig. 4. Rama esculenta,}

\section{Fig. 5 Rana esculenta,}

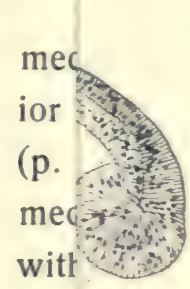

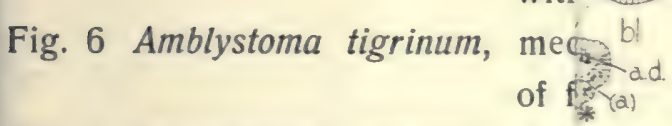

Fig. 7 Amblystoma tigrinum, mec

$$
\text { of fis ad. }
$$

figs

Fig. 8 Amblystoma tigrinum, mec

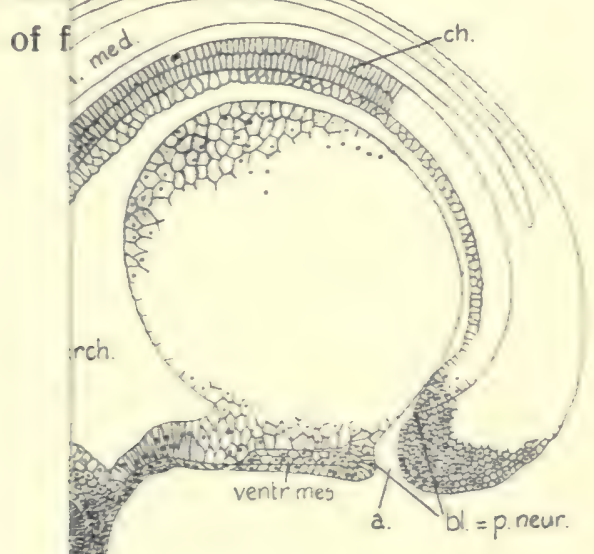

Fig. 8. 



\section{LITERATURE.}

AHLBORN, F., 1884. Ueber die Segmentation des Wirbeltierkörpers.

Zeitschr. wiss. Zool., Bd 40.

ALCOCK, R., 1898. The peripheral Distribution of the Cranial Nerves of Ammocoetes. Journ. Anat. Phys., Vol. 33.

ALlMAN, J., 1853. On the anatomy and physiology of Cordylophora.

Philos. Trans. R. Soc. London. Vol. 143.

ANDREWS, E. A., 1891. On the eyes of Polychaetae.

Zool. Anz., Bd. 14.

1892 On the Eyes of Polychaetous Annelids.

Journ. Morph., Vol. 7.

ASSHETON, R., 1894. On the Growth in Length of the Frog Embryo.

Quart. Journ. Micr. Sc., Vol. 37.

1905. On Growth Centres in Vertebrate Embryos. Anat. Anz., Bd. 27.

1909. Professor HUBRECHTs Paper on the Early

Ontogenetic Phenomena in Mammals.

Quart. Journ. Micr. Sc., Vol. 54.

AYERS, H., 1890. Concerning Vertebrate Cephalogenesis. Journ. Morph. Boston, Vol. 4.

BAER, C. E. VON, 1828. Entwickelungsgeschichte der Tiere. Beobachtung und Reflection.

BALFOUR, F M., 1875. A comparison of the early stages in the development in Vertebrates.

Quart. Journ. Micr. Sc., Vol. 16.

1876. On the Origin and History of the Urogenital Organs of Vertebrates.

Journ. Anat. Phys., Vol. 10.

1878. A monograph on the Development of Elasmobranch Fishes.

- 1881. A Treatise on Comparative Embryology.

BATESON, W., 1886. The Ancestry of the Chordata.

Quart. Journ. Micr. Sc. (2), Vol. 26. 
BEARD, J., 1884. On the Segmental Sense organs of the lateral Line.

Zool. Anz., Bd. 7.

1885. The System of Branchial Sense Organs

and their associated Ganglia in Ichthyopsida etc.

Quart. Journ. Micr. Sc. (2), Vol. 26.

$1888 a$. The old mouth and the new.

Anat. Anz., Bd. 3.

1888b. A contribution to the Morphology of the Nervous System of Vertebrates.

ibid.

BELL, C., 1811. An idea of a new Anatomy of the Brain: submitted for the observations of his friends.

Bemmelen, J. VAN, 1889. Ueber die Herkunft der Extremitäten- und Zungenmuskulatur bei Eidechsen.

Anat. Anz., Bd. 4.

BENEDEN, Ed. VAN, and CH. JULIN, 1884a. La segmentation chez les Ascidiens et ses rapports avec l'organisation de la larve. Arch. Biol., T. 5.

$1884 b$ Recherches sur la formation des annexes foetales chez les mammifères (lapin et cheiroptères). ibid., T. 5.

niciers.

ibid., T. 6.

BerTACCHINI, P., 1899. Morfogenesi e teratogenesi negli Anfibi anuri.

Intern. Monatschr. Anat. Phys., Bd. 16.

BLES, E. J., 1905. The Life-History of Xenopus laevis.

Trans. R. Soc. Edinb., Vol. 31.

BOAS, J. E. V., 1914. Phylogenie der Wirbeltiere.

Die Kultur der Gegenwart, T. 3, Abt. 4.

BOEKE, J., 1902. Ueber das Homologon des Infundibularorgans bei Amphioxus.

Anat. Anz, Bd. 21.

Teleosteer.

1904. Beiträge zur Entwickelungsgeschichte der

Petrus Camper, Bd. 2.

Teleostei.

Versl. Kon. Acad. Wetensch Amsterdam.

1908. Das Infundibularorgan im Gehirne des Amphioxus.

Anat. Anz., Bd. 32. 
BOEKE, J., 1911. Beiträge zur Kenntniss der motorischen

Nervenendigungen.

Intern. Monatschr. Anat. Phys., Bd. 28.

- 1913. Die doppelte (motorische und sympathische) efferente Innervation der quergestreiften Muskelfasern.

Anat. Anz., Bd 44.

BOVERI, T., 1892. Die Nierenkanälchen des Amphioxus. Ein Beitrag zur Phylogenie des Urogenitalsystems der Wirbeltiere. Zool. Jahrb. Abt. Anat., Bd. 5.

1904. Uber die phylogenetische Bedeutung der Sehorgane des Amphioxus.

Zool. Jahrb. Suppl., Bd. 7.

BRACHET, A., 1902. Recherches sur l'ontogénèse des Amphibiens Urodèles et Anoures.

Arch. Biol., T. 19.

Rana fusca.

$1905 a$ Recherches expérimentales sur l'oeuf de

ibid., T. 21.

chez les Chordés.

Anat Anz., Bd. 27.

BRAUS, H., 1899. Beiträge zur Entwickelung der Muskulatur und des peripheren Nervensystems der Selachier. I Teil. Die metotischen Urwirbel und spino-occipitalen Nerven. Morph. Jahrb., Bd. 27.

BROHMER, P., 1909. Der Kopf eines Embryos von Chlamydoselachus und die Segmentierung desSelachierkopfes. Jen. Zeitschr. Naturw., Bd. 44.

BROOKS, W. K., 1893. The Genus Salpa.

Mem. Biol. Lab J. Hopkins Univ., Vol. 2.

BuCHS, G., 1902. Ucber den Ursprung des Kopfskeletes bei Necturus.

Morph. Jahrb., Bd. 29.

BüTSCHLI, O., 1883-1887. Protozoa II.

BRONN's Klassen und Ordnungen des Thierreichs.

CARRIĖRE. J., 1885. Die Sehorgane der Tiere, vergleichendanatomisch dargestellt.

CASTLE, W. E., 1896. The early Embryology of Ciona intestinalis.

Bull. Mus. Harvard Coll., Vol. 27,

Cerfontaine, P., 1906. Recherches sur le développement de l'Amphioxus.

Arch. Biol., T. 22. 
ConkLin, E. G., 1897. The Embryology of Crepidula. Journ. Morph., Vol 13.

Ascidian Egg.

Journ. Acad. Nat. Sc. Philadelphia (2), Vol. 13.

CORNING, H. K., 1895. Ueber die Entwickelung der Zungenmusculatur bei Reptilien.

Verh. anat. Gesellsch, Rd. 10.

DAVENPORT, C. B., 1893 Studies in Morphogenesis. I. On the Development of the Cerata in Aeolis.

Bull. Mus. Harvard Coll., Vol. 24

DELSMAN, H. C., 1910. Beiträge zur Entwicklungsgeschichte von Oikopleura dioica.

Verhl. Rijksinstituut Onderzoek Zee, III.

1910. De voortplanting van de mossel.

Versl. Staat Nederlandsche Zeevisscherijen.

1912. Weitere Beobachtungen über die Entwicklung von Oikopleura dioica.

Tijdschr. Ned. Dierk. Ver. (2), DI. 12.

1913a. Der Ursprung der Vertebraten.

Mitth. Zool. Station Neapel, Bd. 20.

1913b. Ist das Hirnbläschen des Amphioxus dem

Gehirn der Cranioten homolog ?

Anat. Anz., T. 44.

obtusata.

1914. Entwicklungsgeschichte von Littorina

Tijdschr. Ned. Dierk. Ver. (2), Dl. 13.

1916a. Eifurchung und Keimblattbildung von Scoloplos armiger.

\section{ibid. (2) Dl. 14.}

1916b. On the relation of the first three cleavage planes to the principal axes in the embryo of Rana fusca.

Proc. R. Acad. Sc. Amsterdam, Vol, 19.

Rana fusca.

1916c. The Gastrulation of Rana esculenta and

$$
\text { ibid., Vol. } 19
$$

balanoides.

1917a. Die Embryonalentwicklung von Balanus

Tijdschr. Ned. Dierk. Ver. (2), D1. 15.

$1917 b$. On the relation of the anus to the blas-

topore and on the origin of the tail in Vertebrates.

Proc. R. Acad. Sc. Amsterdam, Vol. 19. 
DELSman, H. C., 1917. Short history of the head of Vertebrates.

ibid., Vol. 20.

1918. The egg-cleavage of Volvox globator and its relation to the movement of the adult form and to the cleavage types of Metazoa.

ibid., Vol. 21.

DOHRN, A., 1875. Der Ursprung der Wirbelthiere und das Princip des Funktionswechsels.

- 1881 - 1902. Studien zur Urgeschichte des Wirbelthierkörpers, I-XXII.

Mitth. Neapel, I3d. $3-15$.

einer Lösung des Wirbeltierkopfproblems.

Anat. Anz., Bd. 5.

DRÜNER, L., 1901, 1904. Studien zur Anatomie der Zungenbein-, Kiemenbogen- und Kehlkopfmuskeln der Urodelen. .

Zool. Jahrb. Abt. Anat. Ont. Bd. 15, 19

DURHAM, H. E., 1886. Note on the presence of a neurenteric canal in Rana

Quart. Journ. Micr. Sc, Vol. 26.

EDGEWORTH, F. H., 1911. On the Morphology of the

Cranial Muscles in some Vertebrates.

ibid., Vol 56.

EISIG, H, 1881. Ueber das Vorkommen eines schwimmblasenähnlichen Organs bei Anneliden.

Mitth. Zool. Stat. Neapel, Bd. 2.

1887. Die Capitelliden des Golfes von Neapel. Fauna Flora Neapel, Monogr. 16.

telliden.

Mitt Zool. Stat Neapel, Bd: 13.

ERLANGER, R. VON, 1890. Ueber den Blastoporus der anuren Amphibien, sein Schicksal und seine Beziehungen zum bleibenden After

Zool. Jahrb. Abt. Anat. Ont., Bd. 4.

Amphibien.

1891. Zur Blastoporusfrage bei den anuren

Anat Anz., Bd. 4.

EYCLESHymer, A. C., 1893 The Development of the Optic Vesicles in Amphibia.

Journ. Morph., Vol. 8. 
Eycleshymer, A. C., 1895. The early Development of Amblystoma, with Observations on some other Vertebrates ibid. Vol. 10.

bian Embryo.

1898. The location of the Basis of the Amphi-

ibid Vol. 14

1902. The Formation of the Embryo of Necturus, with Remarks on the Theory of Concrescence

Anat. Anz., Bd 21.

FAUVEL, P, 1902. Les otocystes des annélides polychètes.

C. R. Acad. Paris, T. 135.

1907. Recherches sur les Otocystes des Annélides polychètes.

Ann. Sc. Nat. (9) T. 6

FiELD, H. H, 1891. The development of the pronephros and segmental duct in Amphibia.

Bull. Mus Comp. Zool. Harvard Coll. Vol. 21.

FRAIPONT, J, 1884. Recherches sur le sysțème nerveux central et périphérique des Archiannélides.

Arch. Biol., T. 5.

$$
\text { 1887. Le genre Polygordius. }
$$

Fauna Flora Neapel.

FRORIEP, A., 1882. Ueber ein Ganglion des Hypoglossus und Wirbelanlagen in der Occipitalregion.

Arch. Anat. Phys. Abth. Anat., 1882.

1885. Uber Anlagen von Sinnesorganen am Facialis, Glossopharyngeus und Vagus etc.

ibid. 1885.

1887. Bemerkungen zur Frage nach der Wirbeltheorie des Kopfskelettes.

Anat. Anz., Bd. 2.

1891. Zur Entwickelungsgeschichte der Kopf-

nerven. 2. Ueber die.Kiemenspaltenorgane der Selachierembryonen.

Verh. Anat Ges. 5. Vers München.

- 1901. Ueber die Ganglienleisten des Kopfes und des Rumpfes und ihre Kreuzung in der Occipitalregion. Arch. Anat Phys. Abt. Anat. 1901.

1902. Einige Bemerkungen zur Kopffrage.

Anat. Anz., Bd. 21 .

1905. Die occipitalen Urwirbel der Amnioten im Vergleich mit denen der Selachier.

Verh. anat. Ges., 19. Vers. 
FRORIEP, A., 1906. Die Entwickelung des Auges der Wirbelthiere.

HERTWIG's Handbuch, Bd. 2.

1906. Ueber den Ursprung des Wirbeltierauges

Münch. mediz. Wochenschr. Jahrg. 53.

FüRBRINGER, M., 1879. Zur Lehre von den Umbildungen der Nervenplexus.

Morph. Jahrb., Bd. 5

1897. Ueber die spino-occipitalen Nerven der Selachier und Holocephalen und ihre vergleichende Morphologie.

Festschr. Gegenbaur, Bd. 3.

GARBOWSKI, T., 1898. Amphioxus als Grundlage der Mesodermtheorie.

Anat. Anz., Bd. 14.

GaRSTANG, W., 1894. Preliminary Note on a new Theory of the Phylogeny of the Chordata.

Zool. Anz., Bd. 17.

GASKELL, W. H., 1908. The Origin of Vertebrates.

London,

GAST, R, 1909. Die Entwickelung des Oculomotorius und seiner Ganglien bei Selachierembryonen

Mitth. Zool. St. Neapel, Bd. 19.

GAUPP, E., 1893. Beiträge zur Morphologie des Schädels. I Primordialcranium und Kieferbogen von Rana fusca.

Morph. Arbeiten G. Schwalbe Bd II. 1898. Die Metamerie des Schädels.

Ergebn. Anat. Entw. gesch., Bd. 7: 1897.

1906. Die Entwickelung des Kopfskelettes.

HERTWIG's Handbuch, Bd. III, T. 2.

GegenbauR, C., 1871. Ueber die Kopfnerven von Hexanchus etc.

Jen. Zeitschr., Bd. 6.

1872, Untersuchungen zur vergl. Anatomie der Wirbelthiere. Heft 3: Das Kopfskelet der Selachier, Leipzig Wirbeltheorie des Kopsketettes.

Morph. Jahrb., Bd. 13

GEOFFrOY ST-HILAIRE, 1822. . Discours sur l' Anatomie.

Mém. Soc. Linn. Paris, T. 2.

GOETTE, A, 1869. Untersuchungen über die Entwickelung des Bombinator igneus.

Arch. mikr. Anat., Bd. 5. 
GOETTE, A., 1875. Die Entwickelungsgeschichte der Unke (Bombinator igneus) als Grundlage einer vergleichenden Morphologie der Wirbeltiere.

1890. Entwicklungsgeschichte des Flussneunauges.

Abhandl. Entw. gesch der Tiere, Heft 5, T. I.

1895. Ueber den Ursprung der Wirbelthiere.

Verh. deutsch. zoöl. Ges. 5 Jahresvers.

Zool. Jahrb. Abt. Anat., Bd. 21.

GOODRICH, E. S., 1897: On the relation of the Arthropod

Head to the Annelid Prostomium.

Quart. Journ. Micr. Sc. (2), Vol. 40.

of Amphioxus.

1902. On the Structure of the Excretory Organs

ibid. Vol. 37.

1909. Vertebrata Craniata.

Treatise of Zoology, Part 9.

1911. On the Segmentation of the Occipital

Region of the Head in the Batrachia urodela.

Proc. Zool. Soc. London.

1914. Metameric Segmentation and Homology.

Quart. Journ. Micr. Sc., Vol. 59.

brates.

ibid., Vol. 62.

1919. On the Development of the Segments

of the Head in Scyllium.

ibid., Vol. 63.

GREEFF, R, 1876. Ueber das Auge der Alcyopiden. Marburg.

GROBBEN, C., 1908. Die systematische Eintheilung des

Tierreiches.

Verh. Zool. Botan. Ges. Wien.

GUTHKE, E., 1906. Embryologische Studien uber die Ganglien und Nerven des Kopfes von Torpedo ocellata.

Jen. Zeitschr., Bd. 42.

HAECKEL, E., 1895. Systematische Phylogenie.

HARRIS, R. H., 1903. Die Statocysten der Cephalopoden.

Zool. Jahrb. Anat. Ont., Bd. 18.

HATSCHEK, B., 1878. Studien über Entwickelungsgeschichte der Anneliden.

Arb. Zool. Inst Wien, Bd. 1. 
HATSCHEK, B., 1881. Studien über die Entwickelung des Amphioxus.

ibid., Bd. 4.

1884. Mitteilungen über Amphioxus.

Zool. Anz., Bd. 7.

- 1885. Entwicklung der Trochophora von Eupomatus uncinatus Phil.

Arb. Zool. Inst. Wien, T. 6. gordius.

ibid.

xus.

Anat. Anz., Bd. 3.

1888. Ueber den Schichtenbau des Amphio-

1888-'91, Lehrbuch der Zoologie, Jena.
1892. Die Metamerie des Amphioxus und des
Ammocoetes.

Verh. Anat. Ges., 6. Vers.

1893. Ueber den gegenwårtigen Stand der

Keimblättertheorie.

Verh. deutsch. zoöl. Ges. 3. Vers.

- 1906. Studien zur Segmenttheorie des Wirbeltierkopfes. 1. Das Acromerit des Amphioxus.

Morph. Jahrb., Bd. 35.

Wirbeltierembryos.

ibid., Bd. 39.

1910. id. 3. Ueber das Akromerit und über

echte Ursegmente bei Petromyzon.

ibid., Bd. 40.

Leipzig.

1911. Das neue zoologische System.

HEIDER, K, 1914. Phylogenie der Wirbellosen.

Die Kultur der Gegenwart, T. 3. Abt. 4.

HERTWIG, O., 1882, 1883. Die Entwickelung des mittleren Keimblattes der Wirbeltiere.

Jen. Zeitschr., Bd. 15, 16.

1892. Urmund und Spina bifida.

Arch. mikr. Anat., Bd. 39.

1906. Die Lehre von den Keimblättern.

Handb. Entw. Wirbeltiere, Jena.

HESS, C., 1909. Die Accomodation der Cephalopoden.

Arch. Augenheilk., Bd. 64, Ergånzungsheft. 
HESS, C., 1914. Neue Versuche liber Lichtreaktionen bei Tieren.

Münchn. mediz. Wochenschr., Bd. 61 .

HESSE, R., Untersuchungen über die Organe der Lichtempfindung bei niederen Tieren.

Zeitschr. wiss. Zool:, Bd. 63.

1899. V. Die Augen der polychäten Anneliden. ibid., Bd. 65.

1900. VI. Die Augen einiger Mollusken. ibid., Bd. 68.

1901. VII. Von den Arthropodenaugen. ibid., Bd. 70.

1902. Allgemeines.

ibid., Bd. 72.

HEYMANS, J. F., and O. VAN DER STRICHT, 1898. Sur

le système nerveux de l'Amphioxus et en particulier sur

la constitution et la genèse des racines sensibles.

Mém. Ac. R. Sc. Belg., T. 56.

HIs, W., 1874. Unsere Körperform und das physiologische Problem ihrer Entstehung.

1876. Untersuchungen über die Entwicklung

von Knochenfischen, besonders über diejenige des Salmens. Zeitschr. Anat. Entw. gesch.

1886. Zur Geschichte des menschlichen Rücken-

marks und der Nervenwurzeln.

Abh. Math.-Phys. Sächs. Ges. Wiss., Bd. 13.

Kopfnerven.

1887. Die morphologische Betrachtung der

Arch. Anat. Phys. Abth. Anat, 1887.

ibid., 1893.

HoFER, B., 1907. Studien über die Hautsinnesorgane der Fische

HOFFMANN, C. K., 1894. Zur Entwickelungsgeschichte des Selachierkopfes.

Anat. Anz., Bd. 9.

der Selachii.

1896-1899. Beiträge zur Entwickelungsgeschichte

Morph. Jahrb., Bd. 24, 25, 27.

1901. Zur Entwicklungsgeschichte des Sympathicus. I. Acanthias vulgaris.

Verh. Kon. Acad. Wetensch,, Deel 7. 
HousSay, F. and BATAILlon, 1888. Segmentation de l'oeuf et sort du blastopore chez l'axolotl.

Comptes Rendus Ac. Sc. Paris, T. 107.

HousSAY, F., 1893. Études d'embryologie sur les vertébrés: développement et morphologie du parablast et de l'appareil circulaire.

Arch. zool. exp. gén. (III), T. I.

HUBRECHT, A. A. W., 1883. On the Ancestral Form of the Chordata.

Quart. Journ. Micr. Sc. N. S., Vol. 23.

1890. Studies in Mammalian Embryology. ibid. Vol. 30, 31.

sius spectrum.

1902. Furchung und Keimblattbildung bei Tar-

Verh. Kon. Acad. Wetensch. (2), deel 8, nr. 6.

1905. Die Gastrulation der Wirbelthiere.

Anat. Anz., Bd. 26.

1908. Early ontogenetic Phenomena in Mammals and their Bearing on our Interpretation of the Phylogenie of the Vertebrates.

Quart. Journ. micr. Sc., Vol. 53.

Huntsman, A. G., 1913. On the Origin of the Ascidian Mouth.

Proc. Roy. Soc. B, Vol. 86.

HUXLEY, T. $H_{\text {s, }}$ 1858. On the theory of the Vertebrate skull.

Proc. Roy. Soc. London, Vol. 9. 1877. The Anatomy of Invertebrated Animals. IHLE, J. E. W., 1910 Ueber die sogenannte metamere Segmentierung des Appendicularienschwanzes.

Zool. Anz., Bd. 35.

1913. Die Appendicularien.

Ergebn. u. Fortschr. Zool., Bd. 3, Heft 4.

IKEDA, S., 1902. Contributions to the Embryology of

Amphibia: The Mode of Blastopore Closure and the

Position of the Embryonic Body.

Journ. Coll. Sc, Imp. Univ. Tokyo, Vol. 17.

ISHIKAWA, C., 1908. Ueber den Riesensalamander Japans.

Mitt. deutsch. Ges. f. Natur- und Völkerkunde Ostasiens. T. 11.

JANET, Ch., 1912. Le Volvox, Limoges.

JELGERSMA, G., 1906. Der Ursprung des Wirbelthierauges.

Morph. Jahrb., Bd. 35. 
JOHNSON, A., 1884. On the Fate of the Blastopore and the Presence of a Primitive Streak in the Newt (Triton cristatus).

Quart. Journ. Micr. Sc., Vol. 24.

JOSEPH, H., 1904. Ueber eigentümliche Zellstrukturen im Zentralnervensystem von Amphioxus.

Verh. anat. Ges., 18. Vers.

JULIN, C., 1887. Le système nerveux grand sympathique de l' Ammocoetes (Petromyzon Planeri).

Zool. Anz, Bd. 2.

KASTSCHENKO, N, 1888. Zur Frage über die Herkunft der Dotterkerne im Selachierei.

Anat. Anz., Bd. 3.

KEIBEL, F., 1889. Ueber die Entwickelungsgeschichte der Chorda bei Säugern.

Arch. Anat. Phys. (Anat. Abt.)

1897. Normentafeln zur Entwicklungsgeschichte des Schweins.

Normentafeln zur Entwicklungsgeschichte der Wirbelthiere.

der Wirbelthiere.

Ergebn. Anat. Entw. gesch., Bd. 10.

KENNEL, J. VON, 1891. Die Ableitung der Vertebratenaugen von den Augen der Anneliden.

Dorpat.

KEPNER, A., and J R. CASH, 1915. Ciliated pits of Stenostoma. Journ. Morph, Vol. 26.

KING, H. D., 1902. Experimental Studies on the Formation of the Embryo of Bufo lentiginosus.

Arch. Entw. Mech., Bd. 13.

KLAATSCH, H., 1897. Bemerkungen über die Gastrula des Amphioxus.

Morph. Jahrb., Bd. 25.

KLEINENBERG, N., 1886. Die Entstehung des Annelids aus der Larve von Lopadorhynchus etc.

Zeitschr. wiss. Zool., Bd. 44.

KLINKHARDT, W., 1905. Beiträge zur Entwicklungsgeschichte der Kopfganglien und Sinneslinien der Selachier. Jen. Zeitschr. Naturw., Bd. 40.

KOLTZOFF, N. K., 1902. Entwickelungsgeschichte des Kopfes von Petromyzon Planeri.

Bull. Soc. Imp. Nat. Moscou, T. 15. 
KOPSCH, F., 1896. Experimentelle Untersuchungen über den Keimhautrand der Salmoniden.

Verh. anat. Ges.

1900. Über das Verhältnis der embryonalen Axen zu den drei ersten Furchungsebenen beim Frosch. Intern. Monatsschr. f. Anat. u. Phys., Bd. 17.

KORSCHELT, E. und C. HEIDER, 1910. Lehrbuch der vergleichenden Entwickelungsgeschichte $\mathrm{der}^{\circ}$ wirbellosen

Thiere. Allgem. Theil, Cap. 8.

KOWALEWSKY, A., 1866. Entwickelungsgeschichte der einfachen Ascidien.

Mém. Acad. St. Pétersbourg, Série 7, Vol. 10.

1871. Weitere Studien über die Entwicklung der einfachen Ascidien.

Arch. mikr. Anat., Vol. 7.

1877. Weitere Studien über die Entwickelungsgeschichte des Amphioxus lanceolatus, nebst einem Beitrage zur Homologie des Nervensystems der Würmer und Wirbelthiere.

Arch. mikr. Anat., Bd. 13.

Kunitomo, K, 1911. Die Keimblattbildung des Hynobius nebulosus.

Anat. Hefte, 1. Abt., Bd. 44.

KUPFFER, K. VON, 1887 . Ueber den Canalis neurentericus der Wirbelthiere.

Sitz. ber. Ges. Morph. Phys. München, Bd. 3.

1890. Die Entwickelung von Petromyzon Planeri. Arch. mikr. Anat., Bd. 35.

1894. Die Deutung des Hirnanhanges.

Sitz. ber. Ges. Morph. Phys. München.

1894. Studien zur vergleichenden Entwickelungsgeschichte des Kopfes der Cranioten.

systems.

Hertwig's Handb. Entw. Vert, Bd. 2.

LAMEERE, A., 1891. L'origine des Vertébrés.

Bull. Soc. belge Micr., T. 14

1905, L'origine de la Corde dorsale.

Ann. Soc. R. Malac. Belg., T. 40.

Zoologie.

ibid., T. 44. 
LANGE, D., de, 1907. Die Keimblätterbildung des Megalobatrachus maximus Schlegel.

Anat. Hefte, Bd. 32.

1912, 1913. Mitteilungen zur Entwicklungsgeschichte des japanischen Riesensalamanders

Anat. Anz., Bd 42, 43.

LANKESTER, E. R, 1880. Degeneration, a chapter in Darwinism.

LEYDIG, F., 1864. Vom Bau des tierischen Körpers. Handbuch der vergl. Anat., Tübingen

LwOFF, B., 1893. Uber den Zusammenhang von Markrohr und Chorda beim Amphioxus und ähnliche Verhältnisse bei Anneliden.

Zeitschr. wiss. Zool., Bd. 56.

1894. Die Bildung der primären Keimblätter und die Entstehung der Chorda und des Mesoderms bei den Wirbeltieren.

Bull. Soc. Impér. Nat. Moscou (2), T. 8.

MACBRIDE, E. W. 1898. The early Development of Amphioxus.

Quart. Journ. Micr. Sc, Vol. 40.

Amphioxus.

ibid., Vol. 43.

1909. The Formation of the Layers in Amphi-

oxus and its Bearing on the Interpretation of the Early Ontogenetic Processes in Vertebrates.

ibid., Vol. 54.

MALBRANC, M., 1876. Von der Seitenlinie und ihren Sinnesorganen bei Amphibien.

Zeitschr. wiss. Zool., Bd. 26.

MARCUS, H., 1910 Beiträge zur Kenntniss der Gymnophionen.

I. / Morph. Jahrb., Bd. 40

II. Festschrift Rich. Hertwig.

MARTINI, E., 1909. Ueber die Segmentierung des Appendicularienschwanzes.

Zeitschr. wiss. Zool., Vol. 94.

1910. Weitere Bemerkungen übet die sogenannte metamere Segmentierung des Appendicularienschwanzes. Zool. Anz., Bd. 35.

MASTERMAN, A. T., 1897. On the Diplochorda, I and II. Quart. Journ. Micr. Sc., Vol. 40. 
MAURER, F., 1906. Die Entwickelung des Darmsystems, 5. Die Entwickelung des Afters.

HERTWIG's Handbuch, Bd. 2, T. 1.

MEYER, E, 1890. Die Abstammung der Anneliden.

Biol. Centralbl., Bd. 10.

MiHALKOVICS, V. VON, 1877. Entwickelungsgeschichte des Gehirns.

Milnes MARShall, A., 1879. The Morphology of the Vertebrate Olfactory Organ.

Quart. Journ. Micr. Sc., Vol. 19.

1881. On the Head Cavities and associated Nerves of Elasmobranchs.

ibid., Vol. 21.

1883. The segmental Value of the Cranial Nerves. Journ. Anat. Physiol., Vol. 16.

MiNOT, Ch. S., 1897. Contribution à la détermination des ancêtres des Vertébrés.

Arch. zool. expér. (3), T. 5.

MORGAN, T. H., 1890. On the amphibian Blastopore.

Stud. Biol. Lab. Baltimore.

(also '89, John Hopkins Univ. Circul.)

1894. The Formation of the Embryo of the Frog. Anat. Anz, Bd. 9.

1895 The formation of the fish embryo.

Journ. Morph., Vol. 10

Frog's Egg.

Quart Journ. Micr. Sc, Vol 35.

MülleR, W., 1873. Uber die Hypobranchialrinne der Tuni-

caten und deren Vorhandensein beim Amphioxus und den Cyclostomen.

Jenaische Zeitschr., Bd. 7.

Sehorganes der Wirbeltiere.

Festgabe an C. Ludwig.

NEAL, H. V., 1897. The Development of the Hypoglossus

Musculature in Petromyzon and Squalus

Anat. Anz., Bd. 13

in Squalus Acanthias.

Bull Mus. Comp. Zool., Vol. 31.

Journ. Morph., Vol. 25. 
ONODY, A. D., 1885. Ueber die Entwickelung des sympathischen Nervensystems.

Arch. mikr. Anat., Bd. 26.

OSAWA, G., 1902. Beiträge zur Anatomie des Riesensalamanders.

Mitt. med. Fak. K. Jap. Univ. Tokio, Bd. 5.

OSTROUMOFF, A., 1889 Ueber die Froriep'schen Ganglien bei . Selachiern.

Zool. Anz., Bd. 12.

PARKER, G. H., 1905. The function of the lateral-line Organs in Fishes.

Bull. Bur. Fisheries Washington, Vol. 24.

PATTEN, W., 1891. On the Origin of Vertebrates from Arachnids. Quart. Journ. Micr. Sc., Vol. 31.

PERENYI, J., 1888. Ueber das Verharren des Blastoporus bei den Fröschen.

Math. Nat. Ber. Ungarn., Bd. 5.

PERRIER, Ed., 1898. L'origine des Vertébrés.

C. R. Ac. Paris, T. 126.

PETER, K., 1898. Die Entwicklung und funktionelle Gestaltung des Schädels von Ichthyophis glutinosus.

Morph. Jahrb., Bd. 25.

PflüGER, E., 1883. Ucber den Einfluss der Schwerkraft auf die Teilung der Zellen.

Arch. ges. Physiologie, Bd. 32.

PlatT, J. B, 1891. Further Contributions to the Morphology of the Vertebrate Head.

Anat. Anz., Bd. 8.

derms in Necturus.

Arch. mikr. Anat., Bd. 43.

1896. Ontogenetic Differentiations of the Ecto-

derm in Necturus. II. On the Development of the peripheral Nervous system.

Quart. Journ. Micr. Sc., Vol 38.

1896. The development of the thyroid gland and of the suprapericardial Bodies in Necturus.

Anat. Anz., Bd. 11.

1897. The Development of the cartilaginous skull etc. in Necturus.

Morph. Jahrb., Bd. 25.

RABL, C., 1888. Uber die Bildung des Mesoderms.

Anat. Anz. Bd. 3. 
RABL, C., 1889. Theorie des Mesoderms.

Morph. Jahrb., Bd. 15.

- 1892 Ueber die Metamerie des Wirbeltierkopfes.

Verh. anat. Ges., 6. Vers.

RAcovitZA, E. G, 1896. Le lobe céphalique et l'encéphale des Annélides polychètes.

Arch. zool. expér. (3), T. 4.

RANSOM, W. B and W. D'ARCY THOMPSON, 1886. On the Spinal and Visceral Nerves of Cyclostomata.

Zool. Anz., Bd. 9 .

RHUMBLER, L., 1902. Zur Mechanik des Gastrulationsvorganges.

Arch. Entw. Mech, Bd. 14.

ROBINSON, A., and R. ASSHETON, 1891. The Formation and Fate of the primitive Streak, with Observations on the Archenteron and Germinal Layers of Rana temporaria.

Quart, Journ. Micr. Sc., Vol. 32.

RouX, W., 1888. Ueber die Lagerung des Medullarrohrs im gefurchten Froschei.

Anat. Anz., Bd. 3.

1903. Ueber die Ursachen der Bestimmung der Hauptrichtungen des Embryo im Froschei.

ibid., Bd. 23.

SALENSKY, M., 1887. Études sur le développement des Annélides, 2.

Arch. Biol., T. 6.

SARASIN, P., 1882. Entwicklungsgeschichte der Bithynia tentaculata.

Arb. Zool. Inst. Würzburg, Bd. 6.

SCHANZ, F., 1887. Das Schicksal des Blastoporus bei den Amphibien.

Jen. Zeitschr., Bd. 21.

SCHNEIDER, A., 1879. Beiträge zur vergleichenden Anatomie und Entwickelungsgeschichte der Wirbeltiere, I-III. Berlin.

SCHULTZE, O., 1887. Ueber Achsenbestimmung des Froschembryos.

Biol. Centralbl., Bd. 7.

\section{des Froscheies.}

Verh. phys.-medic. Ges. zu Würzburg, Bd. 23.

SCOTT, W. B., and H. F. OSBORNE, 1879. On some points in the early development of the common newt.

Quart. Journ. Micr. Sc., Vol. 19. 
SEDGWICK, A., 1884. On the Origin of metameric Segmentation and some other morphological Questions.

ibid, Vol. 24.

SEEmANN, J., 1907. Ueber die Entwicklung des Blastoporus bei Alytes obstetricans.

Anat. Hefte, 1. Abt., Bd. 33.

SEMPER, C., 1875. Die Stammverwandtschaft der Wirbelthiere und Wirbellosen.

Arb. Zool. Inst. Würzburg, Bd: 2.

SETERS, W. H. VAN, 1921. De ontwikkeling van het chondrocranium van Alytes obstetricans voor de metamorphose.

Diss. Leiden.

SEWERTZOFF, A., 1895. Die Entwickelung der Occipitalregion der niederen $V$ artebraten.

Bull. Soc. Imp. Nat. Moscou, T. 9.

1897. Beitrag zur Entwickelungsgeschichte des Wirbeltierschädels.

Anat. Anz., Bd. 13.

1899. Die Entwickelung des Selachierschädels.

Festschr. CARL V. KUPFFER.

SiDEBOTHAM, H , 1888. Note on the fate of the blastopore in Rana temporaria.

Quart. Journ. Micr. Sc., Vol. 29.

SmITH, B. G., 1912. The embryology of Cryptobranchus alleghaniensis.

Journ. Morph. Phil., Vol. 23.

SOBOTTA, J., 1897. Beobachtungen über den Gastrulationsvorgang beim Amphioxus.

Verh. phys.-med. Ges. Würzburg N.F., Bd. 31.

SPENCER, W. B., 1885 . On the fate of the blastopore in Rana temporaria.

Zool. Anz., Bd. 8.

1885. Some notes on the early Development of Rana temporaria.

Quart. Journ. Micr. Sc. (2), Vol. 25, Suppl.

SPENGEL, J.W., 1881. Oligognathus Bonelliae, eine schmarotzende Eunice.

Mitth. Zool. St. Neapel, Bd. 3.

1893. Die Enteropneusten.

Fauna Flora Neapel, Monogr. 18.

1904. Ueber Schwimmblase, Lungen und Kiementaschen der Wirbelthiere.

Zool. Jahrb. Suppl. 7. 
STEINACH, E., 1895. Motorische Function hinterer Spinalnervenwurzeln.

Arch. ges. Physiol., Bd. 60.

STEndell, W., 1914. Die Hypophysis Cerebri.

Lehrb vergl. mikr. Anat., T. 8.

STöHR, P., 1879. Zur Entwickelungsgeschichte des Urodelenschädels.

Zeitschr. wiss. Zool., Bd. 33.

schädels.

ibid., Bd. 36.

SUMNER, F. B., 1904. A Study of Early Fish Development.

Arch. Entw. Mech., Bd. 17.

TRIEPEL, H., 1914. Chorda dorsalis und Keimblätter.

Anat. Hefte, Abt. 1, Bd. 50.

1918. Gastrulation und Chordulation.

Zeitschr. f. angew. Anat. u. Konstitutionslehre, Bd. 2.

VEIT, O., 1916. Zur Theorie des Wirbeltierkopfes.

Anat. Anz., Bd. 49

WENCKEBACH, K. F., 1887. Verslag omtrent op de ansjovis betrekking hebbende onderzoekingen.

Versl. Staat Nederl Zeevisscherijen over 1886.

WIEDERSHEIM, R., Grundriss der vergleichenden Anatomie der Wirbeltiere, many editions.

WYHE, J. W. van, 1880. Over het visceraalskelet en de zenuwen van den kop der Ganoiden. Leiden.

- 1882. Ueber die Mesodermsegmente und die Entwickelung der Nerven des Selachierkopfes.

Natuurk. Verh. Kon. Acad. Wetensch., DI. 22.

1884. Ueber den vorderen Neuroporus und die phylogenetische Funktion des Canalis neurentericus der Wirbeltiere.

Zool. Anz, Bd. 7.

1886. Ueber die Kopfsegmente und die Phylogenie des Geruchsorganes der Wirbeltiere.

ibid., Bd. 9.

beim Amphioxus etc.

Petrus Campe, , D1. 1.

Anat Anz., Bd. 8 $\left.-1894^{1}\right)$ 
WYHE, J. W. VAN, 1901. Beiträge zur Anatomie der Kopfregion des Amphioxus lanceolatus.

Petrus Camper, DI. 4.

$\longrightarrow 1905^{1}$ ).

1906. Die Homologisierung des Mundes des

Amphioxus und die primitive Leibesgliederung der Wirbeltiere.

Petrus Camper, DI. 4. $1907^{1}$ ). $\left.1914^{1}\right)$.

WiLleY, A., 1891. The later larval Development of Amphioxus.

Quart. Journ. Micr. Sc., Vol. 32.

1893. Studies on the Protochordata.

ibid., Vol. 34. 35.

1894. On the Evolution of the Praeoral Lobe. Anat. Anz., Bd. 9.

tebrates.

Columbia Univ. Biol., Vol. 2.

WILSON, H. V., 1900. Formation of the Blastopore in the Frog Egg.

Anat. Anz., Bd. 18.

1902. Closure of Blastopore in the normally placed Frog Egg.

ibid, Bd. 20.

WOLTERECK, R., 1902. Trochophorastudien.

Zoologica.

1904. Beiträge zur praktischen Analyse der

Polygordius- Entwicklung etc.

Arch. Entw. Mech., Vol. 18.

1905. Zur Kopffrage der Anneliden.

Vern. deutsch. zool. Ges.

ZIEGLER, E. H., 1908 . Die phylogenetische Entstehung des

Kopfes der Wirbelthiere.

Jen. Zeitschr., Bd. 43.

Anat. Anz., Bd. 48.

ZIEGLER, F., 1892. Zur Kenntniss der Oberflächenbilder der Rana-Embryonen.

Anat. Anz., Bd. 7.

1) cf. note to the Preface. 






\section{PLEASE DO NOT REMOVE}

CARDS OR SLIPS FROM THIS POCKET

\section{UNIVERSITY OF TORONTO LIBRARY}

QL Delsman, Hendricus Christoffel

605 The ancestry of vertebrates

D45 as a means of understanding the principal features of their

BioMed structure and development 
